\title{
Development of the High Speed Craft Slam Impact Seat Test Rig
}

by

\author{
Owen C. Roberts \\ A thesis submitted to \\ the Faculty of Graduate and Postdoctoral Affairs \\ in partial fulfilment of \\ the requirements for the degree of \\ Master of Applied Science \\ in \\ Mechanical Engineering
}

Ottawa-Carleton Institute for Mechanical and Aerospace Engineering

Department of Mechanical and Aerospace Engineering

Carleton University

Ottawa, Ontario, Canada

January 2015

Copyright (C)

2015 - Owen C. Roberts 


\section{Abstract}

This thesis details the design process that led to the fabrication of a machine that is capable of reproducing large-amplitude motions and freefall slam impacts that are similar to those experienced by the seat deck of a high-speed craft in a wide range of operational conditions.

The machine features computer-controlled motor-driven motion of a suspension seat in two directions; emulating the heave and sway of a watercraft. A freefall slam impact can also be simulated as the seat can be dropped onto electrorheological dampers, which are electronically controlled to provide a tunable response force.

In this document, first, a background and the driving motivation are presented. Then, defining steps of the conceptual development are discussed. The assemblies and major parts are described in detail. Finally, structural analysis is presented as a combination of conventional stress calculations and finite element analysis (FEA). 


\section{Acknowledgments}

This research project was a tremendous undertaking with many tasks. The accomplishments of this project would not have been possible without the assistance of the following individuals.

Dr. Robert Langlois and Dr. Fred Afagh. My two supervisors. I would not have made it to the end of this large project without their endless support, guidance, and patience.

Frank Sorensen. My partner and protege. He's halfway through MASc and has inherited working with the machine. He gets the privilege of teaching SISTR how to play smart through its commissioning and testing stages of development. Inevitably, he'll also get to pick up my lost pieces for anything I didn't get around to fitting into this project.

Will Dods. An engineer and skilled machine tech like myself. We contracted him as a capable helping hand and he became a valuable partner. We painted and built up big steel frames. We turned a lot of bolts. He works with a smile, and it's contagious. 
Alex Proctor, Kevin Sangster, and Ian Lloy of the Mech \& Aero Engineering Machine Shop. This has been my second home since after my second year of undergraduate studies. They trusted me as a capable builder and allowed me to walk in and work on anything at any time. If I had to wait in line like a typical student, this project could have taken another year.

Graham Beard, Steve Tremblay, Ron Roy, and Glenn of the Science Technology Centre, at Carleton University. Professional; capable; high quality; kind and courteous. Most of the beautiful complex parts were built here. I knew they had a new waterjet cutter and so I designed many parts from sheets and plates and could get long smooth curves and stencilled text. Parts had a clean surface finish and were reliably accurate. In general, great machining and welding capabilities. I was always thinking up an excuse for another visit to see my parts in progress.

Manfred Wegner, Branch Manager, and Chris Young, Automation Engineer, of Motion Industries, which is the distributor of Control Techniques and Emerson products.

Joachim Funke, CTO of Fludicon Gmbh. which is the manufacturer of the RheDamp electrorheological damping technology. 


\section{Table of Contents}

Abstract $\quad$ ii

Acknowledgments $\quad$ iii

Table of Contents $\quad$ v

List of Figures $\quad$ ix

1 Introduction 1

1.1 Motivation .......................... 1

1.2 Literature Review . . . . . . . . . . . . . . . . . . 6

1.2.1 Understanding HSC Motion . . . . . . . . . . . . . 7

1.2.2 The State of Available Seat Testing Machines . . . . . . . . . 9

1.2.3 Review of Motion Simulating Machines . . . . . . . . . . . . 16

1.3 Thesis Objective . . . . . . . . . . . . . . . . . . 20

1.4 Thesis Overview . . . . . . . . . . . . . . . . . . . . . . 22 
2.1 Requirements of the Machine . . . . . . . . . . . . . 23

2.2 Design Constraints . . . . . . . . . . . . . . . . . . . . . 27

2.3 Evolution and Evaluation of Design Concepts . . . . . . . . . . 28

2.3.1 Horizontal Motion . . . . . . . . . . . . . . . 29

2.3.2 Vertical Motion . . . . . . . . . . . . . . . . 34

2.3.3 Producing the Slam Impact . . . . . . . . . . . . . . . . . 40

3 Technical Description of the Machine 48

3.1 Rail Support Assembly . . . . . . . . . . . . . . . . . . 49

3.2 Cart Assembly . . . . . . . . . . . . . . . . 51

3.3 Deck Assembly . . . . . . . . . . . . . . . . . 61

3.4 Drive Systems . . . . . . . . . . . . . . . . . . . 68

3.4.1 Horizontal Drive System . . . . . . . . . . . . . 68

3.4 .2 Vertical Drive System . . . . . . . . . . . . . 75

3.5 Electrorheological Dampers . . . . . . . . . . . . . . 84

3.6 Data Acquisition, Power, and Control Systems . . . . . . . . . . . 87

3.6.1 Sensors....................... 87

3.6.2 Data Acquisition .................. . . . 92

3.6.3 Power and Control Systems . . . . . . . . . . . . . 93

3.7 Component Masses and Inertia Ratios . . . . . . . . . . . . . . 98 
4.1 Stress States Caused by Drive Systems _ . . . . . . . . . . . . 102

4.1.1 Horizontal Drive System . . . . . . . . . . . . . . . . . . 103

4.1.2 Vertical Drive System _ . . . . . . . . . . . . . . . . 109

4.2 Stress States Caused by Inertial Loads . . . . . . . . . . . . . . 122

4.2 .1 Deck Assembly . . . . . . . . . . . . . . . . . . . 123

4.2 .2 Cart Assembly . . . . . . . . . . . . . . . . . . . . . 129

4.2 .3 Rail Support Assembly . . . . . . . . . . . . . . . . . . . . . 142

4.3 Stress States Caused by Freefall Slam Impact . . . . . . . . . . . 144

4.4 Summary . . . . . . . . . . . . . . . . . . . . . 151

5 Conclusions 152

5.1 Accomplishments . . . . . . . . . . . . . . . . 152

5.2 Future Work . . . . . . . . . . . . . . . . . . 156

$\begin{array}{ll}\text { References } & 158\end{array}$

$\begin{array}{ll}\text { Appendix A Matlab Programs } & 161\end{array}$

A.1 Baldor Motor Suitability . . . . . . . . . . . . . . . . 161

A.2 Horizontal Drive Stress Analysis . . . . . . . . . . . . 163

A.3 Vertical Drive Stress Analysis . . . . . . . . . . . . . 165

A.4 Ram Impactor . . . . . . . . . . . . . . . . . . . 171 
A.5 Masses and Inertia . . . . . . . . . . . . . . . . . . 173 


\section{List of Figures}

1.1 Stock image of a HSC flying over a wave. . . . . . . . . . . . . . . 2

1.2 A 20 second sample of accelerometer data in the vertical direction (top) and in the lateral direction (bottom), measured at sea. . . . . . . 8

1.3 The phases of a typical acceleration profile during at-sea testing. Phase (a) is the freefall, phase (b) is the slam impact, and phase (c) is the hydrodynamic reentry. . . . . . . . . . . . . . . . . . 9 9

1.4 Drop Tower used by the SHOXS suspension seat manufacturer. . . . 10

1.5 Drop Tower used by the UK Ministry of Defense. Sand is used as the impact absorbing material. . . . . . . . . . . . . . . . .

1.6 An example of the acceleration profiles of the boat deck and a seat pan during at-sea testing. . . . . . . . . . . . . . .

1.7 An example of the acceleration profiles of the carriage deck and the seat pan during a drop test. . . . . . . . . . . . . . .

1.8 The seat shake rig at Virginia Polytechnic Institute features vertical motion from a hydraulic ram. . . . . . . . . . . . . . .

1.9 Sample of a position profile input for the hydraulic actuator. . . . . . 16

1.10 An example of an electromagnetic shaker. . . . . . . . . . . . 17 
1.11 An example of a Stewart-Gough motion platform. . . . . . . . . . . 18

1.12 An example of an industrial robotic arm being used as a motion simulator. 19

1.13 A model of the vertical motion simulator at the NASA AMES Research

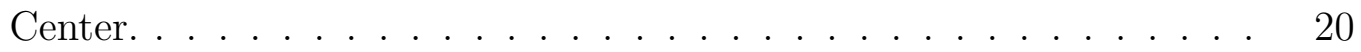

2.1 Model of the horizontal drive system used for the Matlab simulation

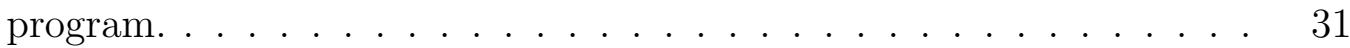

2.2 Plotted results from the Baldor motor suitability program. . . . . . . 32

2.3 Combinations of position amplitude and period of a sinusoidal horizontal motion that result in an ideal motor power of $2 \mathrm{hp} . \quad$. . . . . 34

2.4 Model of the vertical drive system used for the Matlab simulation pro-

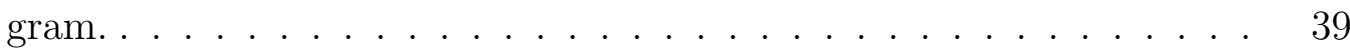

2.5 Models of the two concepts for producing the slam impact response. . 41

2.6 Adjustable shock absorbers from Enidine. . . . . . . . . . . . . . . 44

2.7 The RheDamp 63 damper with its corresponding control signal amplifier. 46

2.8 Response force profile of the RheDamp 63 damper. . . . . . . . . . . 47

3.1 Front view of SISTR with labelled assemblies. . . . . . . . . . . . . . 49

3.2 End view of a channel beam with a support post and a profiled rail. . 50

3.3 Rail end brace and the location of the polymer bumpers. . . . . . . . 51

3.4 Primary structural elements of the cart assembly. . . . . . . . . . . 52

3.5 Features of the back and side of the cart assembly. . . . . . . . . . . . 54

3.6 Elements of an aircraft fuselage. . . . . . . . . . . . . 55 
3.7 Door attached to the front of the cart with identified locations of hinges and clamps. . . . . . . . . . . . . . . . . . . 56

3.8 Top pulley beams, the nameplate, and the top corner braces. . . . . . 57

3.9 Lower section of the cart assembly. . . . . . . . . . . . . . . . . . 59

3.10 Bottom sheets viewed from under the cart. . . . . . . . . . . . . . 60

3.11 Exploded view of the two deck assemblies and the load cell. . . . . . 61

3.12 Load deck assembly. . . . . . . . . . . . . . . . . . . . . . . 62

3.13 Dual-Vee bearing wheel. . . . . . . . . . . . . . . 63

3.14 Seat deck assembly. . . . . . . . . . . . . . . . . . . 64

3.15 Top view of the deck assembly installed into the cart assembly. Note the placement of the Dual-Vee wheels in each corner. . . . . . . . . . 66

3.16 Detail of bolts and clamping tubes used to mount a seat to the seat deck assembly. . . . . . . . . . . . . . . . . . . . . 67

3.17 An example layout of four clamping tubes used to mount a seat to the seat deck assembly. . . . . . . . . . . . . . . . .

3.18 Quarter-sectioned view of the drive shaft and labelled components of the horizontal drive system. . . . . . . . . . . . . . . . .

3.19 The Baldor induction motor and the worm gear speed reducer driving the wire rope pulley. . . . . . . . . . . . . . .

3.20 One of the wire rope end fittings attached to a wire rope bracket of the cart assembly. . . . . . . . . . . . . . . . . 
3.21 Photo of the horizontal drive pulley during assembly. One of the two plates is shown here to demonstrate the lacing method of the wire rope between the two plates. . . . . . . . . . . . . . . 73

3.22 Pulley with spooled wire rope when the cart assembly is close to it. . 74

3.23 Pulley with spooled wire rope when the cart assembly is far from it. . 74

3.24 Wire rope pulleys at the far end of the rail support assembly. . . . . . 75

3.25 Interior of the cart assembly with labelled components of the vertical drive system. . . . . . . . . . . . . . . . . 76

3.26 Synchronous toothed belt connecting the Emerson motor to the spool pulley assembly. . . . . . . . . . . . . . . . . . . . . 77

3.27 Exploded view of the spool pulley assembly. . . . . . . . . . . . . . 78

3.28 Labelled image of the far end of spool pulley assembly. . . . . . . . . 79

3.29 Vertical drive spool during the assembly process. . . . . . . . . . . . . 82

3.30 Photograph of the far-end spool pulley with the wire guide levers. . . 83

3.31 Deck assembly at the top of the vertical travel. . . . . . . . . . . . . 84

3.32 Section view of a RheDamp damper. . . . . . . . . . . . . 85

3.33 Photograph of the RheDamp dampers mounted vertically in the cart. $\quad 86$

3.34 Accelerometer that is fixed to the load deck assembly. . . . . . . . . 88

3.35 Aluminum blocks with three uniaxial accelerometers on each block. . 88

3.36 String potentiometer used to measure the horizontal displacement of the cart. . . . . . . . . . . . . . . . . . . . . 89 
3.37 String potentiometer used to measure the vertical displacement of the deck assembly. . . . . . . . . . . . . . . . . . . . . . . . 90

3.38 The Omega 250 load cell installed on top of the load deck assembly. . 91

3.39 Measurement sensing range of the Omega 250. This model has the US-3600-18000 calibration. . . . . . . . . . . . . . . .

3.40 Limit switch attached to the deck. Its triggering lever is located behind the rail. . . . . . . . . . . . . . . . . . . 92

3.41 Power supplies and the motor drives. . . . . . . . . . . . . . . . . . . 94

3.42 The flexible cable carrier, the junction box, and the rubber cable cover. 96

3.43 Desktop control panel used for programmable process control buttons and an emergency stop. . . . . . . . . . . . . . . . . . . . 97

4.1 Horizontal drive system. This is a partially-sectioned view with one quarter removed to show the shaft inside other parts. . . . . . . . . . 104

4.2 FEA results of the horizontal drive system's motor base. . . . . . . . 105

4.3 Stress state in the horizontal drive system's wire rope pulley from the maximum applied torque from the motor. . . . . . . . . . . . . . . 107

4.4 Wire rope pulleys at the far end of the horizontal drive system. . . . 108

4.5 Stress state caused by the tension in the wire rope around the pulley. 108

4.6 Stress state in the end bracket from the maximum tensile force of the wire rope. . . . . . . . . . . . . . . . . . . . . . . . 109

4.7 Vertical drive system parts. . . . . . . . . . . . . . . 110 
4.8 Section view of the belt side end of the spool assembly for the vertical drive system. . . . . . . . . . . . . . . . . . . . . . . 113

4.9 Free body diagram used for the bending stress analysis of the spool. . 114

4.10 Bending moment diagrams of spool assembly. . . . . . . . . . . . . 115

4.11 Stress state in the deck block from the maximum tensile force of the wire rope. . . . . . . . . . . . . . . . . . 118

4.12 Stress state in the top pulleys beam from the peak downward force from the wire rope pulley. . . . . . . . . . . . . . . . . . . . 119

4.13 Stress state in the cart's lower plates during the peak torque output from the Emerson motor. . . . . . . . . . . . . . . . . . . 121

4.14 Free body diagram of the deck assembly with a scaled image of the SHOXS 6500 suspension seat. . . . . . . . . . . . . 125

4.15 Stress state resulting from an inertial load of a horizontal acceleration of $1 \mathrm{G}$ and vertical force of $12 \mathrm{kN}$. . . . . . . . . . . . . . . 127

4.16 Stress state resulting from an inertial load of a horizontal acceleration of 1 g. . . . . . . . . . . . . . . . . . . . . . 128

4.17 Stress state resulting from a vertical acceleration caused by a $6 \mathrm{kN}$ force in each wire rope. . . . . . . . . . . . . . . . . . . . . . 129

4.18 Labelled diagram of the cart assembly. . . . . . . . . . . . . . . . . 131

4.19 Free body diagram of the cart showing bending moment from a horizontal acceleration. . . . . . . . . . . . . . . . . . 133

4.20 Cut section of the cart corner posts used for bending stress analysis. . 134 4.21 Screen capture from the CAD software showing the cut section properties. 137 
4.22 Load path indicating torsion from an unbalanced deck load. . . . . . 138

4.23 Free body diagram of the cart assembly for the reaction forces under the longitudinal beams. . . . . . . . . . . . . . . . . . . . . . 141

4.24 Stress state in the longitudinal beams from a vertical acceleration. . 142

4.25 Stress state in the rail channel beam from an a reaction of the combined maximum vertical and horizontal accelerations of the cart assembly.

4.26 Image of a polymer compression spring of the rail support assembly in contact with an aluminum collision tube of the cart assembly. . . . . 144

4.27 Load path through the deck assembly from impact loading. The dotted lines follow the load path and the arrows at the bottom indicate the pockets where the ER dampers contact the assembly. . . . . . . . . . 146

4.28 Seat deck showing stress state from a $25 \mathrm{kN}$ force. . . . . . . . . . . . 147

4.29 The load cell lid plate (above the load cell) and attached brackets showing stress state from a $40 \mathrm{kN}$ force. . . . . . . . . . . . . . . . 147

4.30 The load cell pan plate (below the load cell) and attached brackets showing stress state from $40 \mathrm{kN}$ force. . . . . . . . . . . . . . . 148

4.31 Stress state in one of the deck blocks resulting from a $40 \mathrm{kN}$ force applied by each ER damper. . . . . . . . . . . . . . . . . 149

4.32 Stress state in the cart plates resulting from a $10 \mathrm{kN}$ force applied by each ER damper. . . . . . . . . . . . . . . . . . . . . 149 


\section{Chapter 1}

\section{Introduction}

This chapter presents the motivation and literature review for this research. The objectives and an overall outline are also provided.

\subsection{Motivation}

The use of high-speed craft (HSC) is essential in military, law enforcement, and search and rescue operations at sea. When travelling at high speed in various sea states, these small watercraft can be subjected to an extremely harsh operating

environment. The operators and passengers experience repeated high-g shocks and violent whole body vibrations [1]. Throughout this document, HSC will refer to a vessel class with a length between 9-12 m, and that can travel in excess of 40 knots. These are commonly in the form of a rigid-hulled inflatable boat (RHIB) or a high-speed planing craft.

Several quantitative studies report high rates of injuries with these boats, ranging 
from acute spinal injury to motion-induced fatigue and reduced situational awareness post-transit that are attributed to the HSC motion environment [2]. Furthermore, advances in technology are providing stronger boats and more powerful engines, increasing the top speeds of the boats, and correspondingly the potential of serious injury for the occupants [3]. An example of a HSC flying over a wave is shown in Figure 1.1.

Advances toward ensuring the safety of the occupants are not keeping pace with the expanding roles of the HSC, and with the evolution of the crafts' capabilities [2]. Therefore, there is a need to improve the methods of mitigating the transmission of slam impacts to the occupants.

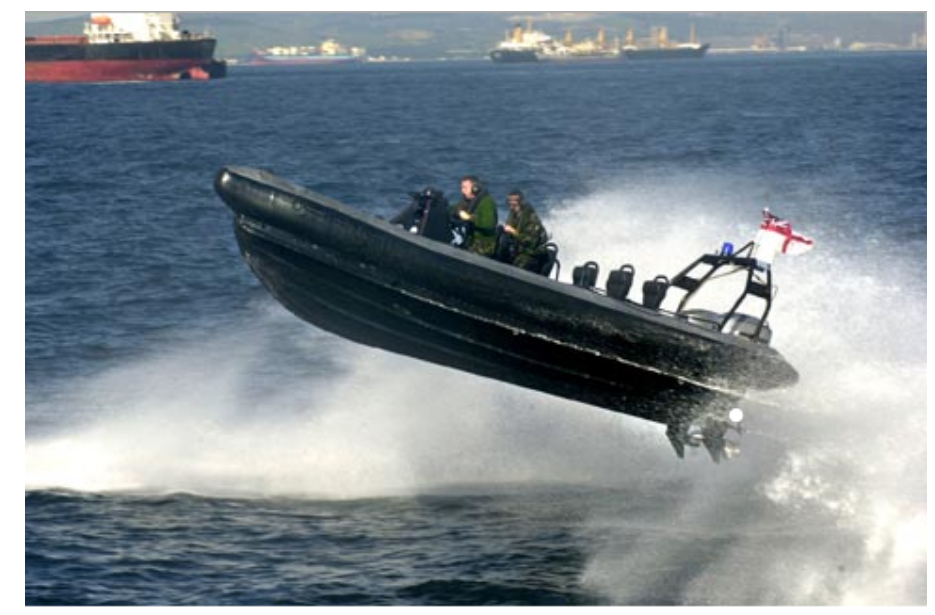

Figure 1.1: Stock image of a HSC flying over a wave. [4]

There are several approaches to reducing the transmitted shock loads between the hull of the boat and the occupants [5]. Redesigning the hull to accommodate the safety and comfort of the occupants would be effective but normally this objective competes with the requirements of maximizing the boat's speed and strength, and the solutions would be complex and costly [6]. Personnel raining programs can equip 
the occupants with awareness of the risks and methods of reducing the potential for injury, and with driving skills to better navigate different sea states at high speeds. Although these programs can be beneficial for improving awareness and skills, there would be a limited effectiveness against severe slam impact events that in some instances are unavoidable. The seats form the link between the boat and the occupants. Suspension seats can be retrofitted onto existing watercraft and different types of seats can be chosen for various applications. Furthering the development of suspension seat technologies appears to be the most viable option for improving the safety of passengers.

Several manufacturers produce suspension seats specifically for the HSC industry. The seats are designed and built with advanced materials, mechanisms, and suspension components. It can be assumed that each manufacturer has a research and development program that progressively tests and improves the technology and effectiveness of their seats. This would be necessary to remain competitive in the industry.

The standards for measuring suspension seat effectiveness can be defined in different ways. Reduction in transmissible accelerations is a simple design criterion. However, more complex metrics exist that are based on acceptable thresholds of human exposure, such as the reduction of the dynamic response index (DRI) [7], ride quality index (RQI) [8], impact count index (ICI) [9], vibration dose value (VDV) [7], SED-8 [10], $\mathrm{R}_{\text {score }}$ [11], or the shock response spectrum (SRS) ratio [12]. Each of these measures forms the basis for an injury risk model from a different government agency or manufacturer. At the moment, there is no consensus within the international community on the most appropriate standard for human exposure limits and for evaluating suspension seat effectiveness. 
Two of the major suspension seat manufacturers are producing seats with semi-active damping technology. These seats are capable of automatically and continuously adjusting the damping properties of the suspension system. Each seat includes an onboard computer that uses a sensor to monitor the ride conditions. The computer then calculates and actuates the suspension adjustments. The method of changing the damping properties differs between manufacturers in that it is either controlled by a solenoid actuated valve, which can change the flow area for the fluid passing the damper's piston, or with the use of magnetorheological fluid, which can change its viscosity based on electrical input. Both manufacturers claim that they are the only one that offers truly capable semi-active suspension solutions [11] [13].

The electronic control systems within semi-active suspension seats have the potential for providing soft responses to large amplitude and low-frequency wave motions experienced at slow boat speeds as well as providing the ability to attenuate a rapidly-applied impact or series of impacts from high-speed operations. Conventional suspension seats have passive suspension components that are preset to offer their best protection during a limited range of operating conditions. This unfortunately results in a seat that may either be uncomfortably stiff during slow speeds or it may bottom out during the harder impacts. The true capability of these relatively-new types of suspension seats and a comparison to conventional passive suspension seats would have to be evaluated by an organization that represents the end user and is not influenced by the manufacturers. This evaluation would also require a repeatable test program with internationally-recognized standards of performance in order to form a comparison. 
Defence Research \& Development Canada - Atlantic (DRDC), as part of an international working group, has pursued an initiative to improve the state of the art for modelling, simulation, testing, and evaluation of shock mitigation seat technologies. This has led to a collaboration with the Carleton University Applied Dynamics Laboratory. The shared goals are to understand the current state of technology, develop a standard test procedure, promote development of more effective technologies from the manufacturers, and to provide technical support on issues relating to HSC analysis and testing. Later, the standardized test procedure can be used as an evaluation tool as part of the procurement process for new seats. [5]

Regarding implementing a test program, there are two distinct options: testing at sea and testing on land using a motion simulating machine. Testing of suspension seating at sea allows for true re-creation of operational conditions. It can be real in all senses, as there is no required simulation of conditions. Any test at sea should be performed with the cooperation of the end users of the seats. Testing at sea requires the use of their watercraft, and their skilled operators to drive them on an appropriate body of water. Otherwise, the research group would need to buy and maintain the equipment, and hire operators. Cooperation with the end users is also an opportunity to include their evaluations for ease of use and relative effectiveness of the seats into the research.

Unfortunately, testing at sea also subjects any occupants to potential injury when pushing the craft to its operational limits and through potentially-dangerous sea conditions. During the testing, the results are dependent on weather and wave conditions. There is no guarantee that a desired motion or sequence of motions will be experienced during the particular test so the results are not repeatable. Due to the necessary time and computer processing power, results are typically analyzed 
after returning to shore. Furthermore, all onboard test equipment must be tolerant of the harsh environment, meaning it should be secured and water resistant. At least, arranging the time and resources can be costly and inconvenient for both the end users and the researchers.

The alternative is to conduct testing on shore using a machine that is capable of simulating the motions that would be experienced at sea. The difficulty in this case is acquiring or developing a suitable machine. This cost could represent a significant initial investment and it would require recurring expenses to support a maintenance program. However, with a suitable machine, the cost per test could be much lower. Use of a machine should also provide more control of the desired conditions, which would be important for implementing a standard testing procedure. Colwell et al. [5] concluded that, "the only reliable method currently available for performing repeatable tests is to develop shore-based testing devices that can accurately replicate full-scale motions and impacts".

\subsection{Literature Review}

Use of a machine to test suspension seats will require background information of the required motion and of the available machines that could be used to simulate the motion. 


\subsubsection{Understanding HSC Motion}

Understanding what happens in this harsh environment is an important step towards developing methods of reducing the risk of injury. Accelerometer data was provided ${ }^{1}$ from testing at sea with a small HSC. These data samples were collected over five days at sea in order to capture various operating conditions. The data sets included accelerations for the astern $(\mathrm{x})^{2}$, starboard $(\mathrm{y})^{3}$, and vertical $(\mathrm{z})$ directions from two types of accelerometers and from two locations: the bow ${ }^{4}$ and amidships ${ }^{5}$. Most of the data was plotted and studied with the intent of gaining a familiarity with the shapes and features of the boat deck's acceleration profile.

A typical example of an acceleration profile in the vertical direction and lateral direction that was extracted from the provided data is shown in Figure 1.2. This acceleration profile corresponds to high-speed travelling conditions. This sample was collected with a Crossbow NAV420CA-100 GPS-aided MEMS inertia system, which was located at the bow, and the sampling frequency was $100 \mathrm{~Hz}$. The data was filtered with a $10 \mathrm{~Hz}$ low-pass filter to isolate the desired multi-body dynamic response, and remove high-frequency noise and structural vibrations. A cutoff frequency of $10 \mathrm{~Hz}$ is recommended for this purpose [14].

Although each impact cycle is unique, there are distinctly recognizable phases within the cycles that contain the most severe impacts. Referring to Figure 1.3, after the boat is launched off the edge of a wave, a freefall is experienced as the boat approached the next wave. Initial contact with the next wave produces the

\footnotetext{
${ }^{1}$ DRDC Canada - Altantic

${ }^{2}$ towards the rear of the boat

${ }^{3}$ towards the right side of the boat

${ }^{4}$ the front of the boat

${ }^{5}$ the centre of mass of the boat
} 

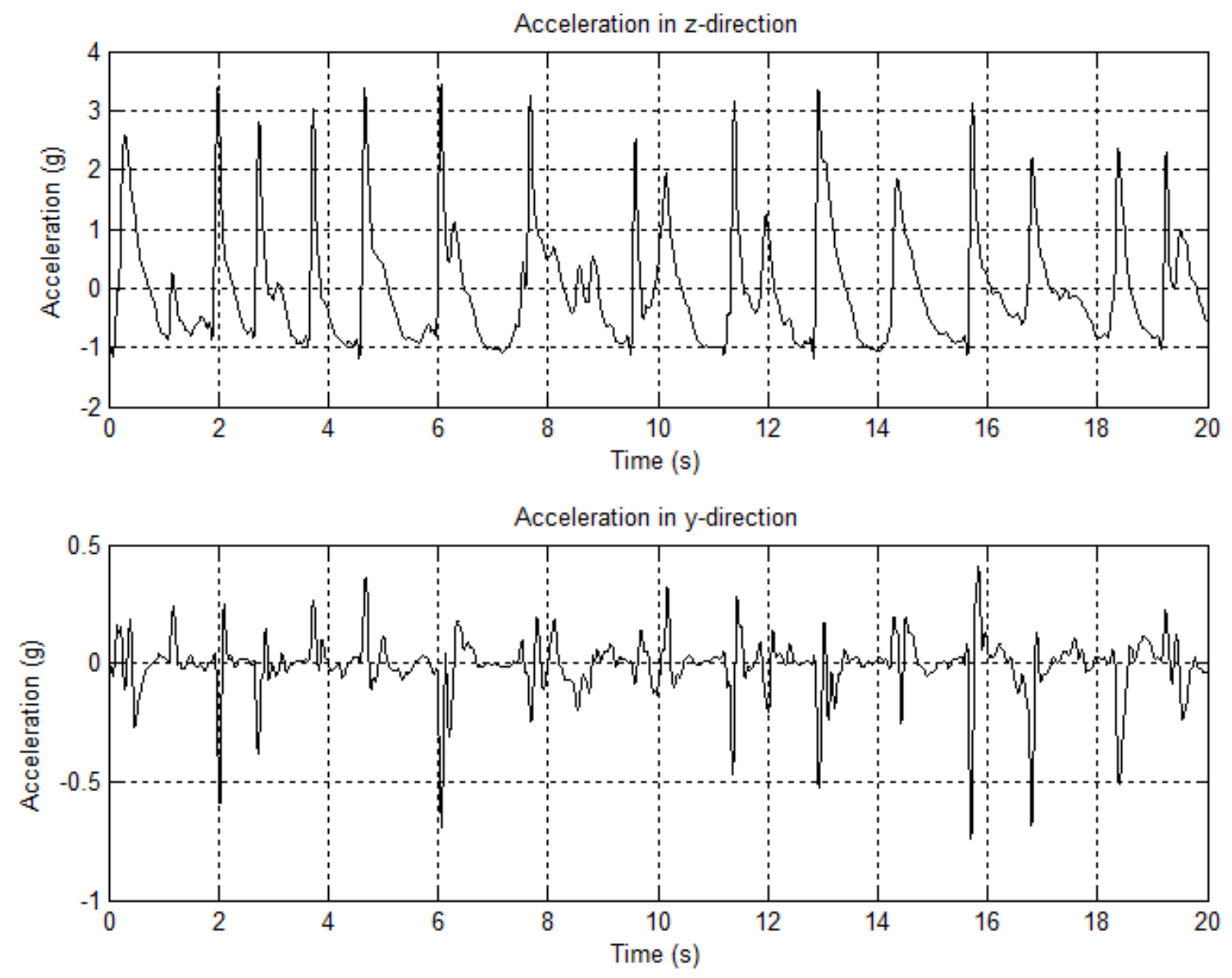

Figure 1.2: A 20 second sample of accelerometer data in the vertical direction (top) and in the lateral direction (bottom), measured at sea.

nearly-instantaneous spike of the slam impact. Then, the hydrodynamic reentry appears as a gradual decrease in acceleration as the buoyancy and lift forces reset the boat's position on the water. This transitions into the negative acceleration of a new freefall phase when the boat is launched off the next wave.

The sample that is shown in Figure 1.2 can be considered to be representative of a large amount of data that was studied. The maximum acceleration magnitudes that were observed were less than $5 \mathrm{~g}$ in the vertical direction, and were less than $1 \mathrm{~g}$ in the lateral direction. The data set was limited to a 5 day period, so it is possible 


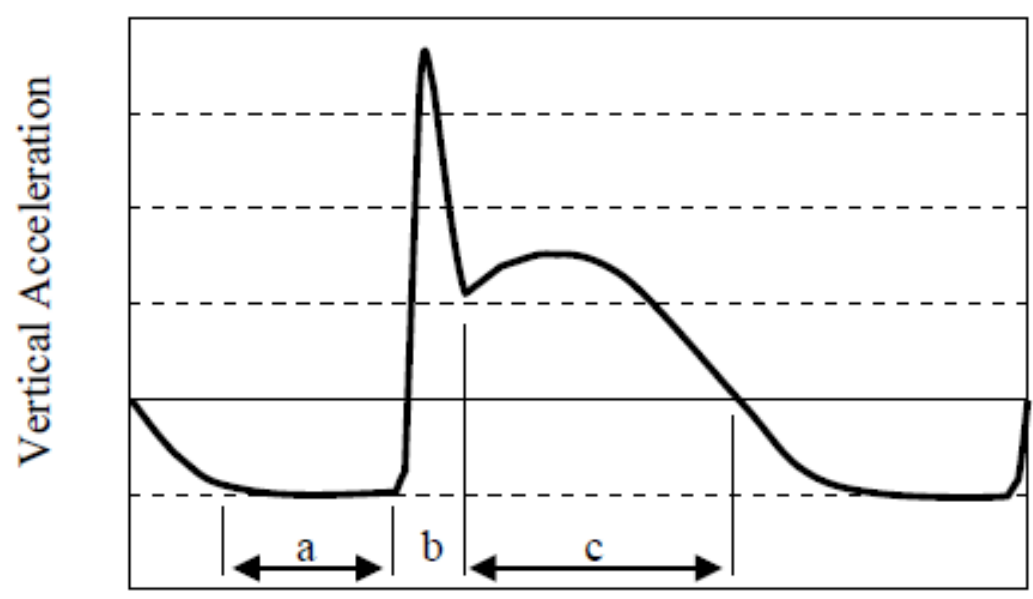

Time

Figure 1.3: The phases of a typical acceleration profile during at-sea testing. Phase (a) is the freefall, phase (b) is the slam impact, and phase (c) is the hydrodynamic reentry. [5]

that higher accelerations may be experienced.

\subsubsection{The State of Available Seat Testing Machines}

Almost all shore-based testing of suspension seats has been performed with some type of drop tower. A drop tower is capable of producing a single impulsive acceleration profile with a potentially very large magnitude, which can resemble the initial high acceleration peak that is present in slam impacts observed at sea. Testing with a drop tower is also preferred because the construction and operation of a drop tower is quite simple. The structure involves an upright frame that vertically guides the motion of a rigid table or carriage. The tested seat is mounted onto the table and is raised by a winch or hoist to a specific height. A mechanism releases the lifting connection and the mass freefall drops onto an object or material that dampens the impact energy. The shape of the dynamic response is dependent on the drop height 
and the type of impact absorbing material that is placed under the dropped table. A higher drop height produces a more severe impact and a softer damping material lengthens the duration of the impulse. The results are not easily predicted by these two parameters but they have good repeatability. Figure 1.4 shows the drop tower used for SHOXS suspension seats by Coast Dynamics Group and Figure 1.5 shows the drop tower that is used by the UK Ministry of Defence.

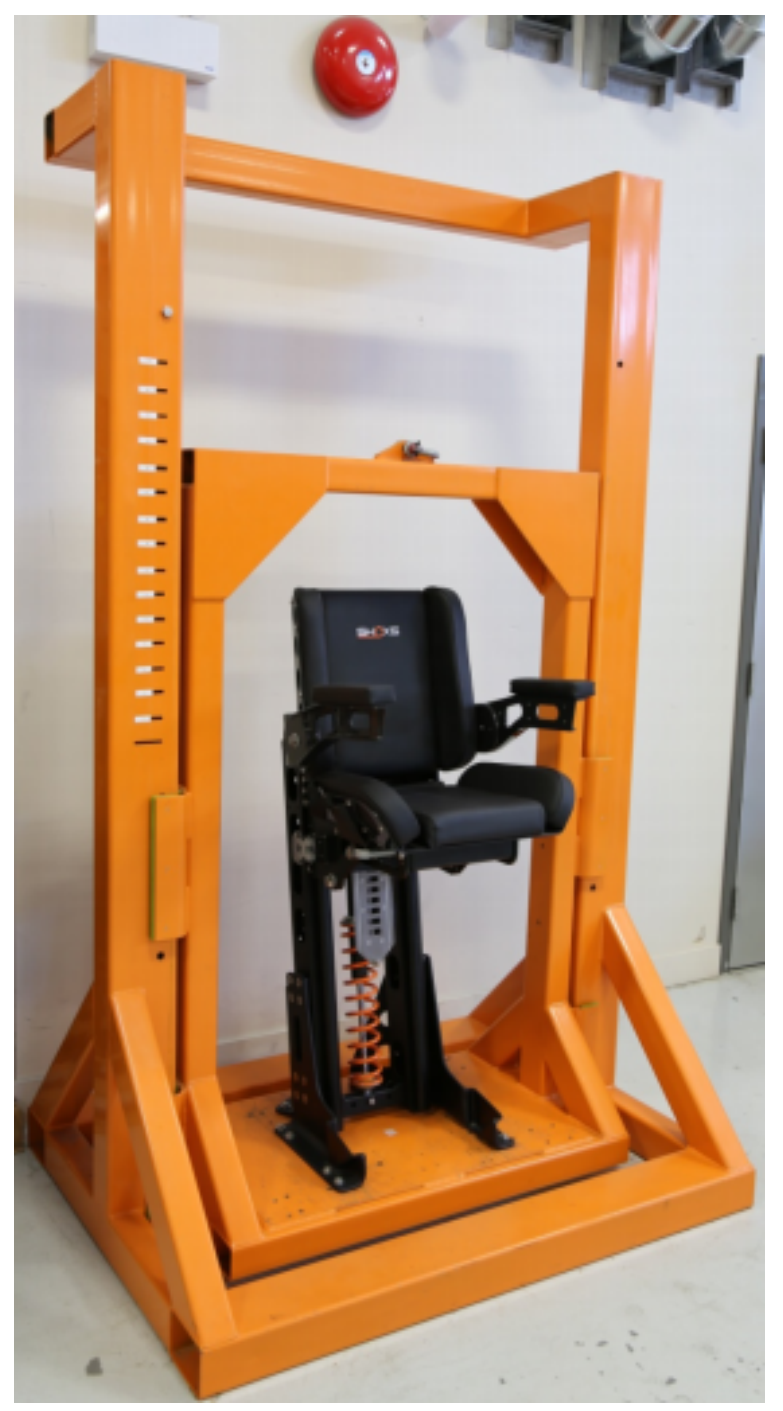

Figure 1.4: Drop Tower used by the SHOXS suspension seat manufacturer. [11]

Drop impact testing is not a new field and it is not exclusively used for seat testing. 


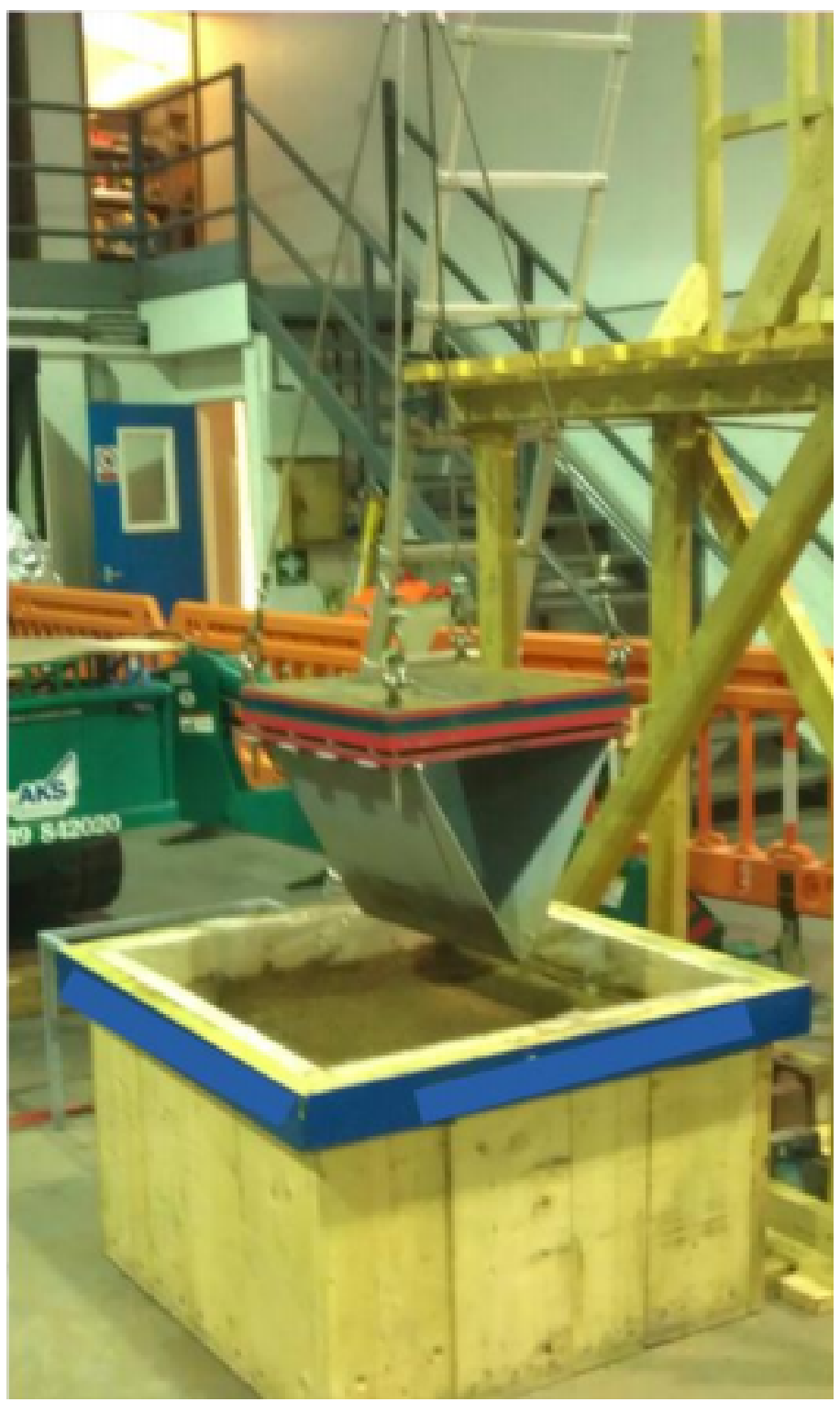

Figure 1.5: Drop Tower used by the UK Ministry of Defense. Sand is used as the impact absorbing material. [12]

Many other products must undergo drop testing as a method of simulating a collision or an explosion. Drop testing is well-suited for simulating those applications. A drop test is a single event simulating a collision between two objects, which is also a single event. Before a collision, the two objects are independent, and then afterwards, they settle to an equilibrium state together. Commonly, one of the two objects is highly 
rigid, like a concrete structure, and is assumed to have zero deflection and infinite resistive force. This is not fully applicable to the continuous interaction between a boat and waves.

The only similarity between the behaviour shown in drop testing and the behaviour of an HSC on water is the freefall phase and the slam impact. Refer to Figure 1.3 for a diagram showing these phases. During the hydrodynamic reentry phase, an upward force is still applied to the seat base and it gradually diminishes as the acceleration profile transitions into the freefall phase of the next period. Higher-frequency oscillations can exist throughout the hydrodynamic reentry but they are commonly of low amplitude around the gradual transition from positive acceleration to the negative acceleration of the freefall. A typical vertical acceleration profile from at-sea testing is shown in Figure 1.6.

A drop test does not capture this complex extended interaction. The impulse from a drop test resembles a decaying sinusoid with positive and negative amplitudes until the transient signal is attenuated to zero acceleration. A typical vertical acceleration profile from a drop test is shown in Figure 1.7.

Although it is understood that the main cause for serious injury is the slam impact, during continuous motion, the seat's response to the hydrodynamic reentry becomes the initial conditions to the next impact cycle, which is especially important if the period between impacts is less than the time needed for the suspension elements to settle from the last impact. There is a higher chance for the seat's suspension travel to bottom out if the suspension is still partially compressed from the last cycle. Continuous motion control of the seat's base is needed because the full response of 


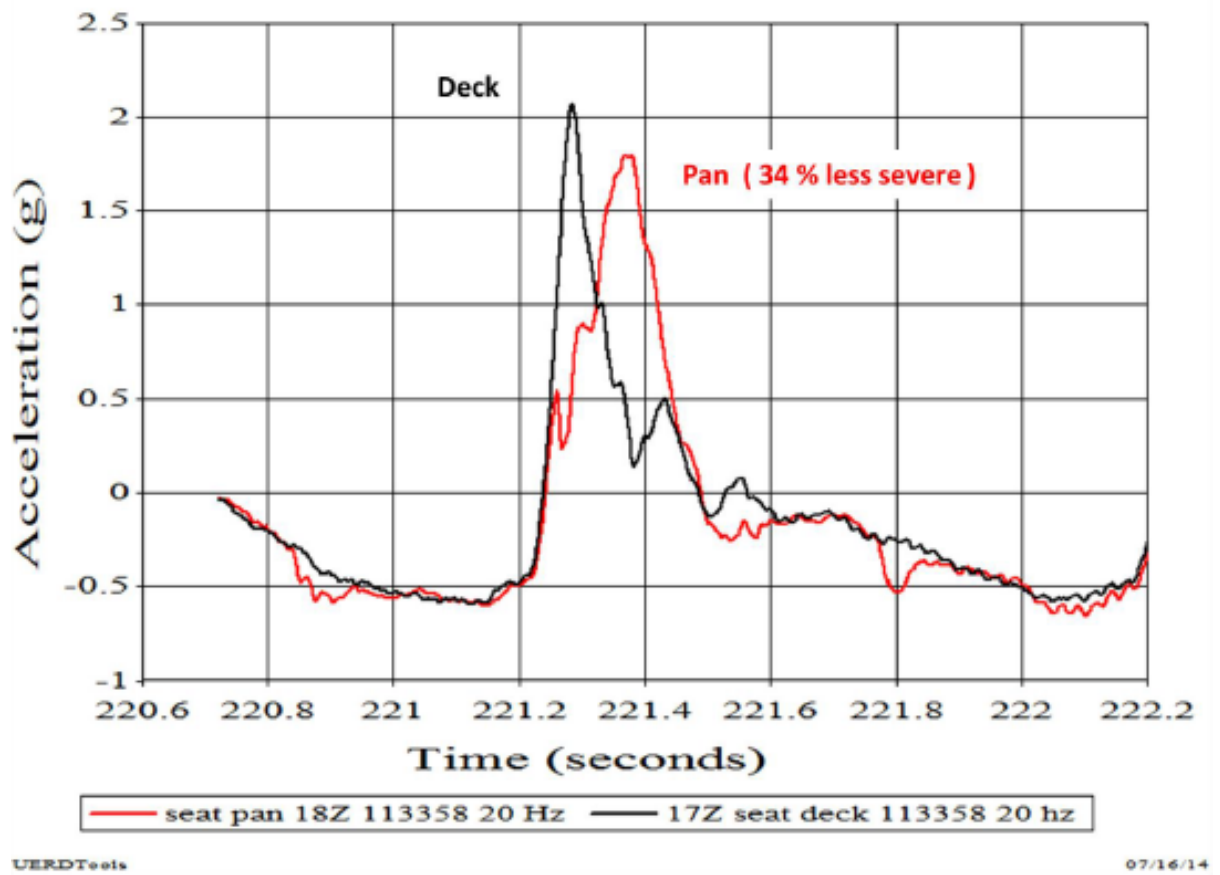

Figure 1.6: An example of the acceleration profiles of the boat deck and a seat pan during at-sea testing. [12]

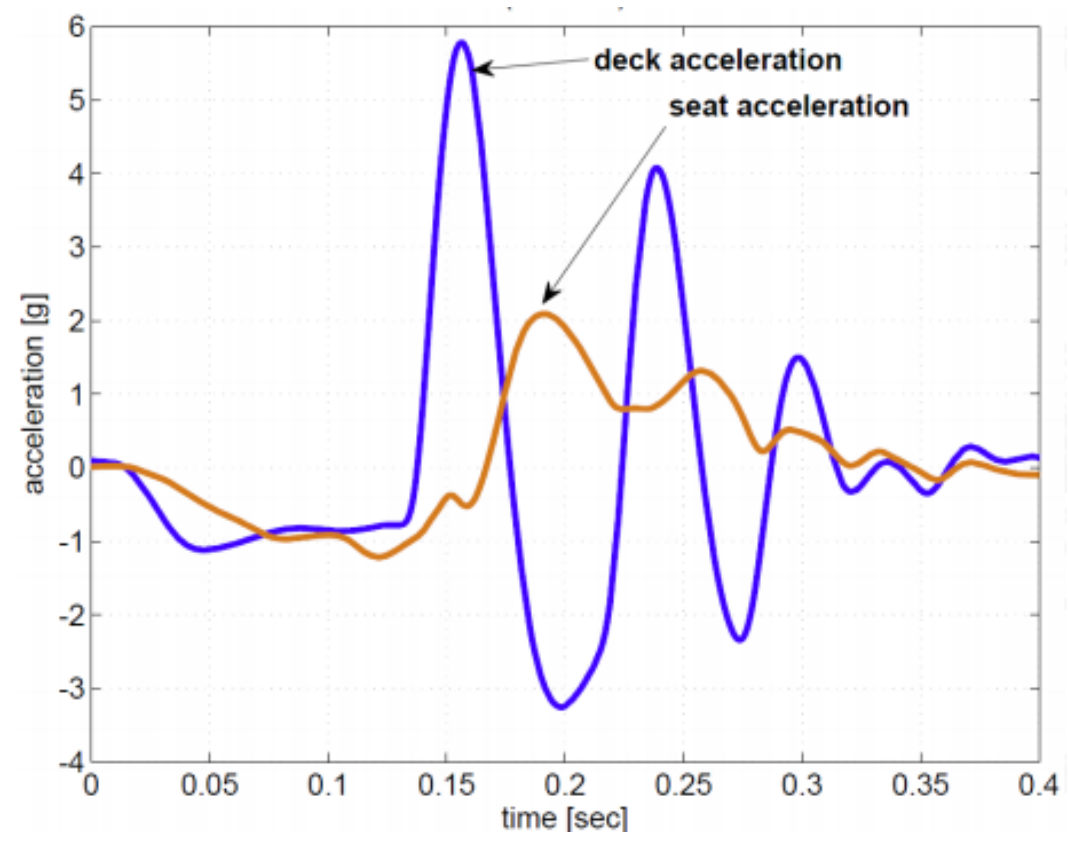

Figure 1.7: An example of the acceleration profiles of the carriage deck and the seat pan during a drop test. [11] 
the seat in at-sea conditions is continuous.

A seat testing machine was built at the Virginia Polytechnic Institute, within the last five years, which is capable of actuated and controlled continuous motion. Its construction was part of the research project by Christopher Liam [15]. The machine consists of a rectangular frame that guides the vertical motion of an inner carriage. The motion of the carriage is actuated by a hydraulic cylinder with a \pm 2 inch stroke and a force capacity of 2200 pounds. The system is electronically controlled with position and force modes, and it is capable of measuring the force, acceleration, and displacement of the carriage's response. A photo of the machine is shown in Figure 1.8.

A significant advantage with this machine over drop testing is the ability to produce a continuous vertical excitation of a seat's base. Acceleration profiles that were measured from different-sized watercraft were used as input signals to the machine. The acceleration profile was integrated twice to produce a displacement profile and then filtered to isolate frequencies into a range that limited the displacements to be within the 4 inch stroke of the hydraulic cylinder. As an example, the excitation signal that represented the "small-sized craft", being a 36 foot planing craft, was filtered to isolate frequencies between 2.1 and $70 \mathrm{~Hz}$, in order to limit the displacement. A sample of the displacement profile used as an input signal is shown in Figure 1.9. Sinusoidal and square wave motions were also produced to test the frequency response of the seat.

There are some undesirable byproducts of motion simulation with short displacements. By filtering out the low-frequency amplitudes, the hydrodynamic reentry and the freefall phases disappear. The remaining signal looks like a symmetric oscillation that shakes the seat and includes negative accelerations that are greater than $-1 \mathrm{~g}$. 


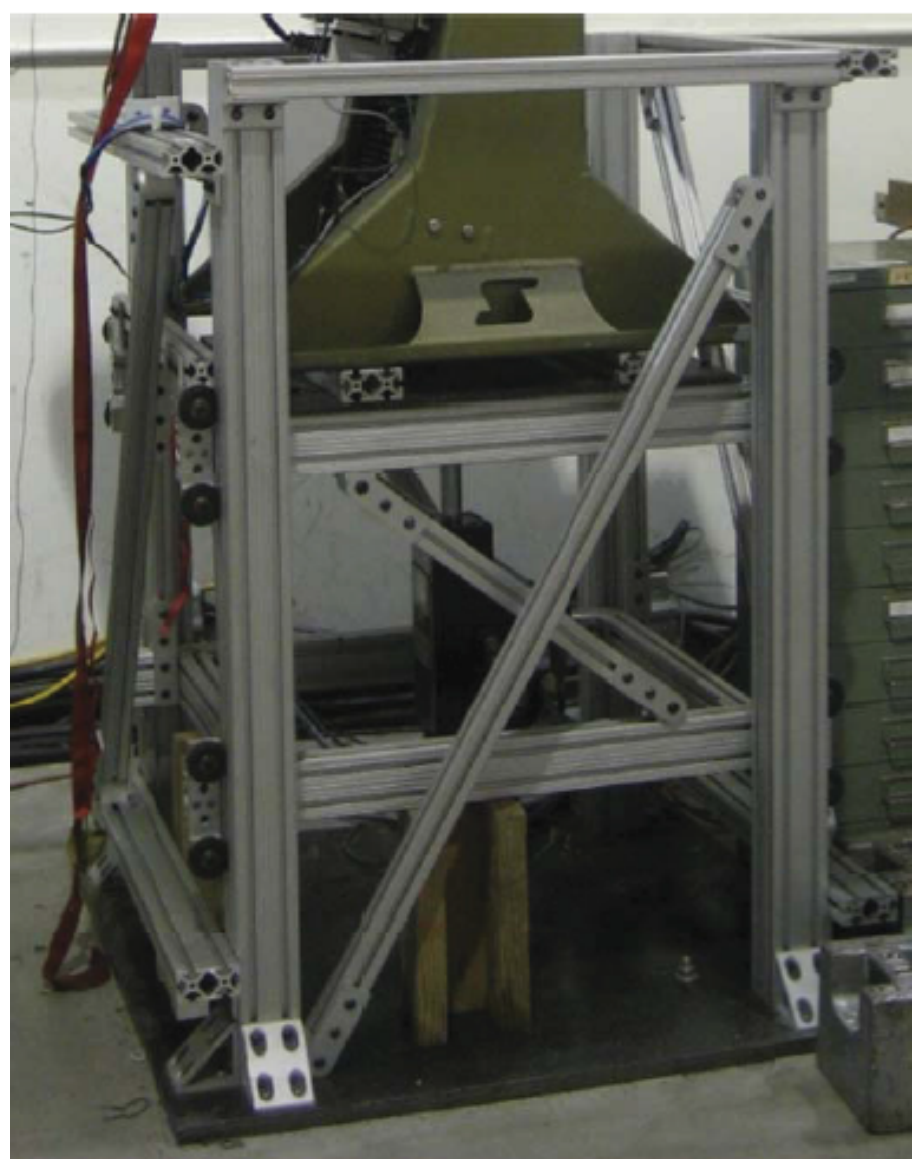

Figure 1.8: The seat shake rig at Virginia Polytechnic Institute features vertical motion from a hydraulic ram. [15]

A larger stroke actuator can capture more of the behaviours of the seat's suspension. The argument for the use of drop tests can also be made with this machine, being that the hydrodynamic reentry and the freefall phases are insignificant because they are low-energy motions and should not lead to injury. These phases affect how the suspension settles between slam impacts. Reproduction of full-amplitude motion can investigate the relative effects of the three phases.

Semi-active seats should have the capability of providing appropriate damping for a variety of conditions. Understanding how the control systems of the currentlyavailable semi-active suspension seats perform under different conditions may only 


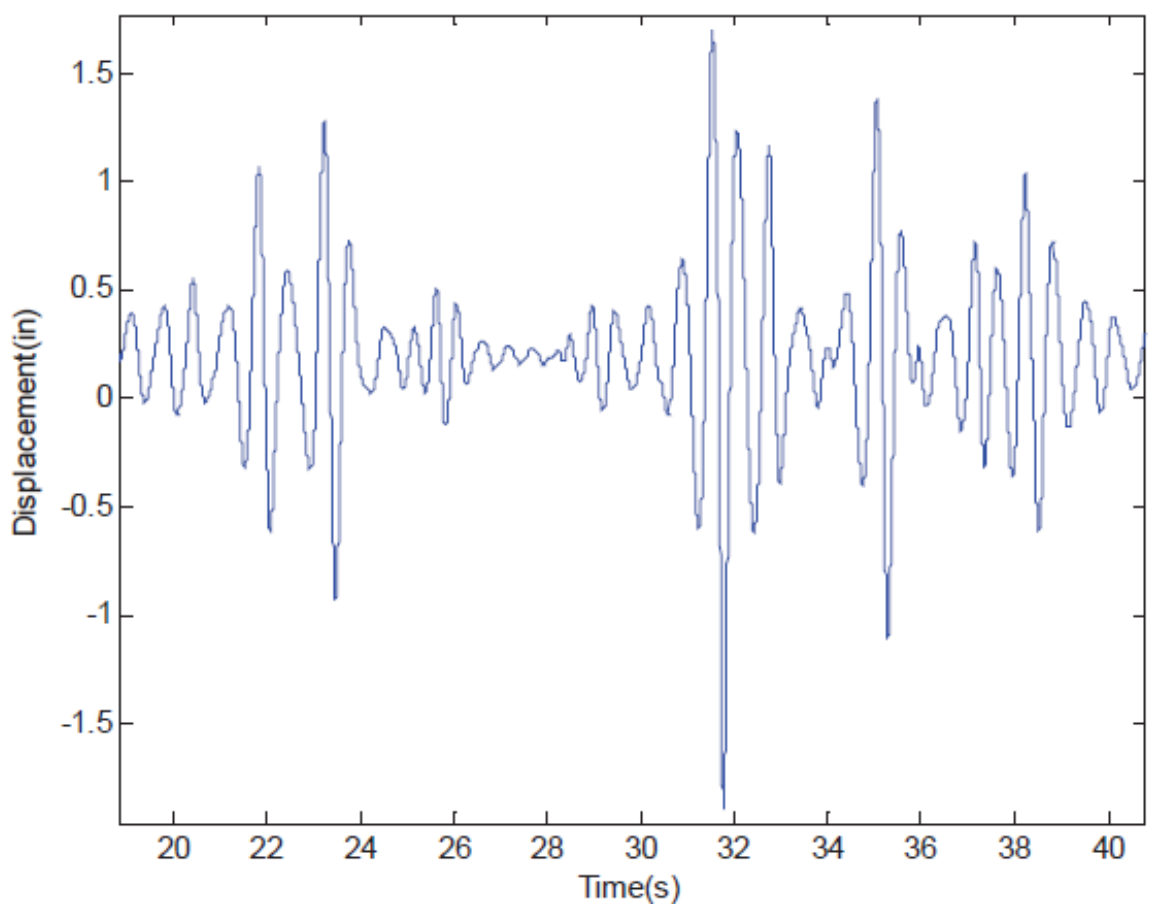

Figure 1.9: Sample of a position profile input for the hydraulic actuator. [15]

be possible by repeatable tests that would include full-scale motions and slam impacts [5]. Based on the review of available seat testing machines, it is evident that a different machine needs to be used, which incorporates the abilities of both of the existing types of machines.

\subsubsection{Review of Motion Simulating Machines}

Many other machines exist for the purpose of simulating motions or impacts. Purchasing an existing machine would only be a feasible option if an existing machine satisfied all requirements and constraints, which are described in Chapter 2.

An electromagnetic shaker is a commonly used machine for vibration testing. An 
example of one of these shakers is shown in Figure 1.10. These machine are used for testing seats for the transportation industry, where the tests aim to evaluate the quality of comfort over an extended length of time. They can reproduce high accelerations, but with short amplitudes. Coe et al. [6] evaluated the use of shakers for HSC suspension seating and argue against the practicality of their use as a testing solution.

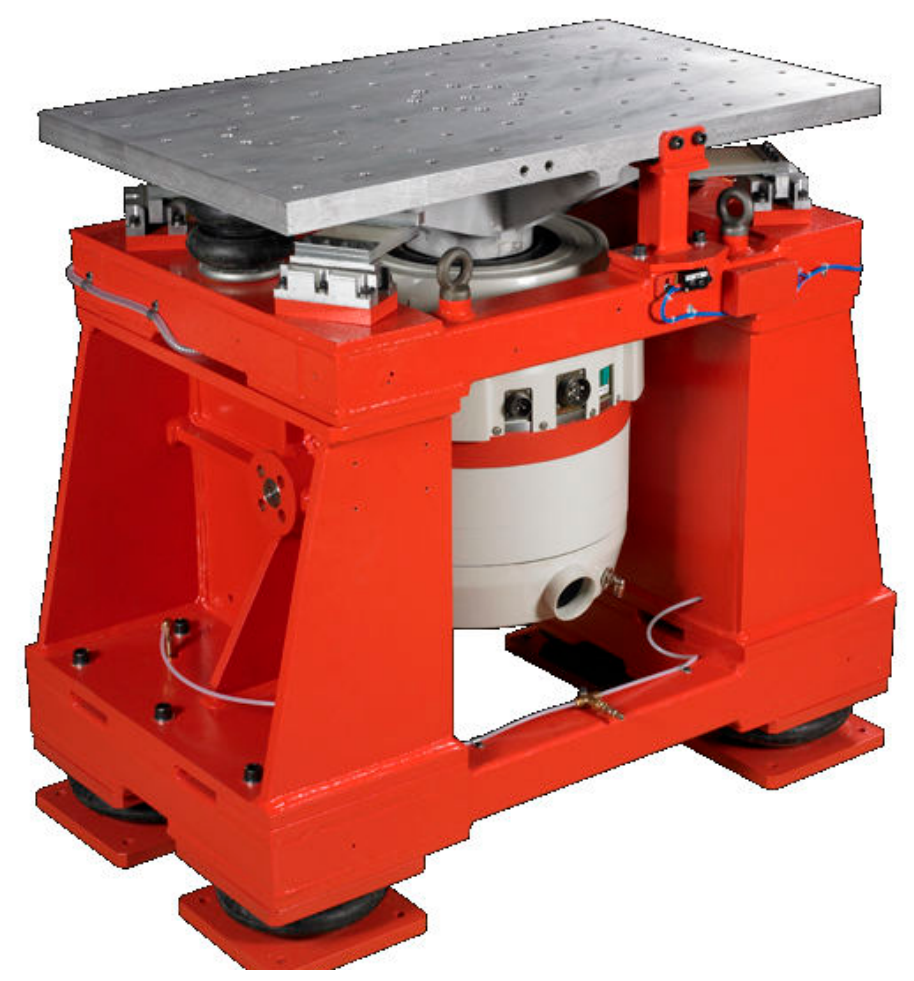

Figure 1.10: An example of an electromagnetic shaker. [16]

Stewart-Gough platforms are commonly used for training operators for aircraft or automobiles, where a simulated cockpit and control interface would be built on the top platform. An example of one of these motion platforms is shown in Figure 1.11. They have an excellent capability for continuous motion with 6 degrees-of-freedom (DOF), but there is no indication of their ability to produce a large impulsive acceleration. Installing such a machine in the allocated laboratory space would require the removal of an existing concrete wall. 


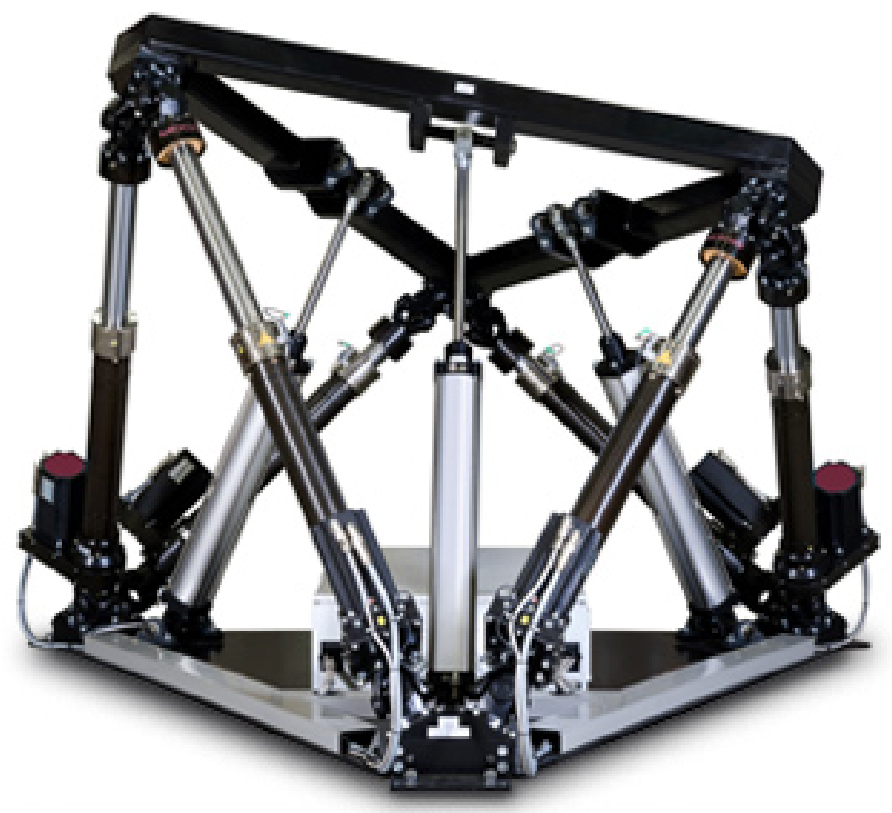

Figure 1.11: An example of a Stewart-Gough motion platform. [17]

An industrial articulated robotic arm can provide large-amplitude motion in multiple degrees-of-freedom. These machines are commonly used for manipulation of parts in industrial environments. An example of one of these robotic arms being used as a flight simulator is shown in Figure 1.12. Although this may be suitable, the robotic arm would be very large and likely very expensive for the required payload and range of motion.

The vertical motion simulator at the AMES Research Centre is a massive motion simulator that features $\pm 30 \mathrm{ft}$ translations in the vertical and $\pm 20 \mathrm{ft}$ translations in the horizontal directions. A model of the simulator is shown in Figure 1.13. This massive machine features guided vertical motion along two posts and a boom that spans between them. The testing cockpit is on top of a conventional-sized 6DOF motion platform, that is on another translating platform, which slides in two 


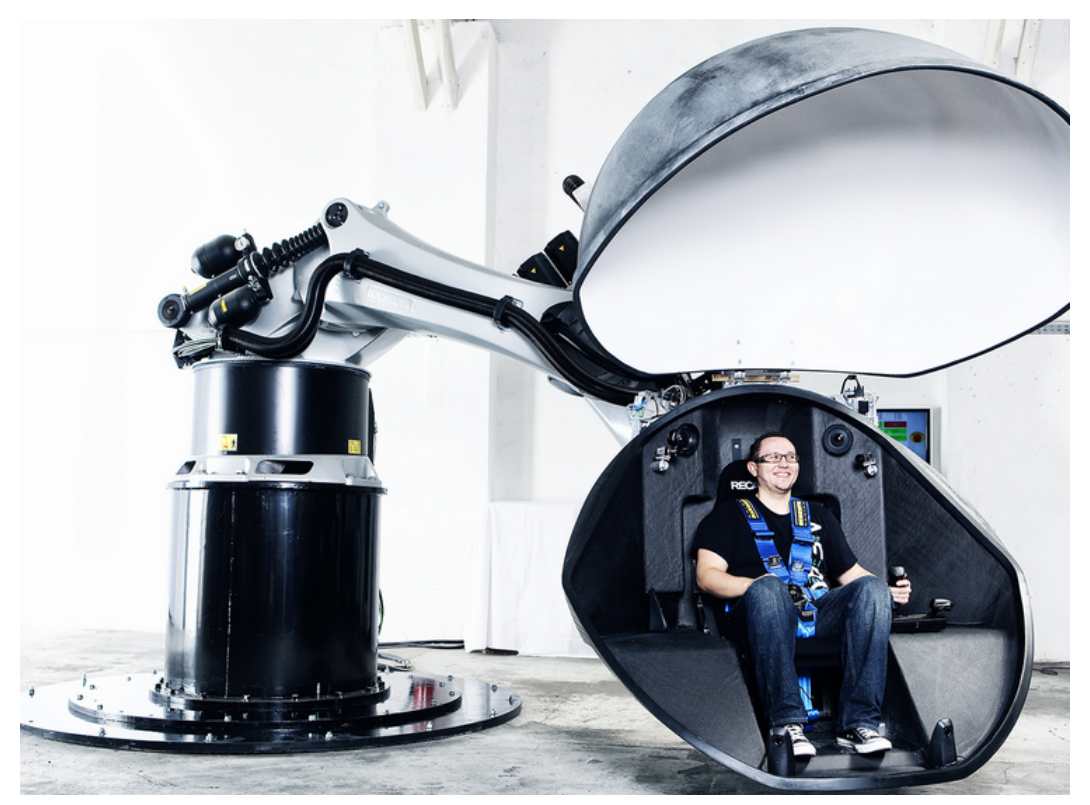

Figure 1.12: An example of an industrial robotic arm being used as a motion simulator. [18]

directions on top of the horizontal boom. The 6DOF motion platform provides the rotational motions directly under the cockpit. Although this is not a commercially available machine, an important design concept is illustrated here. By forming the conceptual design around two orthogonal sets of sliding rails, the size of the simulator can be easily scaled up or down to enclose the desired 2DOF motion envelope without affecting the length of the machine's third dimension. This is not the case for motion platforms or for industrial robots, which must be scaled equally in all directions.

Based on a review of commonly manufactured motion simulating machines, no particular machine was found to be suitable for reproducing large-amplitude motions and impulsive high-g accelerations that can specifically be acquired for this application. A new machine should be designed with the inclusion of some features of distinctly different types of existing machines. The combination of a versatile 


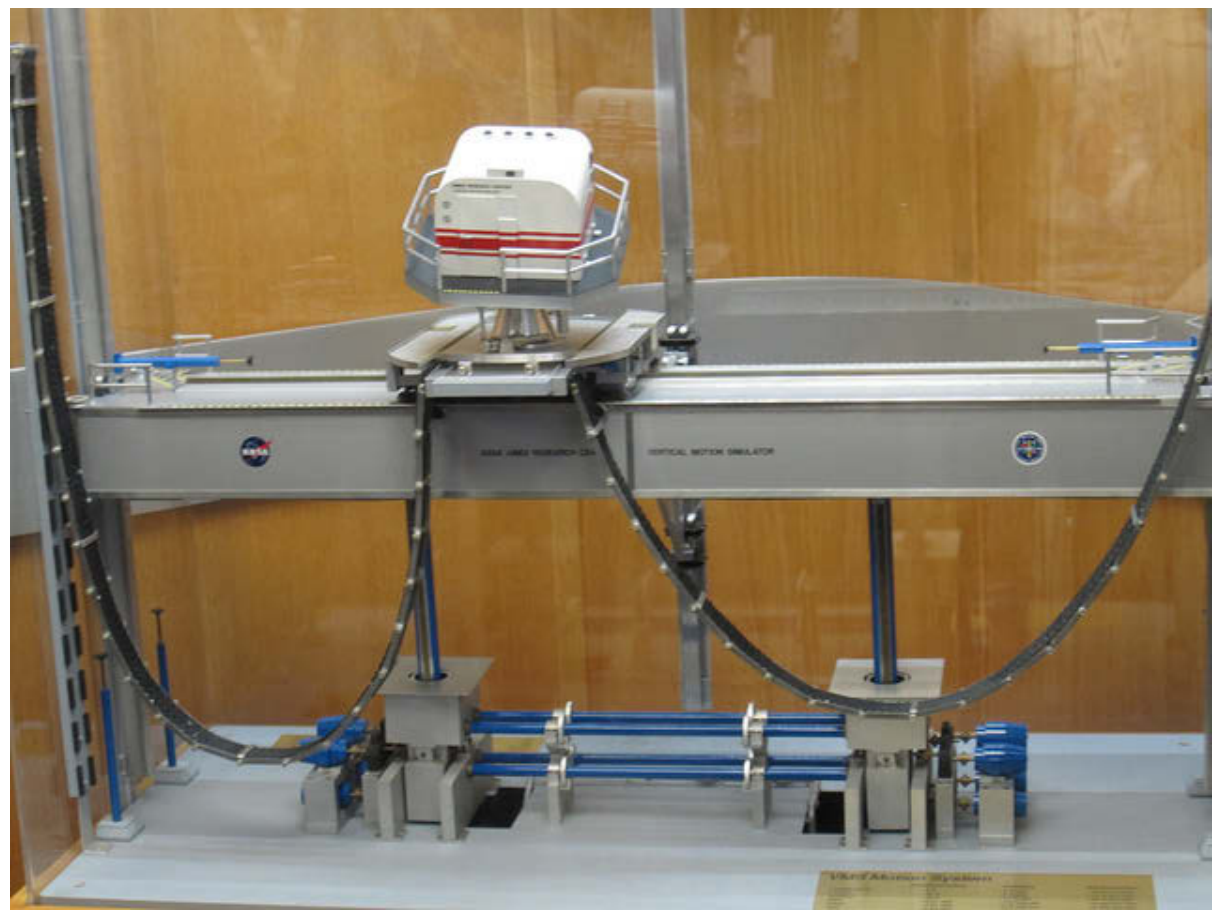

Figure 1.13: A model of the vertical motion simulator at the NASA AMES Research Center. [19]

new machine with a comprehensive testing program may be the best solution for properly evaluating the effectiveness of existing suspension seats and potentially lead to recommending improvements in the technology.

\subsection{Thesis Objective}

The objective of this research project is to design and build a machine for the purpose of testing marine suspension seating. The machine must be capable of producing large-scaled computer-controlled linear motion in the vertical and lateral directions from the perspective of the seat. The machine must include a means of providing a slam impact to the base of the seat in the vertical direction. The machine must have appropriate sensors for the collection of test data. A software interface is needed to 
control the actuation systems, and to monitor and save the machine's sensor output data. The machine would be named the Slam Impact Seat Test Rig (SISTR).

The following steps must be performed to achieve this objective:

- Identify the requirements and constraints of the new machine;

- Evaluate suitable types of drive systems and perform component sizing;

- Follow the mechanical design process, from concepts, to detailed computer-aided drawing (CAD) models, to analysis;

- Procure drive system elements, hardware, sensors, and the data acquisition system;

- Coordinate the bulk of the manufacturing of parts with a professional machine shop;

- Assemble the machine from manufactured parts and purchased hardware;

- Adjust fits for the best alignment between parts and tighten bolts;

- Install wiring connections between components;

- Interface actuation devices to control software; and

- Develop software programming for basic motions.

It can be considered that the machine has four distinct stages of its life: designing, manufacturing, commissioning, and seat testing. Due to the extensive volume of work required throughout these stages, the stages of designing and manufacturing were separated from the stages of commissioning and seat testing. This thesis mainly addresses the designing and manufacturing stages. 
The latter stages are being addressed in a follow-on research project; however, there are relevant recommendations provided throughout this thesis that are also directly related to the aspects of the design. As an overview, during the commissioning stage, the operational performance will be assessed and control procedures will be developed to prepare the machine for the seat testing stage. During the seat testing stage, existing suspension seats will be tested, a standard test procedure will be developed, and accumulated knowledge will potentially assist in the development of new suspension seat technologies.

\subsection{Thesis Overview}

The layout of this thesis resembles the steps in the design process. In Chapter 2, requirements and constraints of the machine are discussed, along with an overview of the development process for the actuation systems. Chapter 3 details the assemblies and parts of the machine; pertaining to their purposes and any notable features. Chapter 4 presents an evaluation of the structural strength of the machine under several critical loading conditions. Chapter 5 concludes the thesis with lists of accomplishments and recommendations for future work. 


\section{Chapter 2}

\section{Development of Design Concepts}

This chapter will detail the approach taken to develop the design from basic requirements to specific features. Before the structural design could be sketched and shaped, it was important to identify the machine's requirements and constraints that should limit the development of the design. The requirements and constraints are each listed. Then, the development of a suitable actuation method for each type of motion is discussed. The content in this section is presented from the perspective of how it was considered while the conceptual designs were developed.

\subsection{Requirements of the Machine}

The objectives of this research project, described in Chapter 1, are also an overview of the requirements of the new machine. Those requirements are described further in this section and other features and abilities that should be included into the designed machine are explained. 
First and foremost, the SISTR machine needs to be capable of reproducing the vertical and lateral deck motions of a HSC in different sea state conditions. Based on the review of the provided acceleration profiles from the at-sea testing data sample, the machine should be capable of producing accelerations of at least $0.5 \mathrm{~g}$ in the lateral directions and at least $2 \mathrm{~g}$ in the upward direction. In the downward direction, the acceleration profile does not exceed $-1 \mathrm{~g}$, which represents a freefall drop. The range of frequencies shown in the acceleration profiles is between 0.5-2 Hz. The acceleration profiles were integrated twice to get the corresponding displacement profiles and it was estimated that the required distance to reproduce the motions should be at least $2 \mathrm{~m}$ laterally and $1 \mathrm{~m}$ vertically. It was understood that this segment of the data sample represented "high speed" motion, because it contained the most severe slam impacts. Other operational conditions may involve larger amplitude motions but with less severe accelerations, such as for "slower speed" motions over a large wave height. Reproducing additional types of motion will be investigated during the commissioning phase of the machine. The available range of motion of the machine should not cause any limitation in future applications, and hence depending on the relevant constraints, the available travel should be a large as possible.

The SISTR machine needs to be capable of continuous operation. A drop tower can produce a single impact event but continuous operation can investigate the behaviour between impact events. The continuous operation should also be capable of producing a different response profile for every cycle in order to reproduce an acceleration profile that is either from at-sea measurements or from synthesized reproductions of such measurements. The kinematics of each motion cycle should be controlled and reliably repeatable. 
The SISTR machine needs the ability to cause an impact pulse or a freefall slam impact. The peak acceleration at the start of the pulse can be sharp and brief like an impulse. The actuator that produces large vertical motions should not be expected to also be able to produce these impulses. Based on observations of the provided HSC vertical acceleration profiles, the impulses commonly have magnitudes in the range of 3-5 g and a duration in the range of 40-150 ms. Other documentation indicates that the magnitude of slam impact events can be in excess of $10 \mathrm{~g}$ [8]. A drop tower that is available for the Carleton University Applied Dynamics Laboratory research group is capable of producing single event impacts with $25 \mathrm{~g}$ peak accelerations. The SISTR machine is not a replacement for the drop tower and there may continue to be advantages of testing a given seat's response to severe impacts using the drop tower. For the SISTR machine, the method of producing the impact would need to be capable of controlling the initiation, the magnitude, and the duration of the response in order to match the variety of shapes of at-sea slam impacts.

The machine needs to handle a loaded seat. This statement includes many implications. Obviously, if the machine's purpose is to test the performance of suspension seats, the machine needs a generic mounting platform that can accommodate different suspension seats. The mounting platform needs a method of securing the different seats without significant alteration of the initial structure. Replacing a major component in order to mount a different seat could be inconvenient or even impossible. An opening, loading path, or a door will be necessary, as well as an intended process for installing and removing a seat. The generic mounting platform will be subjected to the inertial loads associated with restraining the loaded seat during the most aggressive tested motions. Describing the seat as being loaded refers 
to the inclusion of a mass mounted onto the seat that represents a typical occupant and equipment. Throughout this project, this mass was estimated to be $100 \mathrm{~kg}$. Naturally, in real operations an occupant can be heavier but this value was chosen as a representative value that includes the most-likely sized occupants. The mass of the tested seat was estimated to be $75 \mathrm{~kg}$, although this mass is heavier than an average seat's mass. Ultimately, it is the combined mass of the payload mass that represents the occupant and the seat that affect the structural loading on the machine.

The machine needs instrumentation to collect results from motion tests. Accelerometers attached to each distinct body will be essential. Other quantities worth measuring may include positions, velocities, and forces. A data acquisition unit will be needed and it must be interfaced with appropriate software to save the results as data files.

The structure of the machine should be as light as is reasonably possible. With a given input power, a lighter mass can achieve greater accelerations. This will be especially important for this machine because a large portion of the mass will have to be in motion while supporting the mass of the tested seat. Of course, this requirement needs to be balanced with the requirement of having an adequately strong structure. Awareness of this balance can reduce the dangerous design loop of adding structures and thickening parts to handle higher loads, but then these heavier masses cause larger inertial loads, which can lead to redesigning with even thicker structures. 


\subsection{Design Constraints}

A detailed list of constraints needs to be produced before developing conceptual designs. Constraints guide the design process by limiting the types and shapes of features that could appear in the conceptual designs. The following is the list of constraints that were considered for this machine.

- Available power: The laboratory that houses this machine has 3-phase electrical power in three voltages: $230 \mathrm{~V}, 480 \mathrm{~V}$, and $560 \mathrm{~V}$.

- Room size: The laboratory space that has been allocated is approximately $5 \mathrm{~m} \times 1.5 \mathrm{~m}$, with a height of $3.8 \mathrm{~m}$. The room has a standard sized door, which prevents the installation of any parts that are larger than this door frame. Use of large lifting machines, such as forklifts or overhead cranes, is not possible.

- Seat size: Every seat has to fit onto the machine's testing platform. The Stidd 800v53 is the largest seat that was provided to the research group for the purpose of this project and was used to define the minimum platform space.

- Shock loading: The transmission of shock loads through drive components should be reduced or avoided. This can lead to premature wear or require that the components are excessively strong in order to compensate for shock loading. This is especially true for gears, toothed belts, and chain links.

- Cost: The design process needs an awareness of expected costs for manufacturing and for purchased parts.

- Manufacturability: If possible, the machine's parts should be machined in a local machine shop to simplify direct communication and minimize shipping costs and time. The machine will be assembled by the research group. Parts 
should be designed with consideration for ease of manufacturing and assembly.

- Complexity: An increase in complexity designed into parts and assemblies is accompanied with an increase in the likelihood that the parts or assemblies may not work properly. Higher reliability is required regarding the dimensional accuracy between the CAD models and the final assembly. This has the potential to increase costs of machining and time for assembly.

- Available time for manufacturing: The machine needs to be designed and built within the allowed time for the research project.

- Using available materials and stock sizing: Metal stock is purchased in standardsized profiles, lengths, and from certain alloys. Straying from commonlyavailable stock has the potential to increase costs and time. Also, the machine should be designed with the dimensional unit of inches to be consistent with local stock sizing.

\subsection{Evolution and Evaluation of Design Concepts}

This section provides an overview of the concepts that were considered throughout the design process for the development of the actuation systems. Potential methods of actuation were evaluated based on the requirements and constraints. The development of the structural design has been omitted due to the difficulty of presenting that process with sketches and incomplete CAD models. A detailed description of the major assemblies and parts of the final design is provided in Chapter 3.

Several Matlab programs were developed to support the design process. Each program was built as a design tool for exploring relationships between parameters 
and to foresee their effect on the dynamic system. They were not intended to be comprehensive simulations. The programs that were most relevant to important design developments are described in this section and the codes are included in Appendix A. These simulations can contribute to future work, where it is anticipated that a dynamic model of the machine will be developed. The development of a dynamic model and any future simulations will need to work cooperatively with experimental motion tests to validate the outputs.

\subsubsection{Horizontal Motion}

In the at-sea testing data, the horizontal motion was similar to a lateral oscillation with an impulsive jerk in each period to mark the slam impact event and reverse the direction of the motion. The acceleration profile was mostly symmetric so a modified sinusoidal position control profile could produce the accelerations as they appeared in the boat data. The peak accelerations were at most $1 \mathrm{~g}$ in each direction, but were commonly less.

Although a range of motion of approximately $2 \mathrm{~m}$ would be sufficient for most sinusoidal motion profiles with frequencies between $0.5-2 \mathrm{~Hz}$, which are typical from at-sea testing, it was decided to maximize the available horizontal travel length in case it would be needed for other types of tests. By the constraint of the room's size, this was projected to be up to $4 \mathrm{~m}$. This long range of motion posed a challenge to the design of a drive system.

There were several options for providing the required long range of horizontal motion. 
The most common solution involved a conveyor belt that was driven by a pulley, and a segment of the belt was attached to the horizontally-moving frame. The motor would be located at one end of the range of motion and a pulley would be located at the far end. The type of conveyor belt could be in the form of a chain, synchronous toothed belt, or a cable. This arrangement offered the most variability of options since the motor size, drive ratio, pulley size, and form of conveyor belt could all be chosen. Another option was a motor-driven rack and pinion. For this, a gear-toothed rack would run the length of the cart's travel, and a gear is driven along the rack. The gear is driven by a motor that is mounted on the cart. Although this concept has an advantage of very low backlash, it was not pursued because of the extra weight of the motor and its supporting frame onto the horizontally-moving cart's frame. Another option was a linear motor. For this, a special rail has electromagnetic segments along its length and an electromagnetic carrier block moves along the rail. Depending on the type of linear motor, one of these can be a permanent magnet. The driving force is from a moving electromagnetic field. It is similar to an electric motor, except with the stator windings unrolled from a loop to a line. An advantage of this system is the lack of small meshing parts like in mechanical systems, so the system appears neat and low-maintenance. Unfortunately, these systems are commonly for smaller applications, except for custom-made large applications like Maglev trains. It was decided that a variation of the motor-driven conveyor belt was the most suitable option.

An electric $2 \mathrm{hp}$ motor and its variable frequency drive (VFD) was available for use because it belonged to a past research project that was decommissioned. The past project was also a motion simulator and the motor was driving a mass horizontally, so the motor was considered to be potentially useful for the new machine. A 20:1 worm gear speed reducer was included and could be fitted onto the end of the 


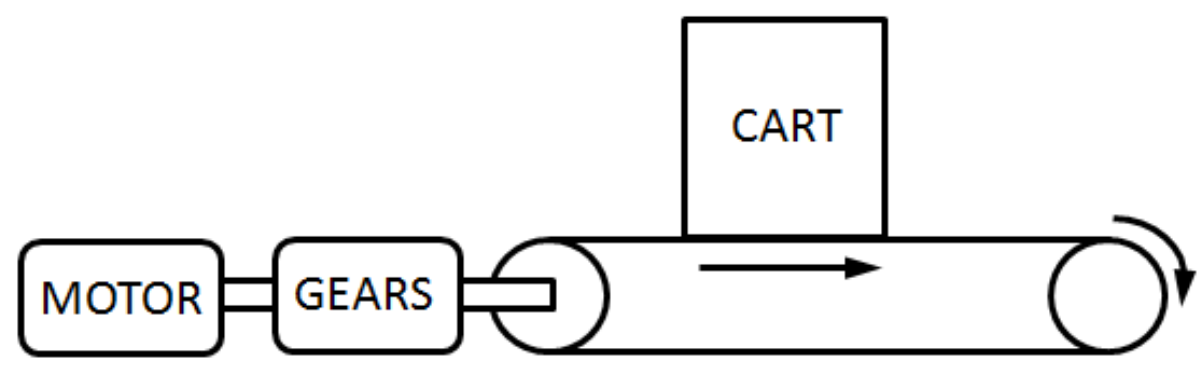

Figure 2.1: Model of the horizontal drive system used for the Matlab simulation program.

motor. Specific information for this motor, drive, and speed reducer is provided in Section 3.4.1. A Matlab program was developed to evaluate the motor's suitability for this project.

The program performed a numerical simulation of a mass translating horizontally. Figure 2.1 shows a diagram that depicts the simulated system and the program code can be found in Section A.1. In the program, a sinusoidal motion profile was defined by an inputted amplitude and period. The boat's horizontal motions are approximately reproduced using a sinusoidal motion profile such that a peak acceleration in each period can represent the effect of the slam impact.

In the program, the position, velocity, and acceleration were calculated for each time increment from the amplitude and period of the defining sinusoid. When combined with a chosen drive ratio, the required torque, motor speed, and ideal motor power could be estimated. This program became a design tool to select the diameter of the pulley based on the apparent greatest possible kinematics of the horizontally-moving mass while working within the limits of the motor's maximum torque, speed, and power. The inputted values for mass, amplitude, period, and pulley diameter could easily be varied and as the program was run, 
the resulting motor parameters could be observed. An example of these plotted results is shown in Figure 2.2. The mass of the moving cart was initially estimated, but as the detailed CAD models were being developed, the program was updated to include a better estimate for the mass. In Figure 2.2, the mass is the maximum mass that was used for the analysis of the drive system. The mass is $475 \mathrm{~kg}$, which includes the cart assembly's mass of $245 \mathrm{~kg}$, the seat deck assembly's mass of $55 \mathrm{~kg}$, the estimated seat mass of $75 \mathrm{~kg}$, and the estimated user mass of $100 \mathrm{~kg}$. The maximum accelerations that could be achieved were approximately $0.5 \mathrm{~g}$.
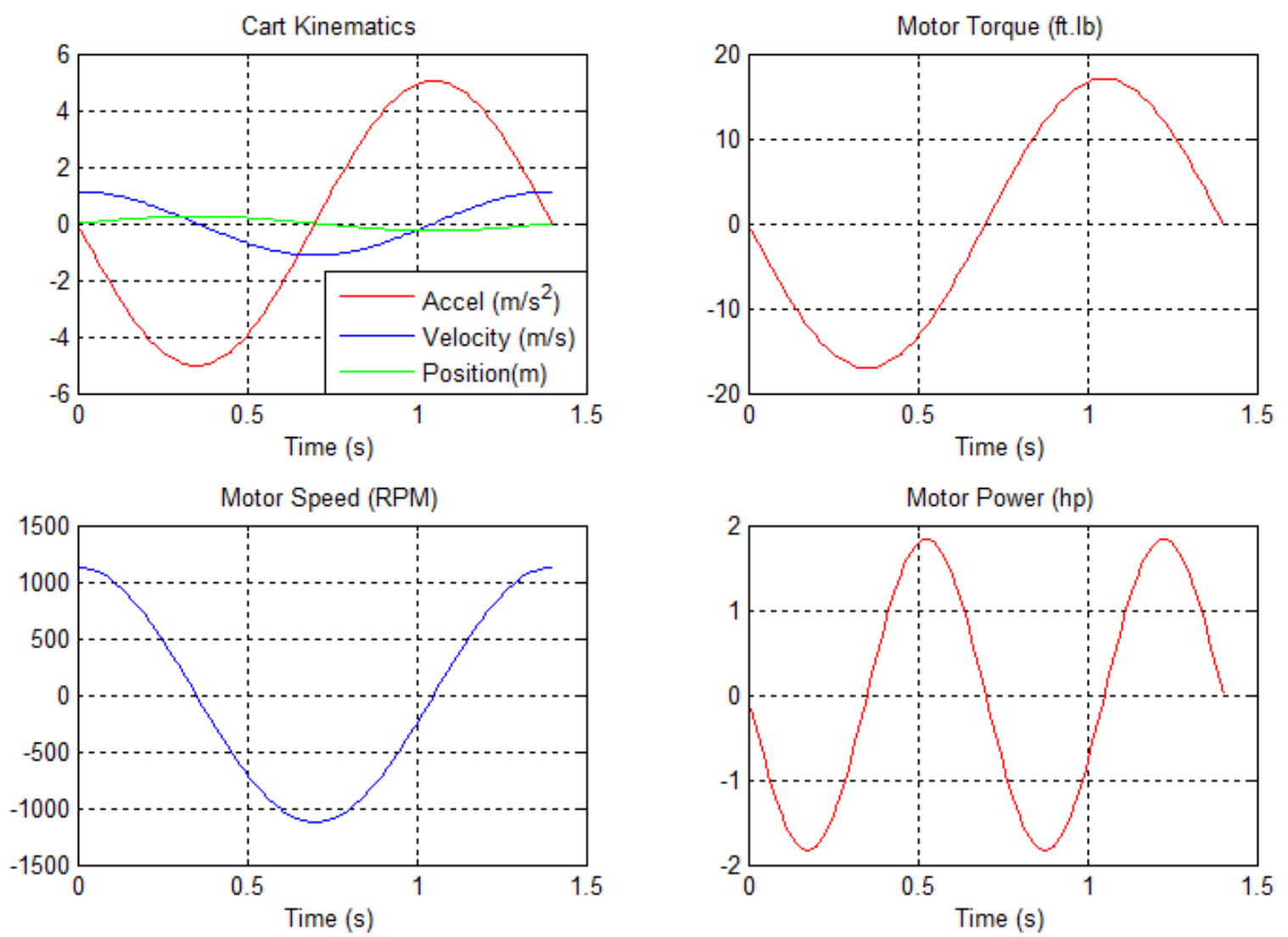

Figure 2.2: Plotted results from the Baldor motor suitability program.

Using the existing 20:1 worm gear speed reducer had an advantage in that a new drive system did not need to be developed, which at one point looked to 
become a custom-designed two-stage chain-driven mechanism with a speed reduction of 8:1. Including the high speed ratio of 20:1 demanded that the pulley or sprocket that would drive the horizontal conveyor motion became much larger as well.

Although this program only evaluated the motor's capability of producing a sinusoidal motion with frictionless conditions and with ideal motor parameters, it still provided good insight into the expected motion. A series of experimental motion tests will later be required to evaluate the motor's full potential for reproducing boat motion. Afterwards, this program can be updated to include efficiency as a derating power factor. Another output of this program was a relationship between the amplitude and period that resulted in an ideal motor power of $2 \mathrm{hp}$. This relationship is plotted in Figure 2.3 and it may be helpful during early motion tests.

Another Matlab program was developed for calculating the stresses of the drive components in the horizontal drive system. The results from this program are presented in Chapter 4 and the program code can be found in Section A.2.

The type of conveyor material was chosen to be a $1 / 4$ inch wire rope cable because of its high strength, it is easily cut to length, and the ability to tension it using the wire end attachments with threaded studs. A \#60 roller chain was an alternative but it would have been much heavier. The length of roller chain would have needed to be greased, which would accumulate dust over time as it would be near the floor. Synchronous toothed belting can be purchased per hundred feet but it would have been several inches wide so the pulley would have been extremely heavy. Also, the attachment brackets on the cart for the wire rope were much simpler than the options for attaching a roller chain or wide belt to the cart. The method of coiling 


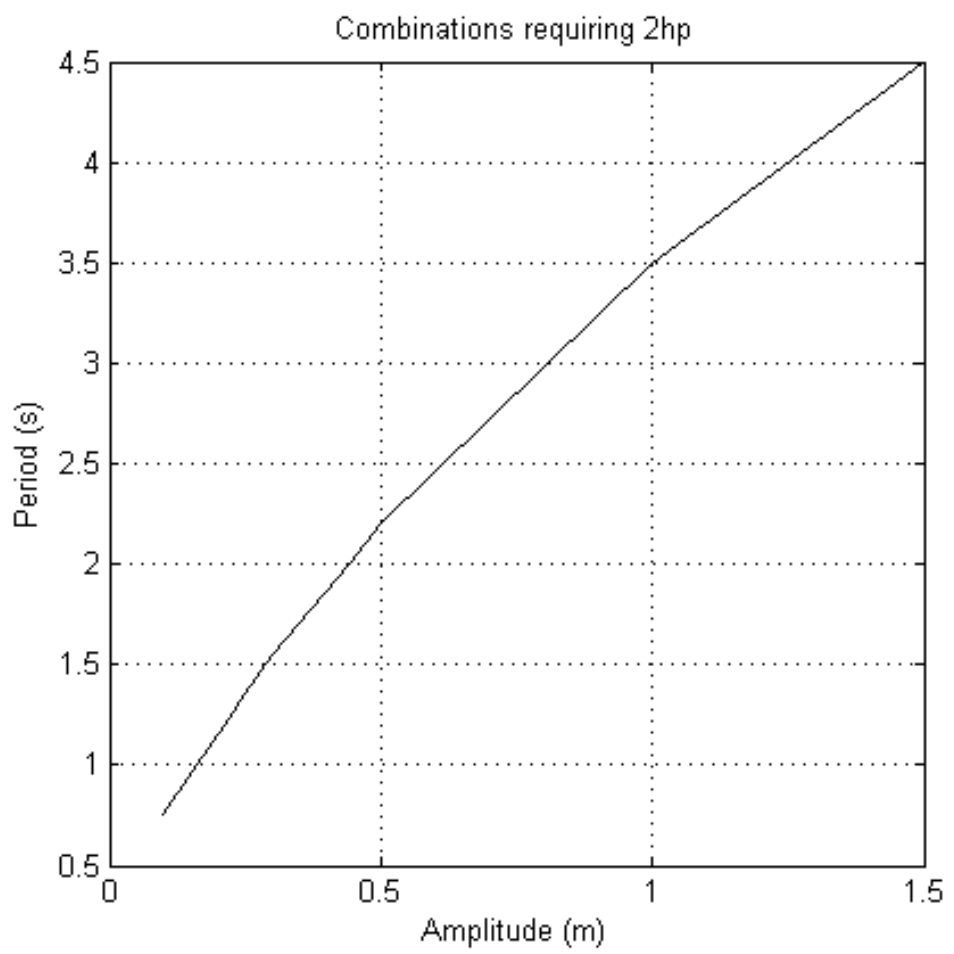

Figure 2.3: Combinations of position amplitude and period of a sinusoidal horizontal motion that result in an ideal motor power of $2 \mathrm{hp}$.

the wire rope around the pulley was inspired by cable spooling machines, where a helical groove is machined into the edge of the pulley to guide the cable.

\subsubsection{Vertical Motion}

It was known from observing the at-sea motion test data that the reproduction of vertical motion would be much more complex than the reproduction of horizontal motions. Vertical motion is very different in that it is always driven against gravity and it is not symmetric. The at-sea testing data shows upward accelerations up to $2 \mathrm{~g}$ within the hydrodynamic phase, and the downward accelerations of the freefall phase are always between 0 and $-1 \mathrm{~g}$. The higher accelerations that appear in the 
initial slam impact of each period were not expected to be reproduced using the drive system. Instead, another device would produce the impulsive force of the slam impact and it would be synchronized with an upward heave from the vertical drive system so the response would appear as a superposition.

Reproducing the full-scale vertical displacements of the boat during at-sea tests would require using all available height in the room. The travel length was estimated to be less than $2 \mathrm{~m}$, even though the available height is $3.8 \mathrm{~m}$, because of the height of a seat and some space is needed for the drive system. Although an integration of the at-sea acceleration profile did not indicate that a longer range of motion was needed, it was thought that this may be a limitation to the capability of the machine. The structural design aimed to maximize the use of the room's height. When installing a new seat, the operator will need to be aware of the available range of motion, and input that value into the motor control software as a position threshold.

By the time that the drive system was being developed, it was decided that the machine's structure would consist of a horizontally-moving cart frame on top of a base frame. The actuator for the vertical drive system would be mounted in the cart's frame and a seat deck frame would move vertically above it. Three methods of actuation were considered: a motor-driven pulley with a conveyor belt, pneumatic pistons, or hydraulic pistons. The use of pneumatic pistons was initially desirable because of the inherent shock-absorbing property of compressed air as opposed to subjecting belts or chains to impacts. Brief calculations for the air consumption needed to produce continuous motion of a long displacement with a large force proved that the pneumatic system would not be feasible as a very large air compressor would be required. Hydraulic pistons could easily provide the large forces but then 
a hydraulic oil compressor would be needed in the room and flexible hydraulic oil lines would have to be fed to the moving cart frame. Similar to the horizontal drive system, a type of conveyor belt was the most reliable solution that could provide the most variability of chosen drive components and the most potential for making the system fit around other space constraints in the cart assembly.

The success of reproducing at-sea conditions will depend on the capability of the vertical drive system. Motion testing will focus on the resulting vertical accelerations when developing programming to produce motions that are comparable to at-sea acceleration profiles. For this reason, a very capable servomotor was purchased along with a versatile drive and its associated control software. The motor selection process required an estimation of the load inertia, top speed, and expected peak torque. A Matlab program was developed to sum the masses of all components as they were designed or purchased and to calculate the rotational inertia of drive system components. The program can be found in Section A.5. The inertias of the pulleys and vertically-moving deck frame were estimated based on geometry and density, and then reflected to a motor's perspective. The ratio of this load inertia divided by a motor's inertia is the inertia ratio, which is an important parameter for an automation engineer during the selection of a suitably-sized motor. The inertia ratio for both drive systems is described at the end of Chapter 3 .

The Emerson servomotor that is used for the vertical drive was chosen based on the best inertia ratio and it was the largest motor that could fit in the cart frame, which was already mostly designed based on the size of the largest seat. The peak torque of the motor is much larger than what is required to reproduce the boat deck accelerations. An upward heave of $4 \mathrm{~g}$ is possible from this motor, which 
includes the static load of $1 \mathrm{~g}$ from gravity. It is good that the power of the motor is not a limitation. Ideally, if the vertical drive can show a capability for impulsive heaves during motion tests, there would be less dependence on a separate device for providing all high-G accelerations. Specific information of the Emerson servomotor and its associated drive is presented in Section 3.4.2.

The vertically-moving seat deck was always intended to be lifted from multiple locations to get a balanced lift with a low tendency to rotate. Two lifting locations would require two pulleys at the bottom and two pulleys at the top. Four lifting locations then seemed excessive. Since the two conveyor belts would always be following the same motion, it was decided to join the two bottom pulleys into a tubular spool. The spool could then be driven on one side and the two bottom pulleys would drive identical conveyor belts. Figure 2.4 shows a diagram of the conceptual design.

As for the belt material itself, the centre-to-centre distance between top and bottom pulleys was not close to a standard size for a synchronous toothed belt, and the belt would have been at least $50 \mathrm{~mm}$ wide. Also, since most motion is expected to occur within the bottom half meter of the travel, the same few teeth would get overused and prematurely worn. Even by traversing the full range of motion, only half of a continuous belt would pass through the pulley. The same issues would apply for roller chains, and a heavy \#80 chain would be needed. The development of a custom made wire rope pulley for the horizontal drive inspired a variation that could be applied to the vertical drive. By attaching one end of a wire rope to the bottom pulley and spooling enough wire rope on the pulley to traverse the range of motion, then the other end can be attached to the seat deck. The drive system would only 
need to lift the seat deck. In the downward direction, the weight of the loaded seat deck drops the seat with an acceleration near to gravity and only slowed by parasitic friction. The drive system can drive backwards at the same rate as the freefalling seat deck to relieve the tension on the wire rope. The wire rope also had the advantage of attaching the same end connector with threaded rods that were used for the horizontal drive system. The threaded rods on the ends of the wire rope offered an easier solution for connecting the ends to the seat deck and for tensioning the lines.

A planetary gearhead with a 7:1 ratio was purchased at the same time as the motor. This ratio was chosen because it was the only available gearbox with a speed ratio that was within a suitable range. The gearhead was bolted to the end of the motor and they became a single unit. Driving the spool from the gearhead required another belted connection. Research into potential drive component combinations led to choosing a synchronous toothed belt from a world-leading manufacturer of belts, Gates Corporation. It produces a series of toothed belts with carbon fibre filaments along the circumference of the belt. When compared to equivalent roller chains, they are much lighter and easier to maintain.

A Matlab program was developed to simulate the behaviour of the vertical drive system when performing an upward heave with a loaded suspension seat. The suspension seat was modelled as two particles with an ideal spring and damper between them. The program code can be found in Section A.3. In the program, each new instance in the numerical simulation is initiated by a simulated torque profile. A value for torque would be transformed into a linear force by a drive ratio and a pulley diameter. That force would cause the estimated mass to accelerate. A numerical integration would then produce values for instantaneous velocity and position. This 
sequence would repeat as a loop for each predefined time increment, which was 0.001 seconds for this program. The torque versus speed profile was defined with an exponential decay function with estimated parameters so that the profile appeared to match the graphed torque versus speed profile from the manufacturer's specifications.

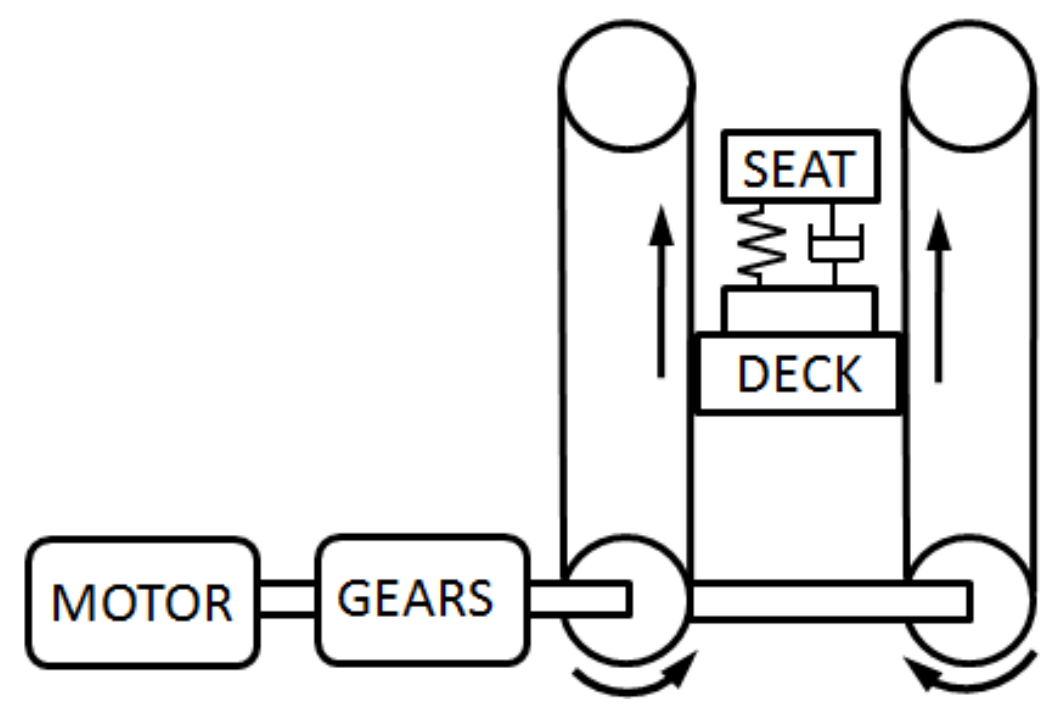

Figure 2.4: Model of the vertical drive system used for the Matlab simulation program.

This program was useful as a design tool for estimating the gear ratio for the 7:1 planetary gearhead that was purchased, and for choosing the pulley sizes of the synchronous toothed belt that connects the gearhead and the cable pulley. This program may be useful during future work if a dynamic model of the vertical drive with a seat is necessary. The program would need to be changed from being initiated from a torque profile to following a position profile, which is how the motion control software operates. 


\subsubsection{Producing the Slam Impact}

The vertical drive system will be expected to reproduce all large amplitude rising and falling motions, but it was anticipated that the slam impact incidents occur too quickly for the drive system to reproduce them properly. In Section 1.2.1, a slam impact is described as a nearly-instantaneous spike in vertical acceleration. Raw accelerometer data showed the existence of slam impacts with peak magnitudes in excess of $20 \mathrm{~g}$ but a large portion of that magnitude was attributed to structural vibration. A low pass filter with a $10 \mathrm{~Hz}$ cutoff eliminated the high frequency content and the remaining profile corresponds to the mechanics of the rigid bodies. The magnitude of the peaks was reduced to a range of $3-5 \mathrm{~Hz}$ for most impacts. Other documentation [8] indicates that the magnitudes of slam impact events can be in excess of $10 \mathrm{~g}$ so the impacting device should aim to achieve this higher requirement while any smaller impacts could still be produced. The duration of the slam impacts are most commonly within the range of $40-150 \mathrm{~ms}$. The method of producing the impact would need to be capable of controlling the initiation, the magnitude, and the duration of the impulse in order to match the variety of shapes of at-sea slam impacts.

A device is needed to deliver an impact to the base of the seat. The seat will be mounted to some kind of moving deck frame so the impact should be delivered to a surface under the deck. Initially, it was thought that the device should be attached to the vertically moving seat deck so that an impact could be produced while the deck was at any position, which appeared to be a valuable feature of the machine. If the device moved with the seat deck, the size and weight of the device became important design constraints, because a large or heavy device would limit the

performance of the drive system. Three types of actuation methods were considered to be capable of delivering a rapid and repeatable impact: compressed air, a spring, 
or an electromagnet. Each of these actuation methods could be integrated into a device that involved a framed shell that would be mounted to the underside of the seat deck, and a ram that could slide vertically within the shell. The ram would be forced upwards at a very high velocity and collide with a surface under the deck. This concept is labelled as Concept A in Figure 2.5. Some form of damping would be required between the ram and the surface because a metal-to-metal collision would provide an unacceptably-short duration of the impact. It was preferable to purchase an existing device instead of designing and building a custom impactor because building a custom device would be a complex and time consuming endeavour.

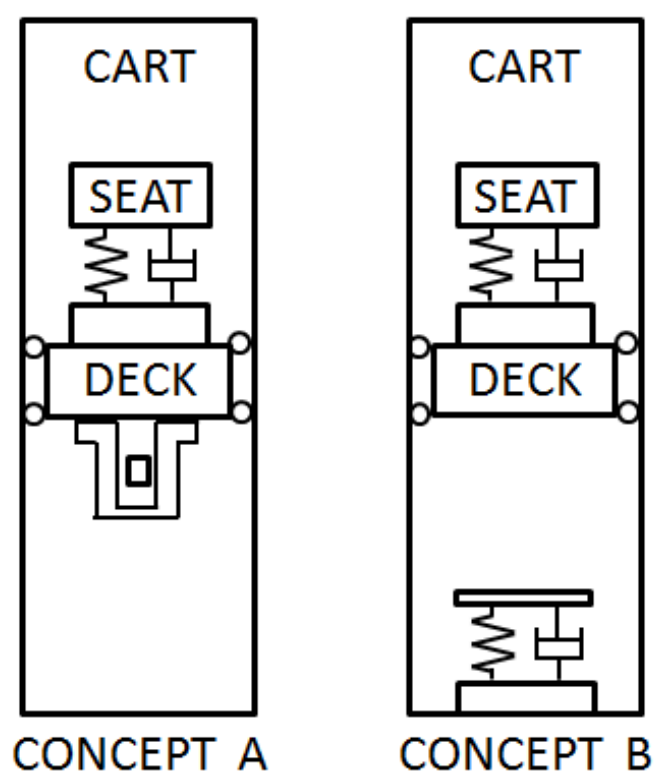

Figure 2.5: Models of the two concepts for producing the slam impact response.

A Matlab program was developed for the purpose of choosing appropriate parameters for a suitable device, particularly choosing the mass and power requirement. The program code can be found in Section A.4. This program simulated the dynamics of two point masses, representing the seat deck and the ram. A force would be applied to the ram mass and it would accelerate up towards the seat deck mass. 
Numerical integration was used to determine the kinematics of the masses for each incremental time step. When the point masses were arbitrarily close, a force from an ideal spring and damper would begin to repel the point masses. The spring's length was chosen to be very short but the stiffness was very high to prevent the two point masses from passes through each other. The repelling force between masses was a basic representation of the impact response. The process of choosing the parameters led to an awareness of the dependence of the impact response on parameters that would inevitably be fixed quantities, such as the mass, stiffness, and stroke length of the sliding ram. Any damping material between the surfaces would also be a preset parameter. The ability to produce a varied impact response could only be controlled by the inputted force to the ram. After the development of this program, the feasibility of an impacting device became less likely.

Regarding the option of a custom-built device, there was an important consideration. This option has an allure of potentially shaping the body of the device to become an integral part in the assembly, and it could have the exact-sized actuator to deliver the ideal impact, as predicted in idealized simulations. Unfortunately, there is a high likelihood that it would not perform in this ideal way because of the complexity of the above-mentioned actuation methods. Any design for a custom-built device would face a limitation by its manufacturability, and various undesirable factors would appear in the behaviour of the final product. Examples of these factors include excessive friction, premature wear, complicated control algorithms, a low range of output variability, unrepeatable results, and a slower cycle time due to the recharging period. Progressing the design by testing a series of proof-of-concept prototypes is one method of overcoming unexpected performance limitations. An entire research project could be devoted to the development of such a device. 
The possibility of purchasing an existing device still needed to be considered. Research into existing devices aimed to find something suitable that was powered by one of these actuation methods. There are compressed-air hammers and large solenoids but no devices could be considered as a feasible option based on the requirements described above. Generally, a device that was powerful enough to produce a significant impact was either very heavy, or there was no indication that a variable response was possible. In all cases, a custom mounting structure would still be required, and there would be no guarantee of useful results until after extensive testing.

It was concluded that having an impacting device attached to the seat deck was not feasible. The alternative concept was to fix the device into the base of the cart. The seat deck would collide with the device as it was near to the bottom of its range of motion. A diagram of this concept is labelled as Concept B in Figure 2.5. This would be similar to seat testing with a drop tower but the addition of the vertical drive system would allow for control of the accelerations before and after the impact. The seat could experience a freefall into the device and the drive system would apply a heaving acceleration at a particular time to synchronize the hydrodynamic reentry with the end of the slam impact. Since the impact energy could be derived from the kinetic energy of the seat deck, the impacting device no longer needed to be an actuator. This results in a much simpler interaction between parts.

With a drop tower, the magnitude and duration of the impact response can be changed by adjusting the drop height, which determines the pre-impact velocity, and changing the shock-absorbing material under the drop tower, which changes 
the damping properties of the reaction force. There is some measure of control since the results have some repeatability and so successive impacts can be predicted based on past responses. In a continuously actuated machine, the pre-impact velocity can be controlled by the vertical drive system. The device at the bottom of the range of motion would need to have a means for adjusting the damping properties.

Commercially-manufactured adjustable shock absorbers were considered. Inside these dampers, the orifice area that allows fluid to flow around the piston can be changed with a manually turned dial on the side of the casing. Adjustments could be made between tests but not between cycles during the continuous motion of a test. This was not an ideal solution. Examples of adjustable shock absorbers are shown in Figure 2.6.

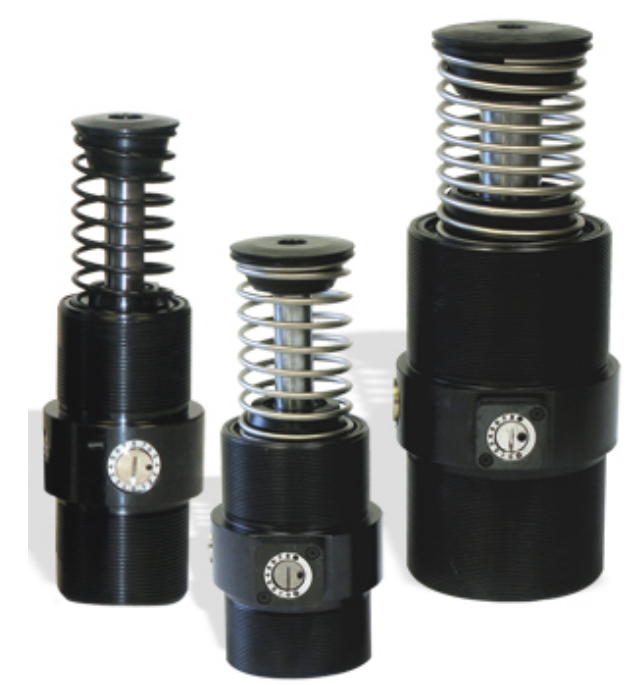

Figure 2.6: Adjustable shock absorbers from Enidine. [20]

Research of suitable products led to discovering electrorheological (ER) dampers. These are viscous fluid dampers that are similar to shock absorbers, but their use of an ER fluid can provide a variable and controllable response force. Instead of 
a variable orifice area, the fluid changes its viscosity as a response to an electric charge. A low viscosity fluid passes easily past the orifice, resulting in a low reaction force and soft damping. A high viscosity corresponds to a high reaction force and hard damping. The dampers also contain compressed nitrogen gas, which extends the piston after the impact.

The electric signal can be sent remotely and the reaction time is of the order of milliseconds. The damper is accompanied by an amplifier that can convert an analog 0-4 $\mathrm{V}$ signal into the electric charge for the damper. An image of one of these ER dampers with an amplifier is shown in Figure 2.7. Further description of these dampers is presented in Chapter 3.

The low voltage analog signals would have to be outputted from the same computer that manages the control of the drive systems in order to synchronize the timing. In theory, if the input signals could be varied during the slam impact event, then the response could be shaped to match an intended acceleration profile. Based on the potential for controlling and varying the response force, and compared to the alternatives, this was the best option.

The manufacturer of these dampers, Fludicon, is based in Germany and is the only manufacturer of ER dampers for industrial applications. ER damping is a relatively new technology and the primary application is for automotive suspension. The technical documentation for these products was limited. Different sized dampers were available and the information guide for each product had a basic diagram showing the response force for each product as a function of speed and as a range between softest and hardest responses. Based on an estimation of the energy transmitted in 


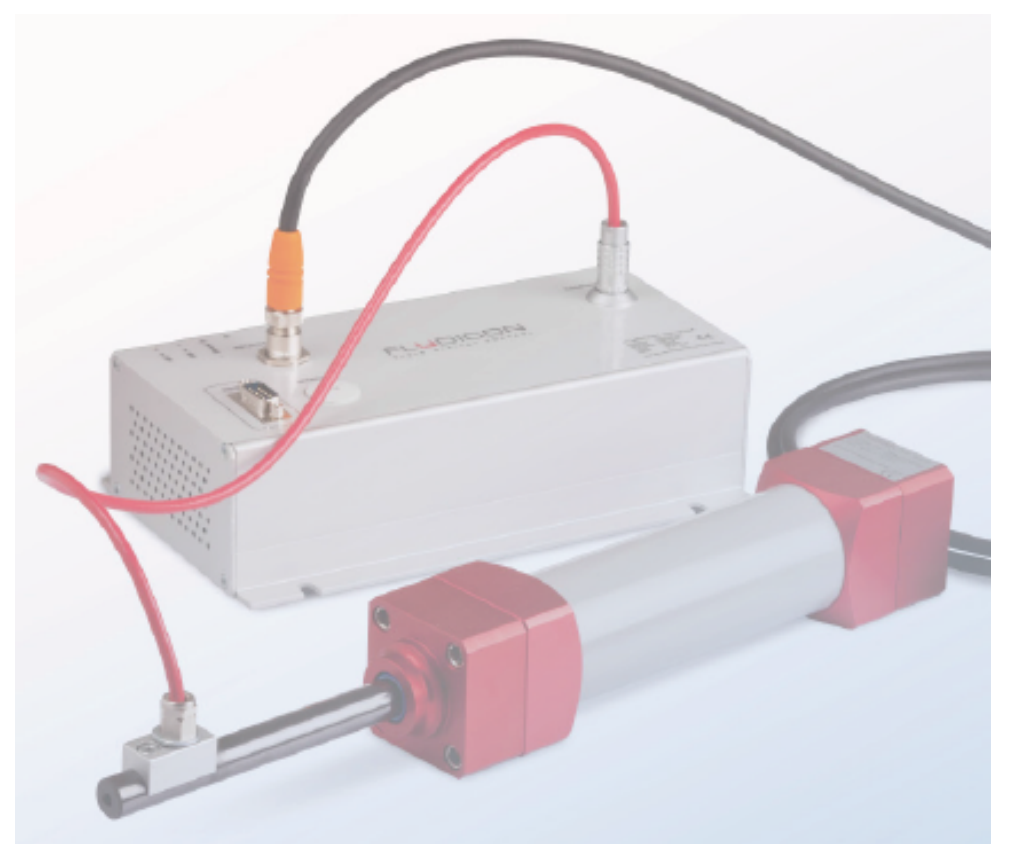

Figure 2.7: The RheDamp 63 damper with its corresponding control signal amplifier. $[21]$

a slam impact and the expected duration of the pulse, all products were too small. Two of the largest available dampers were determined to be sufficient when installed in parallel, as they should be capable of providing a combined maximum reaction force of $14 \mathrm{kN}$, if the initial velocity is near $0.5 \mathrm{~m} / \mathrm{s}$. The diagram of this damper's force response is shown in Figure 2.8. Simulations indicated that the initial velocity may exceed $2 \mathrm{~m} / \mathrm{s}$. The behaviour of these dampers during operating velocities above those from the product documentation will need to be explored. Overall, the relationships between the velocity before impact, test mass, control voltage, and response acceleration will need to be well understood during the development of control algorithms for shaping a desired acceleration profile. This will require controlled experimentation during initial motion tests. Learning the behaviour and tuning the controller should be an essential objective of the commissioning phase of this machine. 


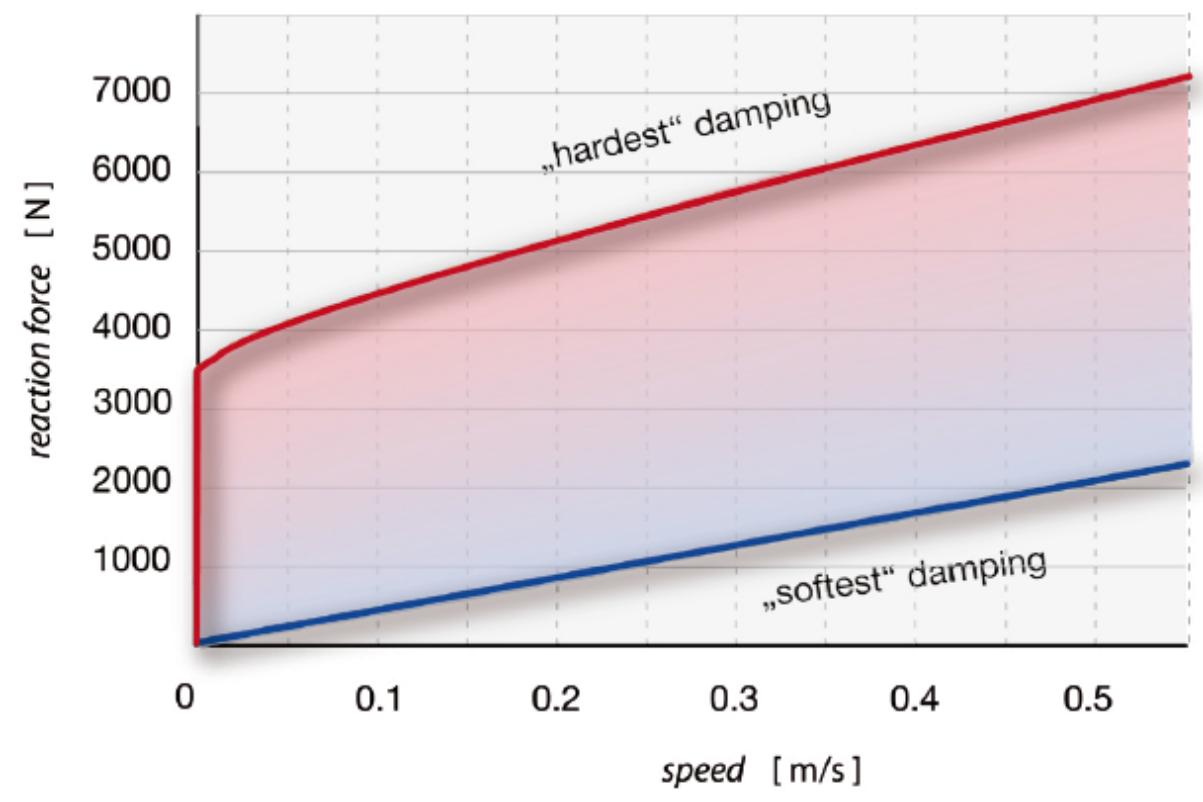

Figure 2.8: Response force profile of the RheDamp 63 damper. [21] 


\section{Chapter 3}

\section{Technical Description of the Machine}

This chapter describes the structural assemblies of the machine. The machine is composed of five main assemblies. They are the rail support, the cart, the seat deck, the horizontal drive system, and the vertical drive system. Refer to Figure 3.1 for the relative placement of these assemblies and the orientation of the coordinate system.

For each assembly, major parts are identified, and their purpose and connections with other parts are described. Then, the electrorheological (ER) dampers will be described, as well as data acquisition and power systems. Finally, the masses of the most significant components will be presented and the inertia ratio of each of the drive systems is shown and discussed.

As a note regarding the units of measurements shown in this chapter, the machine was designed and built with units of inches because of the common use of the American customary units in product information. Standard metal stock sizes and fasteners are sold as fractional increments of inches. Whenever it is reasonably possible, dual dimensioning is shown. Sizes of stock metal profiles and fasteners are 


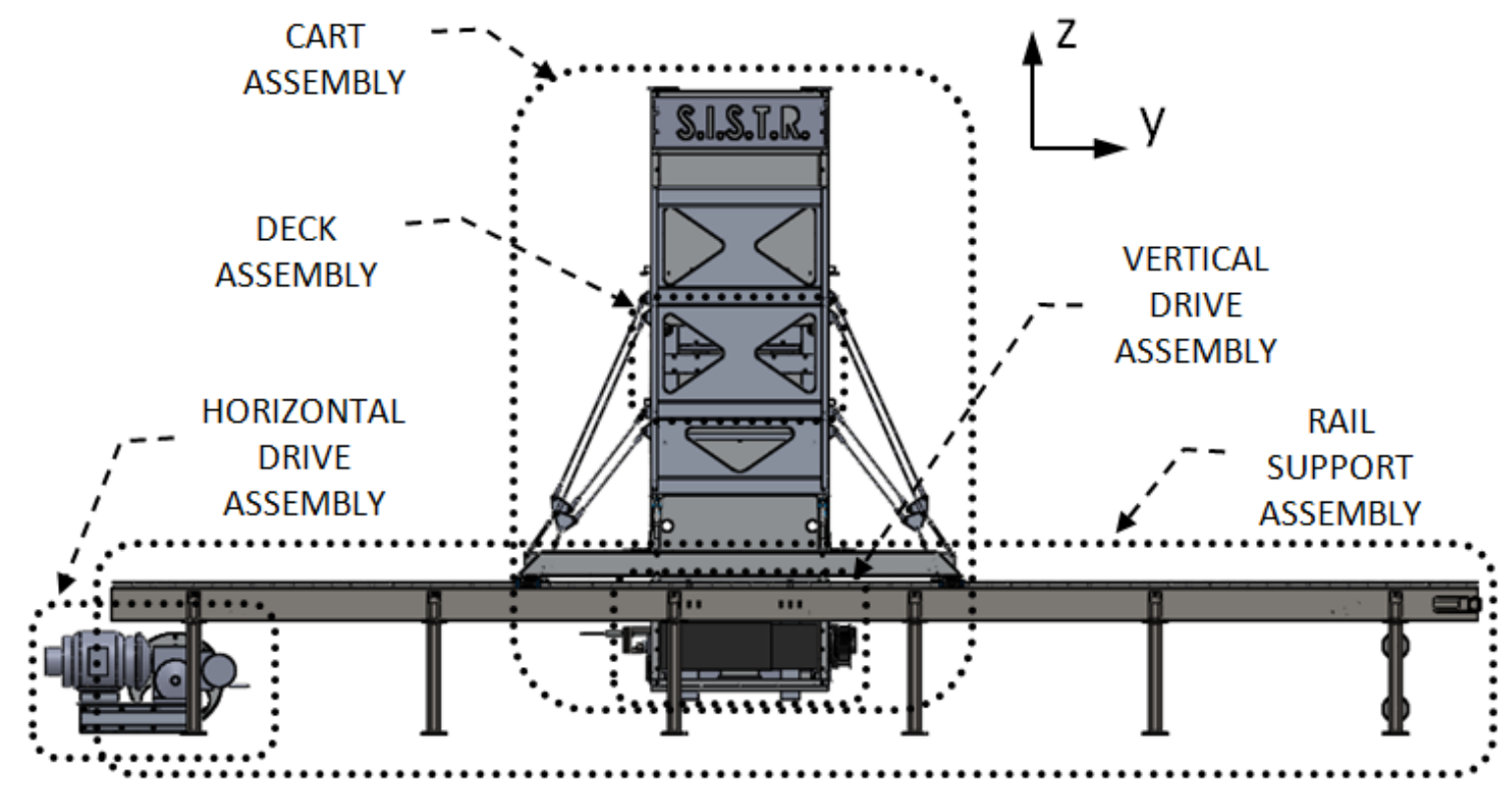

Figure 3.1: Front view of SISTR with labelled assemblies.

only described in inches in order to recognize the original product.

\subsection{Rail Support Assembly}

The rail support assembly is the base frame that supports the rest of the machine.

The main components are two $5.5 \mathrm{~m}$ (18 ft) long structural steel channel beams $(\mathrm{C} 5 \times 6.7)$ on top of fourteen steel rail support posts. The posts are anchored to the floor and to the walls with extra parts called wall braces and $3 / 8$ inch diameter anchors. The posts have a square $2 \times 2 \times 0.25$ inch profile.

A profiled guide rail is bolted to the top of each of the two channel beams. The rail runs the full length of the channel beam. Figure 3.2 shows an end view of a channel beam with a rail on top of it. The rails are manufactured by Thomson, 
with model number 521H30A0. The accompanying guide bearing blocks have model number $511 \mathrm{H} 30 \mathrm{~A} 0$. The rails are attached with M8-1.25 bolts into tapped holes in the channel beams.

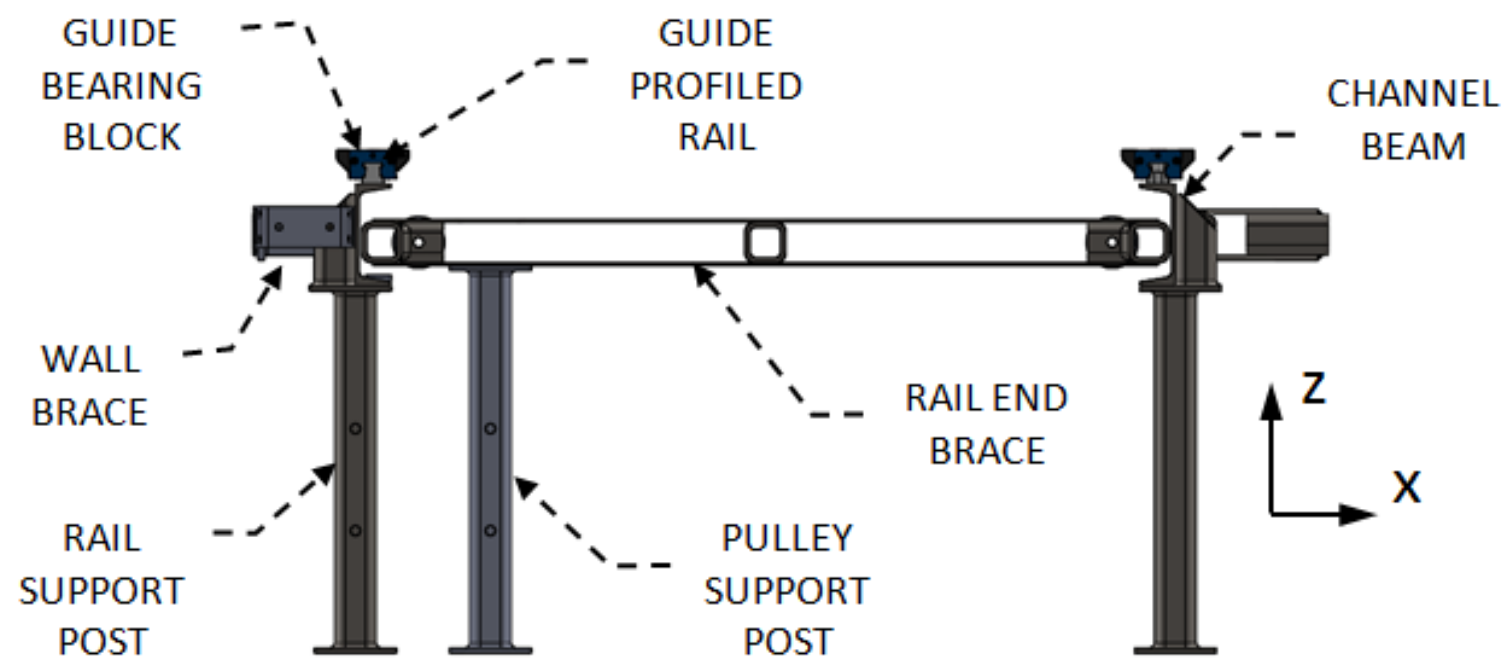

Figure 3.2: End view of a channel beam with a support post and a profiled rail.

At each end of the channel beams, a rail end bumper brace restrains the ends of the channel beams to maintain the spacing between the rails. Refer to Figure 3.3. The rail end brace is a welded steel assembly of tubes and plates. The rail end brace is attached to the web of the channel beams and to two of the fourteen rail support posts with 3/8-16 bolts. The purpose of those two posts is to support the end pulleys of the horizontal drive system. More detail is provided in Section 3.4.1. Each steel bumper brace has two polymer bumpers that absorb some of the energy of a potential impact from the cart assembly. The polymer bumpers are McMaster-Carr product \#9677K26. 


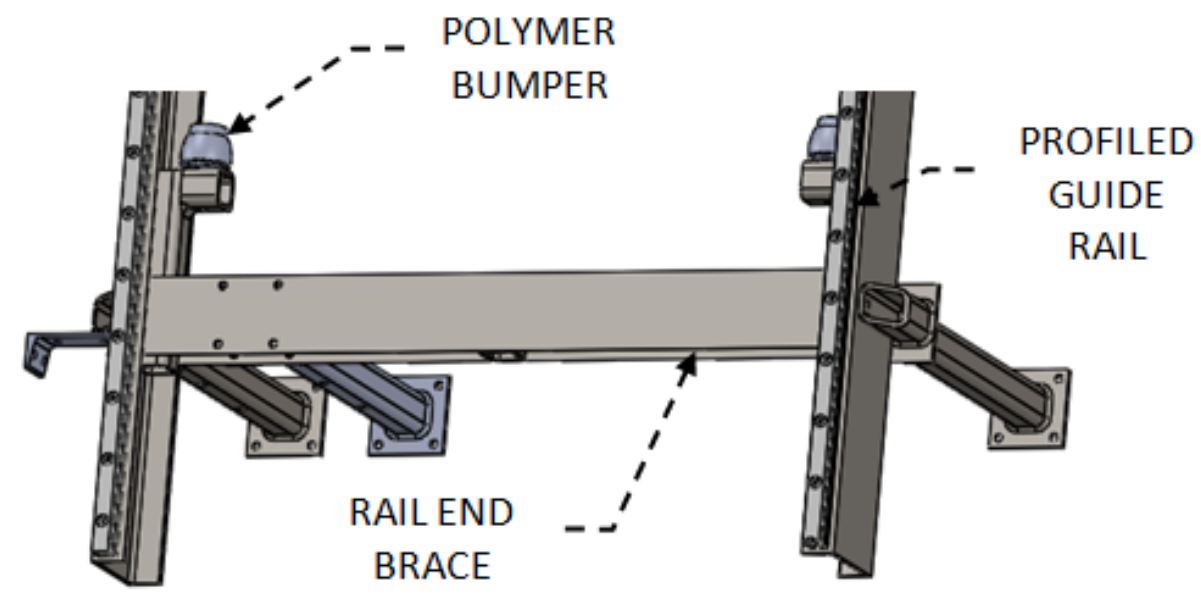

Figure 3.3: Rail end brace and the location of the polymer bumpers.

\subsection{Cart Assembly}

The cart assembly is the main body of the machine and it slides on the horizontal rails. The travel length of this assembly within the rail support assembly is $3.5 \mathrm{~m}$. The cart is primarily built as three orthogonally-placed main sets of beams to become a simple three-dimensional structure as shown in Figure 3.4.

The longitudinal beams run parallel to the two channel beams of the rail support assembly and they support the entire cart on top of the four linear bearing guide blocks. The ends of the lateral beams connect to the longitudinal beams, and a corner post stands vertically in each of the four corners. Each longitudinal beam is a welded steel assembly of a $4 \times 2 \times 0.13$ inch profile tube and $0.006 \mathrm{~m}(1 / 4$ inch $)$ plates. Each lateral beam is 6061-T6 aluminum with a $3 \times 3 \times 0.19$ inch angle profile. Each corner post is structural steel with a $1.25 \times 1.25 \times 0.19$ inch angle profile.

Although most of the machine's structural parts are aluminum to reduce weight, the longitudinal beams and the corner posts are steel for particular reasons. Each 


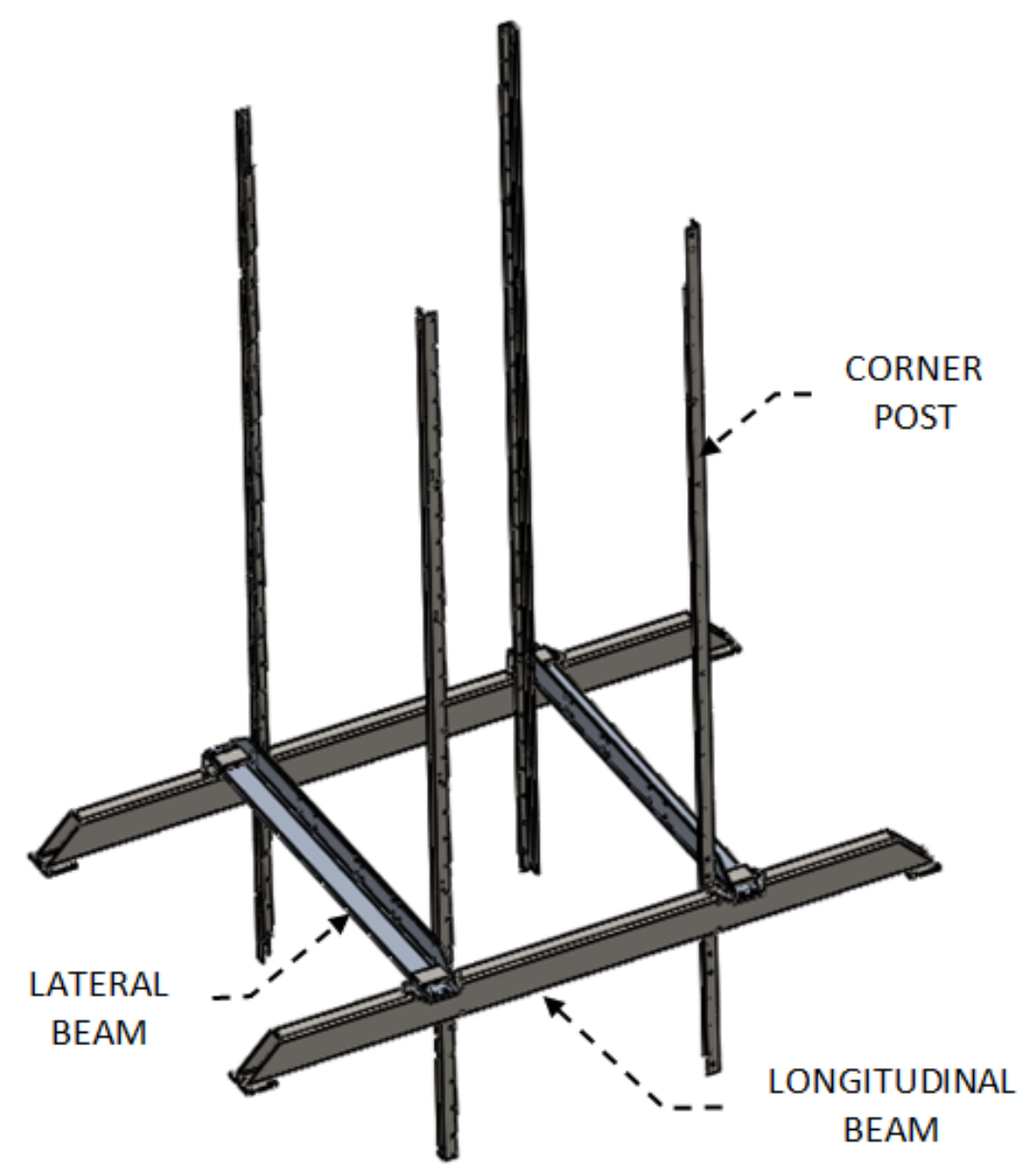

Figure 3.4: Primary structural elements of the cart assembly.

longitudinal beam is a welded assembly, which does not significantly lose its strength from the welding process. This is a significant disadvantage of 6061-T6 aluminum, in which the annealing process from welding reduces the strength to approximately one-fifth. Welded aluminum parts should subsequently be heat treated again to restore the T6 temper. The corner posts are steel to benefit from the extra stiffness, in order to reduce the potential for buckling, which is their most significant failure mode. Steel is approximately three times stiffer than aluminum.

An interesting feature of the corner posts is that one side of each corner post has 30 
holes, drilled at $0.076 \mathrm{~m}$ (3 inch) increments and with $0.007 \mathrm{~m}$ (0.26 inch) diameter, to mate with the profiled rails that guide the vertical motion of the deck assembly. Many of these holes were used as attachment points for other parts to the corner posts so that the total number of drilled holes was reduced. This is particularly noticeable in the back view of the cart, shown in Figure 3.5. The profiled rails are part of the size 3 Dual-Vee roller guide system, manufactured by Bishop-Wisecarver. The model number is TS30727525. The roller wheels that accompany these rails are attached to the corners of the load deck assembly. The bearing wheels are described in the next section.

At the back of the cart, the back sheet holds the position of the two back corner posts and serves as a primary support against in-plane horizontal inertial forces. The back sheet is made from two sheets of $0.001 \mathrm{~m}$ (0.031 inch) 3003-H14 aluminum, with one sheet placed above the other. A $0.003 \mathrm{~m}$ (1/8 inch) thick seam plate was made to join the upper and lower halves of the back sheet. Along the height of the back sheet are six $1 \times 1 \times 0.12$ inch angle-profiled bars that are rivetted to the sheet and bolted to the corner posts. These bars reduce the risk of sheet buckling.

At each side of the machine and above the lateral beam, two side tubes and the top pulley beam hold the correct distance between the front and back corner posts. The side tubes are bolted to the corner posts with 5/16-18 bolts, along with a side sheet. The side sheet resists the torsional shear of the cart around the cart's central z-axis with its thin strips angled at $45^{\circ}$. The side tubes are 6061-T6 aluminum with a $1 \times 1 \times 0.06$ inch square profile and the side sheet is $0.001 \mathrm{~m}(0.031$ inch $)$ thick 3003-H14 aluminum. 


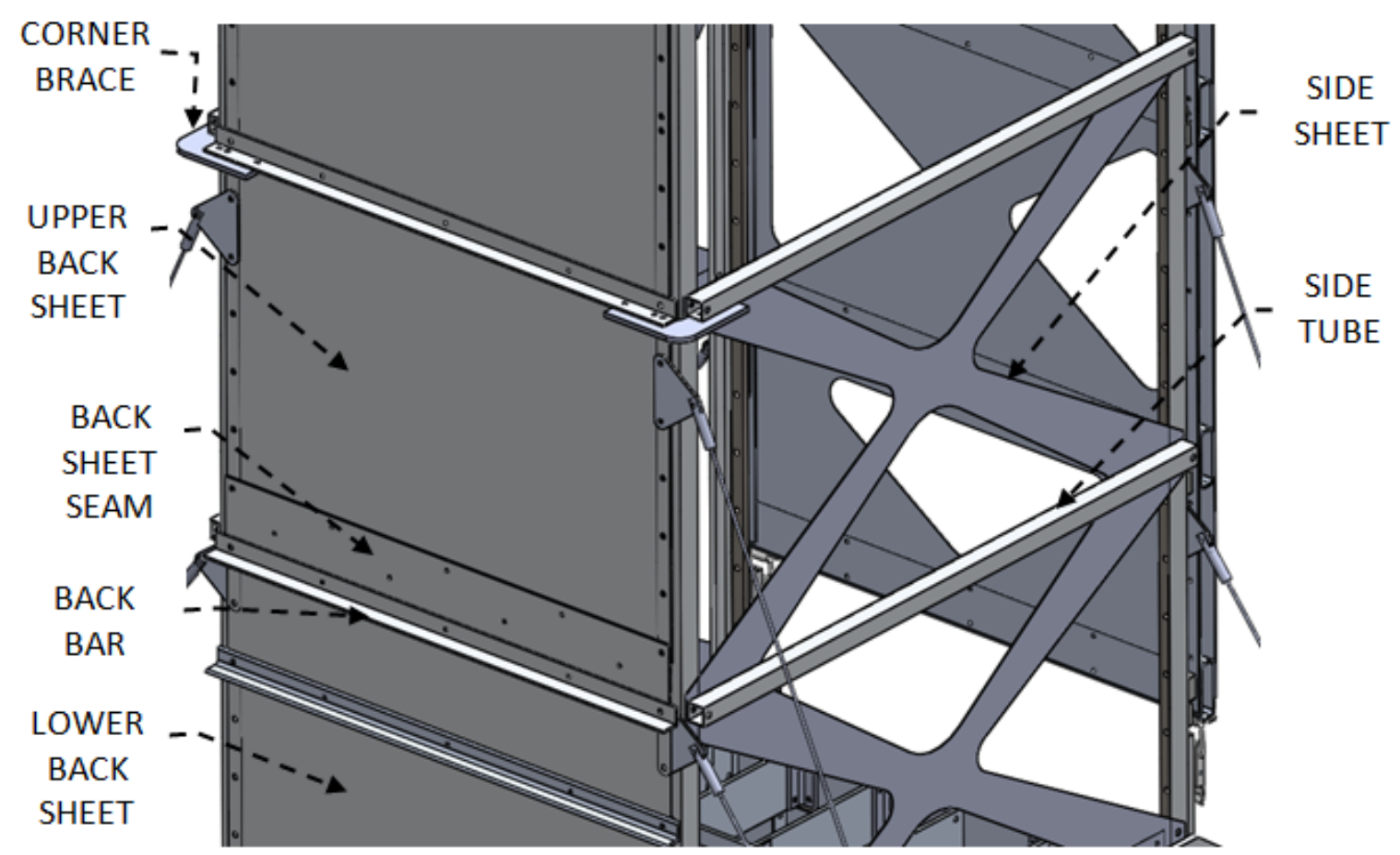

Figure 3.5: Features of the back and side of the cart assembly.

The structural shell of the cart's frame was designed to be similar to the truss of an aircraft fuselage. An example of an aircraft fuselage is shown in Figure 3.6 where the corner posts represent the longerons and all the parts that support the corner posts represent the struts. A key feature of the struts is that they have shared end points. An aircraft fuselage is a common example of a lightweight structure.

The door holds the proper spacing between the front corner posts and it is removable so that a seat can be mounted into the machine. The door is made from four rectangular tubes with a $3 \times 1 \times 0.12$ inch profile that are rivetted to a $0.001 \mathrm{~m}$ (0.031 inch) thick 3003-H14 aluminum sheet. Refer to Figure 3.7 for locations of the following parts. The door sits on eight zinc hinges (McMaster-Carr \#11955A73), where the male halves of the hinges are attached to the front corner posts and the female halves are attached to the door. Four toggle latches pull on the door to 


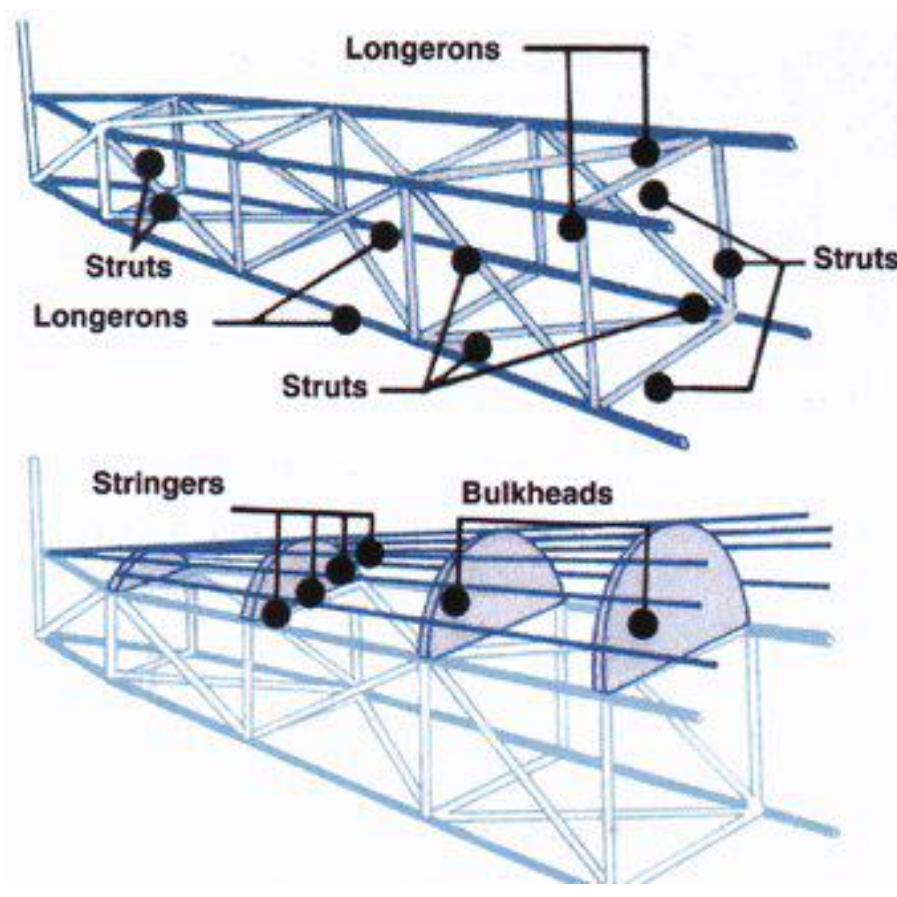

Figure 3.6: Elements of an aircraft fuselage. [22]

keep the door in place and keep loads through the door in tension. Two of the latches (McMaster-Carr \#6139A21) pull down from the front corner posts, and the other two latches (McMaster-Carr \#11605A19) pull to the sides from the front guy lines. The guy lines are short lengths of $1 / 8$ inch galvanized steel wire ropes (McMaster-Carr \#3332T52) with two clevis-type end connectors (McMaster-Carr \#3473T63). To remove the door, the four latches are released and then the door is lifted up off the hinges. The door must be properly attached before operating the machine.

Twelve triangular plates were made as end connections for the guy lines. These end connector plates are located at two points along the length of each corner post and attached to the latches or the turnbuckles at the ends of the longitudinal beams. The latches are described in the previous paragraph as they pull on the door, and the turnbuckles are McMaster-Carr \#3001T51. These triangular plates and the 


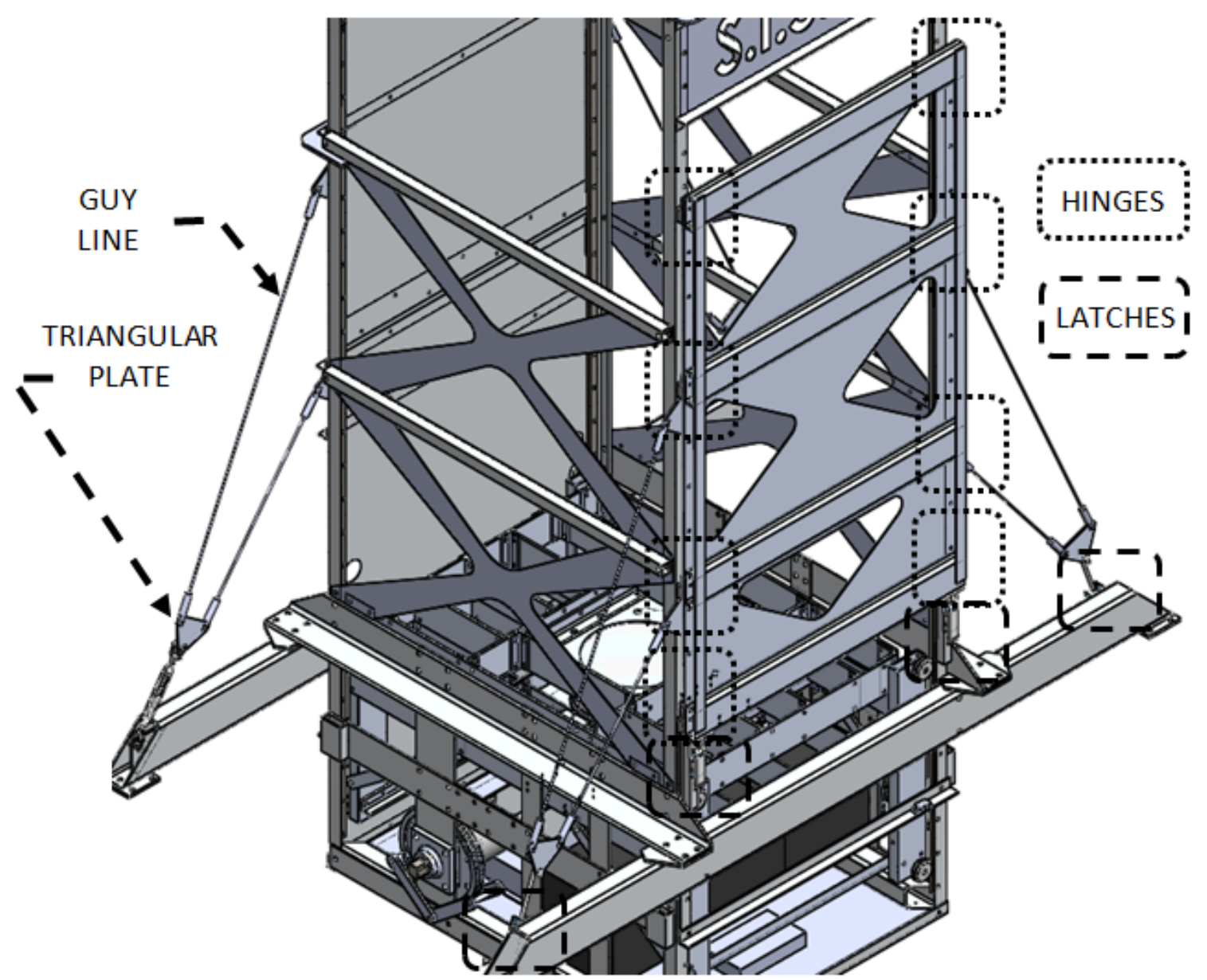

Figure 3.7: Door attached to the front of the cart with identified locations of hinges and clamps.

guy lines are shown in Figure 3.7. They are made from $0.003 \mathrm{~m}$ (1/8 inch) thick 6061-T6 aluminum. They were designed to be identical, regardless of where they were placed, to reduce the number of unique parts. It was intended that the bottom end of each pair of guy lines would attach to one triangular plate and then into a turnbuckle or a latch with an adjustable length. It was known that it would be difficult to cut the wire rope and install the wire end connectors such that the final length between clevis pins would be identical to the length in the CAD model. By pinning the bottom ends of two guy lines to a triangular plate, the draw length of the turnbuckle or latch could be shortened until both guy lines would be reasonably tight. 
At the top of the corner posts, two top pulley beams support the wire rope pulleys. Each top pulley is made from $6061-T 6$ aluminum with a $3 \times 1 \times 0.12$ inch tube profile. Two plates provide reinforcement at mid-span of each top pulley beam. Above the door, the nameplate helps maintain the spacing and resist skewing distortion between the front two corner posts. The plate is $0.001 \mathrm{~m}$ (0.031 inch) thick 3003-H14 aluminum and the lettering was cut with a waterjet cutter. Two aluminum angle-profiled bars frame the thin nameplate sheet. These angle-profiled bars are identical to the back bars. These parts are shown in Figure 3.8.

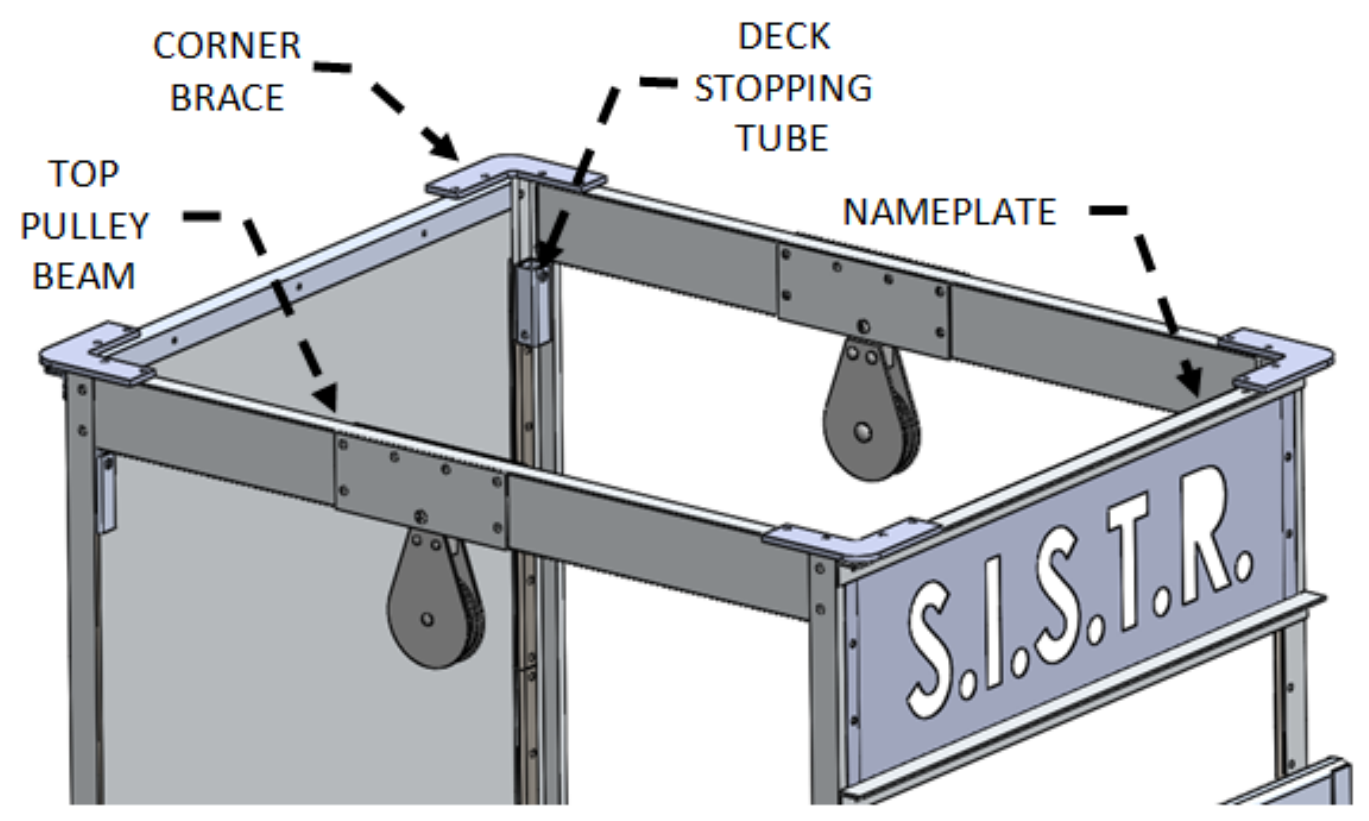

Figure 3.8: Top pulley beams, the nameplate, and the top corner braces.

The longitudinal and lateral beams form the stiff rectangular shape for the cart assembly but they cannot maintain that shape at the top of the corner posts. Aluminum corner braces assist in maintaining the rectangular shape at the top of the cart. The plates are $0.006 \mathrm{~m}(1 / 4 \mathrm{inch})$ thick. There are four around the top corners of the cart, as shown in Figure 3.8. There are two more braces at the back, 
which are bolted between one of the back bars and a side tube, and are shown in Figure 3.5.

Below the lateral beams, the cart plates form a grid with two horizontal plates and three vertical plates on each side. They restrain two of the major components of the vertical drive system, the Emerson motor and the spool pulley assembly. Two more plates cross the centre of the cart and support the electrorheological (ER) dampers. All plates are made from 6061-T6 aluminum with a $0.003 \mathrm{~m}$ (1/8 inch) thickness, and are bolted with 5/16-18 bolts. Some of the highest loads pass through these plates and are distributed outwards to the corner posts and upwards to the lateral beams. These plates are shown in Figure 3.9.

On each of the two vertical $0.102 \mathrm{~m}$ (4 inch) wide plates, the bushing flange mounts support the spool pulley assembly. Each bushing flange mount is attached with 3/8-16 bolts that are threaded into an aluminum backing plate. That backing plate also prevents the spool assembly from moving laterally.

At the bottom of the vertical cart plates, two tubes help to support the Emerson motor and assist in distributing the loads from the cart plates to the corner posts. The tubes are made from $6061-T 6$ aluminum with a $2 \times 2 \times 0.12$ inch profile.

Two thin aluminum sheets are attached to the bottom of the cart's bottom tubes. These sheets act as a tray for instrumentation. The bottom sheets are shown in Figure 3.10. 


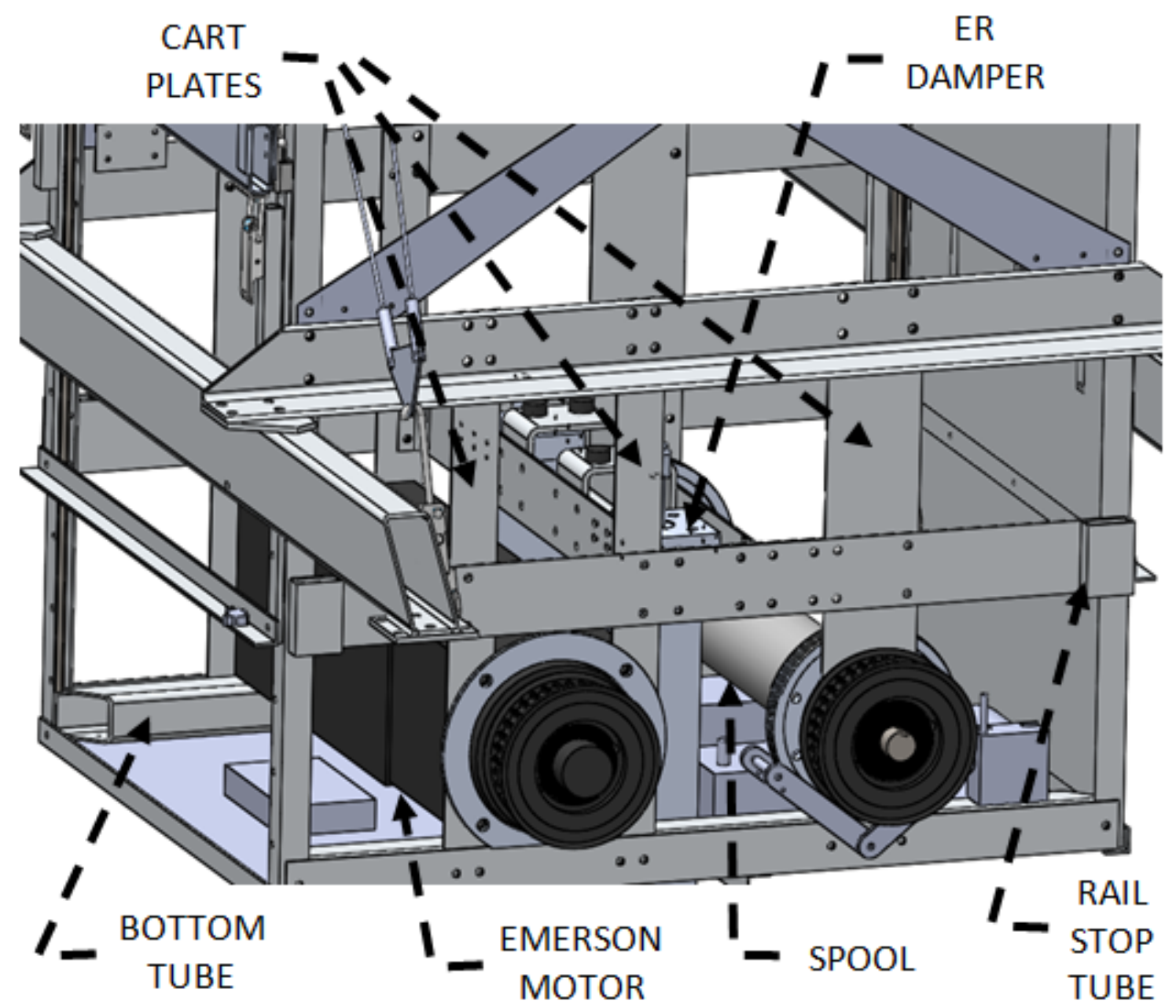

Figure 3.9: Lower section of the cart assembly.

In the event of a collision between the cart assembly and the rail support assembly, there are aluminum tubes attached to the outside of the corner posts that will collide with the polymer bumper tubes of the rail support assembly. These tubes have a rectangular $2 \times 1 \times 0.12$ inch profile and are shown in Figure 3.9, as the rail stop tubes. In the event of a collision between the deck assembly and the top of the cart assembly, there are aluminum tubes that are attached to the inside of the corner posts, above the top ends of the profiled rails. These tubes are called the deck stop tubes, and will collide with the rectangular corner posts of the load deck assembly. They have a square $1 \times 1 \times 0.12$ inch profile, and are shown in Figure 3.8. 


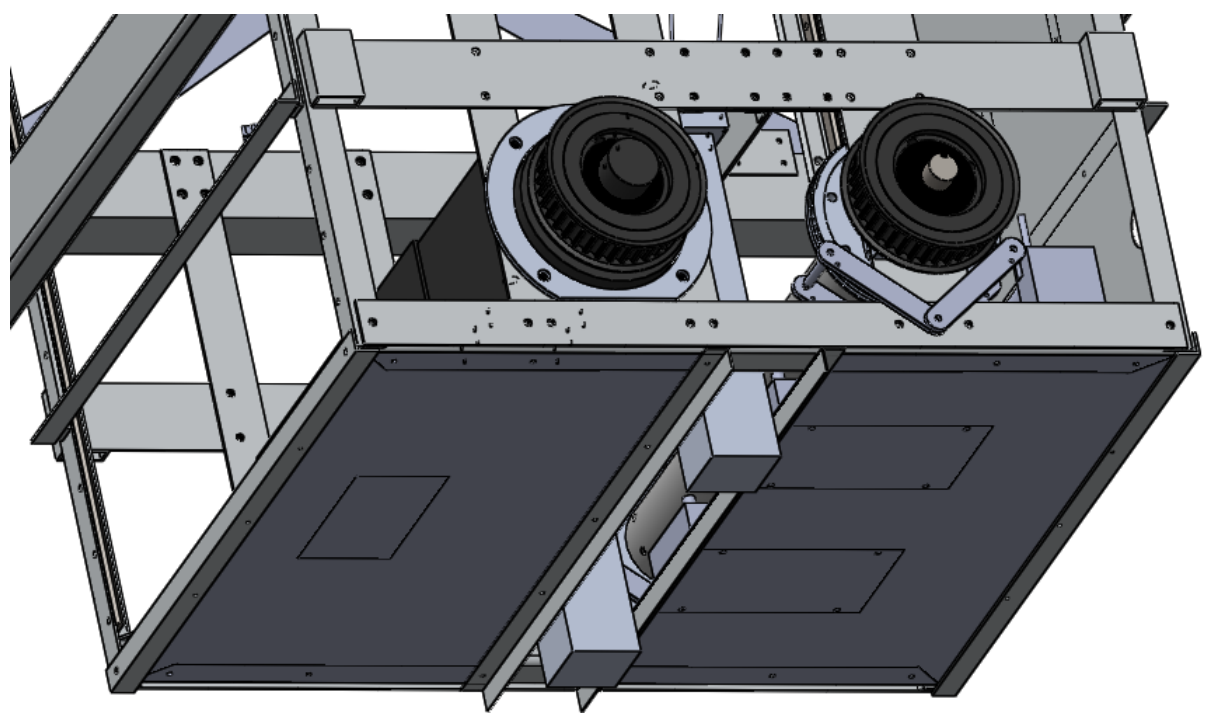

Figure 3.10: Bottom sheets viewed from under the cart. 


\subsection{Deck Assembly}

The deck assembly moves vertically within the cart assembly and is composed of three main components: the load deck assembly, the Omega 250 load cell, and the seat deck assembly. Figure 3.11 shows an exploded view of these three components. The travel length of this assembly within the cart assembly is $1.6 \mathrm{~m}$.

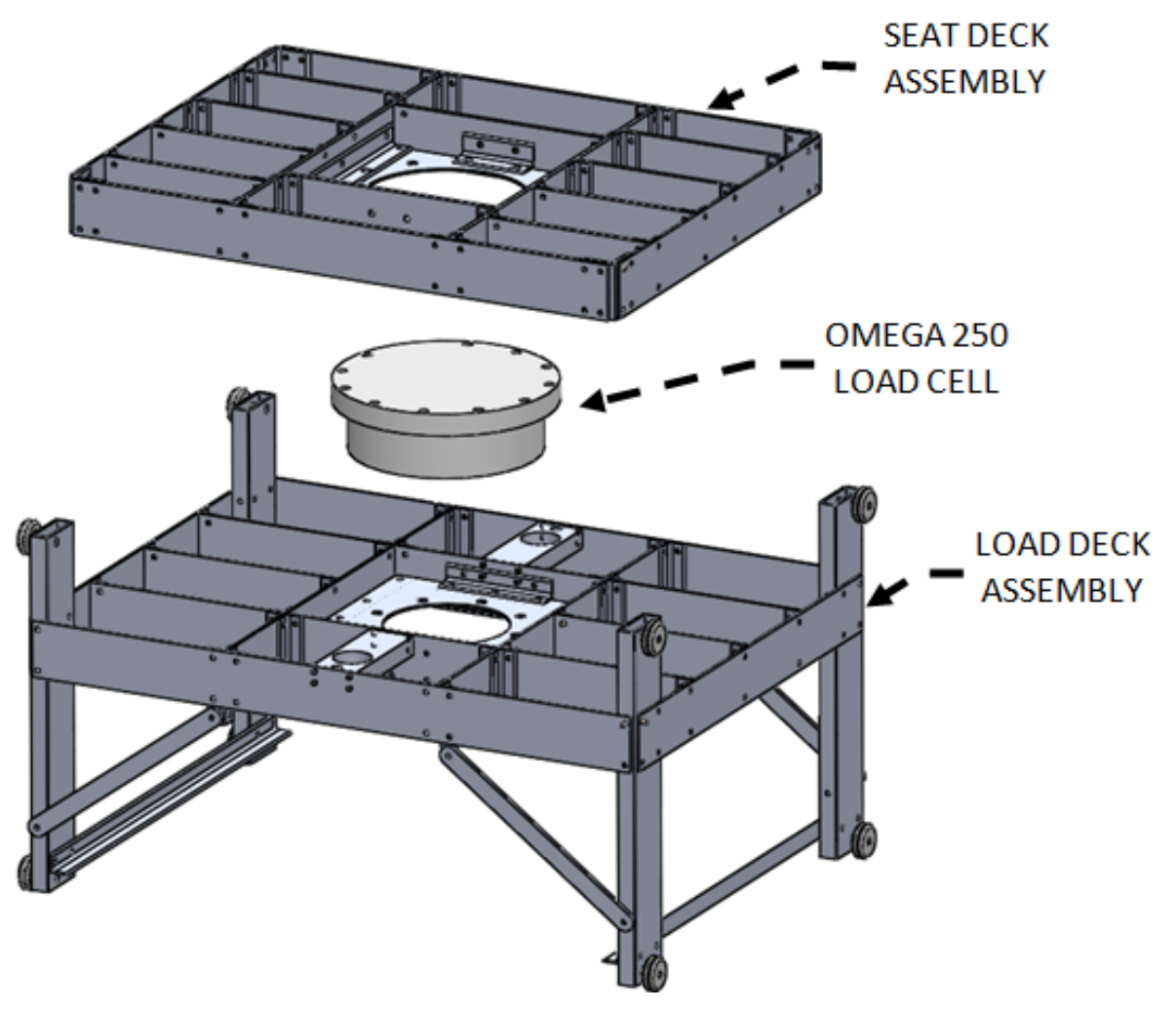

Figure 3.11: Exploded view of the two deck assemblies and the load cell.

The load deck assembly is a frame that supports the Omega 250 load cell, the seat deck assembly, and the seat. Figure 3.12 shows the assembly and notable parts are labelled. The vertically-oriented plates are all $0.003 \mathrm{~m}$ (1/8 inch) thick and bolted together with $1 / 4-20$ bolts through $1 \times 1 \times 0.12$ angle-profiled brackets. All parts in the assembly are made from 6061-T6 aluminum. 


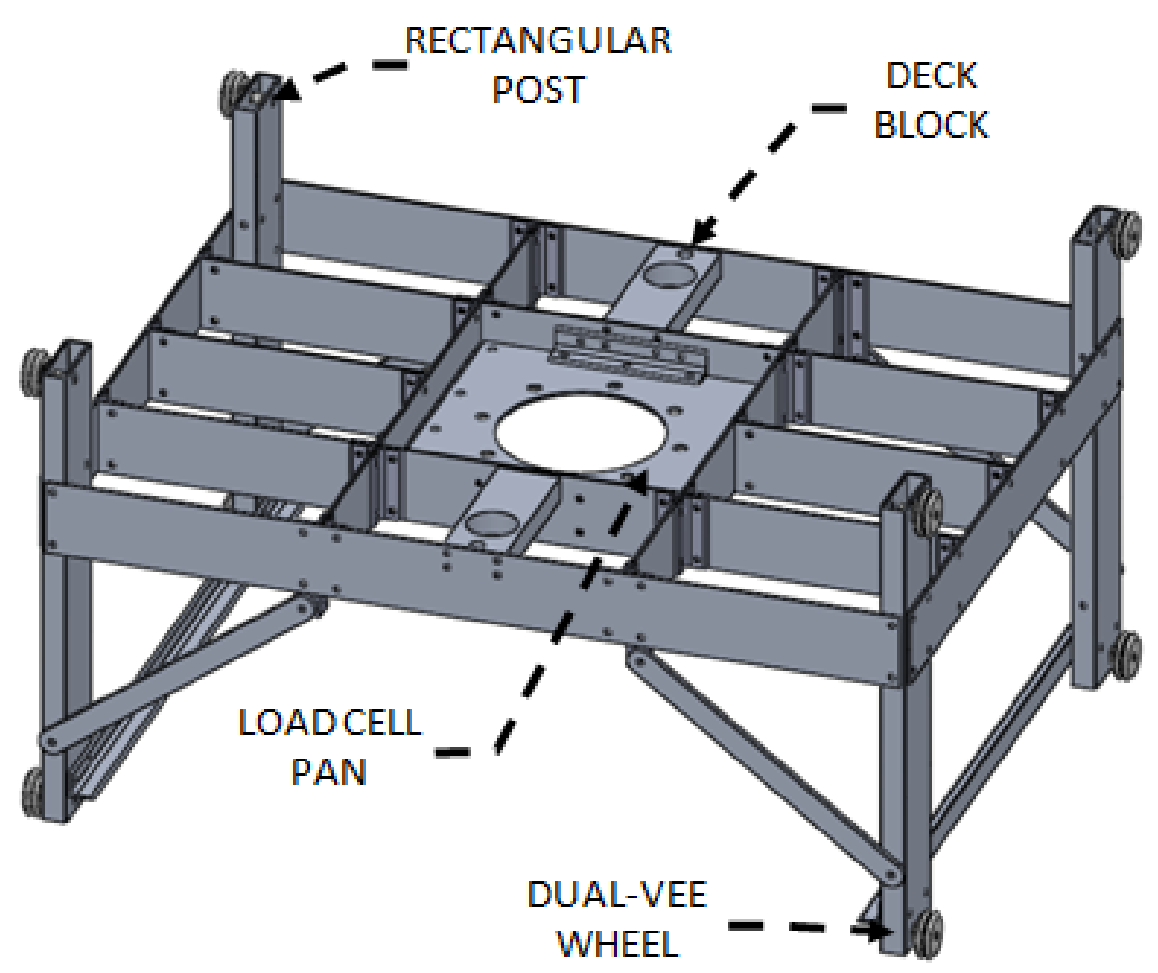

Figure 3.12: Load deck assembly.

Each of the eight corners of the load deck has a wheel that rolls along the profiled rails that are attached to the cart's corner posts. The wheels are called Dual-Vee integrated rolling wheels from Bishop Wisecarver. The model number for these wheels is SWIE3.

Each Dual-Vee bearing wheel has an integrated threaded stud that allows it to be fastened to the rectangular post. Figure 3.13 shows a Dual-Vee wheel on a profiled rail and a section view of a wheel. Due to the narrow clearance between the deck assembly and the back sheet of the cart assembly, four holes are cut in the back sheet that are large enough to insert the Dual-Vee wheels during the assembly process.

The rectangular posts extend above and below the load deck to improve its ability to resist inertial moments from the mounted seat during horizontal accelerations. To 


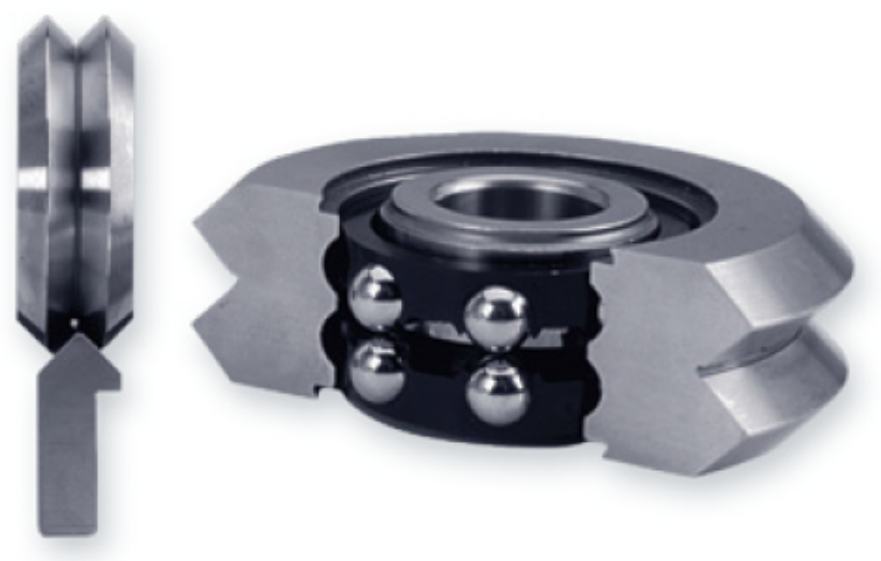

Figure 3.13: Dual-Vee bearing wheel.

support the Dual-Vee bearing wheels, the rectangular posts are braced between posts with angle-profiled bars and diagonally up to the plates of the deck with $0.006 \mathrm{~m}$ (1/4 inch) thick strips. The rectangular post has a $3 \times 1 \times 0.12$ inch profile.

The deck blocks are solid aluminum blocks that are located on either side of the load cell pan. They are the force application points for the ends of the wire ropes from the vertical drive system and they collide with the RheDamp shock absorbing dampers during a slam impact. Therefore, they are a primary link in the load path for all vertically-applied loads. The large hole in the block is included as a means of saving weight.

The load cell pan is a horizontal mounting plate for the Omega 250 load cell. This plate is made from 6061-T6 aluminum and is $0.003 \mathrm{~m}$ (1/8 inch) thick. Six brackets that are made from $1 \times 1 \times 0.12$ inch and $1.25 \times 1.25 \times 0.12$ inch angle-profiled bars attach the plate to the surrounding vertical plates of the load deck assembly. The circular bolt pattern in the centre is specifically sized to mate with the Omega 250. 
The Omega 250 load cell is used as a fixture to join the two deck assemblies. All inertial forces that the tested seat applies to the supporting structures is transferred through the Omega 250, allowing these forces to be measured directly. Further information on the Omega 250 as a sensor is described in Section 3.6 below.

The seat deck assembly is a frame that is mounted to the top of the Omega 250 load cell. This assembly of plates serves as an interface platform for mounting a suspension seat. The plates are all $0.006 \mathrm{~m}$ (1/4 inch) thick and bolted together with 1/4-20 bolts through $1 \times 1 \times 0.12$ angle-profiled brackets in interior connections and $2 \times 2 \times 0.25$ angle-profiled brackets in the outer four corners. The assembly is shown in Figure 3.14.

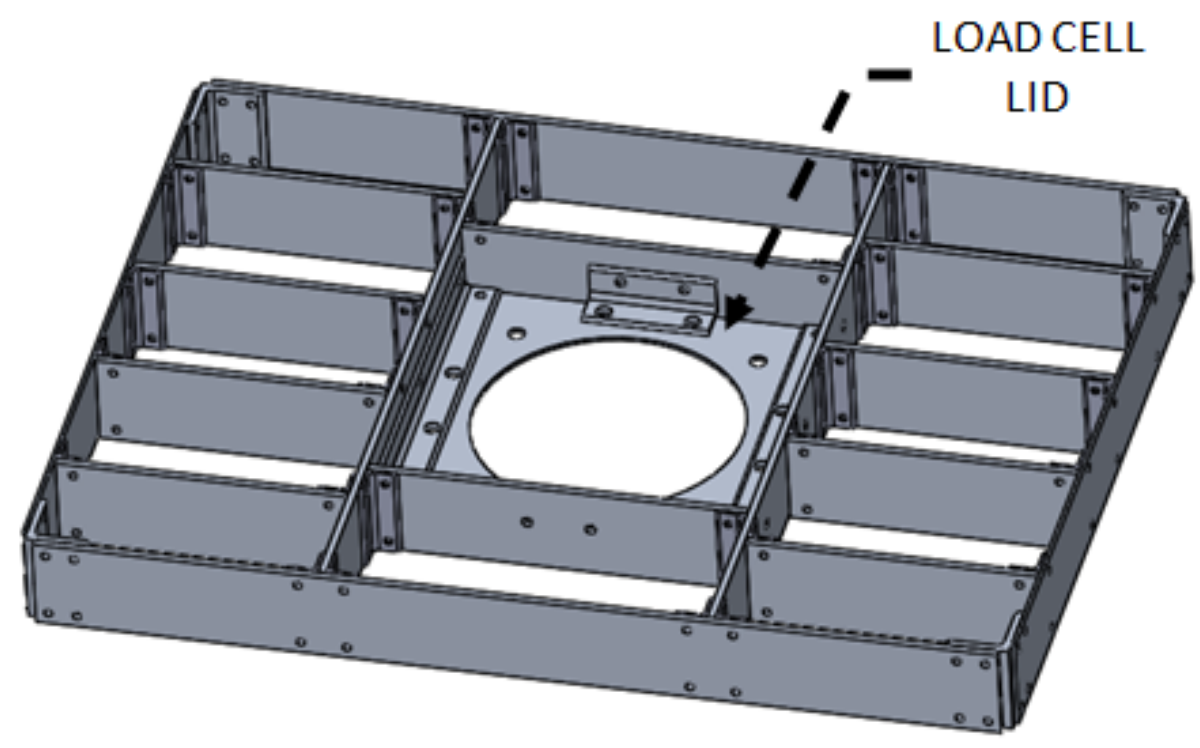

Figure 3.14: Seat deck assembly.

The load cell lid is a horizontal mounting plate for the Omega 250 load cell. This plate is made from $6061-\mathrm{T} 6$ aluminum and is $0.003 \mathrm{~m} \mathrm{(1/8} \mathrm{inch)} \mathrm{thick.} \mathrm{Four} \mathrm{brackets}$ that are made from $1.25 \times 1.25 \times 0.12$ inch angle-profiled bars attach the plate to the 
surrounding vertical plates of the load deck assembly. The circular bolt pattern in the centre is specifically sized to mate with the Omega 250. All four of the corner brackets are intentionally included in the bolt pattern to improve rigidity for the load path between the load cell and the vertical plates.

Figure 3.15 shows a top view of the seat deck assembly and the load deck assembly under it. Note how the Dual-Vee bearing wheels work in pairs to contain the deck within the cart. A small clearance between the wheels and the rails provides low-friction vertical motion while containing the deck horizontally.

A suspension seat can be fastened to the seat deck by using threaded rods or long bolts through mounting holes in the base of a seat, then down through an opening in the load deck, through a clamping tube that is located in the $0.038 \mathrm{~m}$ (1.5 inch) space between the two decks. Tightening nuts on the bolts will clamp the seat to the seat deck. Figure 3.16 shows how 5 inch long 3/8-16 bolts can be used to mount a seat to the deck. Two of the clamping tubes are visible under the seat deck plates.

Each clamping tube that is used should be secured with at least two threaded rods or bolts through mounting holes in the base of the seat. The minimum arrangement for clamping a seat should involve two of these clamping tubes, either in a front and back or a left side and right side configuration. Figure 3.17 shows the underside of one of the suspension seats with four clamping tubes. 


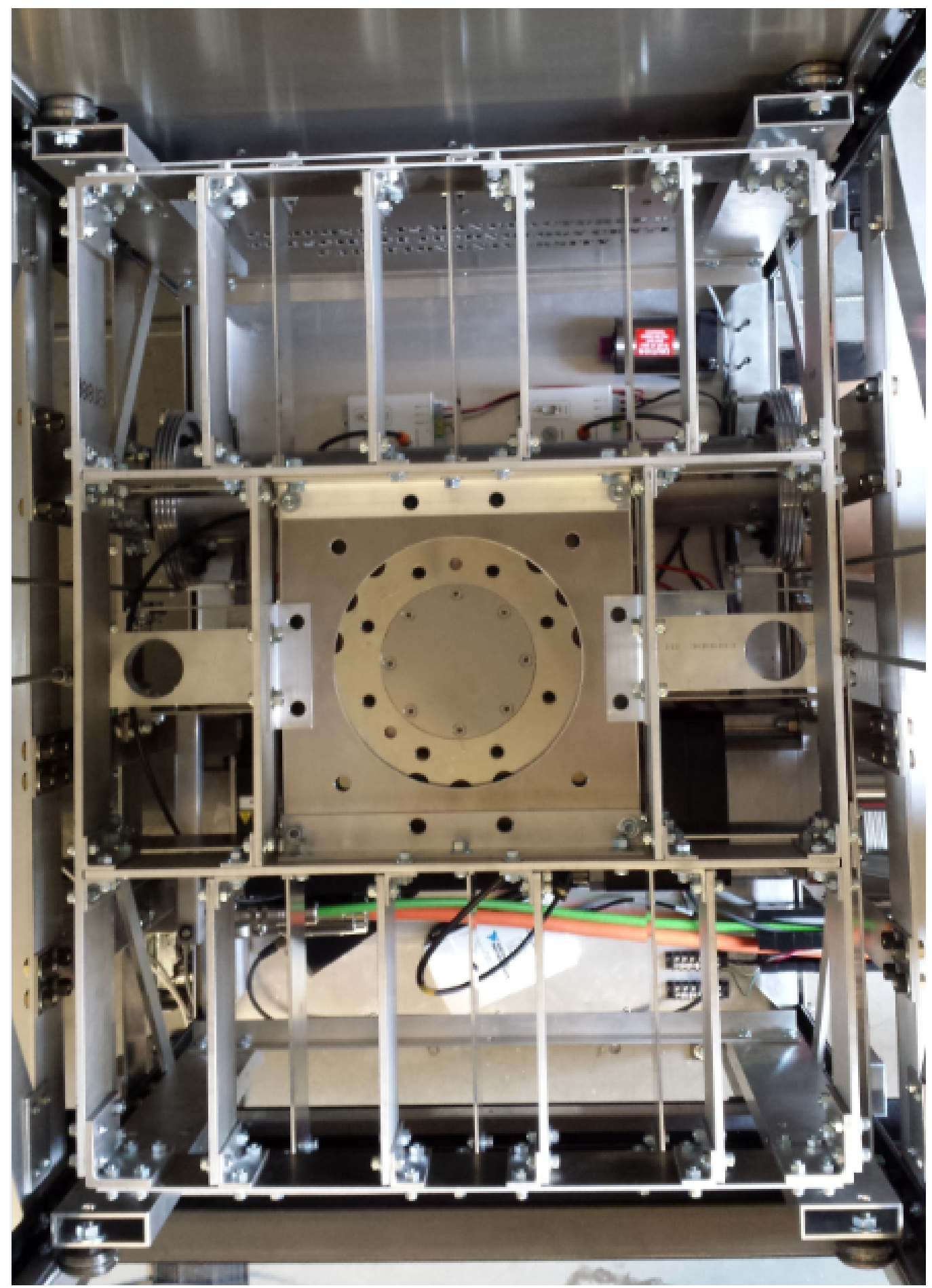

Figure 3.15: Top view of the deck assembly installed into the cart assembly. Note the placement of the Dual-Vee wheels in each corner. 


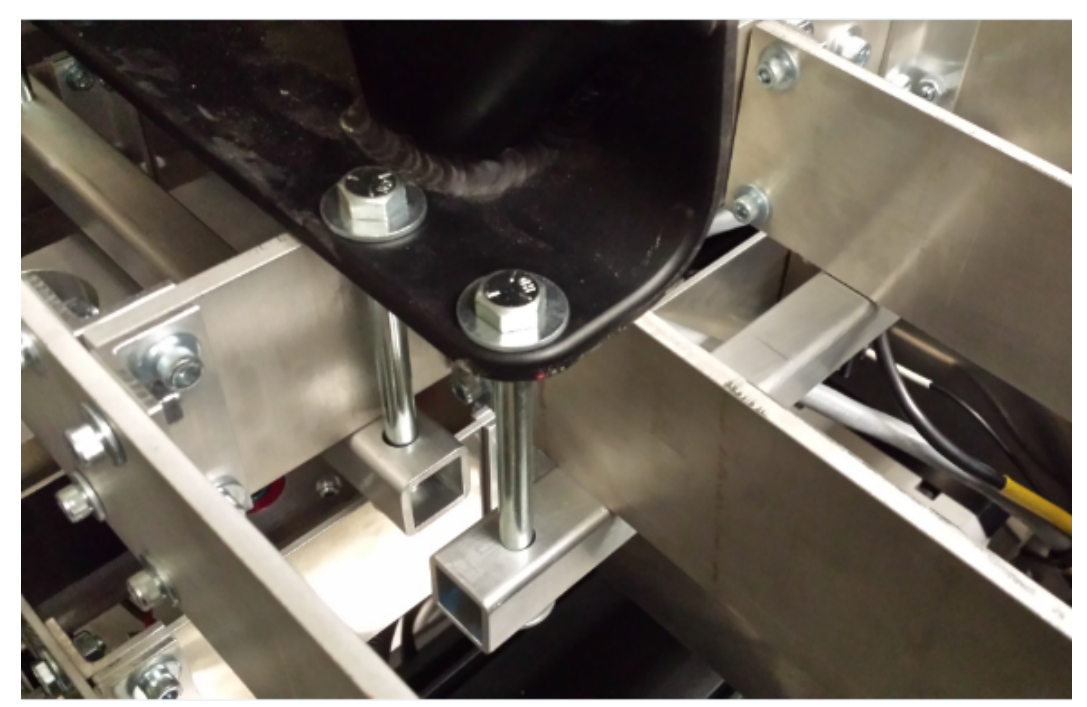

Figure 3.16: Detail of bolts and clamping tubes used to mount a seat to the seat deck assembly.

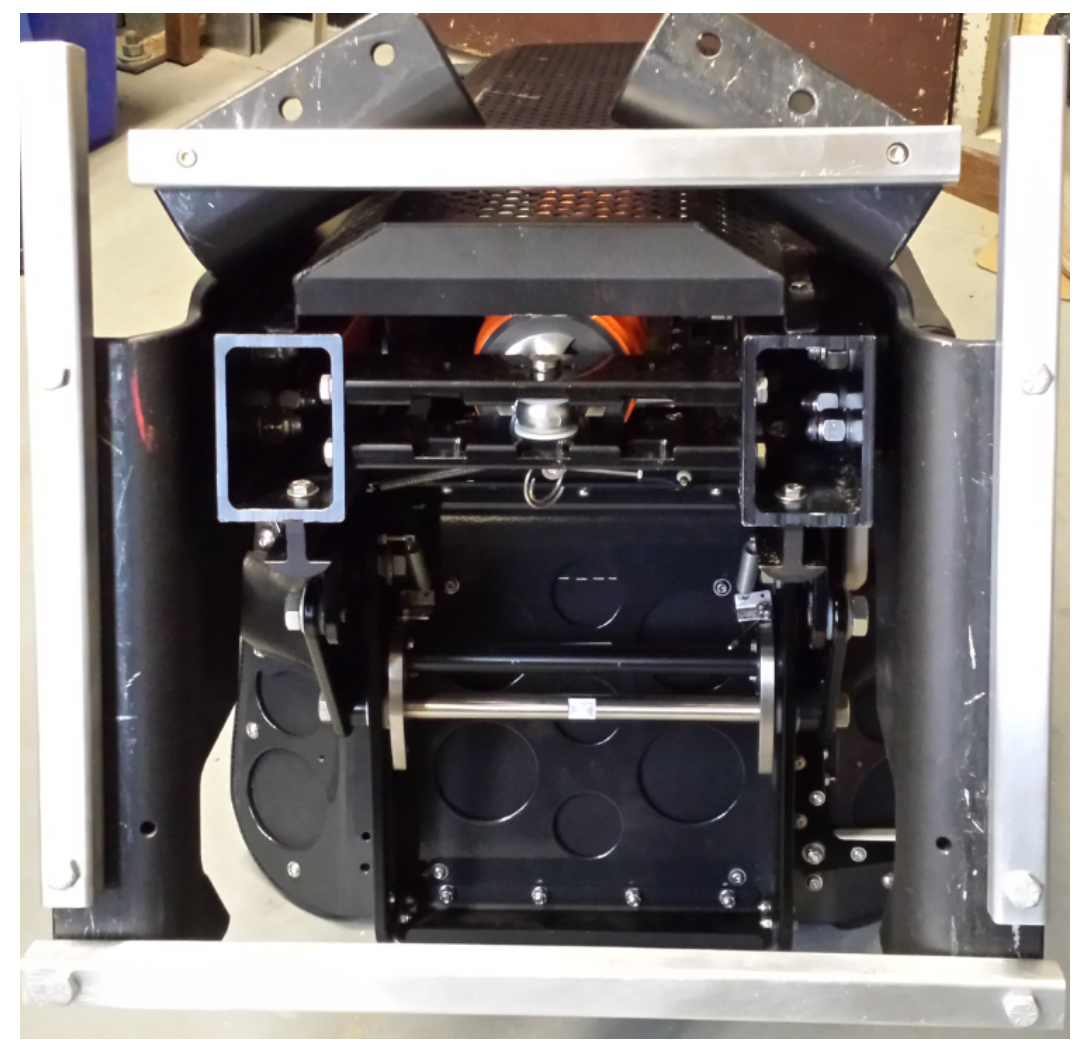

Figure 3.17: An example layout of four clamping tubes used to mount a seat to the seat deck assembly. 


\subsection{Drive Systems}

The machine's 2DOF motion is driven by two independent mechanical systems. The horizontal drive system is mounted to the ground and it moves the cart assembly along the horizontal guide rails. The vertical drive system is mounted in the bottom of the cart assembly and it moves the deck assembly vertically within the cart's corner posts. The following sections describe these two drive systems in detail.

\subsubsection{Horizontal Drive System}

This actuation system is responsible for producing horizontal motions of the cart assembly. The system features a numerically-controlled electric motor, a worm gear speed reducer, and a custom-designed wire rope spooling pulley. In this section, the major components will be described in detail, regarding their purpose, product information, important dimensions, and any other notable features. This discussion will progress from the electric motor to the connections with the cart assembly. Refer to Figure 3.18 for a labelled diagram of the first few parts that are described in this section.

The motor that drives the system is a Baldor $2 \mathrm{hp}$ induction motor. The model is ZDNM3669T. Its corresponding drive controller is a Baldor Vector drive. The model is $\mathrm{ZD} 18 \mathrm{H} 402-\mathrm{E}$. A worm gear speed reducer is mounted directly to the face plate of the Baldor motor. The speed reducer has a ratio of 20:1 and the model number is GSF2030. 


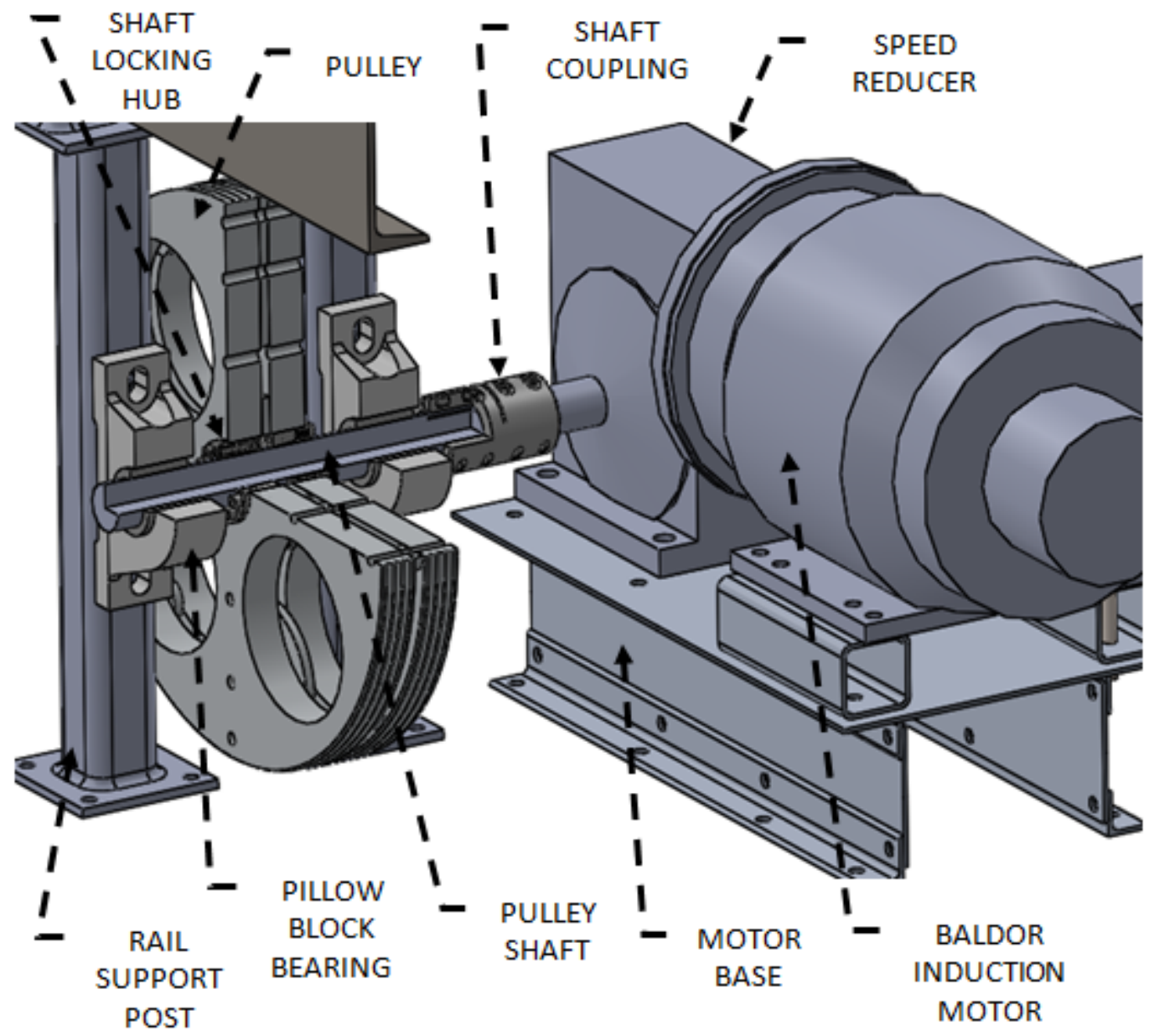

Figure 3.18: Quarter-sectioned view of the drive shaft and labelled components of the horizontal drive system.

The output shaft of the speed reducer is coupled to the pulley's shaft with a rigid steel shaft coupling. The coupling is McMaster-Carr product \#60845K39. The shaft coupling clamps onto both shafts to transmit torque, but a $0.006 \mathrm{~m}(1 / 4 \mathrm{inch})$ keyway was cut into the coupling and the pulley shaft to increase the torque carrying capability. The pulley shaft is cut from McMaster-Carr product \#5936K29, which is a Nitride-coated 1045 steel bar with diameter of $0.032 \mathrm{~m}$ (1.25 inch). The bar is precision ground and is intended for use as a spinning shaft.

The pulley shaft is supported on both sides of the drive pulley with pillow block 
bearings. The pillow block bearings are each McMaster-Carr product \#5057N3. These bearing blocks are supported by two of the posts of the rail support assembly. These posts are steel tubes with a $0.006 \mathrm{~m}(1 / 4$ inch) wall thickness. The pulley shaft drives the custom-designed spooling pulley with two screw-clamp shaft locks that connect the pulley to the shaft. Each is McMaster-Carr product \#1058K16. The shaft lock mechanism has two tapered split collars that expand when the collars are tightened together.

The pulley is made from two identical $0.025 \mathrm{~m}$ (1 inch) 6061-T6 aluminum plates and several $0.006 \mathrm{~m}(1 / 4$ inch $)$ discs that are clamped between the large plates. A 4 threads per inch groove was cut into the circumferential surface with a $0.006 \mathrm{~m}$ (1/4 inch) diameter round cutter. The result is a continuous round-shaped helical groove that progresses around the pulley four times. The diameter of the wire rope is also $0.006 \mathrm{~m}(1 / 4 \mathrm{inch})$ so when it is wound onto the pulley, three full turns can be spooled cleanly without overlapping itself or falling over the edge. An overlapping cable would change how the deck is being pulled and it has the potential to prematurely fray the wire rope. This method of spooling the wire rope is similar to the Lebus spooling system used for winches and overhead cranes [23].

After the wire rope is wound, the distance between centres of the wire ropes is $0.38 \mathrm{~m}$ (15 inch), which becomes the pitch line diameter of the pulley. The full linear travel of the cart assembly corresponds to approximately three turns of the spool assembly. One of the design criteria for deciding the diameter of the pulley was to ensure that the necessary length of wire rope, for the linear travel, could be spooled onto a $0.025 \mathrm{~m}$ ( 1 inch) thick plate using a $0.006 \mathrm{~m}(1 / 4$ inch $)$ thick wire rope. The $0.38 \mathrm{~m}$ (15 inch) diameter was the smallest pulley size that satisfied this criteria 


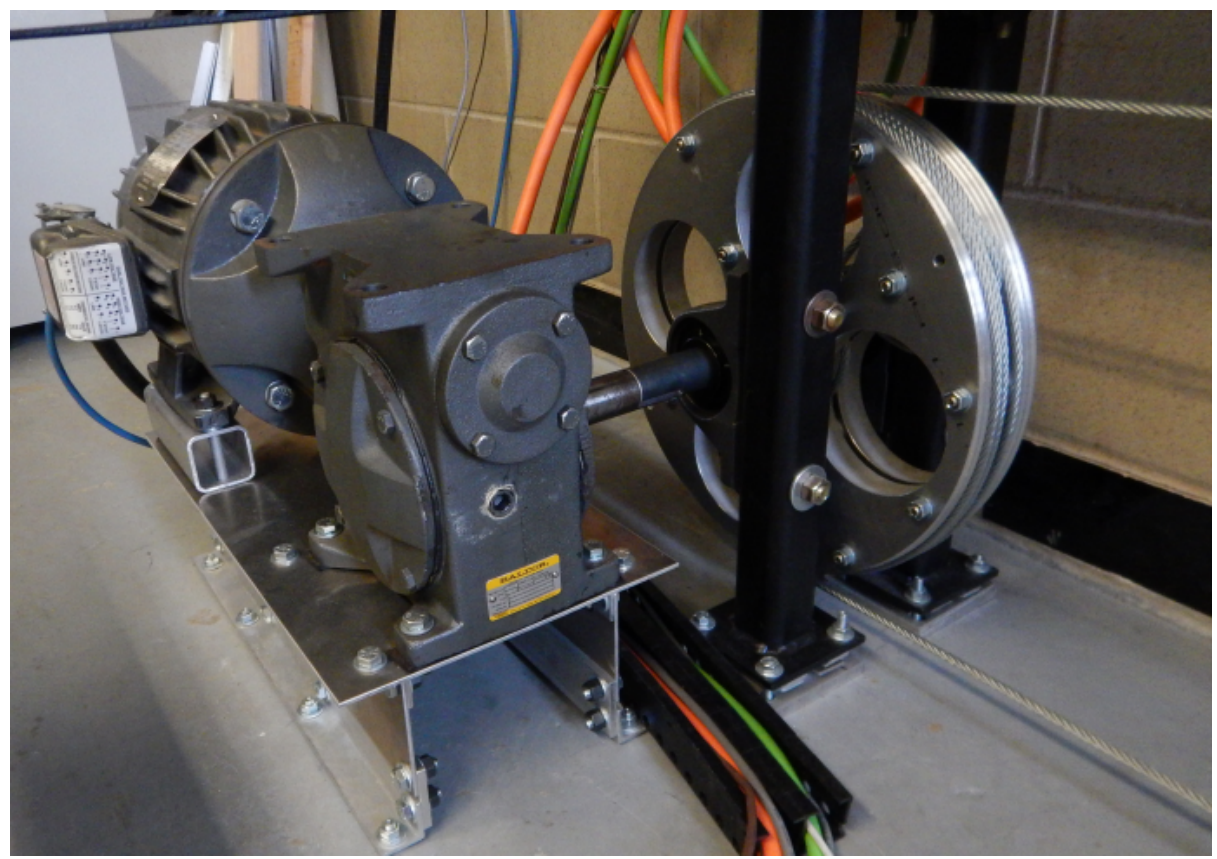

Figure 3.19: The Baldor induction motor and the worm gear speed reducer driving the wire rope pulley.

and worked well with the 20:1 speed ratio to provide an overall suitable drive ratio between the motor rotation and the linear displacement of the cart. Figure 3.19 shows a photograph of the motor, speed reducer, and spool pulley with the wire rope.

The wire rope is galvanized steel, $0.006 \mathrm{~m}$ (1/4 inch) diameter, and is cut from McMaster-Carr product \#3323T21. The wire rope has a $6 \times 37$ strand pattern, which was chosen for its improved flexibility over other patterns. Both ends of the wire rope are attached to the cart assembly with an end fitting that has a 1/2-20 threaded stud, which is McMaster-Carr product \#3475T211. The threaded studs fit into steel brackets that are attached to the sides of the cart. Figure 3.20 shows an end fitting attached to one of the brackets. After installation, the wire rope was tightened using the two threaded rods of the end fittings. During the commissioning 
phase, the tension can be increased as desired.

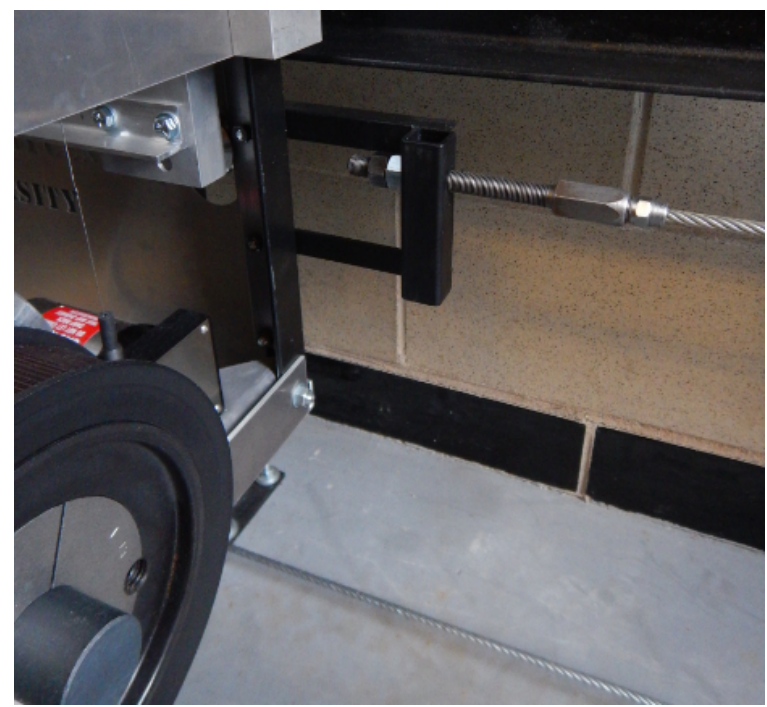

Figure 3.20: One of the wire rope end fittings attached to a wire rope bracket of the cart assembly.

One continuous length of wire rope is used for the horizontal loop, which is approximately $15.5 \mathrm{~m}$ long. One end starts at the side of the cart that is closest to the the Baldor motor, and then it is wound over the top of the pulley. It is wound around the plate that is close to the wall, and then towards the central space between the two plates. The wire rope is then fed in between the two plates and around aluminum discs, crossing itself twice, and then back out from the central space. Figure 3.21 shows the lacing method through the space between the two pulley plates during the assembly process, and the small discs are placed near to their actual locations in the final assembly. The smaller discs prevent the wire rope from falling into the central space for the first quarter rotation around the pulley because this is also the portion of the helical groove that transitions over the edge. This lacing method locks the wire rope in place when the two plates are bolted together, and the wire rope is not bent, crimped, or damaged. After exiting the central space between the plates, the wire rope is wound around the 
other plate and then travels out from the bottom of the pulley towards the far end of the rail support assembly. Two pulleys redirect the wire rope back towards the cart.

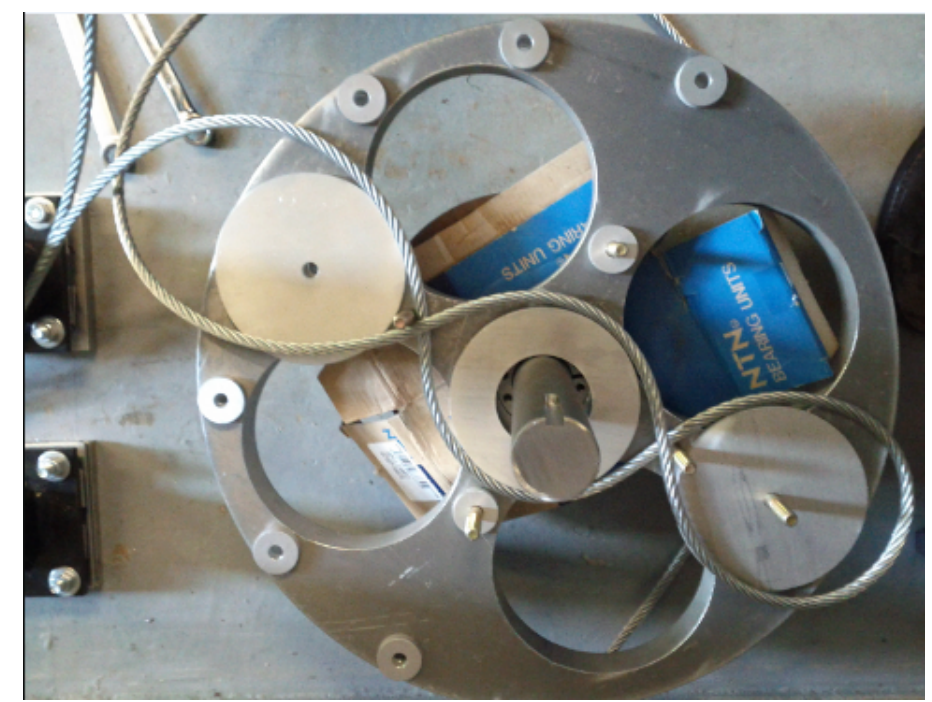

Figure 3.21: Photo of the horizontal drive pulley during assembly. One of the two plates is shown here to demonstrate the lacing method of the wire rope between the two plates.

The result of this particular lacing method is the unique operation of the pulley. As the cart travels from one end to the other, one of the pulley's plates is spooling the wire rope, while the other plate is letting out the other end. Figure 3.22 shows the spooled wire rope around one side of the pulley when the cart is close to the pulley, and Figure 3.23 shows the spooled wire rope around the other side of the pulley when the cart is at the far end of the rail support assembly.

The two pulleys at the far end of the rail support assembly are McMaster-Carr product \#3175T42. They are steel pulleys mounted on bronze bushings. The two pulleys slide on $0.019 \mathrm{~m}$ (3/4 inch) diameter rods. The rods are both McMaster-Carr product \#6061K113, which are polished 1045 steel rods, intended for use as precision shafts. The two pulleys and the rods are shown in Figure 3.24 as they are installed through 


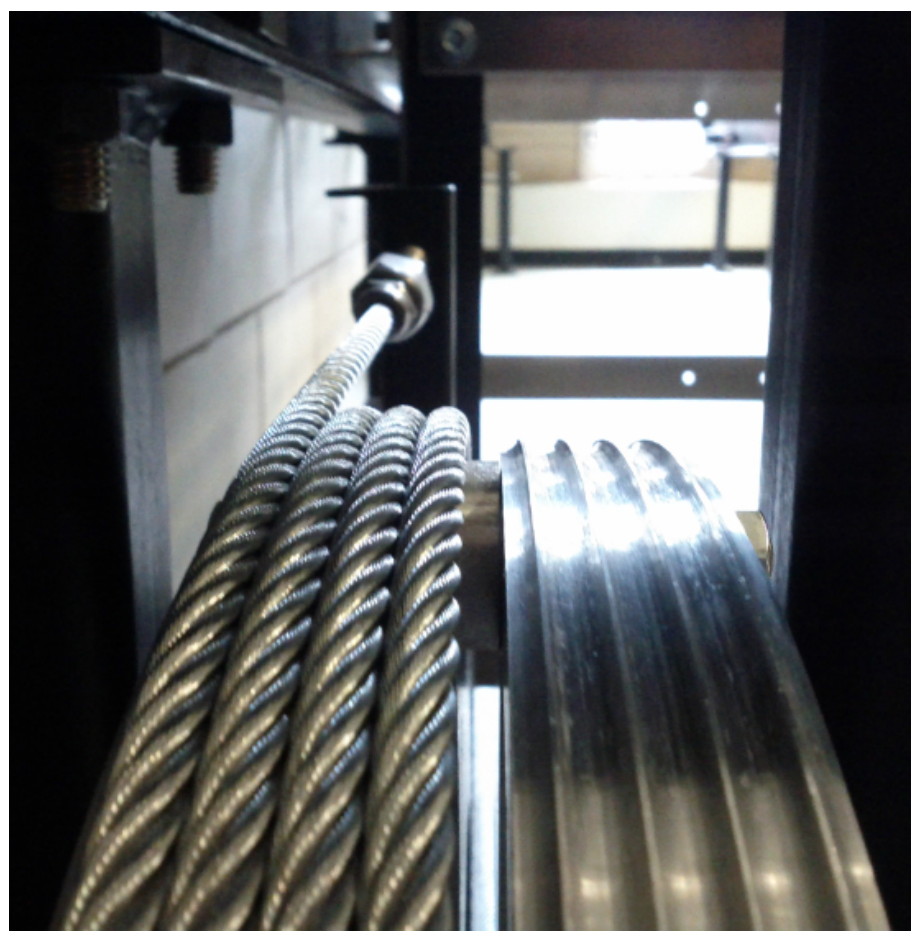

Figure 3.22: Pulley with spooled wire rope when the cart assembly is close to it.

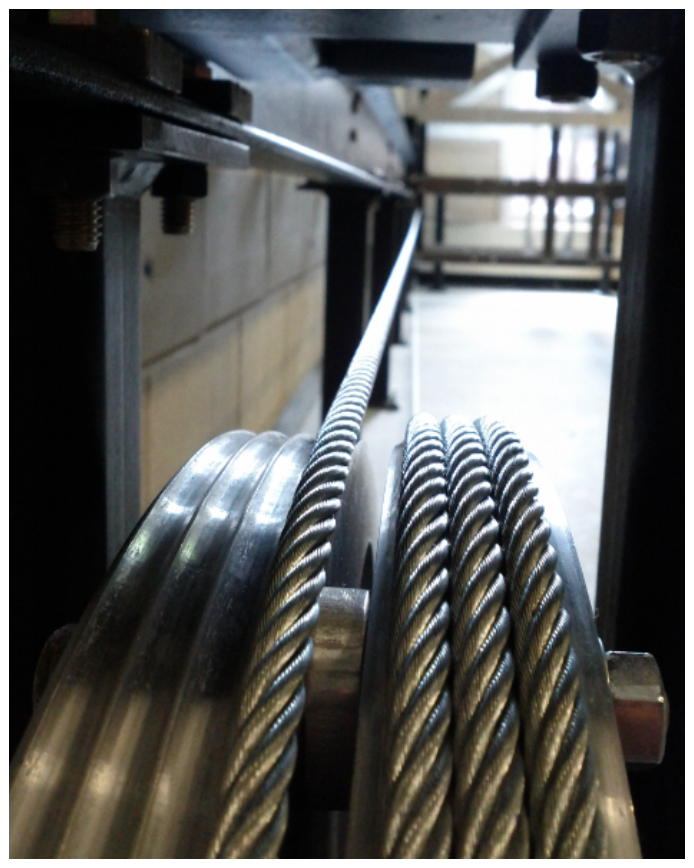

Figure 3.23: Pulley with spooled wire rope when the cart assembly is far from it. 
the posts of the rail support assembly.

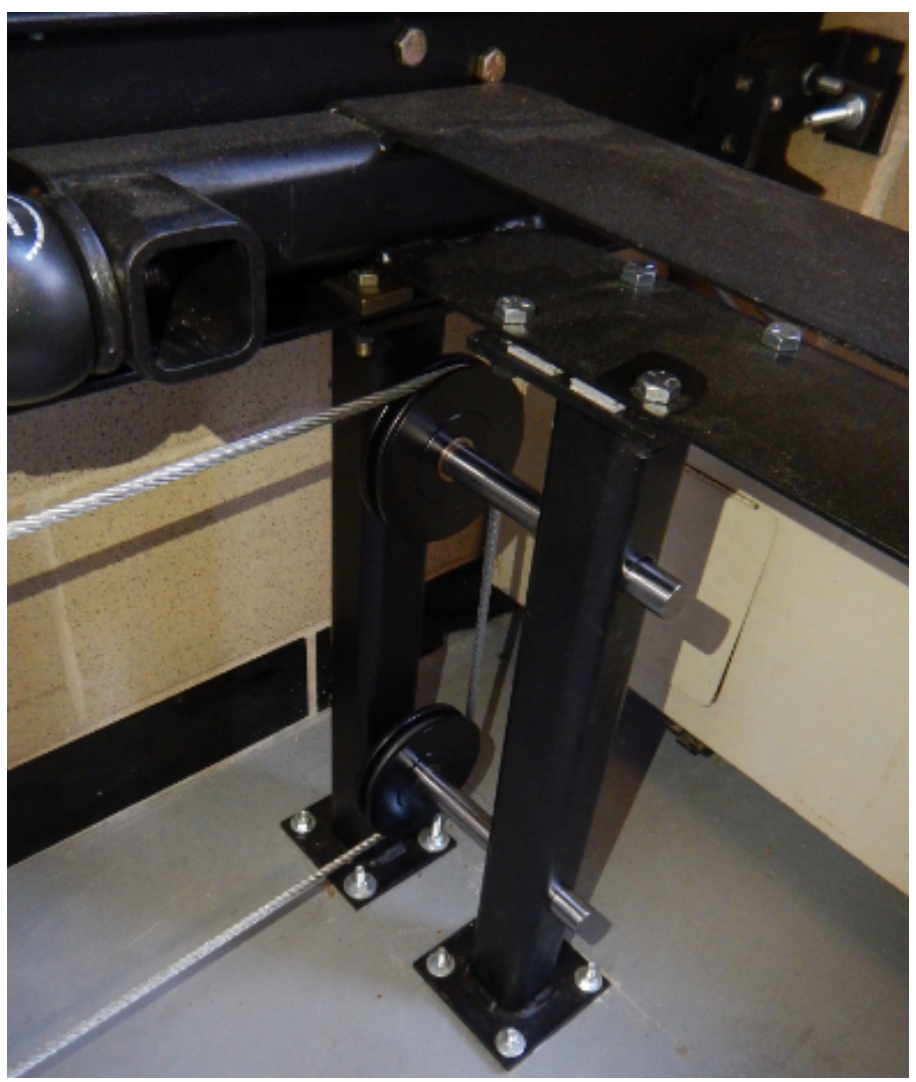

Figure 3.24: Wire rope pulleys at the far end of the rail support assembly.

\subsubsection{Vertical Drive System}

This actuation system is responsible for producing vertical motions of the deck assembly and the mass of the tested components. The system features a numericallycontrolled electric motor, a planetary gearhead, a synchronous-toothed belt, and a custom-designed wire rope spooling pulley. In this section, the major components will be described in detail, regarding their purpose, product information, important dimensions, and any other notable features. This discussion will progress from the electric motor to the connections with the deck assembly. Refer to Figure 3.25 for a labelled photograph of the first few parts that are described in this section. 


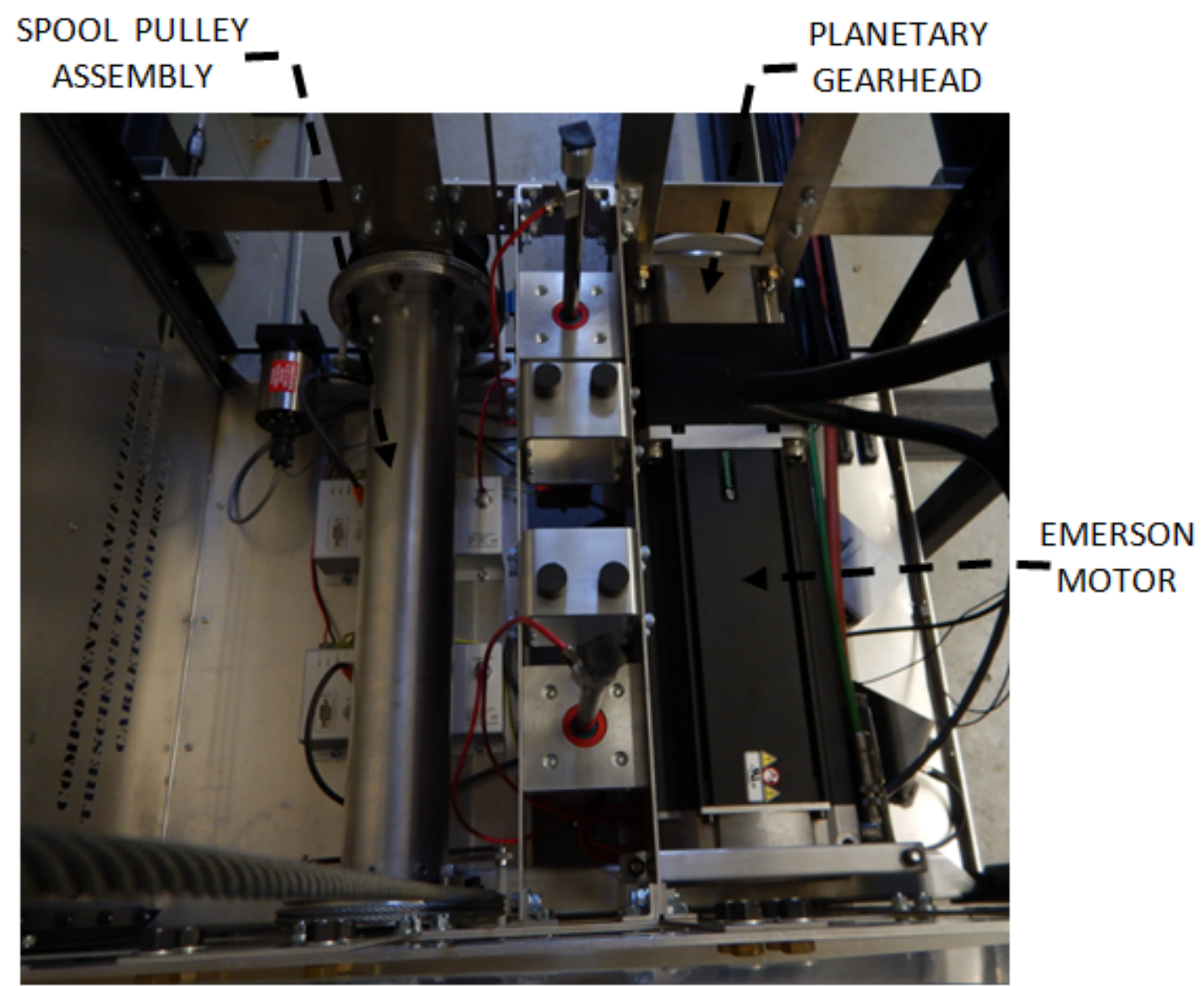

Figure 3.25: Interior of the cart assembly with labelled components of the vertical drive system.

The motor is from the Emerson 14 hp Unimotor FM servomotor product series, with model number 190E2F201BACAA215320. The motor drive controller is an Emerson Unidrive SP3202. This particular motor was selected based on the most suitable rotor inertia to match the inertia of the load, and the available torque. The motor is equipped with a mechanical holding brake that must be powered with $24 \mathrm{~V}$ DC to release it. 
A planetary gearhead is mounted directly to the Emerson motor and it provides a speed reduction of 7:1 from the motor's rotational speed. The planetary gearhead is a Thomson Micron ValueTrue inline gearhead, with model number VT018-007-0-RM180. The mounting flange of the gearhead is secured to the cart plates below the lateral beams and the rear end of the motor is restrained to one of the cart's bottom tubes with a clamp made from a contoured tube and threaded rods.

The shaft of the planetary gearhead drives the spool pulley using a synchronous toothed belt, as shown in Figure 3.26. The belt is from Gates Corporation's product series named Polychain GT Carbon. The belt's pitch is $14 \mathrm{~mm}$, the width is $37 \mathrm{~mm}$, and the model number is 14MGT-1190-37. The two pulley sheaves are identical and the model number is 14MX-36S-37 2517 GT2 SPKT. This product series is described as the best choice for low-speed, high-torque applications.

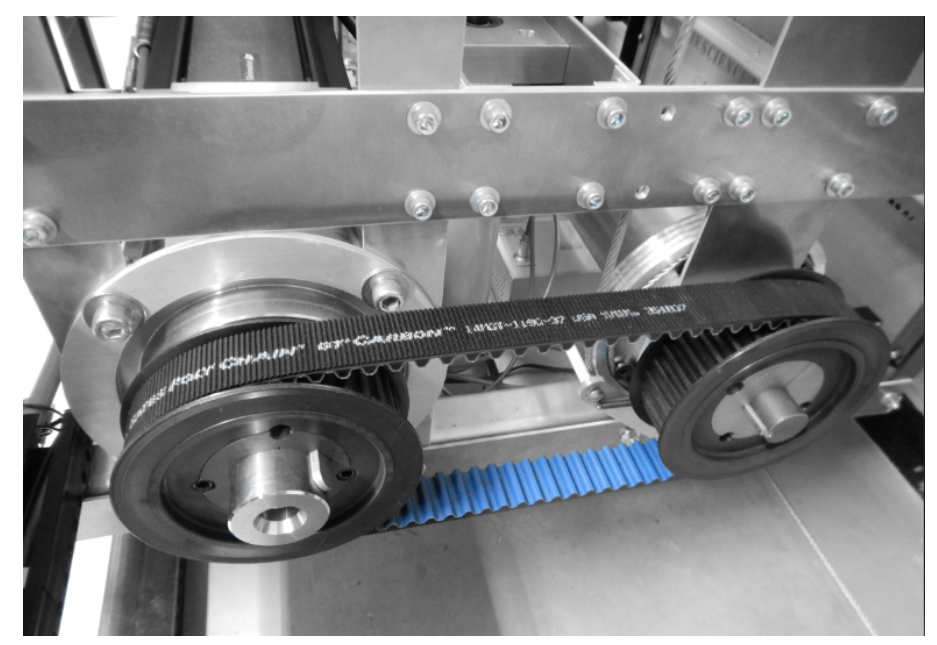

Figure 3.26: Synchronous toothed belt connecting the Emerson motor to the spool pulley assembly.

The spool pulley is a custom-designed assembly that converts the rotational motion of the motor to the linear motion needed to move the seat deck vertically. Figure 3.27 
shows an exploded view of the spool pulley assembly. All of these parts are bolted together with $5 / 16-18$ bolts.

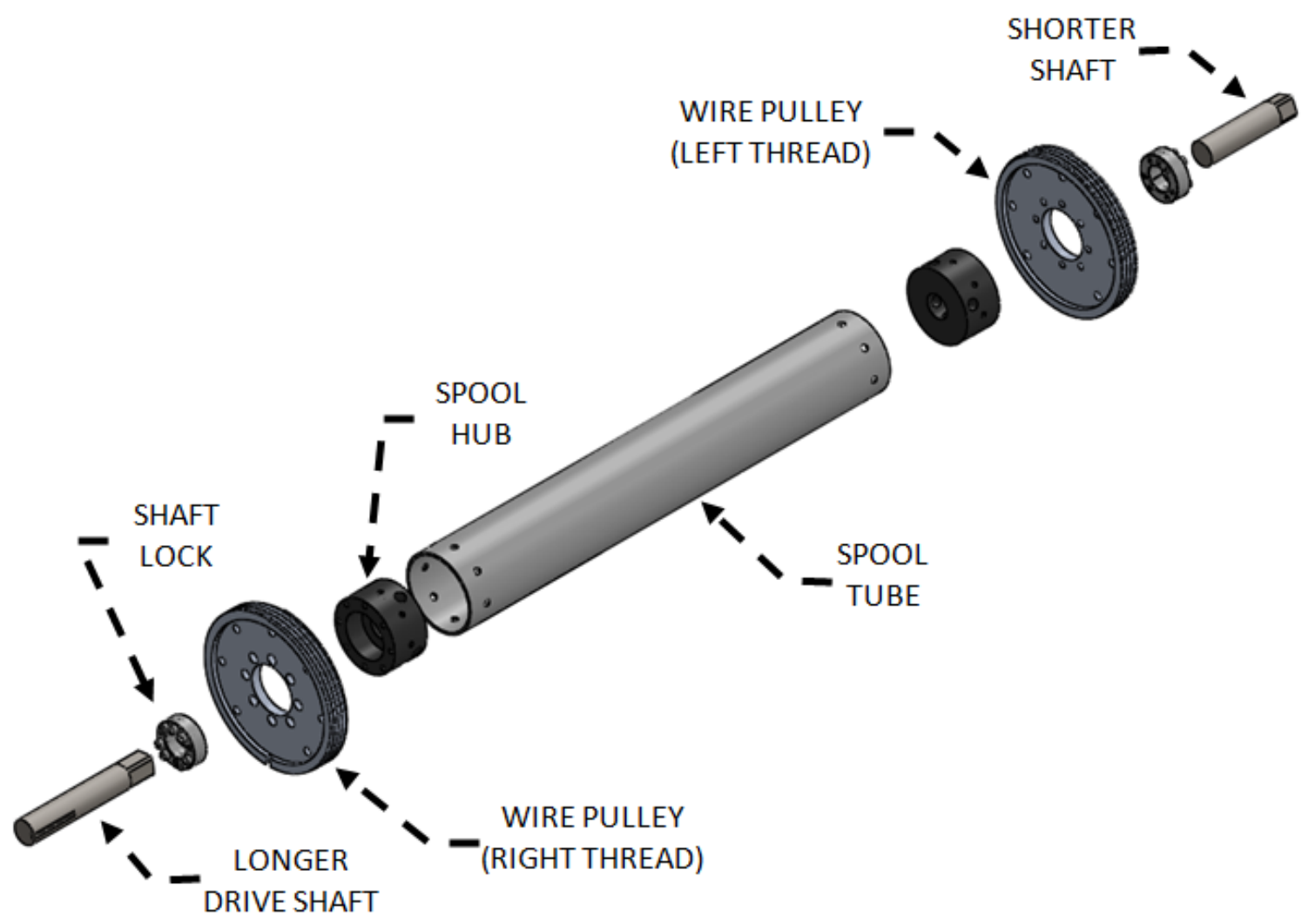

Figure 3.27: Exploded view of the spool pulley assembly.

The spool pulley assembly is supported on bronze bushings that are installed into the bushing flange mounts of the cart assembly. On each side of the cart, the backing plate of the bushing flange mount is in contact with the outer side of the wire rope pulley, which prevents the spool assembly from moving laterally. Bronze bushings were chosen instead of ball bearings because these bushings have a higher load rating than most roller bearings and they are significantly smaller, making them easier to accommodate into the design. Although the bushings are manufactured with a Polytetrafluoroethylene (Teflon) coating, during installation, the bushings and the surface between the bushing flange mount backing plate and 
the wire pulley were greased to protect the surfaces from galling. The bushings are McMaster-Carr product \#60695K8, which are steel-backed bronze bushings for heavy duty applications. These parts are shown in Figure 3.28.

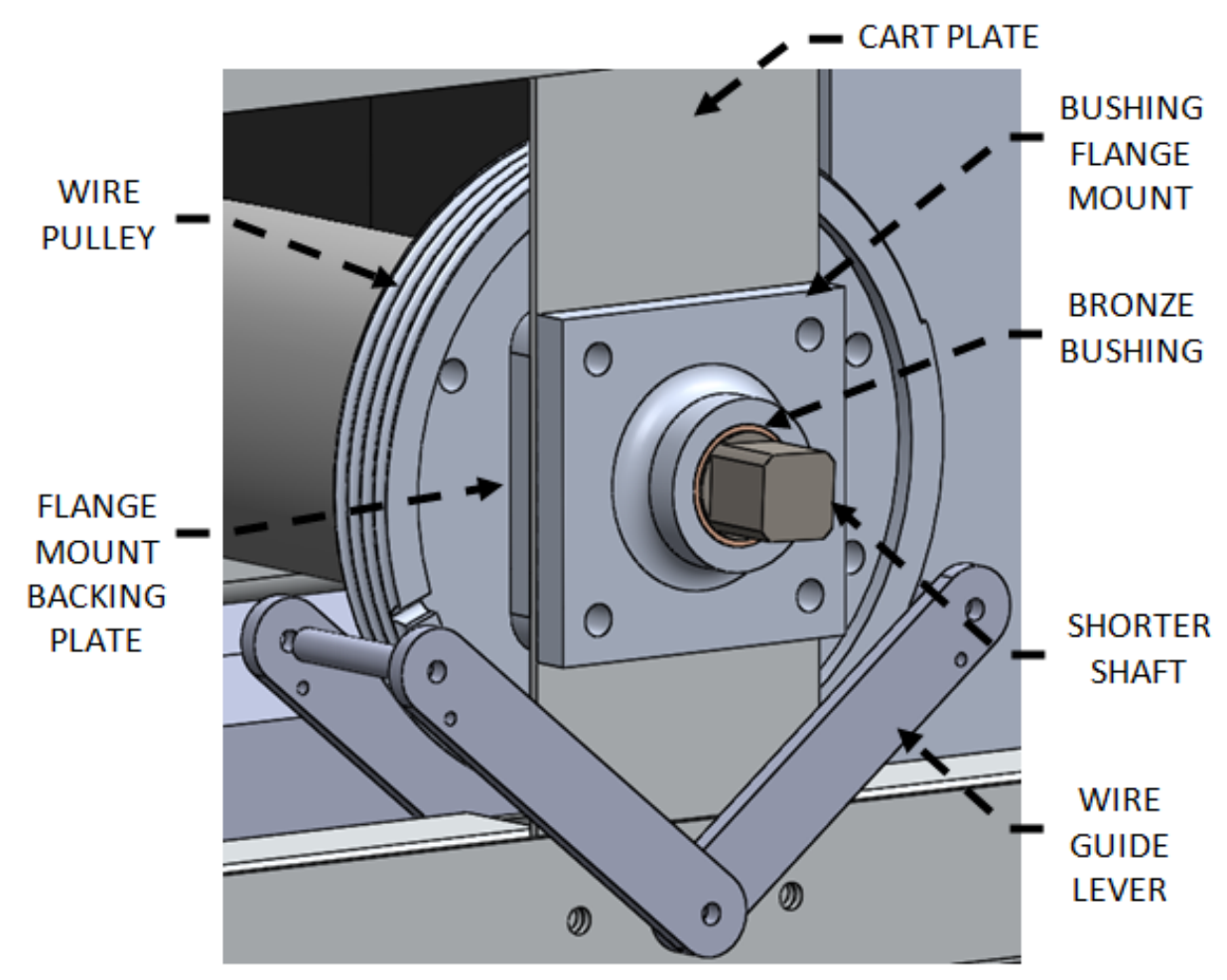

Figure 3.28: Labelled image of the far end of spool pulley assembly.

Both end shafts are cut from McMaster-Carr product \#5936K29, which is a Nitride-coated 1045 steel bar with a diameter of $0.032 \mathrm{~m}$ (1.25 inch). The bar is precision ground and intended for use as a spinning shaft. The longer shaft has a cut $0.006 \mathrm{~m}$ (1/4 inch) keyway and it is driven by the synchronous toothed belt outside of the cart. On the opposite side of the cart, the shorter shaft protrudes past its supporting bushing, shown in Figure 3.28. The end of the shorter shaft features machined flats into a square shape. Using a 1 inch crescent wrench, the spool can be manually rotated. This can be useful to tension the wire ropes and lift the seat deck without driving the belt with the motor. Lifting the seat deck is only possible if the 
seat deck is not loaded.

A screw-clamp shaft lock secures each shaft to a spool hub. The shaft lock mechanism has two tapered split collars that expand when the collars are tightened together. The screw-clamp shaft lock is McMaster-Carr product \#2328K14. Since the longer shaft transmits the motor's torque to the spool pulley assembly, the hub on that side has four 5/8-11 set screws that are fastened onto four machined flats on the inner end of the longer shaft.

The spool hub is a 6061-T6 cylindrical part that joins the shaft, wire pulley, and spool tube together. To accomplish this, it has a bolt pattern for each connection. After assembly, the two hubs are hidden inside the spool tube. The spool tube transmits the torque along the width of the cart's frame to the second wire pulley. It is a 6061-T6 aluminum tube with outer diameter of $0.102 \mathrm{~m}$ (4 inch) and wall thickness of $0.003 \mathrm{~m}(1 / 8$ inch).

The wire rope pulley is a 6061-T6 mirrored part that is attached to each end of the spool assembly and drives the motion of the vertical wire ropes. A 4 threads per inch groove was cut into the $0.025 \mathrm{~m}$ (1 inch) wide circumferential surface with a $0.006 \mathrm{~m}$ (1/4 inch) diameter round cutter. The result is a continuous round-shaped groove that progresses around the pulley four times. The diameter of the wire rope is also $0.006 \mathrm{~m}(1 / 4$ inch $)$ so when it is wound onto the pulley, three full turns can be spooled cleanly without overlapping itself or falling over the edge. An overlapping cable would change how the deck is being pulled and it has the potential to prematurely fray the wire rope. After the wire rope is wound, the distance between centres of the wire rope is $0.2 \mathrm{~m}$ ( 8 inch), which becomes the pitch line diameter of the pulley. 
The wire pulleys are mirrored parts. One pulley has a right-handed thread and the other has a left-handed thread. The linear travel of the deck assembly corresponds to approximately 2.5 turns of the spool assembly. When the deck assembly is at the bottommost position, there is half a turn of wire rope wound onto the pulley to help guide subsequent turns. The length of each wire rope is approximately $5.2 \mathrm{~m}$ long.

The wire ropes begin on the side walls of the pulleys that are facing outwards to the cart plates and then exit to the grooved surface of the pulley through machined openings. Each wire rope is pinned into a corner along the side wall using seven bolts. Each bolt is a 3/8-16 with a countersunk head, but then a $0.006 \mathrm{~m}(1 / 4 \mathrm{inch})$ radial contour was machined under the head, becoming a clamping surface. When fastening the wire rope with these bolts, the wire rope became visibly crimped and locked in place. The wire rope is galvanized steel, with $0.006 \mathrm{~m}(1 / 4 \mathrm{inch})$ diameter, cut from McMaster-Carr product \#3323T21. The wire rope has a $6 \times 37$ strand pattern, which was chosen for its improved flexibility over other patterns. Figure 3.29 shows a photograph of the spool and the loose wire rope during the assembly process.

The other end of each wire rope is attached to the deck assembly using an end fitting with a 1/2-20 threaded stud, which is McMaster-Carr product \#3475T211. The threaded stud fits into a hole in the aluminum block that is on either side of the load deck. The retaining nuts on the threaded studs were then adjusted until the tensions in the two wire ropes were apparently equal.

The wire rope alignment guide levers are spring-loaded levers that press the wire rope into the pulley grooves. If the motor drives the spool in the direction of lowering the 


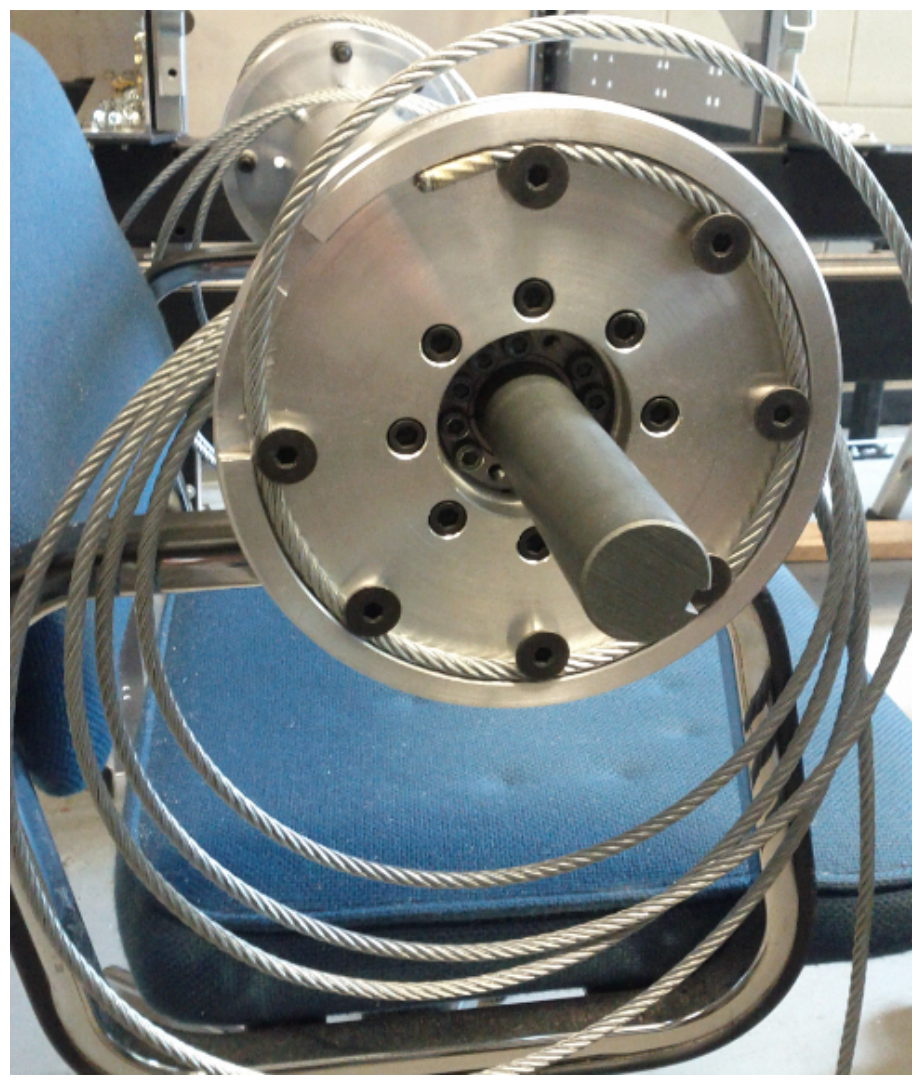

Figure 3.29: Vertical drive spool during the assembly process.

seat deck at a rate that is faster than the rate of a freefalling mass or if it continues to drive in this lowering direction after the seat deck is rested at the bottom of its travel, the wire rope would lose its tension. Slack in the wire rope causes the loops around the pulley to expand and become unseated from the pulley grooves, creating the potential for the wire rope to fall off the side of the pulley when the motor starts to drive the pulley in the upward direction again. The alignment guides ensure that the wire rope stays seated into the grooves by applying pressure with a plastic roller. The guides are attached to the bottom tubes at the sides of the cart. A photograph of the wire rope guide levers on the far-end wire pulley is shown in Figure 3.30.

The top pulley beams support the hanging pulleys that redirect the wire ropes. 


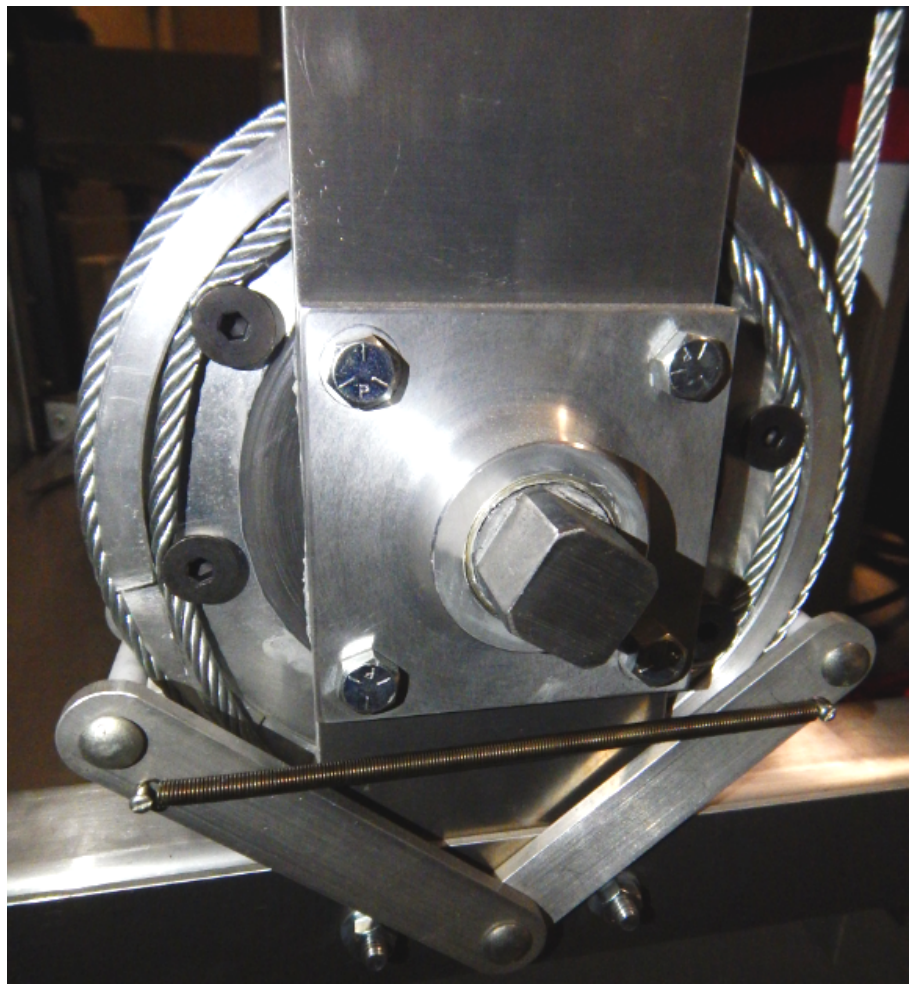

Figure 3.30: Photograph of the far-end spool pulley with the wire guide levers.

The top pulley beams are described in Section 3.2. The hanging pulleys are McMaster-Carr product \#3099T62. Figure 3.31 shows a photograph of the top pulley beams, a hanging pulley, and a wire end connector. Note that this photograph was taken before the Omega 250 load cell and the seat deck assembly were installed. 


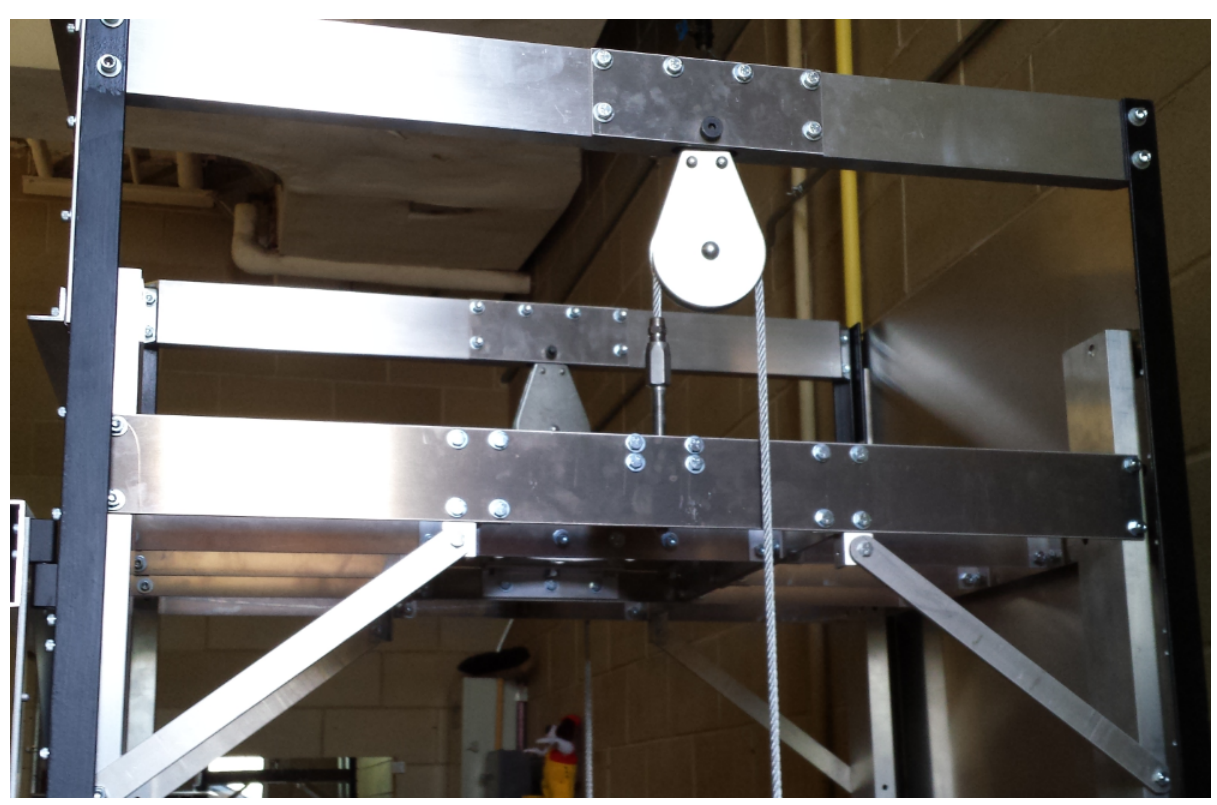

Figure 3.31: Deck assembly at the top of the vertical travel.

\subsection{Electrorheological Dampers}

Electrorheological (ER) dampers are viscous fluid dampers that are similar to shock absorbers, but their use of an ER fluid can provide a variable and controllable response force. The fluid has polarized polymer particles in suspension, which form chains when charged, and increase the viscosity of the fluid. A low viscosity fluid results in a low reaction force and soft damping. A high viscosity corresponds to a high reaction force and hard damping. The inputted electric charge can be remotely controlled and the change is activated within milliseconds. There are no moving mechanical parts involved with adjusting the damping properties. The manufacturer claims that there is no accumulated wear from repeated use. A section view of an ER damper is shown in Figure 3.32.

Two of the RheDamp 63 dampers were purchased from the manufacturer named Fludicon, along with two of their corresponding DampCon 40 amplifiers. The travel 


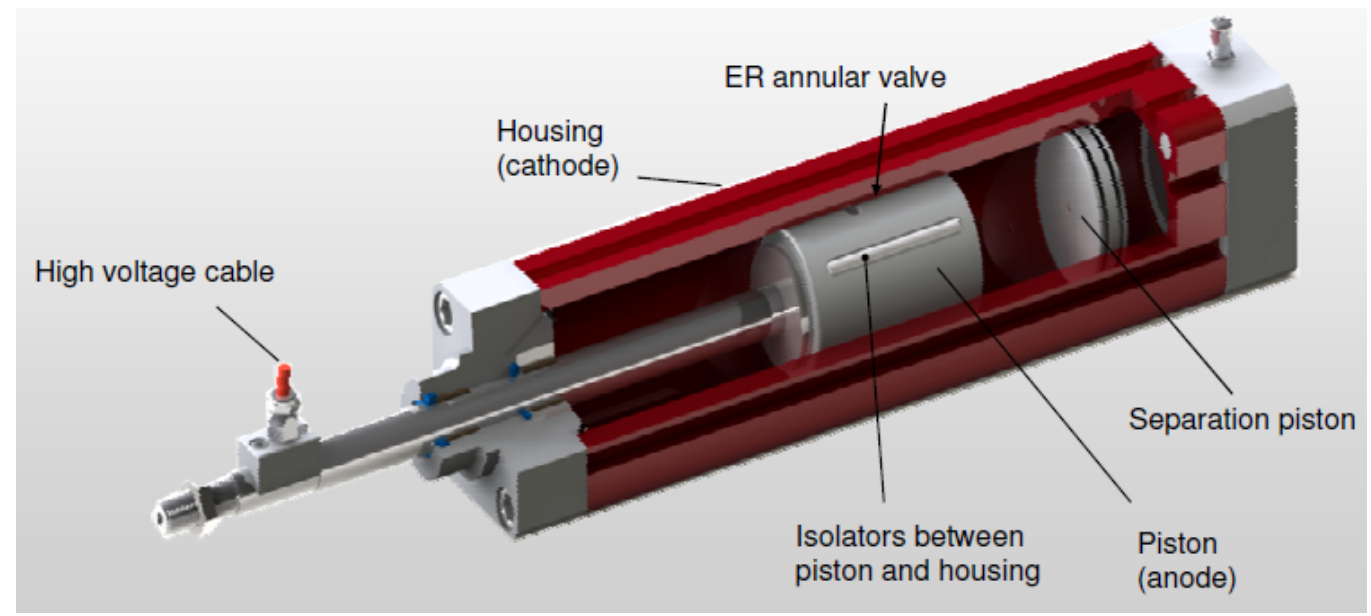

Figure 3.32: Section view of a RheDamp damper. [21]

length is $150 \mathrm{~mm}$. The dampers are charged with compressed nitrogen gas, which forces the piston to naturally be in an extended position. The extension force is approximately $450 \mathrm{~N}$. The dampers are used in parallel to double the available response force.

Figure 3.33 shows a photograph of the two ER dampers installed in the cart assembly. They are suspended from their top mounting flange. During a slam impact, he piston rods will contact the aluminum deck blocks that are on either side of the load deck assembly. The DampCon 40 amplifiers are secured to the bottom sheet of the cart under the spool pulley assembly. The inputted power supply to the amplifiers is $24 \mathrm{~V}$ DC and an electrical ground line connects each component and leads back through the electrical cable carrier from the cart to the junction box.

Control of the response force will depend on low voltage signals in the range of $0-4 \mathrm{~V}$ from the analog output ports of the NI-DAQ 6211 to the DampCon 40 amplifiers. Since there is no feedback control sensor to accompany the devices, a series of controlled experiments with be required with the deck accelerometer and load cell as 
monitoring sensors, data processing to evaluate the results, in order to develop an algorithm for producing predictable results. During the experiments, the dropped mass, velocity before impact, inputted voltage, and resulting peak acceleration should be varied to develop relationships between these parameters. The algorithm would be dependent on these relationships. During seat testing, the mass of the seat and of the representative user may need to be included into the control algorithm.

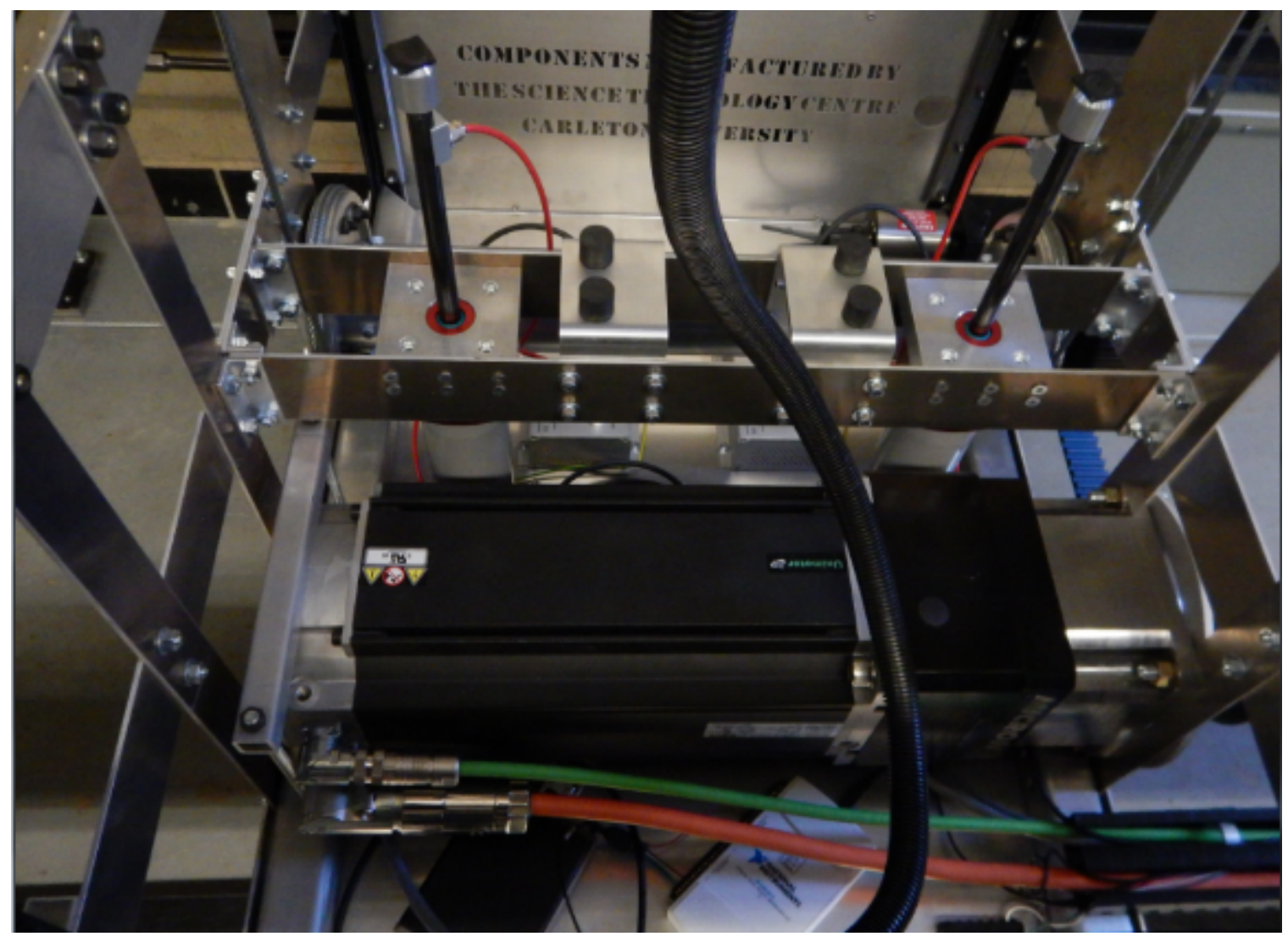

Figure 3.33: Photograph of the RheDamp dampers mounted vertically in the cart. 


\subsection{Data Acquisition, Power, and Control Systems}

As a dynamic motion simulating machine, the kinematics of the mass of the tested components must be measured and recorded. This involves sensors to measure the motion, and a data acquisition (DAQ) device and corresponding software to log the data. All of these devices require a power source and wiring for the power and data signals. This section will provide an overview of the sensors, DAQ system, and the power and control systems of the machine.

\subsubsection{Sensors}

Several types of sensors are required. First and foremost, testing suspension seats will require measuring the accelerations of the seat base and of the seat pad, and then comparing the results for an evaluation of the performance of the seat. The displacements of the seat deck will be measured so that they can accompany the accelerometer data without needing to derive it from integrating the acceleration data. The inertial forces of the seat deck will also be measured as an extra feature of the machine. This section identifies the model numbers for all sensors and describes the mounted locations.

Acceleration of the mass of the tested components is measured at three different locations. There is a triaxial accelerometer fixed to one of the plates of the load deck, and the model number is CXL25GP3. It remains there at all times, and it is shown in Figure 3.34. The other two locations are on the tested seat. At each of those locations, three uniaxial accelerometers, with model number MEAS 4000A-100, are arranged orthogonally and attached to an aluminum block, which also serves as a 
mounting fixture to the seat. One of the blocks is attached onto the sliding carriage frame of the seat, also know as the seat pan. The other block is attached to the mass that represents the seat's occupant. The exact method of mounting is dependent on the seat being tested. The two aluminum blocks are shown in Figure 3.35. As an alternative to the accelerometers attached to the aluminum blocks, a seat pad accelerometer may be used under the mass that represents the seat's occupant.

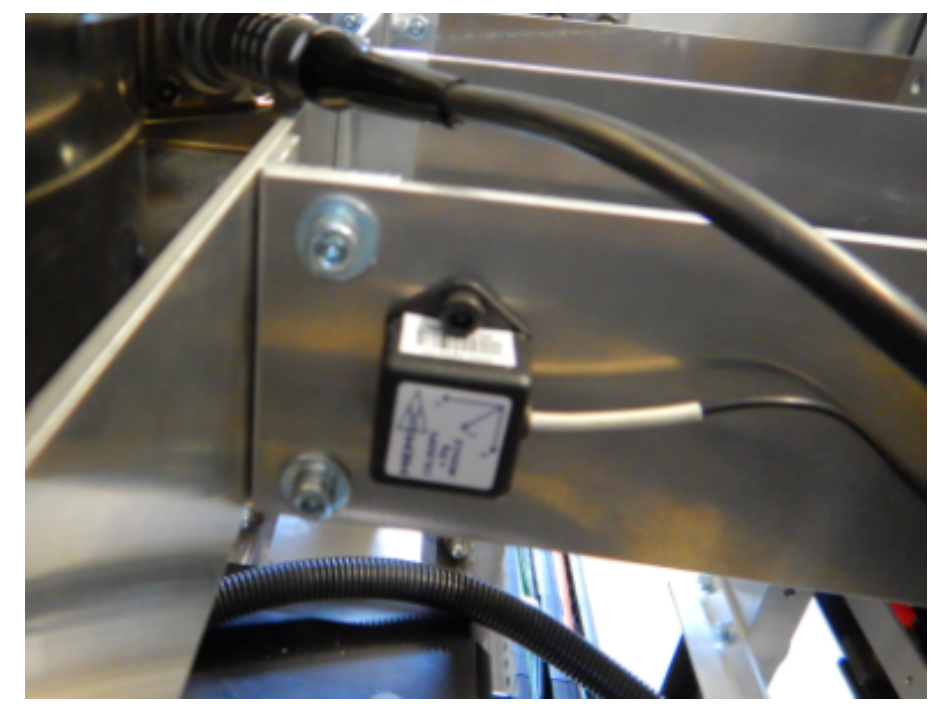

Figure 3.34: Accelerometer that is fixed to the load deck assembly.

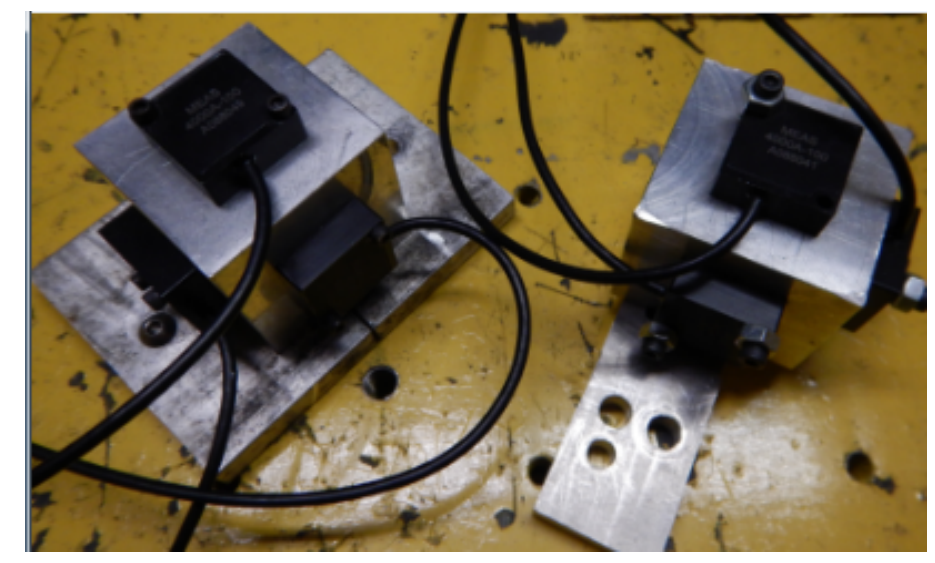

Figure 3.35: Aluminum blocks with three uniaxial accelerometers on each block.

The displacement of the seat deck is measured with two string potentiometers, one 
for each driven axis of motion. The horizontal displacement of the cart's motion is measured with a UniMeasure HX-PA 250. The unit is mounted to the rail support post beside the Baldor motor, as shown in Figure 3.36, and the end of the string is attached to the nearest corner post of the cart. It is assumed that the horizontal displacement of the cart and of the deck assembly are the same. The vertical displacement of the deck assembly is measured with a UniMeasure HX-PA 80. The unit is mounted onto one of the bottom tubes of the cart, as shown in Figure 3.37, and the end of the string is attached to the diagonal support member of the load deck above it. The number in each of the two model numbers refer to the respective wire lengths in inches. Both wire lengths are longer than the length needed for the corresponding range of motion.

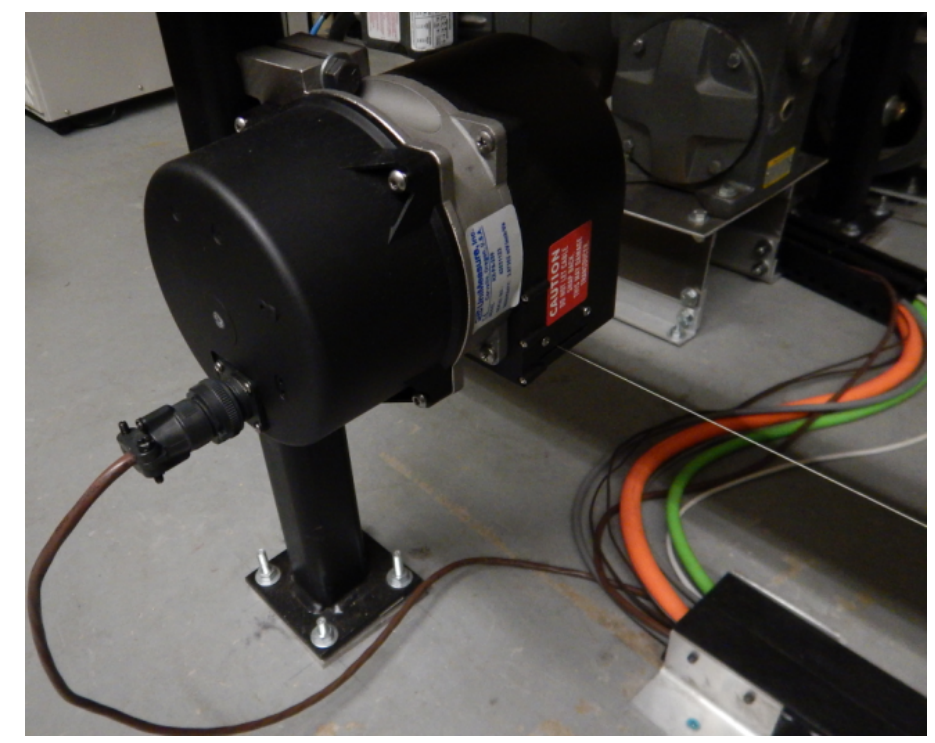

Figure 3.36: String potentiometer used to measure the horizontal displacement of the cart.

A force and torque measurement device, the Omega 250 load cell, has been installed as a permanent fixture that joins the seat deck assembly to the load deck assembly. A plate in the centre of each deck assembly is bolted to one of the two flat surfaces 


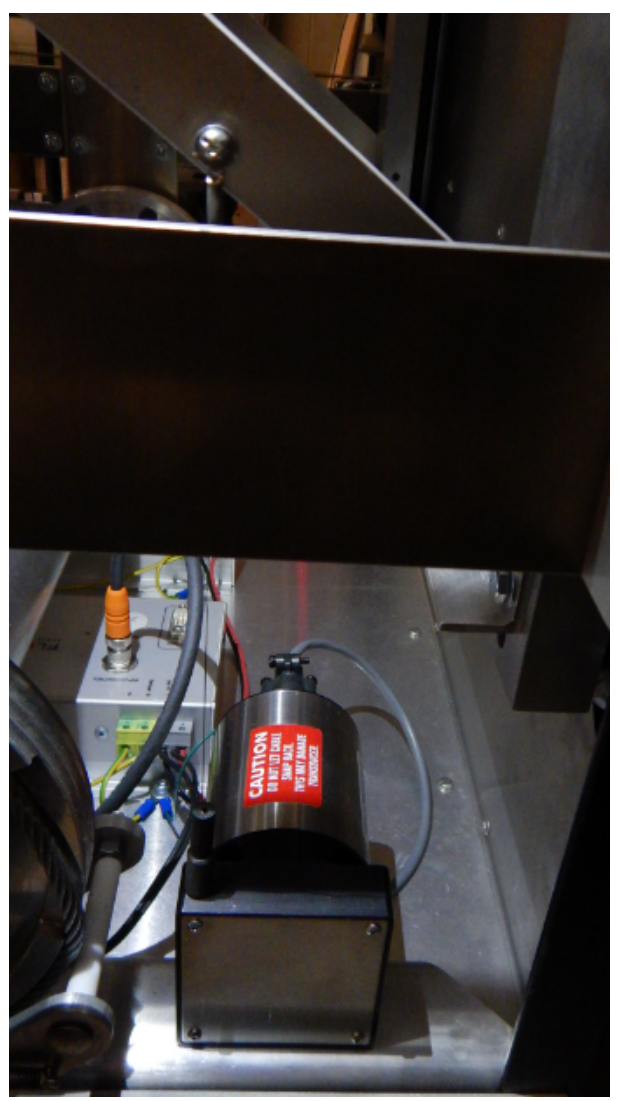

Figure 3.37: String potentiometer used to measure the vertical displacement of the deck assembly.

of the device. Figure 3.38 shows the device installed into the load deck assembly. The device is made by ATI Automation Industries and the model is the Omega 250. The measurement sensing range for the Omega 250 is shown in Figure 3.39, listed as the US-3600-18000 calibration. Although the device is capable of measuring forces in the three principle directions and moments about the three axes. The forces in the vertical $(\mathrm{z})$ direction and the lateral $(\mathrm{y})$ direction, and the moments about the forward (x) axis, are the primary measurements of interest because they correspond to the directions of motions. This device requires a power supply unit that is a small rectangular box, which will be mounted to the bottom sheet of the cart assembly. 


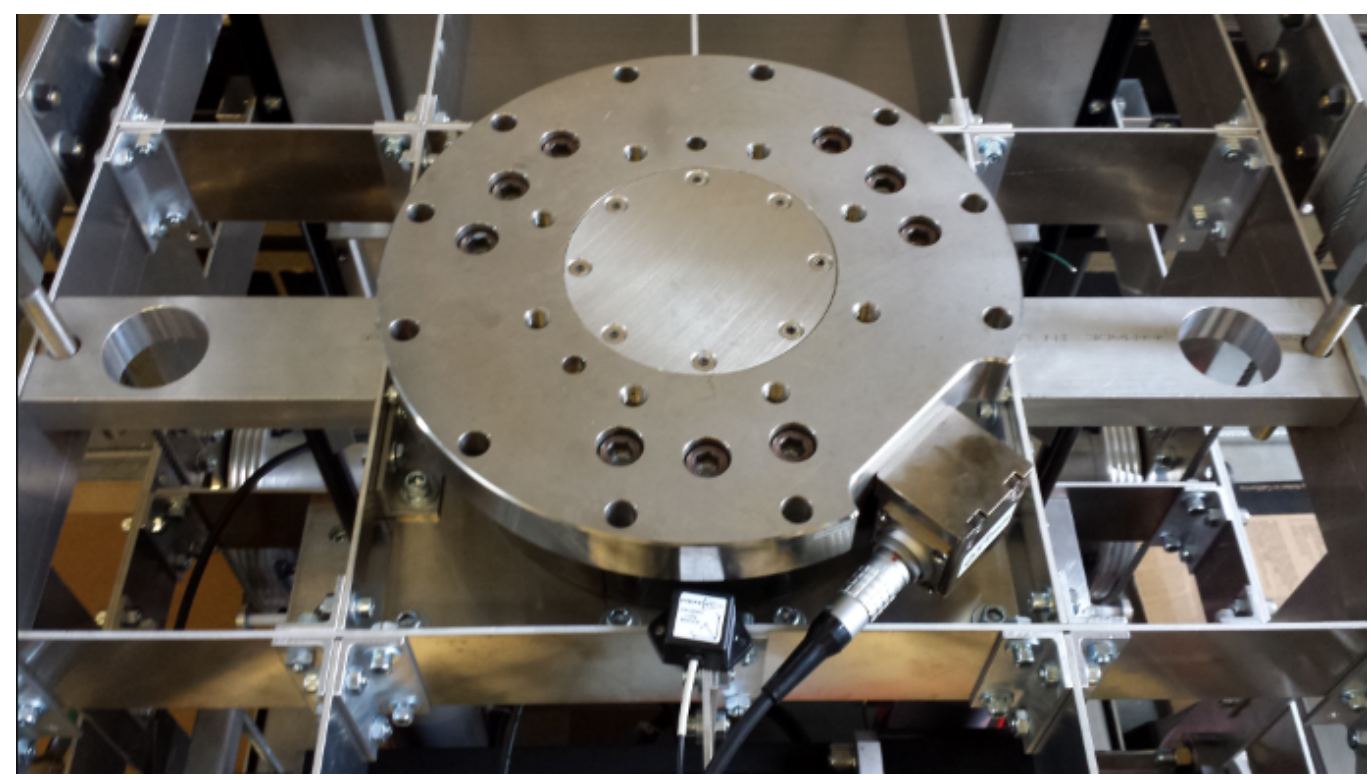

Figure 3.38: The Omega 250 load cell installed on top of the load deck assembly.

F/T Transducer Installation and Operation Manual
Document \#9620-05-transducer section-17

US (English)

4.17.2 CTL Calibration Specifications

\begin{tabular}{|c|c|c|c|c|c|c|c|c|}
\hline Calibration & $F x, F y$ & $\mathbf{F} \mathbf{z}^{\star \star \star}$ & Tx, Ty & Tz & Fx, Fy & $F z^{\star \star \star}$ & Tx, Ty & $\mathrm{Tz}$ \\
\hline US-900-4500 & $900 \mathrm{lbf}$ & $1800 \mathrm{lbf}$ & $4500 \mathrm{lbf}-\mathrm{in}$ & 4500 lbf-in & $1 \mathrm{lbf}$ & $1 \mathrm{lbf}$ & $2 \mathrm{lbf}-$ in & 2 lbf-in \\
\hline US-1800-9000 & $1800 \mathrm{lbf}$ & $3600 \mathrm{lbf}$ & $9000 \mathrm{lbf}-\mathrm{in}$ & $9000 \mathrm{lbf}$-in & $2 \mathrm{lbf}$ & $2 \mathrm{lbf}$ & $5 \mathrm{lbf}-$ in & $5 \mathrm{lbf}-$ in \\
\hline \multirow[t]{2}{*}{ US-3600-18000 } & $3600 \mathrm{lbf}$ & $7200 \mathrm{lbf}$ & $18000 \mathrm{lbf}-$ in & $18000 \mathrm{lbf}$-in & $5 \mathrm{lbf}$ & $5 \mathrm{lbf}$ & $10 \mathrm{lbf}-$ in & $10 \mathrm{lbf}-$ in \\
\hline & \multicolumn{4}{|c|}{ SENSING RANGES } & \multicolumn{4}{|c|}{ RESOLUTION } \\
\hline
\end{tabular}

Figure 3.39: Measurement sensing range of the Omega 250. This model has the US-3600-18000 calibration. [24]

Two limit switches are used to identify the home positions for the two drive controllers. The measured displacements are relative to these references. A homing sequence must be performed during the startup of the two motor drives. For the horizontal axis, a switch is attached to the cart, which gets activated by a small lever located inside the front channel beam. The zero position is identified as the centre of the $3.5 \mathrm{~m}$ travel length. For the vertical drive, a switch is attached to one of the rectangular posts of the load deck assembly, as shown in Figure 3.40, and it 
gets triggered by a magnet attached to the inside surface of the Dual-Vee profile rail. The zero position is identified as the bottom of the $1.6 \mathrm{~m}$ travel length.

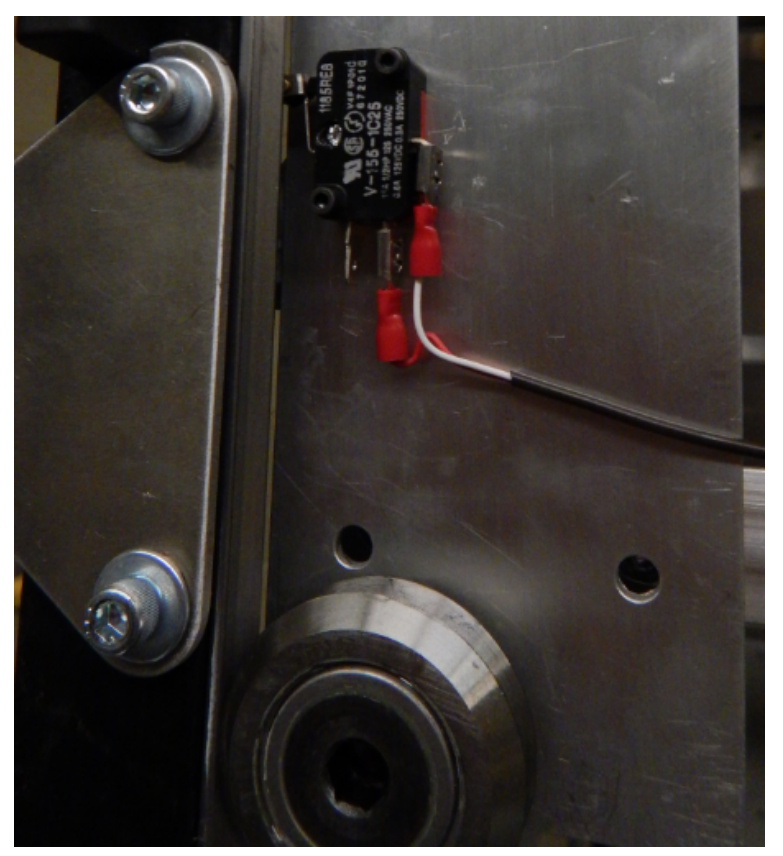

Figure 3.40: Limit switch attached to the deck. Its triggering lever is located behind the rail.

\subsubsection{Data Acquisition}

The machine requires three data acquisition devices in order to collect data from all of the sensors. The three accelerometers are interfaced to an NI-DAQ 6211 device, which is located on the bottom sheet of the cart assembly. The two potentiometers are interfaced to an NI-DAQ 6289 device because the accelerometers occupied all available input channels of the NI-DAQ 6211 device. The NI-DAQ 6289 device is located on the operator station desk. Both of these devices are connected to a desktop computer via USB ports. The Omega 250 has a dedicated DAQ device, which is mounted inside the desktop computer as a PCI-card. All data is logged with Labview software. 


\subsubsection{Power and Control Systems}

All actuators and sensors used in the machine require electrical power. In this section, the power source of each device is identified and then groups of wiring are described. Finally, the softwares and motion programming for the two drives are described.

The following is a comprehensive list of components requiring power, the required power, and the source.

- The Baldor Vector drive receives $460 \mathrm{~V}$ 3-phase AC from a wall source. Refer to Figure 3.41.

- The Emerson Unidrive SP drive receives 230 V 3-phase AC from a wall source. The Emerson motor also receives $24 \mathrm{~V}$ DC for its built-in holding brake. Refer to Figure 3.41.

- The DampCon 40 amplifiers receive 24 V DC from an independent wall-mounted power supply that has been mounted below the Emerson Undrive SP drive.

- The NI-DAQ 6211 receives 5 V DC from the desktop computer's USB port.

- The NI-DAQ 6211 receives 5 V DC from the desktop computer's USB port.

- The Accelerometers receive 5 V DC from the NI-DAQ 6211.

- The string potentiometers receive $12 \mathrm{~V}$ DC from a desktop regulated power supply.

- The Omega 250 load cell receives 5 V DC from the desktop computer through 
the PCI card.

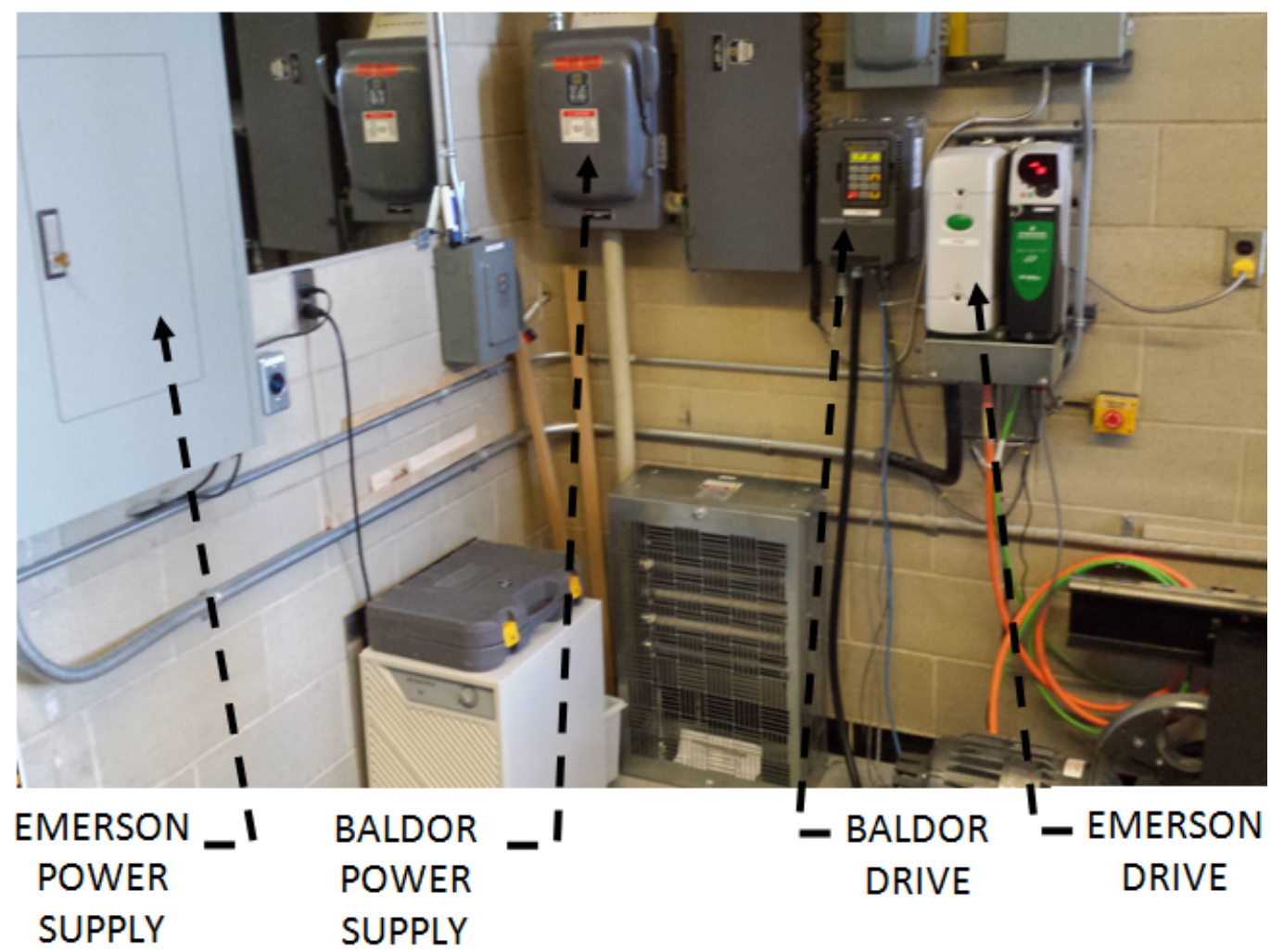

Figure 3.41: Power supplies and the motor drives.

There are three wiring groups. The groups were formed based on the locations of the sources and of the devices.

- A flexible cable carrier runs along the length of the rail support assembly and feeds into the base of the cart assembly. It unrolls as the cart moves away from the Baldor motor. It is made from three lengths of the McMaster-Carr product \#5607K6. The attachment of the cable carrier to the cart assembly is shown in Figure 3.42. Inside the carrier, the Emerson's thick power cable and encoder cable are led from the wall-mounted Emerson drive that is above the horizontal drive's pulley to the motor in the cart. The $24 \mathrm{~V}$ DC power supply lines are also led through the entire length of this carrier.

- Approximately half way along the flexible cable carrier, a steel junction box is 
anchored to the ground and it feeds wiring lines from the flexible cable carrier, under a rubber cable cover that crosses a walkway, and up to the control station desk. The junction box and the rubber cable cover can be seen in Figure 3.42. The rubber cable cover is McMaster-Carr product \#9384K4. The communication cables from the motor drives pass through the first half of the flexible cable carrier and then through the rubber cable cover to the computer. The USB cable from the NI-DAQ 6211 and the cable from the Omega 250 pass through the second half of the flexible cable carrier and then through the rubber cable cover to the computer.

- A cable loom carries the wiring needed for the devices on the deck assembly. The two ends of this loom are fixed to the base of the cart and to the angle-profiled support bar that is between the two front rectangular posts of the load deck assembly. This loom carries the cable from the Omega 250 in the deck assembly to its power supply, all of the signal lines from the accelerometers to the NI-DAQ 6211, and the wires to the limit switch that is attached to the load deck rectangular post. The power supply for the Omega 250 and the NI-DAQ 6211 are both mounted to the bottom sheet of the cart assembly. This loom is shown hanging in Figure 3.33. While installing this loom, the two fixed ends of the loom were directed to induce the loom to coil itself when the deck assembly was lowered. This was necessary to prevent it from being sheared between the deck assembly and the cart assembly.

LabView Software is used for active control of the Baldor drive system. Communication is via a serial data connection. Motion programs were developed to send position commands to the drive. At this stage of development, the capability for motion has been established but the motion profiles are simple sinusoids. 


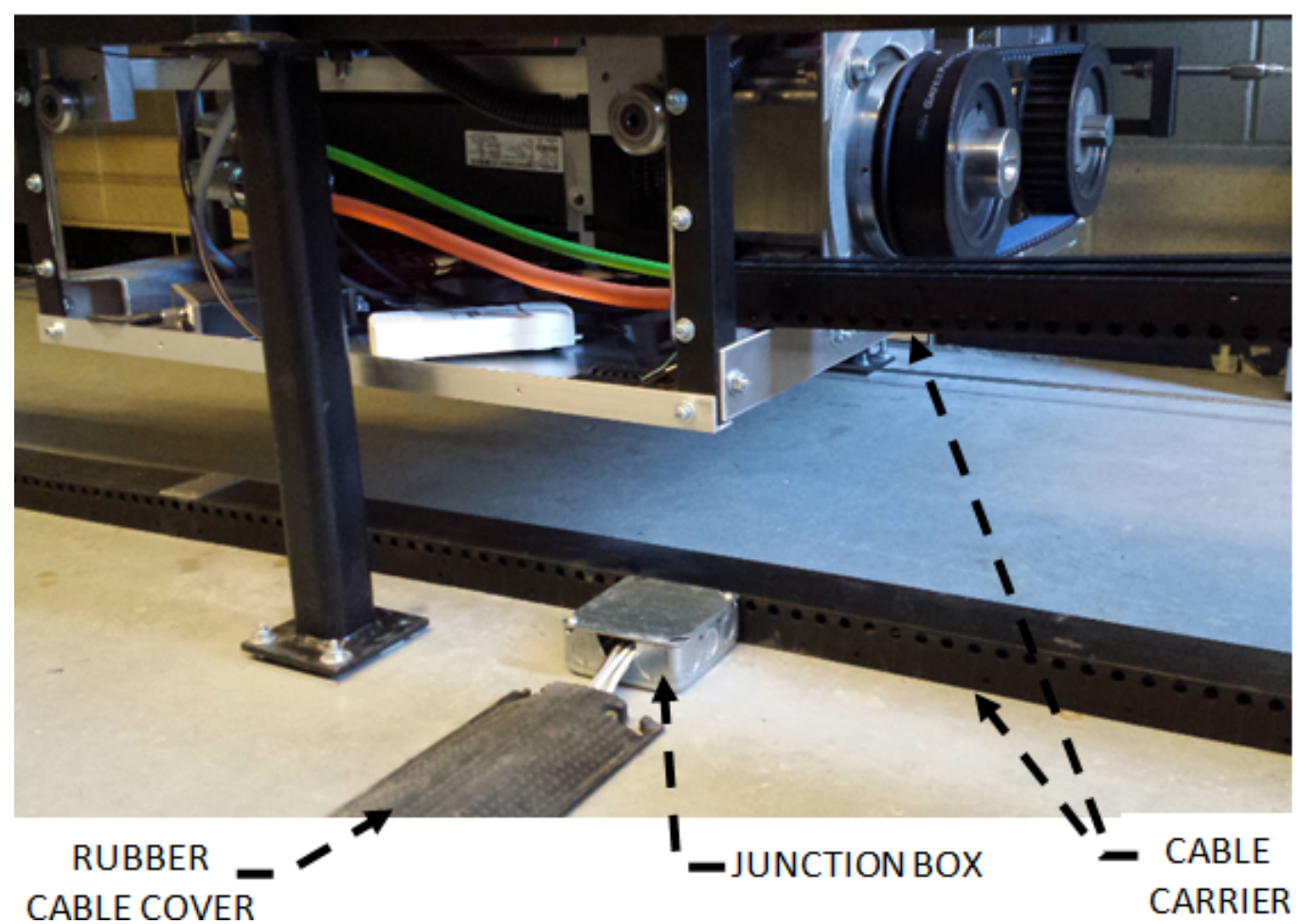

Figure 3.42: The flexible cable carrier, the junction box, and the rubber cable cover.

The Powertools Pro software is used for active control of the Emerson drive system. This is possible with use of the EZ-motion expansion module and communications through an ethernet connection. The software features built-in motion programming of position control in the form of homing, indexes, and cams. PID control is automatically implemented based on stored motor parameters and encoder feedback. A desktop control panel was built and the buttons were connected to the digital inputs of the drive. While a program is running, these buttons can be used as process control instructions and as an emergency stop. Figure 3.43 shows the control panel.

The built-in cam motion programming is the most applicable for reproducing at-sea motion and for other motion profiles used for seat testing. As an example, a 


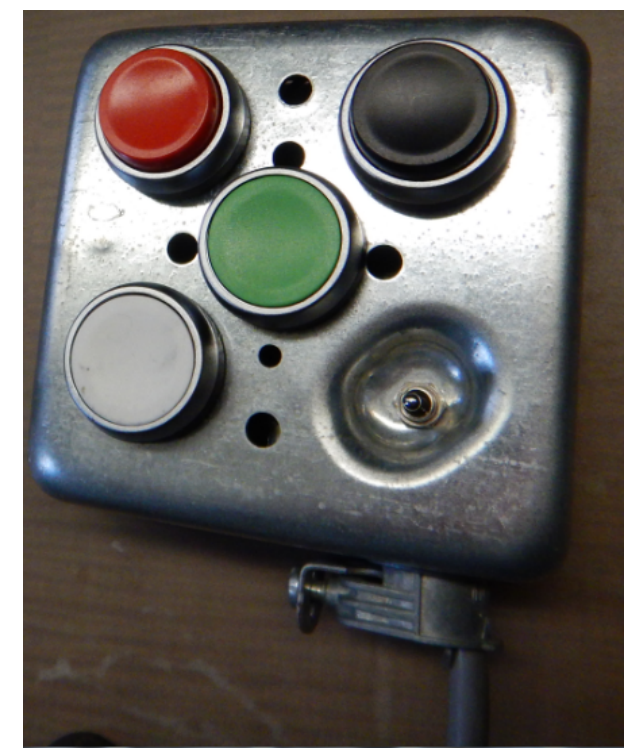

Figure 3.43: Desktop control panel used for programmable process control buttons and an emergency stop.

sinusoidal motion profile can be programmed in Matlab as a two-dimensional array with data points of positions over time. That array can be imported into Powertools Pro as a cam motion profile. The program can be initiated and stopped using the buttons on the control panel.

Coordinated motion of the two drives is available due to the Universal encoder input module, which is connected as an expansion module within the Emerson Unidrive SP 3202 drive. The encoder signals from the Baldor motor feed into the input module and the Powertools Pro software includes motion programming that can link the motion of the vertical axis based on positions of the horizontal axis as a master-slave relationship between the two drives. To continue the example above, first, a sinusoidal motion profile for each axis would be defined in Matlab. An array of horizontal position as a function of time data points would be saved into the file format that is recognized by the Labview motion control program. A second array would be produced with data points of vertical position with respect 
to horizontal position, and then saved as a data file for the Powertools Pro motion control program. After both drives are enabled, the program in Powertools Pro is initiated but there would be no movement yet. The Labview program is initiated, beginning the horizontal motion profile and the vertical drive would also begin to move based on the motion of the horizontal drive.

The DampCon amplifiers are controlled using commands sent from Labview to the NIDAQ 6211, which then outputs low voltage signals to the amplifiers. More information on their operation is provided in Section 3.5.

\subsection{Component Masses and Inertia Ratios}

As a motion simulating machine, the mass of the moving masses directly affects the machine's kinematics. A lighter frame can reach greater accelerations than a heavier frame under the same applied force. As it was described in the machine requirements of Chapter 2, minimizing the mass was a design objective. Although a strict methodology for optimization was not pursued, the concepts of reducing the number of parts and reducing the mass of each part were prevalent throughout the design process. This section will report on the masses of the machine that were relevant to the design of the machine and some that will be relevant to the operation of the machine.

The representative user mass has been estimated to be $100 \mathrm{~kg}$. This estimation is guided by the mass of a typical male adult with some carried gear. In reality, the mass of an occupant with gear on a suspension seat could range between 80-120 kg. The value was chosen as an average to be used in calculations. The mass of the 
tested suspension seat was estimated to be $75 \mathrm{~kg}$. This estimation was the perceived maximum mass of a seat, based on a review of product information that is posted on the websites of seat manufacturers. This mass was combined with the mass of the representative user into a total payload mass of $175 \mathrm{~kg}$ for the structural analysis of the machine.

The mass of the unloaded deck assembly is $55 \mathrm{~kg}$. This mass includes the mass of the load deck, the load cell, and the seat deck. The mass of the cart without a seat or representative user is estimated to be $300 \mathrm{~kg}$. These values were calculated from the CAD models with a material density chosen for all parts and from the manufacturer's listed mass for purchased parts. There may be a small variation that is estimated to be $3 \%$, which would be due to the sum of rounded values.

An inertia ratio is a parameter that is commonly considered during the selection process of an electric motor. It is defined as the ratio between the load's inertia of the machine to the inertia of the motor rotor. The load's inertia must be reflected through the drive speed reduction ratio to the shaft of the motor. Ideally, the ratio should be as close to 1:1 as possible. There is a generally accepted rule of thumb to keep the inertia ratio below 10:1 because it reduces excessive power consumption and increases system stability. The stability of the drive system is also dependent on the coupled connection between the motor and the load. A coupling that has high stiffness (low compliance) is ideally recommended. This is particularly relevant if the feedback sensor of the control system is located on the load. This is not the case for either drive system in this machine, as the feedback sensors for both motors are located on the shaft encoders onboard the motors. [25] 
The rotational inertias of all moving parts were evaluated and reflected to the motor. The translating masses that are listed above were also included as lumped masses rotating along the radial edge of their respective driving pulleys. The combination of all relevant inertias becomes the load inertia, which is then compared to the motor's inertia as a ratio. The resulting inertia ratio for the horizontal drive system is approximately 4 and the inertia ratio for the vertical drive system is approximately 5 . These are good values for inertia ratios. Since the motors and the drive speed ratios were selected based on matching their inertia with the estimated load inertias during the design process, it was expected that the actual inertia ratios based on known load inertias were also in the recommended range of values. A Matlab program was developed that included a list of all masses and inertias and it has the equations for calculating the combined load inertias. The code for this program can be found in Section A.5. 


\section{Chapter 4}

\section{Structural Analysis}

This chapter will present discussions and analyses to support the structural integrity of the machine. Three types of loading conditions will be explored.

- The torque from the electric motors is transmitted through a chain of components and then converted into a force in order to accelerate a translating mass. This portion of analysis will sequentially evaluate each component's ability to transmit those torques. The analysis is shown for each of the two drive systems.

- The machine's structures experience inertial loads resulting from the acceleration of the machine's masses. Each major assembly will be evaluated based on its reaction to being accelerated in the horizontal and vertical directions.

- The machine's ability to generate a slam impact between the deck assembly and the ER dampers in the base of the cart produces an impulsive force that is transmitted through both structures. For each affected part of the assembly, a relative static strength is evaluated and used as an operational guideline for impact testing by recognizing the weakest parts in the load paths.

A summary is included at the end of each section. 
As a note regarding the units of measurements shown in this chapter, all analyses were performed using the international system of measurement (SI units) but many dimensions are shown in the American customary system due to their common and familiar use in product information. As an example, a shaft's diameter will be identified as 1.25 inches rather than $0.032 \mathrm{~m}$ because the shaft is sized and sold as a standard fractional increment of inches and it loses meaning as a manufactured product by converting it to SI units. Dual dimensioning is shown whenever reasonably possible.

\subsection{Stress States Caused by Drive Systems}

As a motion simulating machine, SISTR is expected to be changing direction frequently and imposing high accelerations onto the tested masses. Unlike a continuously-running motor in a pump or fan, available horsepower is not the primary interest during the design of the drive systems. Torque is directly related to changing the velocity of the tested components. As an example, in a sinusoidal wave motion, peak torque occurs when the mass of the tested components is instantaneously stationary while it changes direction.

The small losses from friction, mechanical efficiencies, and the rotational inertia of each component are being omitted to simplify the analyses and preserve maximum torque passing throughout the system. In reality, these losses will reduce the available torque for each successive step. These simplifications will underestimate the capacity of the components and provide an extra margin of safety. 


\subsubsection{Horizontal Drive System}

The analysis in this section evaluates the ability of the horizontal drive system to transmit the maximum torque of the electric motor. The analysis, progressively, follows the transmission of torque through components from the motor to the load. For each component, the capability of transmitting the torque is validated. A labelled diagram with the major parts involved in this analysis is shown in Figure 4.1. Please use this diagram as a reference for the relationship between parts. Additional information about the parts that are mentioned in this section is provided in Section 3.4.1.

According to the manufacturer's specifications of the horizontal drive's motor, the maximum torque of the Baldor motor can reach $34 \mathrm{Nm}$ (25 ftlb). The motor is mounted directly to a 20:1 worm gear speed reducer. Using this drive ratio, the maximum torque that can be transferred is $680 \mathrm{Nm}$. The size of the speed reducer was matched to the size of the motor and they were purchased together. It is designed to be sufficient to transmit the motor's maximum torque and power. The motor and speed reducer are mounted together onto a 6061-T6 aluminum base.

This base experiences compression and tension through its side walls and eight concrete anchors from the applied torque from the speed reducer's shaft. Finite Element Analysis (FEA) was performed on this structure because of the complex load distribution. An extra CAD model was made to represent the motor and speed reducer in order to apply the torque and transfer the forces to the motor base. The applied torque on the shaft was $680 \mathrm{Nm}$. The results are shown in Figure 4.2. Compared to the yield strength of $275 \mathrm{MPa}$, the stresses here are very low. 


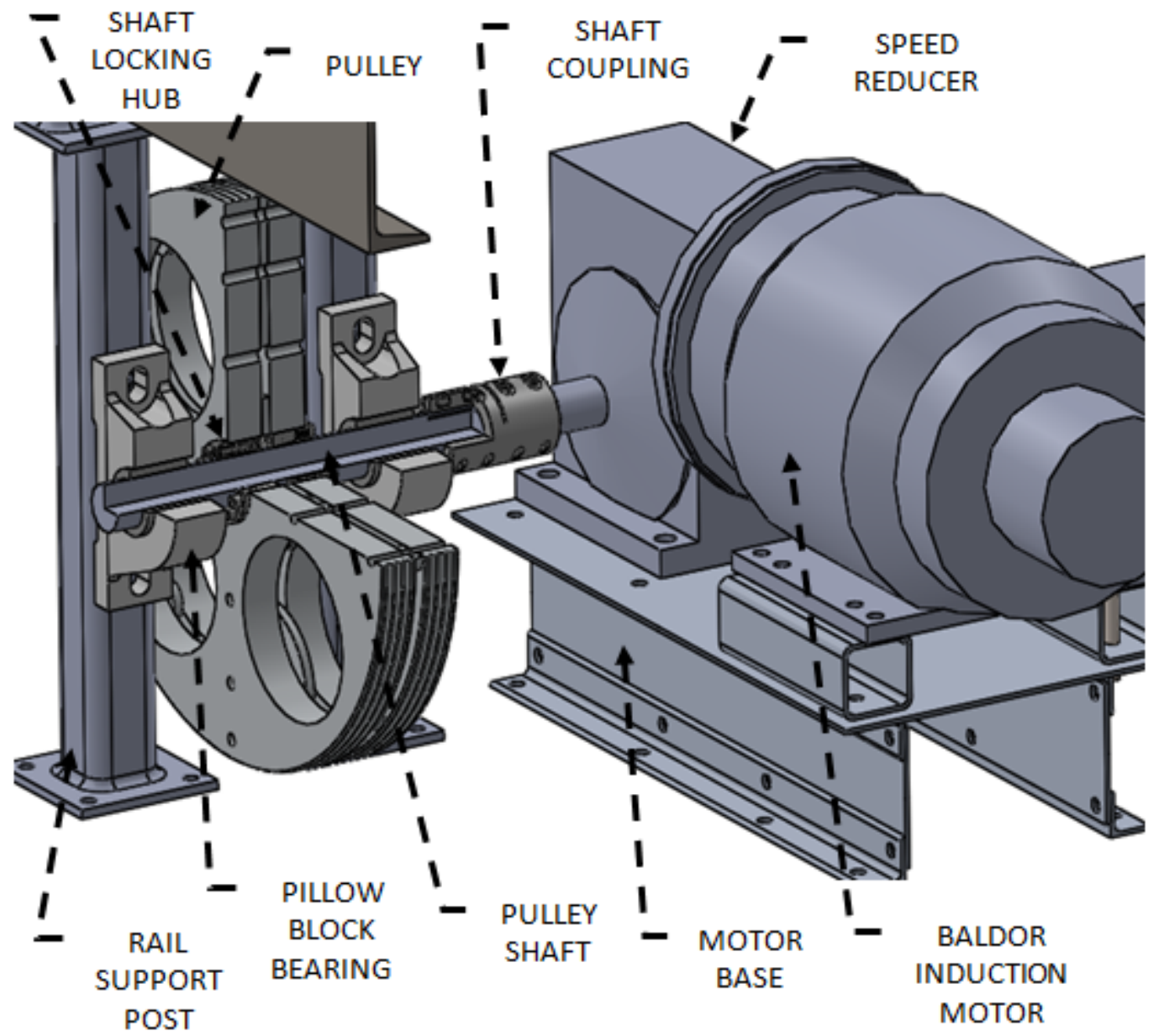

Figure 4.1: Horizontal drive system. This is a partially-sectioned view with one quarter removed to show the shaft inside other parts.

The shaft coupling between the gear reducer shaft and the pulley shaft is rated for $720 \mathrm{Nm}$. There is also a key in the shaft coupling. Although the taper-lock bushing clamps onto the shaft and it should transfer the torque, for simplicity and to show the redundant supporting elements, it was considered that all torque passes through the key. The shear stress in the key is given by:

$$
\tau=\frac{\text { torque } / \text { radius to shear surface }}{\text { shear area of key }}
$$

The torque is $680 \mathrm{Nm}$. The radius of the shaft is $0.016 \mathrm{~m}(5 / 8 \mathrm{inch})$. The key stock 


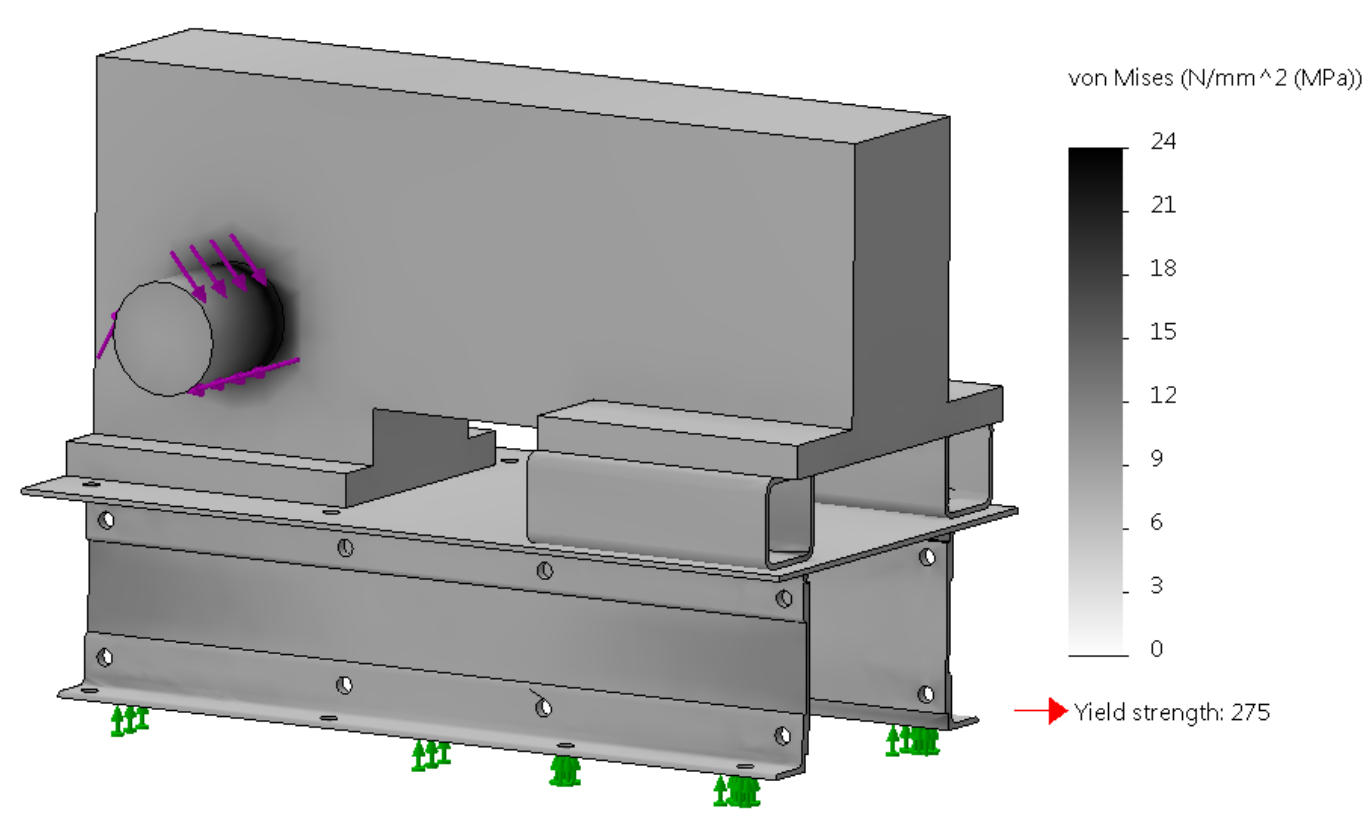

Figure 4.2: FEA results of the horizontal drive system's motor base.

has a shear area of $0.25 \times 1.5$ inch on each shaft. It is mild steel with a yield strength of $250 \mathrm{MPa}$. The shear stress of the key stock is calculated to be approximately $175 \mathrm{MPa}$. Compared to the yield strength, this would appear to be a low margin of safety, but in reality, the shaft coupling also transmits the torque.

From the coupling, the next component is the pulley shaft. The shaft primarily experiences torsional shear stress, which is given by:

$$
\tau=\frac{\text { torque } \times \text { radius of shaft }}{\text { polar moment of inertia }}
$$

The torque is $680 \mathrm{Nm}$. The radius of the shaft is $0.016 \mathrm{~m}(5 / 8 \mathrm{inch})$. The polar moment of area is $9.98 \times 10^{-8} \mathrm{~m}^{4}$. The torsional shear stress is calculated to be $110 \mathrm{MPa}$, which is below the yield strength of $530 \mathrm{MPa}$.

On either side of the wire rope pulley, pillow block bearings support the pulley 
shaft against the tension of the wire rope. Each pillow block bearing has a dynamic load capacity of $25.5 \mathrm{kN}$ (5750 lb). This is much higher than the operational loads experienced here, as the maximum tension in the wire rope is calculated below to be $3.6 \mathrm{kN}$. These bearing blocks are supported by two of the posts of the rail support assembly. There are two screw-clamp shaft locks that connect the pulley to the shaft. Each screw-clamp shaft lock is rated for $540 \mathrm{Nm}$. Two of these provide sufficient torque carrying capability.

The stress in the pulley from a torsion of $680 \mathrm{Nm}$ is very low, as shown in Figure 4.3. The pulley converts the torque into a linear force applied to the wire rope. The wire rope is wound around spacers between the two halves of the pulley in a particular way $^{1}$ that confidently clamps the wire rope without damaging the strands. The tensile force from the torque is given by:

$$
\text { tensile force }=\frac{\text { torque }}{\text { radius of pulley }}
$$

The torque is $680 \mathrm{Nm}$ and the pulley's radius is $0.19 \mathrm{~m}$ (7.5 inch). The maximum tensile load acting on the wire rope from the motor's torque is calculated as $3.6 \mathrm{kN}$. The breaking strength of the wire rope is $30.25 \mathrm{kN}$.

At the far end of the rail support assembly, two pulleys redirect the wire rope to complete the loop. The pulleys are mounted onto bronze bushings and they slide on precision ground shafts. An image of the two pulleys on the shafts is shown in Figure 4.4. FEA was performed for one of the shafts and the resulting stress state is shown in Figure 4.5. Extra extruded blocks were made in the CAD model to represent the pulley in the centre and the wall segments of the tubular rail support

\footnotetext{
${ }^{1}$ Refer to section 3.4.1 for a description and image.
} 


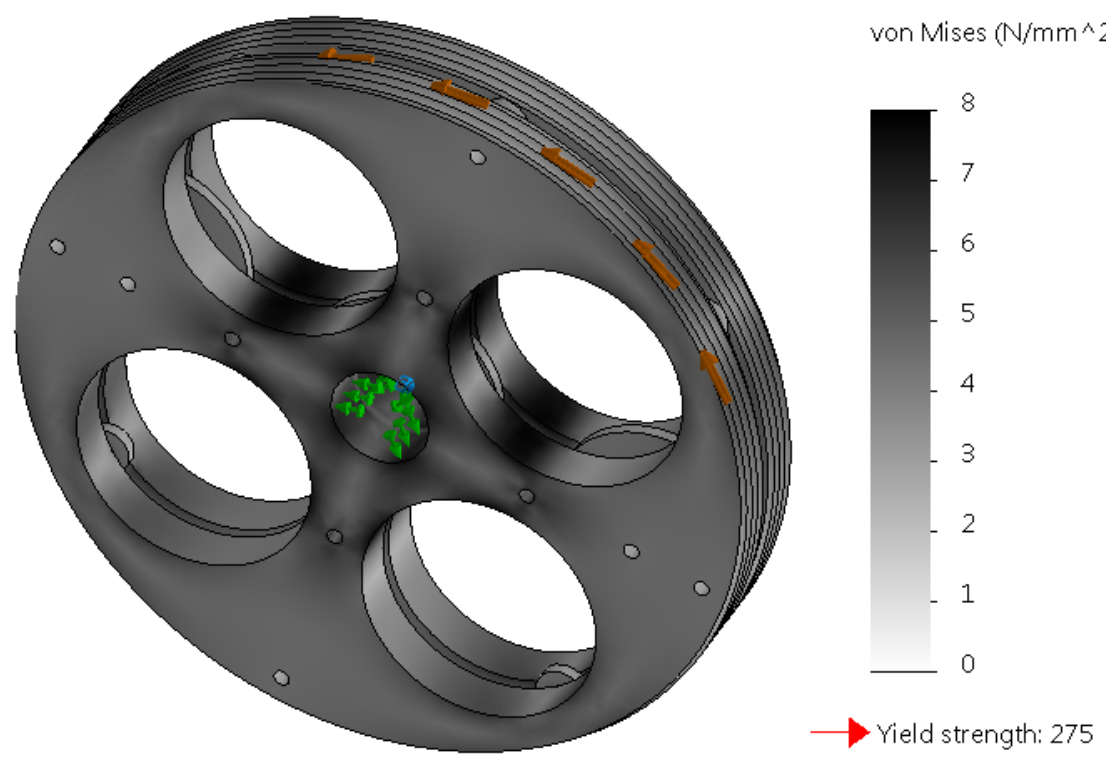

Figure 4.3: Stress state in the horizontal drive system's wire rope pulley from the maximum applied torque from the motor.

posts on either side of the pulley. The applied load on each of these shafts is from the tension in the wire rope, which was calculated above as $3.6 \mathrm{kN}$. The yield strength of the rod is $530 \mathrm{MPa}$. The pulleys have a working load limit of $5300 \mathrm{~N}$ (1200 lb). The shafts and pulleys are sufficiently capable of resisting the maximum applied loads.

Each end of the wire rope is attached to the cart using an end fitting, which are specified for lifting applications and are rated for $30.25 \mathrm{kN}$ (6800 lb). They were installed according to provided instructions, but it is recommended that during the commissioning phase of the machine, the end fittings be tested with the highest applied torque for short motions before they are validated for continuous use. FEA was performed for one of these brackets under the applied load of $3.6 \mathrm{kN}$ force corresponding to the maximum tension in the wire rope (calculated above). The results are shown in Figure 4.6 and the part may reach a yielding condition if the maximum torque is applied by the motor. Based on the shape of the part, if a 


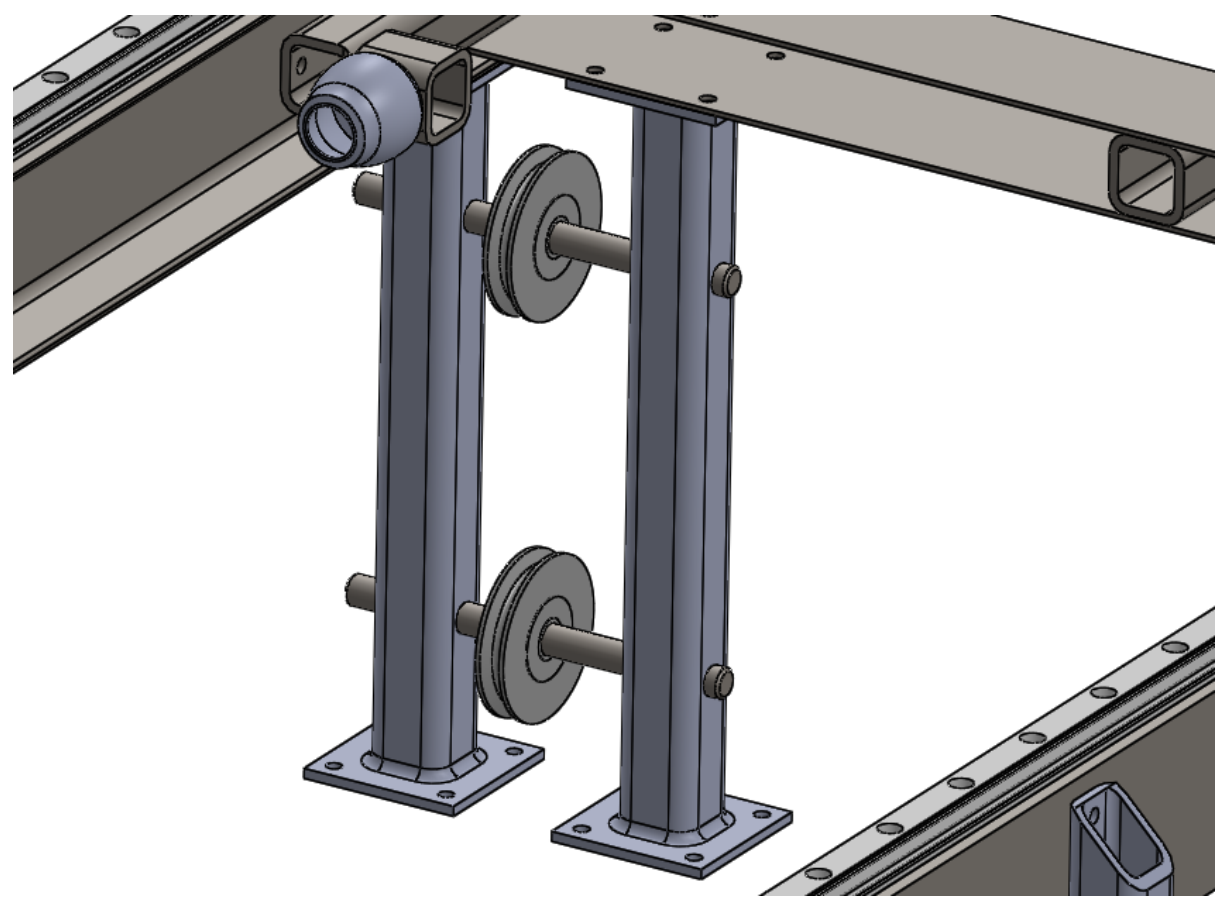

Figure 4.4: Wire rope pulleys at the far end of the horizontal drive system.

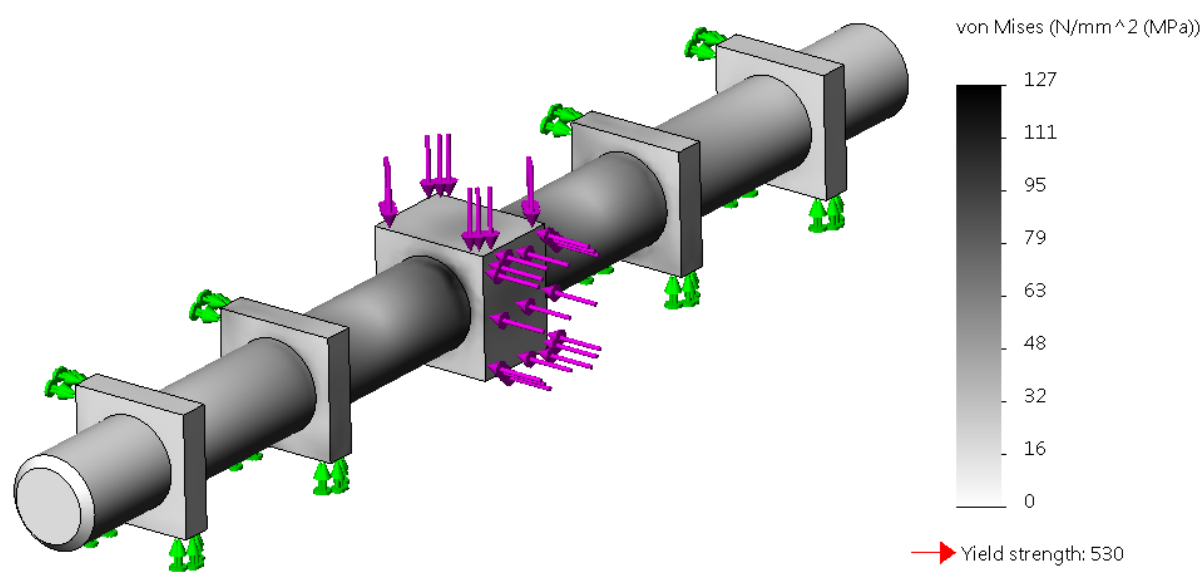

Figure 4.5: Stress state caused by the tension in the wire rope around the pulley.

yielding condition were to occur, there would be a visible curling of the bracket towards the wall because the line of action of the wire rope is not coincident with the plane of the surface that mates with the cart. If this is observed, the part should be replaced with an upgraded design. 


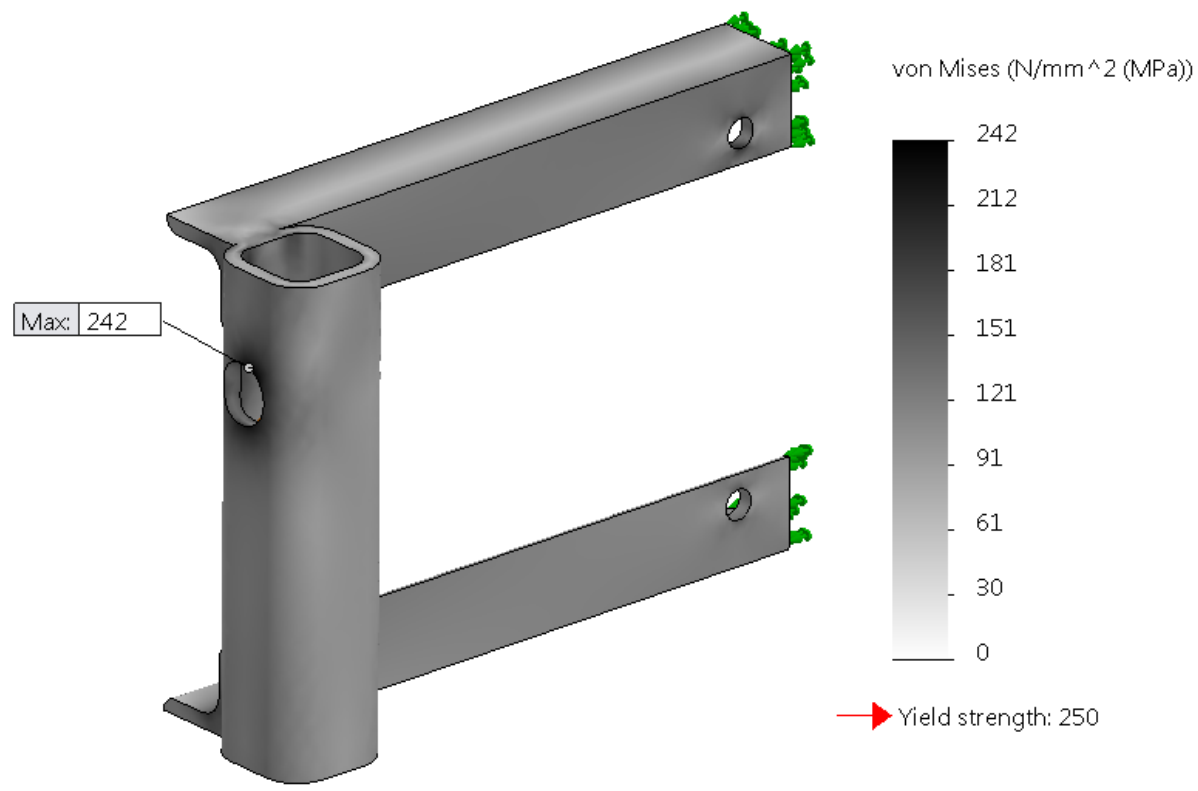

Figure 4.6: Stress state in the end bracket from the maximum tensile force of the wire rope.

In summary, the torque that is applied from the Baldor motor can be directly followed through a chain of connected components, and each drive system component is supported by a structure. The lowest margin of safety appears in the wire rope end bracket. During the commissioning phase of this machine, the operator should inspect these brackets for permanent deflection. The wire end connectors, coincidentally at the same location, should also be monitored during early motion tests.

\subsubsection{Vertical Drive System}

The analysis in this section evaluates the ability of the vertical drive system to transmit the maximum torque of the electric motor. The analysis progressively follows the transmission of torque through components; from the motor to the load. For each component, the capability of transmitting the torque is verified. Refer to Figures 4.7 
and 4.8 for labelled diagrams of the parts discussed in this section. Additional information about the parts that are mentioned in this section is provided in Section 3.4.2.

As it was estimated in Section 2.3.2, the maximum torque from the Emerson motor could produce an upward heave of $4 \mathrm{~g}$ but reproducing the hydrodynamic reentry phase of the slam impact cycles would only require approximately $2 \mathrm{~g}$. Since, it is not expected that the maximum torque will be applied during test procedures, using the maximum torque as a basis for the design loads inherently included a factor of safety for all components related to the vertical drive system.

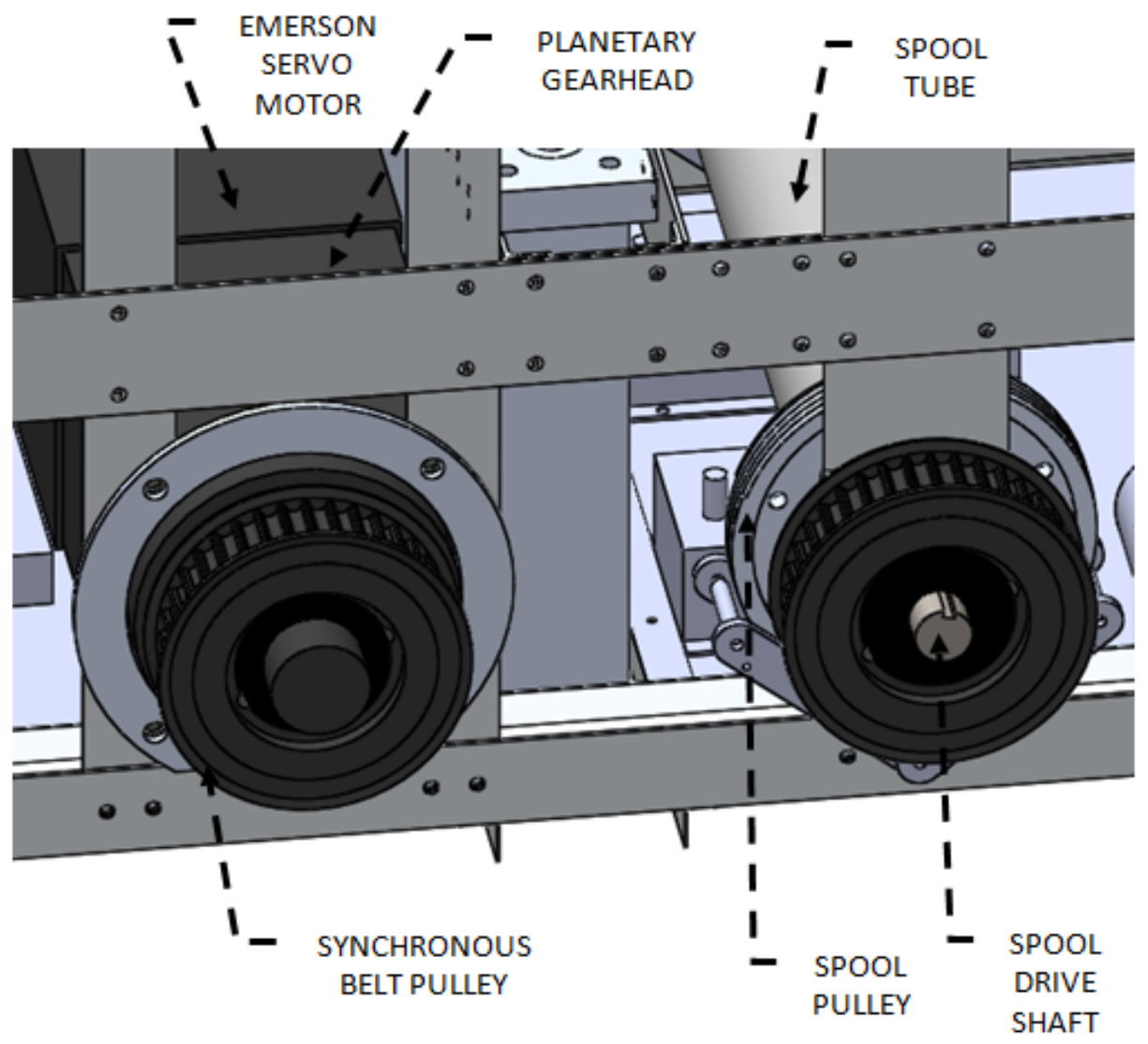

Figure 4.7: Vertical drive system parts.

According to the manufacturer's specifications, the peak torque of the Emerson 
motor is $176 \mathrm{Nm}$. The torque output of the motor is multiplied by the drive ratio of the planetary gearhead, which is $7: 1$. The maximum torque in the shaft of the gearhead would then be roughly $1230 \mathrm{Nm}$. The size of the gearhead was matched to the size of the motor at the time of the purchase. It is designed to be sufficient to transmit the motor's maximum torque and power.

The motor power is then transmitted through a synchronous toothed belt between the gearhead and the vertical drive spool. The selection guide within the product catalog [26] was used to select an appropriately-sized belt to match the Emerson motor's power.

Each of the two identical belt pulleys are mounted onto their shaft with a keyed taperlock hub. Although the taper-lock hub clamps onto the shaft and does effectively transfer some torque, for simplicity and to show the redundant supporting elements, consider that all torque is passed through the key. The shear stress in the key is given by:

$$
\sigma=\frac{\text { torque } / \text { radius to shear surface }}{\text { shear area of key }}
$$

The spool pulley shaft's key is $0.006 \mathrm{~m}$ (1/4 inch) wide and $0.06 \mathrm{~m}$ (2.5 inch) long, so the shear area is $4.0 \times 10^{-4} \mathrm{~m}^{2}$. The torque is $1230 \mathrm{Nm}$. The radius of the shaft is $0.016 \mathrm{~m}$ (5/8 inch). The shear stress of the key stock is calculated to be approximately $192 \mathrm{MPa}$, which is less than its yield strength of $250 \mathrm{MPa}$.

The next several components are connected together as the spool assembly, consisting of the parts shown in Figure 4.8. The spool assembly experiences bending and torsional shear stresses. In order to estimate the magnitude and location of the 
maximum bending stress, all loads acting on the spool assembly needed to be identified. Refer to the free body diagram in Figure 4.9. The labels for the distances and the forces correspond with the Matlab code that supports this analysis, which can be found in Section A.3.

The spool assembly is supported by two bushings, labelled in Figure 4.9 as points A and B. Each bushing has a load capacity of $89 \mathrm{kN}(20,000 \mathrm{lb})$. In this loading scenario, the maximum resultant load on bushing $\mathrm{B}$ (near to the belt) is $16.1 \mathrm{kN}$ and the load on bushing $\mathrm{A}$ (far side away from the belt) is $6.1 \mathrm{kN}$, which are each less than a fifth of the rated capacity.

A bending moment diagram was produced for moments about the x-axis, moments about z-axis, and for the magnitude of the resultant vectors of the two. This is shown in Figure 4.10. The orientation of the spool in the moment diagrams is the same as the spool in the free body diagram of Figure 4.9, with the same axes and the belt on the right. From the diagram of the resultants, the maximum bending moment is located in the portion of exposed shaft that is just inside of the bushing on the belt's side, and the value is $626 \mathrm{Nm}$.

The drive shaft is subject to this bending moment and the full torque from the belt pulley. Axial stress at the surface of the shaft due to bending is given by:

$$
\sigma=\frac{\text { moment } \times \text { radius of shaft }}{\text { second moment of area }}
$$

The bending moment is $626 \mathrm{Nm}$. The radius of the shaft is $0.016 \mathrm{~m}(5 / 8$ inch) and the second moment of area is $4.99 \times 10^{-8} \mathrm{~m}^{4}$. The axial stress at the surface of the 


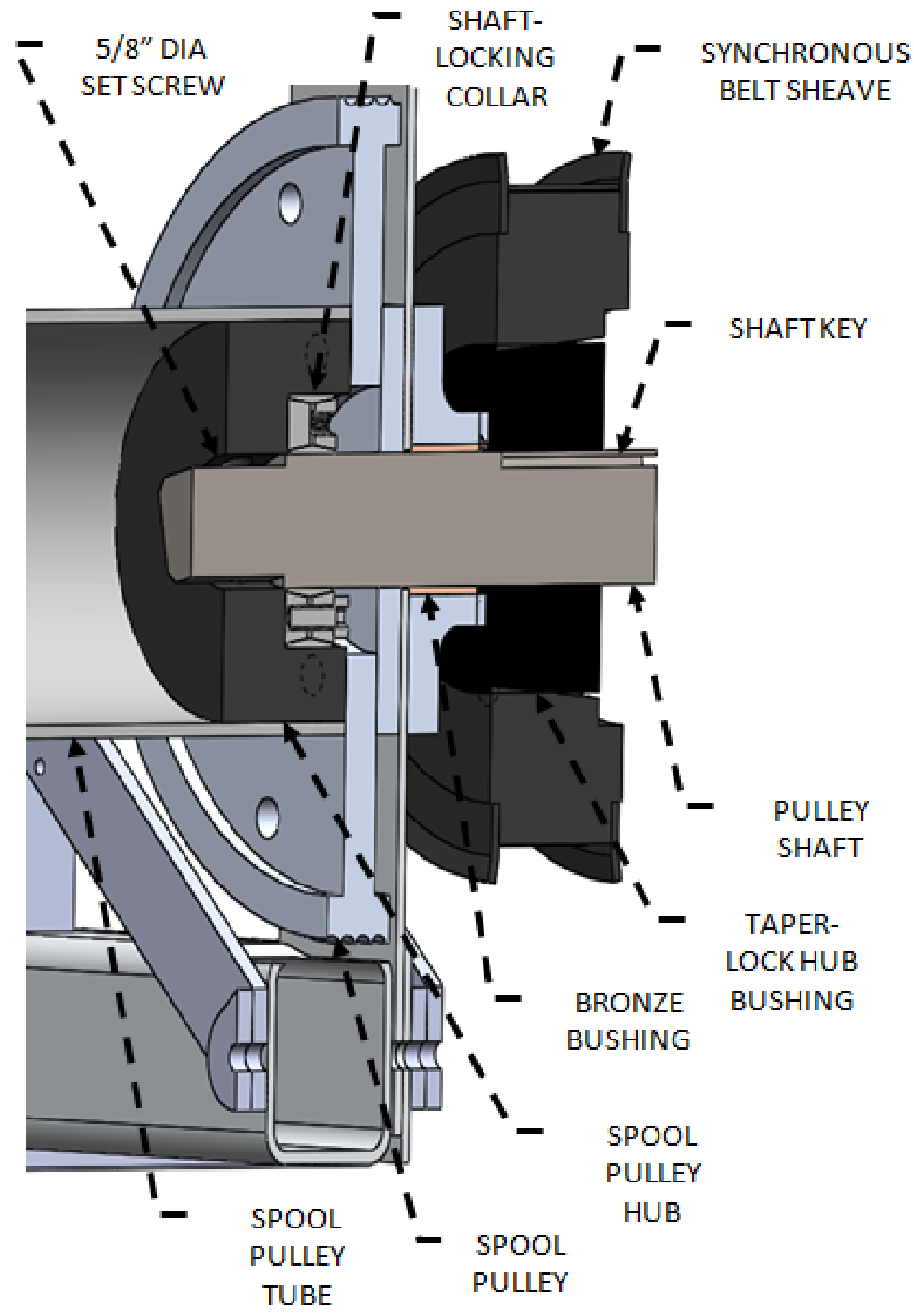

Figure 4.8: Section view of the belt side end of the spool assembly for the vertical drive system.

shaft due to bending is approximately $200 \mathrm{MPa}$. Shear stress at the surface due to the torque is given by:

$$
\tau=\frac{\text { torque } \times \text { radius of shaft }}{\text { polar moment of area }}
$$




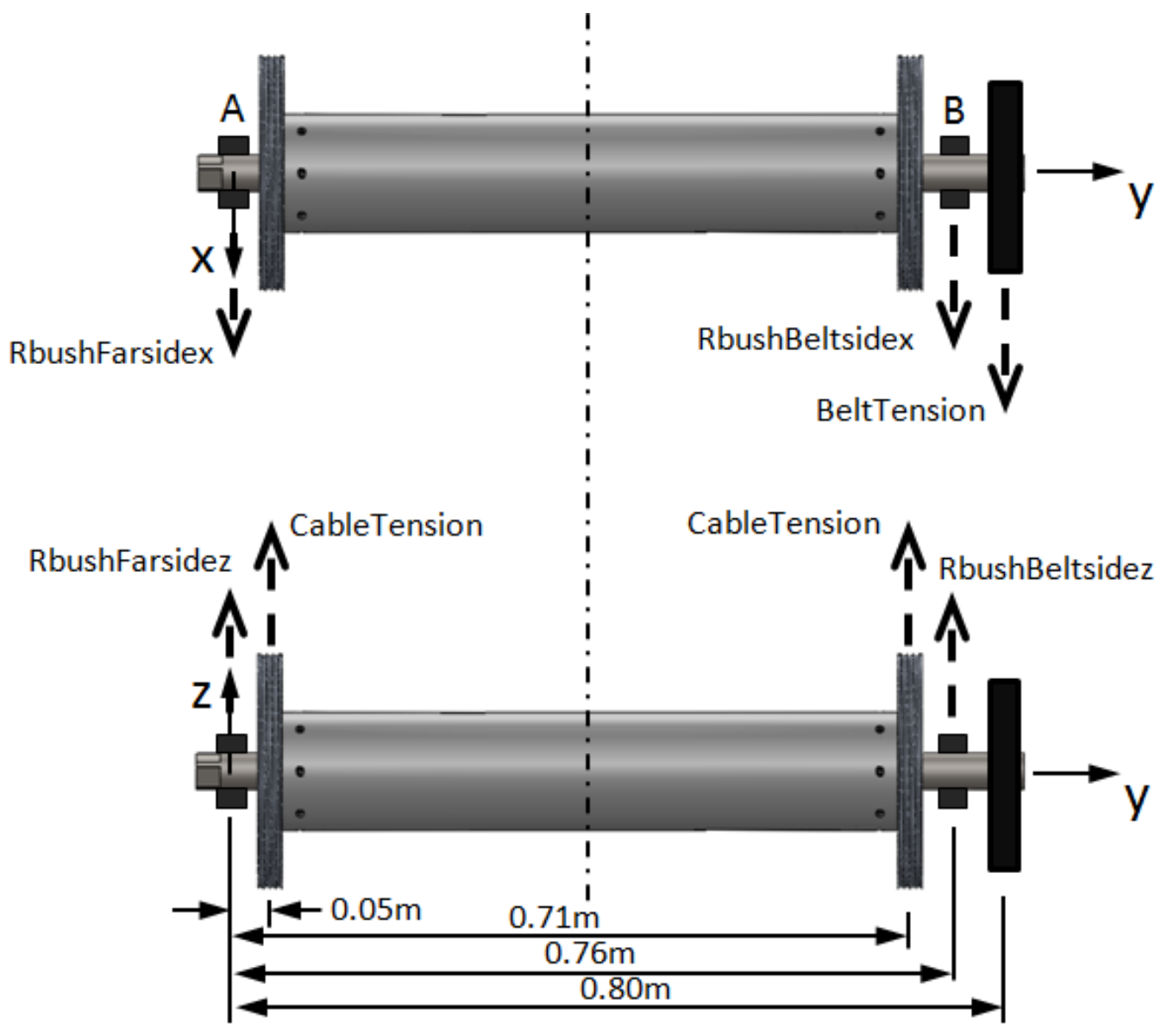

Figure 4.9: Free body diagram used for the bending stress analysis of the spool.

The torque is $1230 \mathrm{Nm}$. The polar moment of area is $9.98 \times 10^{-8} \mathrm{~m}^{4}$. The shear stress due to torsion is calculated to be approximately $196 \mathrm{MPa}$. Based on the Von Mises theory of combined stresses, the effective total stress of the drive shaft is $320 \mathrm{MPa}$. This is below the yield strength of $530 \mathrm{MPa}$.

A bending load in a spinning shaft becomes a fully-reversed cyclic load with the potential for a fatigue failure. The endurance limit for 1045 steel is approximately $300 \mathrm{MPa}$, beginning at $10^{6}$ cycles [27]. Fatigue could be a concern but it is important to note that this stress state represents the maximum loading conditions and it is not expected that a reproduction of at-sea motion will demand the peak torque from 

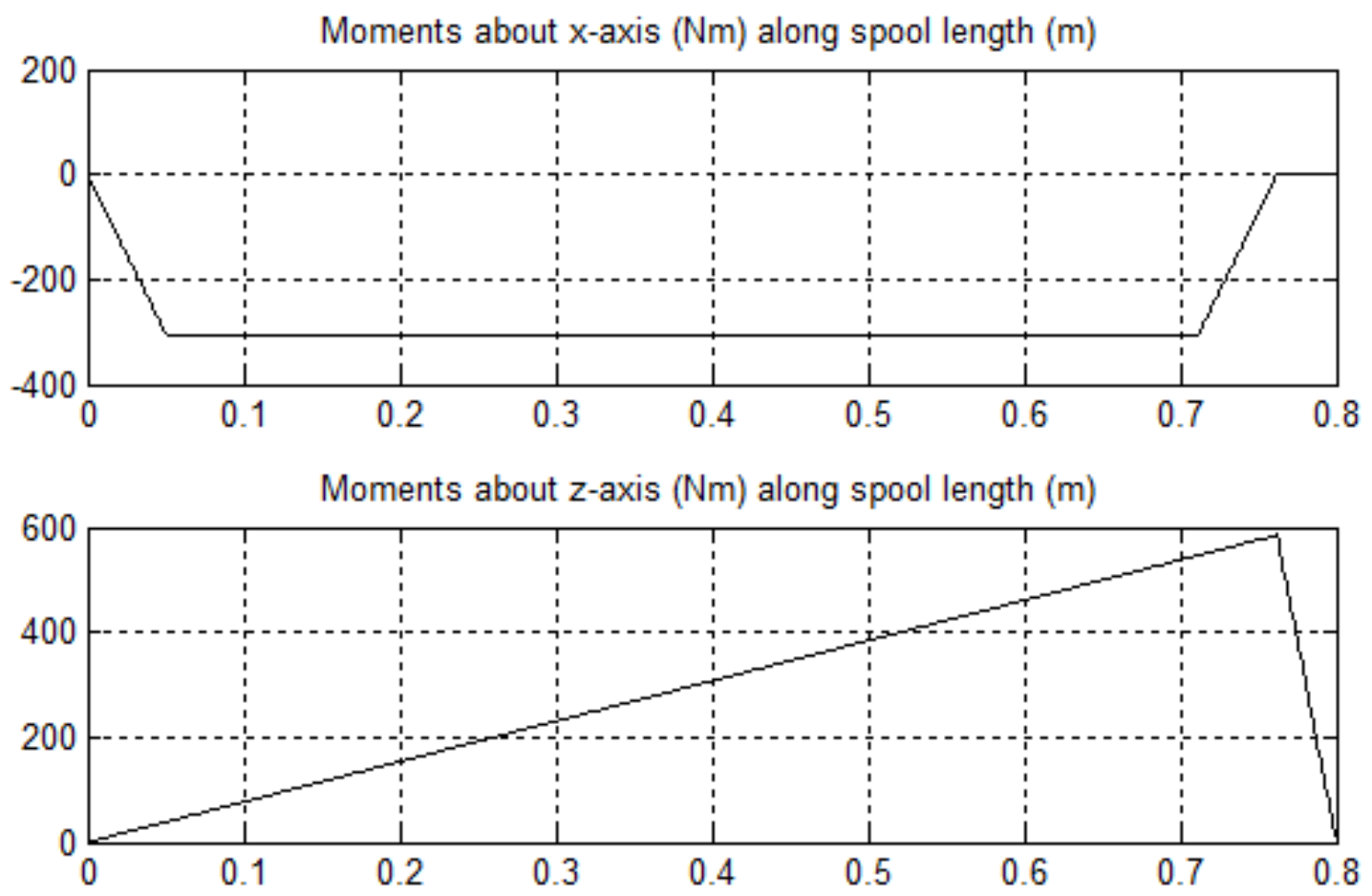

Magnitude of resulting moments $(\mathrm{Nm})$ along spool length $(\mathrm{m})$

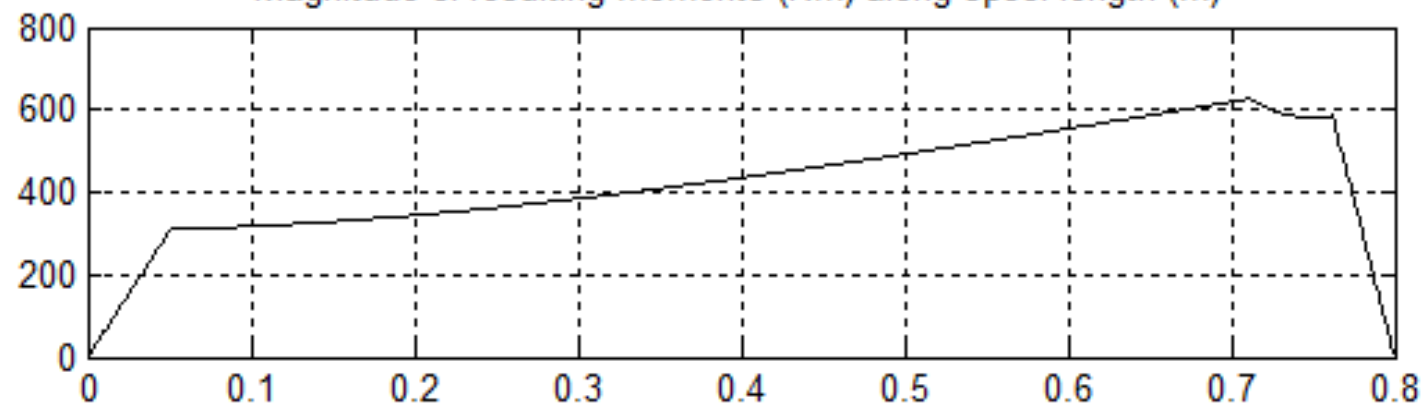

Figure 4.10: Bending moment diagrams of spool assembly.

the motor. Also noteworthy is that the shaft has a polished surface, which reduces the incidence of crack initiation. As a precaution, it is still worthwhile to remove the pulley and inspect the shaft surface for crack initiation as part of a monthly maintenance service.

The shaft connects to the spool pulley hub with a screw-clamp shaft lock collar 
and with four 5/8-11 set screws. The screw-clamp shaft lock is rated for $675 \mathrm{Nm}$. This is insufficient for transmitting the maximum possible torque from the pulley shaft $(1230 \mathrm{Nm})$ so four large set screws were installed into tapped holes in the spool pulley hub, and then were tightened onto machined flat surfaces on the shaft. The exact maximum stress caused by the four set screws preventing the shaft from turning was not calculated for the pulley hub, the set screws, or the shaft because of the indirect force application between the shaft and the set screws. Based on the thick volumes involved here in the 6061-T6 aluminum hub and in the high-strength steel set screws and shaft, it was clear that the stresses were below yielding conditions.

From the spool pulley hub, the inputted torque is transmitted to two pulleys: one is directly connected to the hub and the other is at the far end of the spool tube. Each of the corresponding connections between parts involves the shear loading of eight bolts. The shear stress of each of the eight 5/16-18 bolts is given by:

$$
\sigma=\frac{\text { torque to each spool pulley } / \text { radius to shear surface }}{\text { shear area of eight bolts }}
$$

The torque through any of these connections should be approximately $615 \mathrm{Nm}$, which is half of the maximum torque. The radial distance to the connection between the hub and the tube is $0.048 \mathrm{~m}$ (1.88 inch). The shear area of eight bolts is $2.7 \times 10^{-4} \mathrm{~m}^{2}$. The shear stress is calculated to be only $48 \mathrm{MPa}$. These are grade 8 bolts with a yield strength of approximately $1100 \mathrm{MPa}$.

The torsional shear stress in the tube is given by:

$$
\tau=\frac{\text { torque } \times \text { radius of shaft }}{\text { polar moment of area }}
$$


The torque should be $615 \mathrm{Nm}$. The polar moment of area is $1.2 \times 10^{-6} \mathrm{~m}^{4}$. The shear stress due to torsion is calculated to be approximately $26 \mathrm{MPa}$. The tube is made from 6061-T6 aluminum and the yield strength is $275 \mathrm{MPa}$.

Due to the relatively-long length of the spool tube, the torsional stiffness of the tube was evaluated. Potentially, the torque through the tube may provide an angle of twist that may cause the wire ropes to seem uneven from the perspective of the deck assembly. The angle of twist is given by:

$$
\text { angle of twist }=\frac{\text { torque to each pulley } \times \text { length between pulleys }}{\text { polar moment of inertia } \times \text { shear modulus }}
$$

The length between pulleys is $0.66 \mathrm{~m}$. The polar moment of area of the tube is $1.2 \times 10^{-6} \mathrm{~m}^{4}$ and the shear modulus is $26 \mathrm{GPa}$ for aluminum. The calculated angle of twist is then multiplied by the radius of the pulley, which is $0.102 \mathrm{~m}$ ( 4 inch). Then the difference between the two wire lengths is calculated to be approximately $0.0013 \mathrm{~m}$. This was determined to be negligibly small.

The pulleys convert the applied torque into a tensile force in the vertical wire ropes. The maximum applied tensile load to the wire rope is given by:

$$
\text { tensile force }=\frac{\text { torque to each pulley }}{\text { radius of pulley }}
$$

The maximum torque to each pulley should be approximately $615 \mathrm{Nm}$. The pulley's radius is $0.102 \mathrm{~m}$ ( 4 inch). The maximum tensile force through the wire rope is calculated to be $6.06 \mathrm{kN}$. The wire rope has a breaking strength of $30.25 \mathrm{kN}$.

Each wire rope is connected to an aluminum block in the deck assembly with an 
end fitting that is specified for lifting applications. The end fittings are rated for $30.25 \mathrm{kN}(6800 \mathrm{lb})$. They were installed according to provided instructions, but it is recommended that during the commissioning phase of the machine, the end fittings should be tested with the highest applied torque for short motions before they are validated for continuous use. These tests should be performed with repeated short motions near the bottom of the seat deck's travel in case a fault is observed.

FEA was performed for the aluminum block with the maximum tensile force from the wire rope. Figure 4.11 shows the resulting stress state. A small extrusion of a cylinder was made in the CAD model to represent the nut of the wire end fitting. The ends of the block that bolt into the deck plates are considered fixed boundary conditions. As shown, the stresses are very small when compared to the yield strength of $275 \mathrm{MPa}$ for 6061-T6 aluminum.

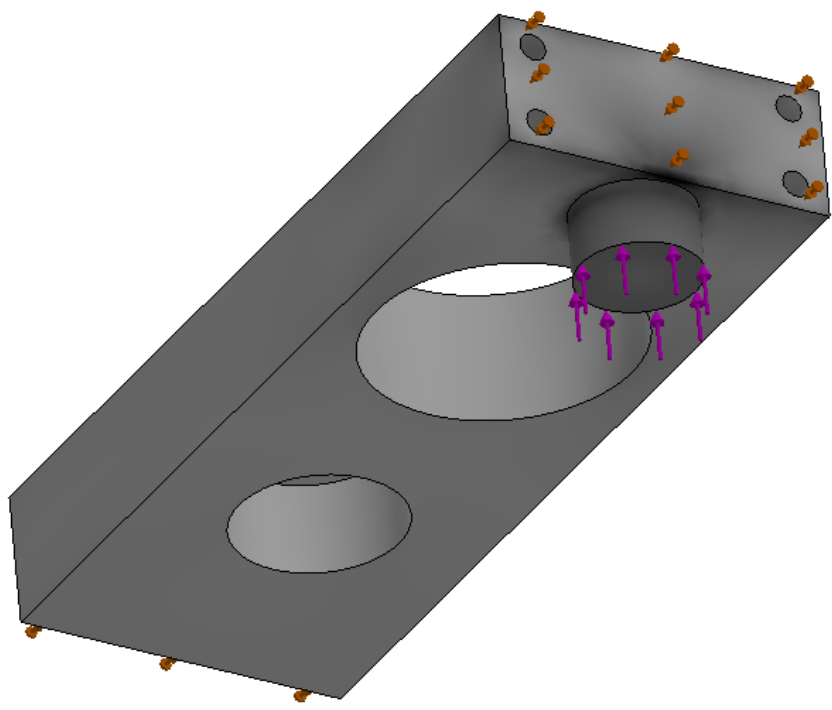

von Mises $\left(\mathrm{N} / \mathrm{mm}^{\wedge} 2(\mathrm{MPa})\right)$

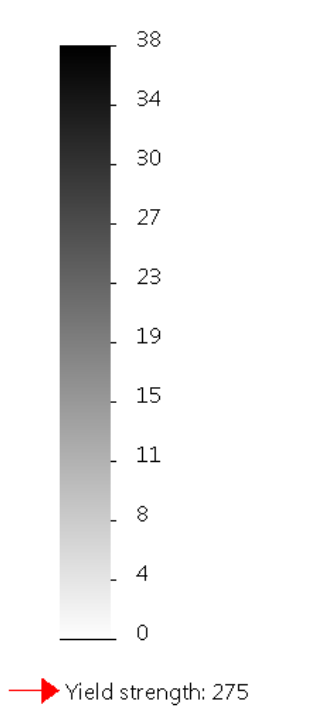

Figure 4.11: Stress state in the deck block from the maximum tensile force of the wire rope. 
The top pulley beams support the hanging pulleys that redirect the wire rope. If the wire rope experiences a maximum tensile force of $6 \mathrm{kN}$, then the resistive force needed to hold up the upper pulley would be approximately $12 \mathrm{kN}$ because the wire rope pulls down on the pulley from both sides of the pulley. FEA was performed for one of the top pulley beams. Extra extruded features were produced in the CAD model to simulate the boundary condition connections with the corner posts and the force application surface of the pulley pin. The resulting stress state is shown in Figure 4.12. There are regions of relatively high stress in the corners of the tube, near to the connections with the corner posts. Although this results in a low margin of safety for this part, the applied load represents the maximum possible force that can be produced by the motor and this stress state cannot be combined with the stress of other loading conditions.

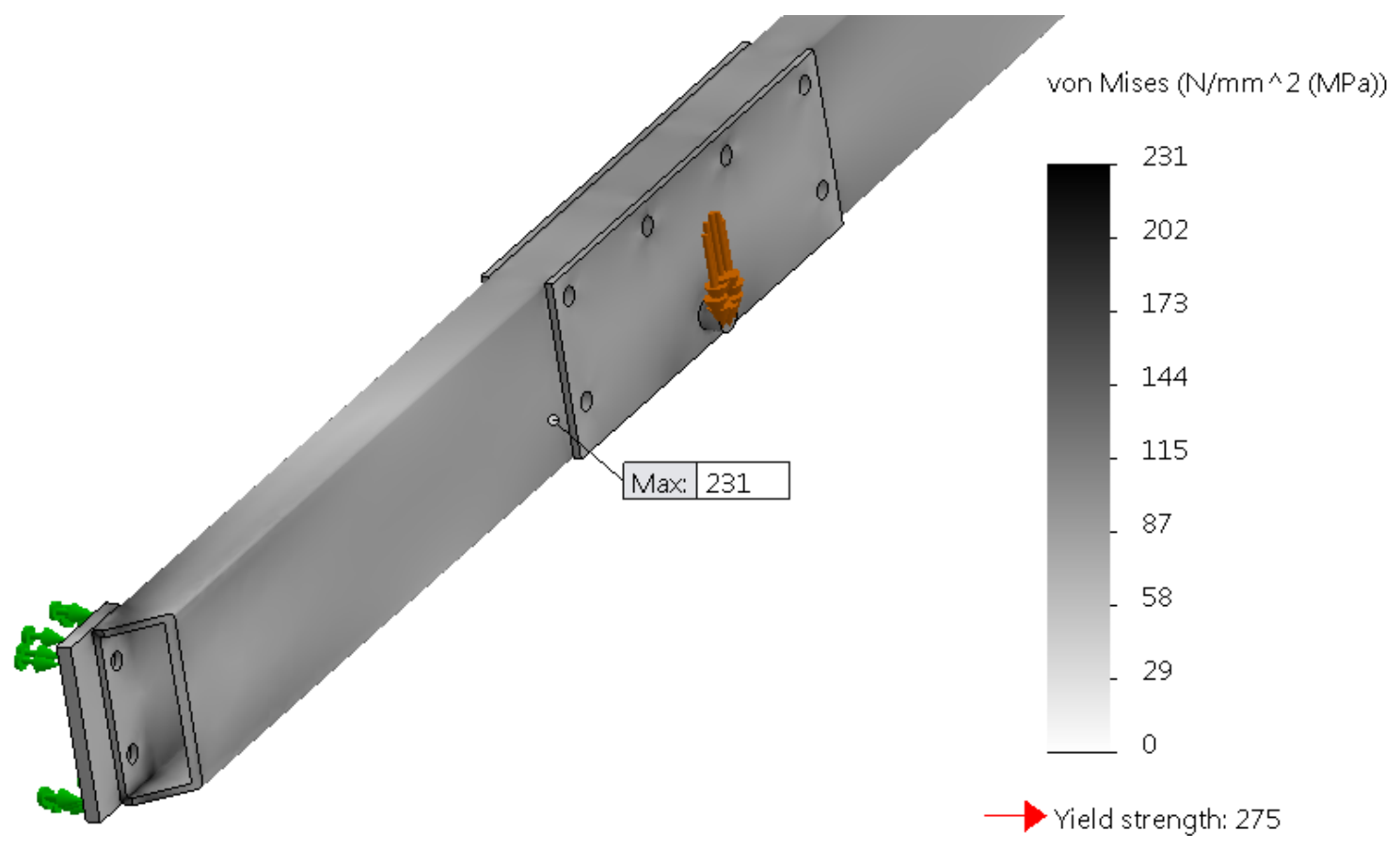

Figure 4.12: Stress state in the top pulleys beam from the peak downward force from the wire rope pulley. 
The hanging pulley has a working cable load limit of $6.9 \mathrm{kN}$ (1550 lb). This results in a low margin of safety when compared to the maximum tension in the wire rope of approximately $6 \mathrm{kN}$. The pulleys were selected because they were the most suitable for the application that could be found. It should be noted that this maximum design load is based on the maximum torque of the Emerson motor, which is not expected to be required for the reproduction of wave conditions. As a reference, in order to produce an upward acceleration of $2 \mathrm{~g}$, the tensile force in the wire rope is estimated to be $3.5 \mathrm{kN}$. As a precaution, these pulleys should be inspected for premature wear of the internal bronze bushing as part of a frequent maintenance schedule.

Most of the vertical drive system's components are contained in the lower section of the cart assembly. A grid of aluminum plates restrains the motor and the spool assembly. The tension in the synchronous belt pulls the motor and the spool together, while the tension in the wire rope pulls the spool upwards. The assembly was modelled as one part and FEA was performed. The resulting maximum stress state is shown in Figure 4.13. In the CAD model, the spool was replaced with a block so that the force of $12 \mathrm{kN}$ could be easily applied to its bottom surface. The motor's weight is represented by two blocks, one for each end, where they each apply a downward force of $500 \mathrm{~N}$ onto the bottom tubes of the cart. The synchronous belt does not have a pretension, so the horizontal force on each of the two shafts is $15.4 \mathrm{kN}^{2}$ when the motor applies its maximum torque. Based on the FEA results, the stresses are low in the cart plates and in the longitudinal beams. A maximum stress of $187 \mathrm{MPa}$ is present on the upper edge of the lateral beams and is caused by the upward force from the wire rope. The yield strength for this 6061-T6 aluminum part is $275 \mathrm{MPa}$. It is in tension so there is no concern for buckling. This region can

\footnotetext{
${ }^{2}$ This value was calculated using the Matlab program that can be found in Section A.3.
} 
be monitored during the commissioning phase of the machine and a brace can be attached as a future addition if deemed necessary.

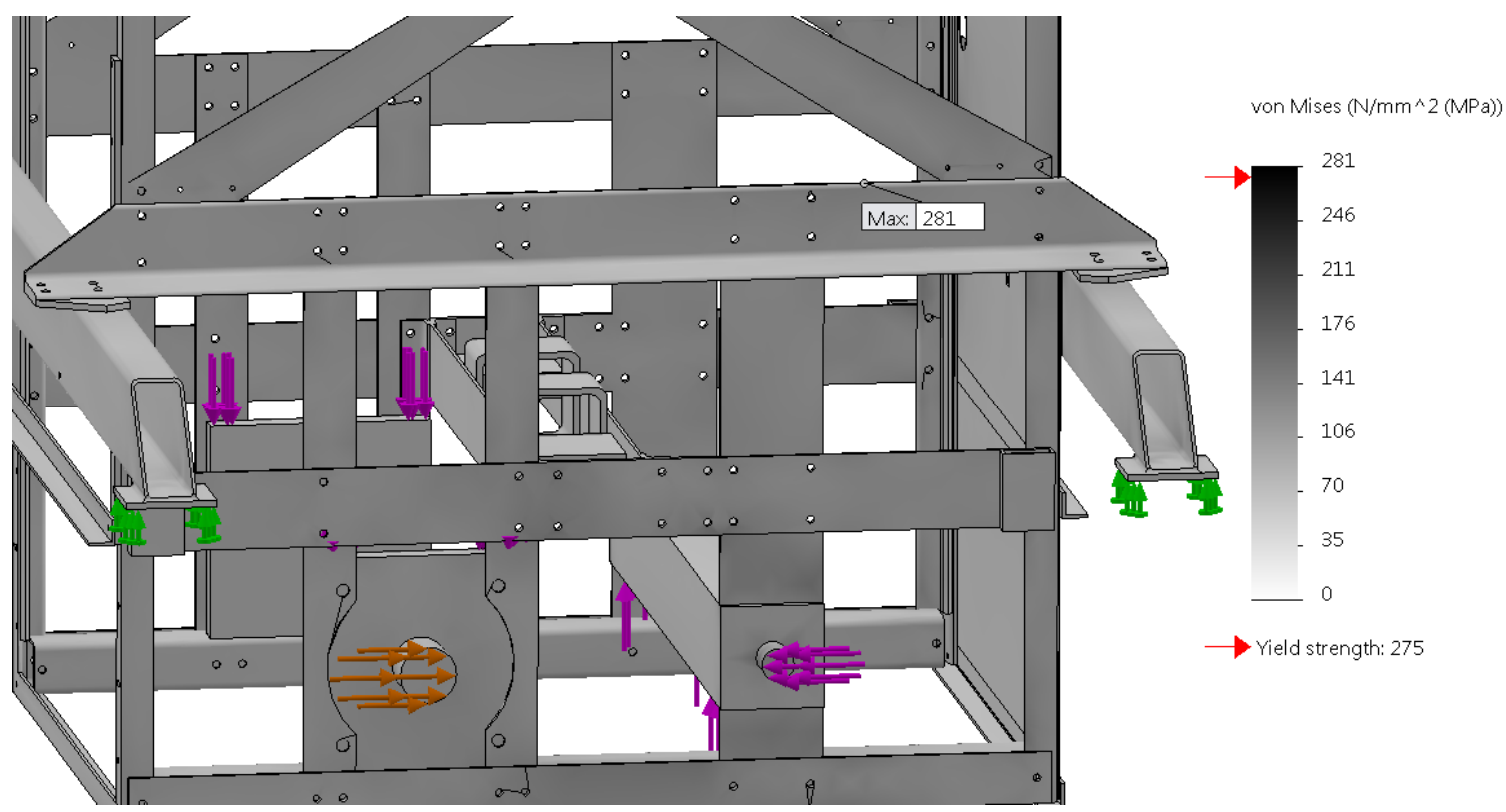

Figure 4.13: Stress state in the cart's lower plates during the peak torque output from the Emerson motor.

In summary, the components in the vertical drive system can withstand the maximum torque from the Emerson motor. A low margin of safety was recognized in the lateral bars, the top pulley beams, and the hanging pulleys. It should be noted that using the maximum torque of the Emerson motor included an extra factor of safety, as it was described at the start of this section. Still, during the commissioning phase, the lateral bars and the top pulley beams should be monitored for excessive deflections and the hanging pulleys should be monitored for premature wear. As a note for machine maintenance on an occasional schedule, the spool pulley shaft should be inspected for crack initiation and the synchronous toothed belt should be inspected for wear and then re-installed in an opposite orientation; meaning the belt should be "flipped and rotated" to extend its lifetime. 


\subsection{Stress States Caused by Inertial Loads}

This section will evaluate the response of the machine's main structural assemblies to inertial loads. When a mass is forced to accelerate, it will apply a reaction force onto its supporting structure. This reaction force is the inertial load. The drive systems prescribe accelerations to particular masses in two orthogonal directions.

The performance simulations of Section 2.3.1 estimated that the horizontal drive system could accelerate the $475 \mathrm{~kg}$ loaded cart assembly up to a maximum of $0.5 \mathrm{~g}$. As a measure of safety, the design loads in this section were based on a maximum acceleration of $1 \mathrm{~g}$. During the commissioning phase of this machine, the horizontal drive system's maximum capability will be tested and the true operational limit will be determined.

The performance simulations of Section 2.3.2 estimated that the vertical drive system could accelerate the $230 \mathrm{~kg}$ loaded deck assembly up to a maximum of $4 \mathrm{~g}$, on top of the static load of $1 \mathrm{~g}$ from gravity, but reproducing the hydrodynamic reentry phase of the slam impact cycles would require approximately $2 \mathrm{~g}$. Using the maximum torque of the Emerson motor as a basis for the design loads introduces a measure of safety because the maximum torque is not expected to be required. Using the maximum torque was also convenient because the vertical drive system directly accelerates the mass of deck assembly and the load is symmetrically supported, thus the design loads that were used for the vertical drive system could also be applied to the supporting structures. As it was determined in Section 4.1.2, the maximum torque of the Emerson motor corresponds to a maximum tensile force in the wire rope of approximately $6 \mathrm{kN}$. As a reference, an 
upward acceleration of $2 \mathrm{~g}$ corresponds to a wire rope tension of approximately $3.5 \mathrm{kN}$.

Each of the next sections will present the most significant inertial loading onto one of the main assemblies. Due to the complexity of these assemblies, several methods of analysis were explored in order to conclude that the assemblies were capable of supporting the maximum inertial loads. Some components and structures could be reliably represented as a CAD model and used for FEA. This worked well for the deck assemblies and for the rail support assembly. Alternatively, for the cart assembly, the strength of the overall assembly was assessed by the strength of a primary structure with the awareness that secondary structures existed to further resist failure.

Throughout this section, the applied stress from design loads are directly compared to the yield strength of the material without an additional factor of safety, because the design loads carry a factor of safety and the worst case loading is applied. The horizontal drive system should be capable of producing maximum accelerations of approximately $0.5 \mathrm{~g}$, yet the design loads are based on horizontal accelerations of $1 \mathrm{~g}$. The design loads were also based on the maximum capability of the Emerson motor, which should be capable of producing maximum accelerations of $4 \mathrm{~g}$, yet it is expected that the drive system will only be required to produce accelerations of up to $2 \mathrm{~g}$.

\subsubsection{Deck Assembly}

As the deck assembly is the attachment fixture for motion testing of the suspension seats, all inertial loads from the seats must be constrained by the deck frames and 
supported by the Dual-Vee wheel bearings. All eight corners of the load deck have a Dual-Vee wheel bearing that rolls along the vertical guide rails of the cart, but the centre of mass of the seat and of the dummy mass are above the upper row of supporting wheel bearings, as shown in Figure 4.14. As noted earlier, the masses of the seat and of the representative user are estimated averages. The heights of those concentrated masses are also estimated.

A horizontal acceleration of these masses causes the deck assembly to rotate. Unlike the Thomson guide blocks and profiled rails that constrain the cart assembly to the rail support channel beams, the Dual-Vee bearings can only press against the vertical rails and cannot pull on the rails. In Figure 4.14, an acceleration to the left is shown because the inertial loads of the deck assembly, seat, and dummy mass are directed to the right in the particular load case considered here. It is assumed in this scenario that the two bearings at point A (front and back) and the two bearings at point D are unloaded, while the pairs of bearings at the other two corners are resisting the tendency to rotate.

The radial reaction forces of the wheels at points $\mathrm{B}$ and $\mathrm{C}$ are calculated by the summation of static moments and forces. If moments were summed about point B, $\Sigma \mathrm{M}_{\mathrm{B}}=0$, then all terms can be included in the expression:

$$
(0.46 \mathrm{~m}) \mathrm{R}_{\mathrm{C}}=(0.8 \mathrm{~m})(1000 \mathrm{~N})+(0.6 \mathrm{~m})(750 \mathrm{~N})-(0.11 \mathrm{~m})(550 \mathrm{~N})
$$

The reaction force at point $\mathrm{C}$ could be solved as $2600 \mathrm{~N}$. Using that value into a summation of the horizontal forces, $\Sigma F=0$, would result in a reaction force at point B of $4900 \mathrm{~N}$. 


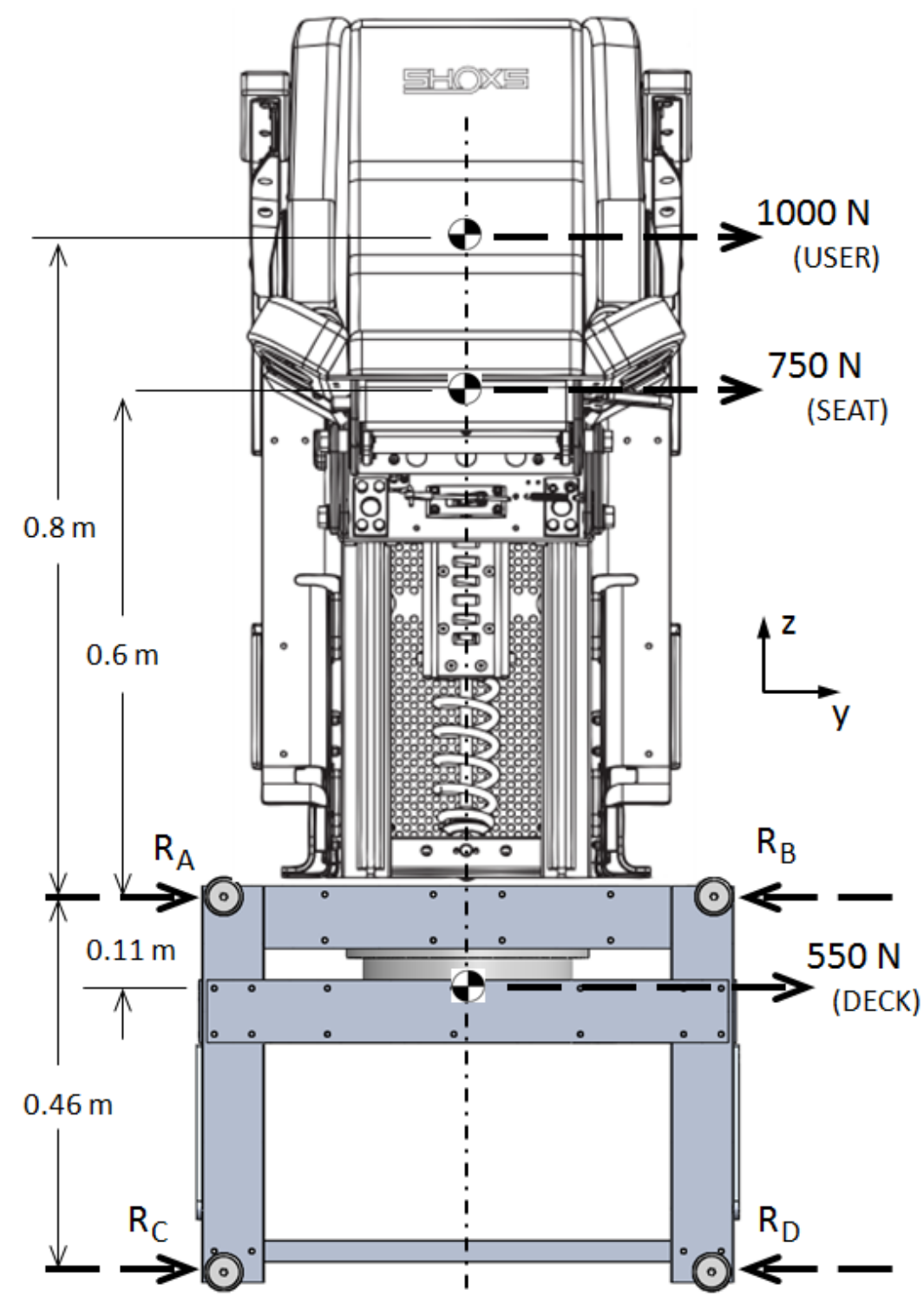

Figure 4.14: Free body diagram of the deck assembly with a scaled image of the SHOXS 6500 suspension seat.

This reaction force of $4900 \mathrm{~N}$ at point $\mathrm{B}$ is shared between two wheels (front and back corners). The wheel bearing Dual-Vee product SWIE3 is rated for $5900 \mathrm{~N}$ of radial load. Even if only one of the wheels happened to be in contact with the rail, due to an uneven alignment or unbalanced forces, the force on one wheel would still be below the rated load. 
The wheels are also rated for $1700 \mathrm{~N}$ of axial load. For all wheels, the axial direction corresponds to the $\mathrm{x}$-axis of the machine. Loading in this direction would occur if a loaded seat's centre of mass was not aligned with the central y-z plane of the machine. The upward force of the wire rope lifts at the geometric centre of the seat deck. If the downward force of the seat's weight was not aligned with the central y-z plane, a pitching moment would exist and the Dual-Vee wheels would be subjected to an axial load to resist the rotation. The restoring forces needed from the wheels is estimated to be far less than their rated capacity. As an example, for an upward heave of $4 \mathrm{~g}$, if the distance between the centre of mass of a loaded seat and the central $\mathrm{y}-\mathrm{z}$ plane was $0.2 \mathrm{~m}$, and the moment was resisted by the top four wheel bearings, then the axial force for each bearing would be approximately $900 \mathrm{~N}$.

FEA was performed for the deck assembly, and the two decks were analysed separately. Since all loads pass through the load cell, it was convenient to isolate each deck and use the load cell as a fixture or as an application surface for forces. For both assemblies, the horizontal forces from an acceleration of $1 \mathrm{~g}$ and a vertical reaction force of $12 \mathrm{kN}$ were chosen as the applied loads. The horizontal loads correspond to the inertial loads that are shown in Figure 4.14.

For the seat deck assembly, an extra CAD model was built onto the deck, which had a representative shape of a mounted seat's footprint and had extruded features that were placed at the same heights as the centres of mass. The foot pads were intentionally placed to only contact the rear segments of the mounting surface, which simulated the weakest connection and worst case loading. In reality, if a seat could not be clamped down to the rear, middle, and front portions of the seat 
deck, then an additional aluminum plate should be included between the top of the deck and the seat's feet to distribute the loads. The clamping tubes under the seat deck should also be extended to be under all three portions. The CAD model also included the top disc of the load cell, which became the fixture for the FEA simulation. It is located under the seat deck in the centre. Figure 4.15 shows that the maximum stresses are still below yielding conditions for the worst case loading from both directions. All parts here are made from 6061-T6 aluminum with a yield strength of $275 \mathrm{MPa}$.

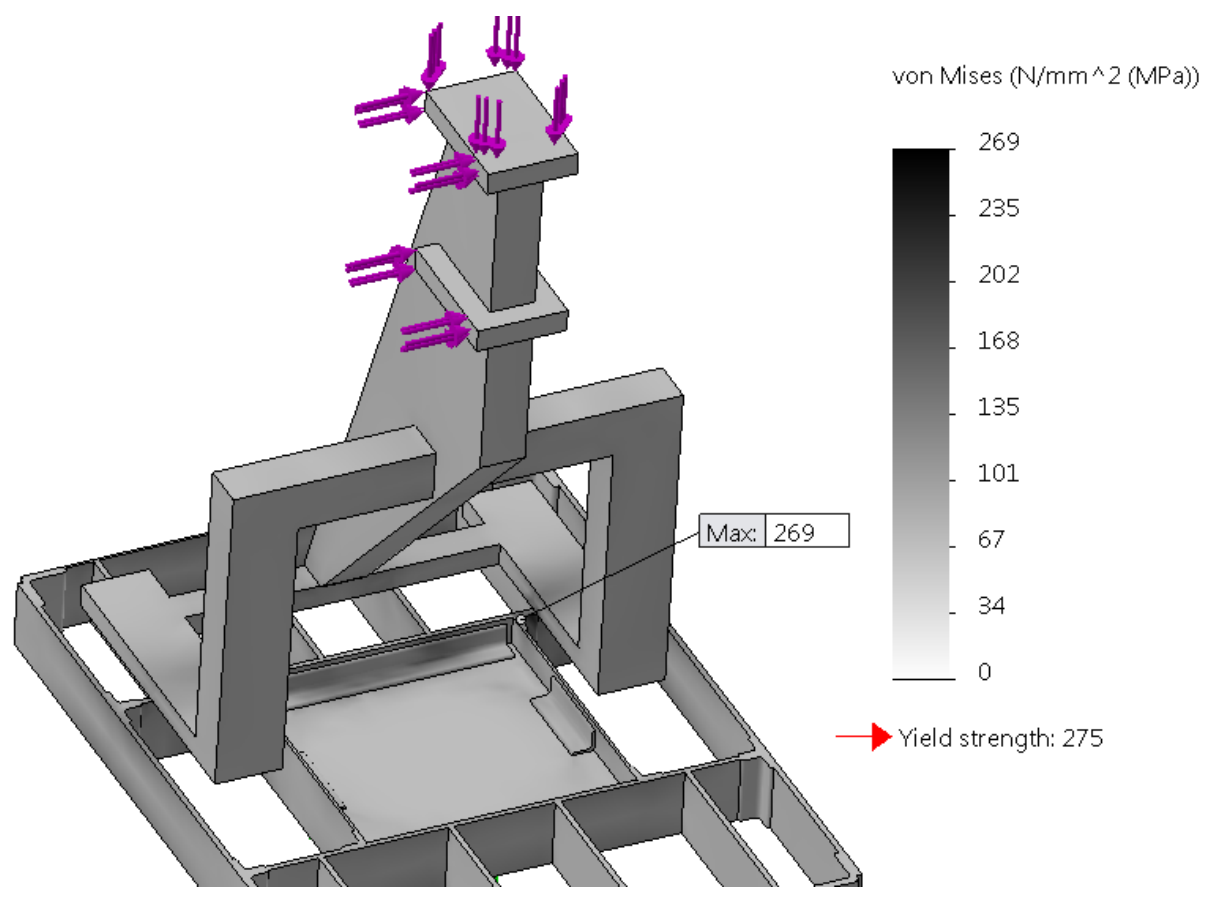

Figure 4.15: Stress state resulting from an inertial load of a horizontal acceleration of $1 \mathrm{G}$ and vertical force of $12 \mathrm{kN}$.

For the load deck assembly, the application of the inertial forces was simulated with a CAD model of a post with an extra extruded block for each centre of mass. The analyses for the horizontal forces and for the vertical forces were performed separately because the rigid fixtures needed for each case would have interfered with 
the results of the other analysis. The stress state from the horizontal forces is shown in Figure 4.16 and the stress state from the vertical force is shown in Figure 4.17. The combined stress state would be the sum of both shown results, which upon inspection, is below the yield strength of $275 \mathrm{MPa}$.

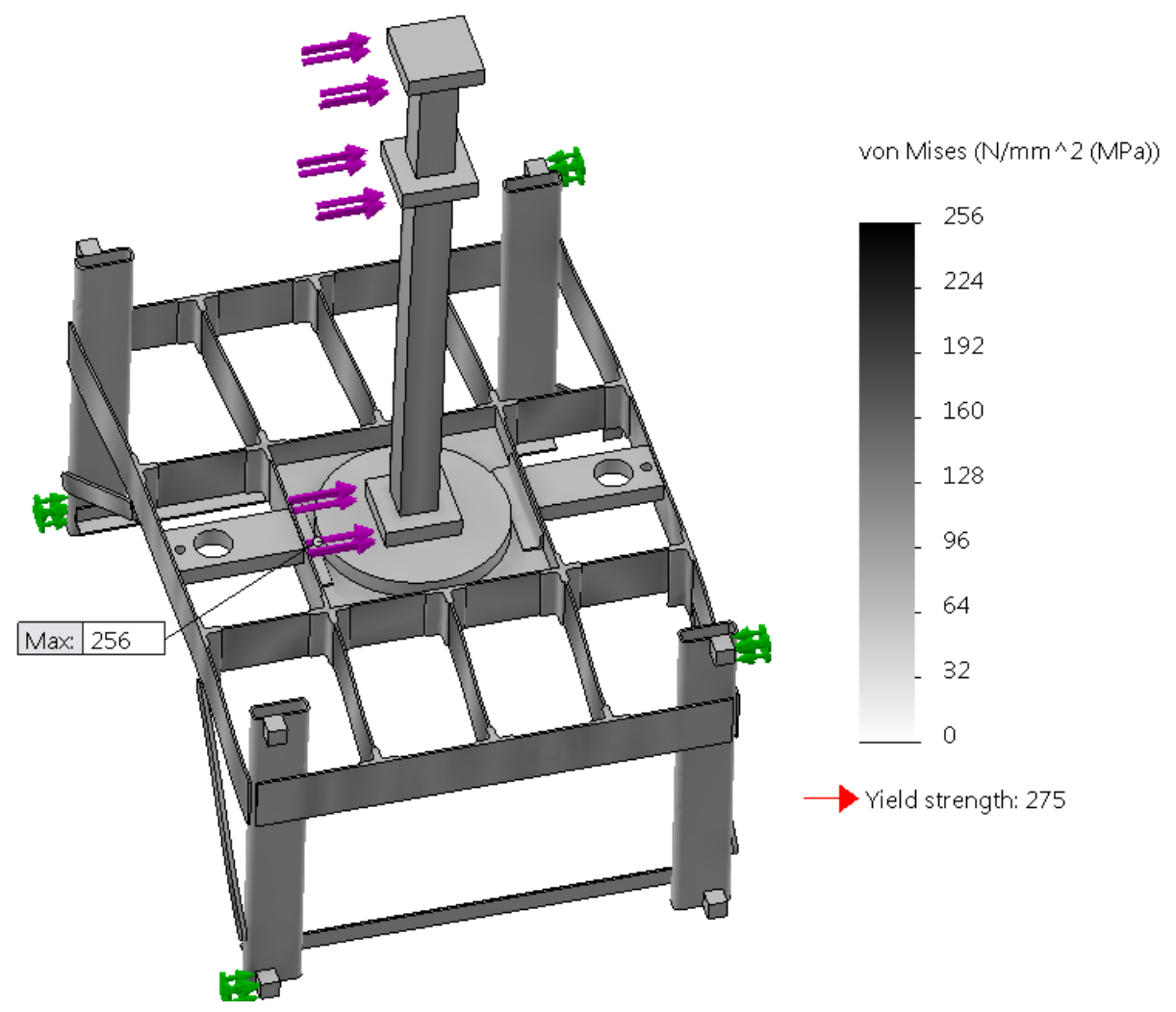

Figure 4.16: Stress state resulting from an inertial load of a horizontal acceleration of $1 \mathrm{~g}$.

In summary, the deck assembly is sufficient to support the inertial loads. According to the FEA results, the lowest margin of safety is located in the seat deck, as shown in Figure 4.15. It is expected that the stress at this corner would be less severe if the mounting feet of the seat would also rest on the front section of the deck. The operator should be aware of this stress concentration and potentially include a plate under each mounting foot to distribute the load onto the front section. 


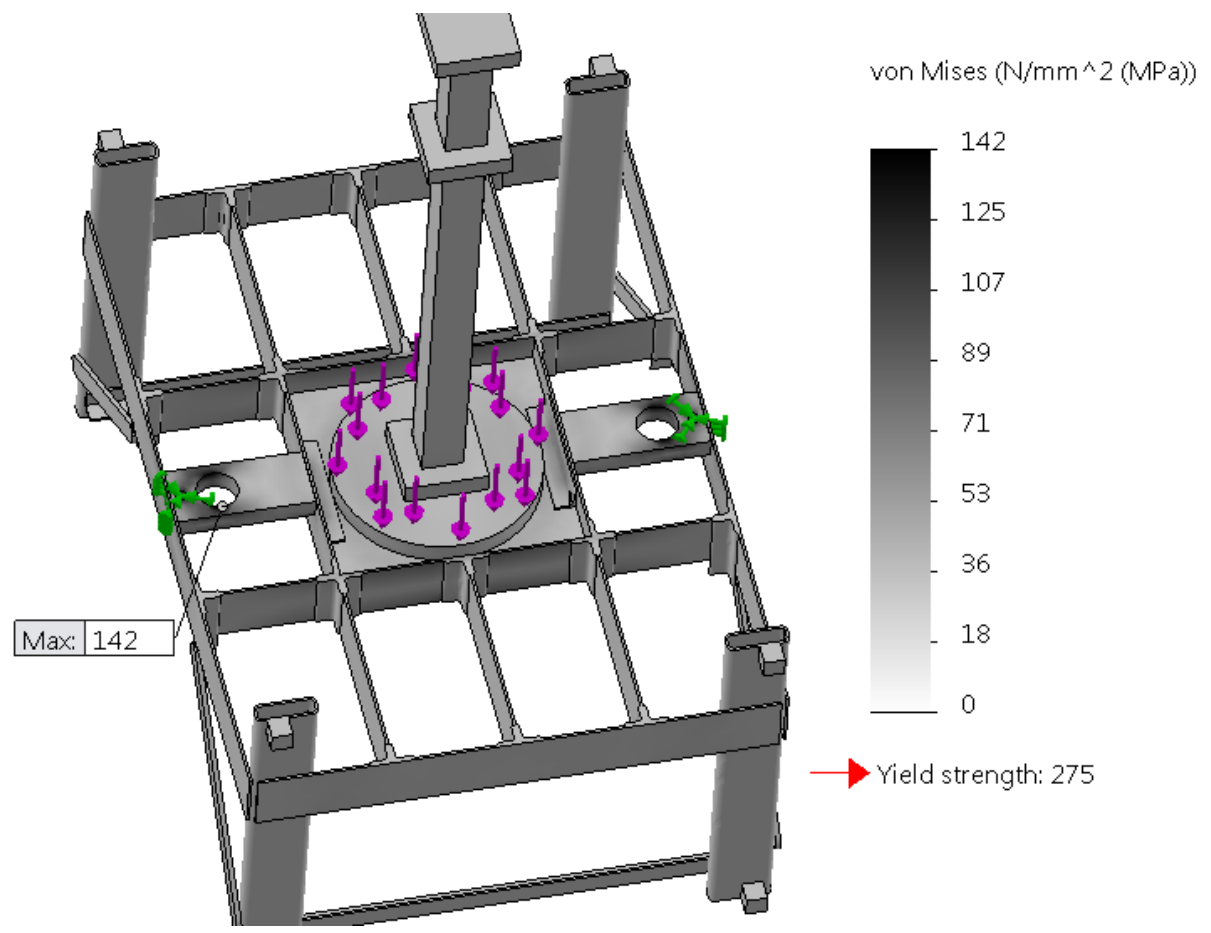

Figure 4.17: Stress state resulting from a vertical acceleration caused by a $6 \mathrm{kN}$ force in each wire rope.

\subsubsection{Cart Assembly}

All accelerations of the seat deck must be supported and constrained within the cart assembly. Consider that the loaded deck assembly accounts for nearly half of the total mass of the loaded cart assembly. The rectangular shell of the cart becomes a composite beam that has the potential for bending, buckling, and torsion from inertial loads from the deck assembly. The most significant bending moment would be produced if the loaded seat deck assembly is near to its topmost position, while the cart was accelerating horizontally. There is a potential for buckling during the horizontal accelerations because that bending moment causes compressive stress in two of the corner posts. Vertical loads caused by upward accelerations also contribute 
to compressive stresses in the corner posts and the potential for buckling. The cart may experience a torque around its central vertical axis from an unbalanced deck assembly, while the cart was accelerating horizontal. Where applicable, the effects of these loading conditions are evaluated and discussed in this section.

Although the following analysis will consider both loading conditions of horizontal and vertical accelerations while the deck assembly is at its topmost position, this situation is highly unlikely to occur because the vertical drive system should never be lifting the deck assembly at a high acceleration while the deck is near the top. This may lead to a collision between the deck assembly and the mechanical stops at the top of the cart because the vertical drive system cannot pull down on the deck to decelerate an upward motion. As an example, during sinusoidal motion, the deck assembly would be experiencing its period of natural downward acceleration due to gravity and the vertical drive system would be minimally loaded.

A primary structure was designed to withstand these inertial loads. The corner posts, the back sheet, and the door form a structural shell that is similar to the longerons and struts of an aerospace fuselage. The corner posts are strongest when used as axially stressed elements, and the back sheet and the door resist shear. The back sheet and door also resist bending by maintaining the spacing between the corner posts, resulting in a high second moment of inertia. The longitudinal beams support the primary structural shell. These primary elements were analyzed using traditional analytical methods.

Other parts were added to the structure with the intention of reinforcing the primary elements to reduce excessive deflections of the structural shell. Since the inclusion of 


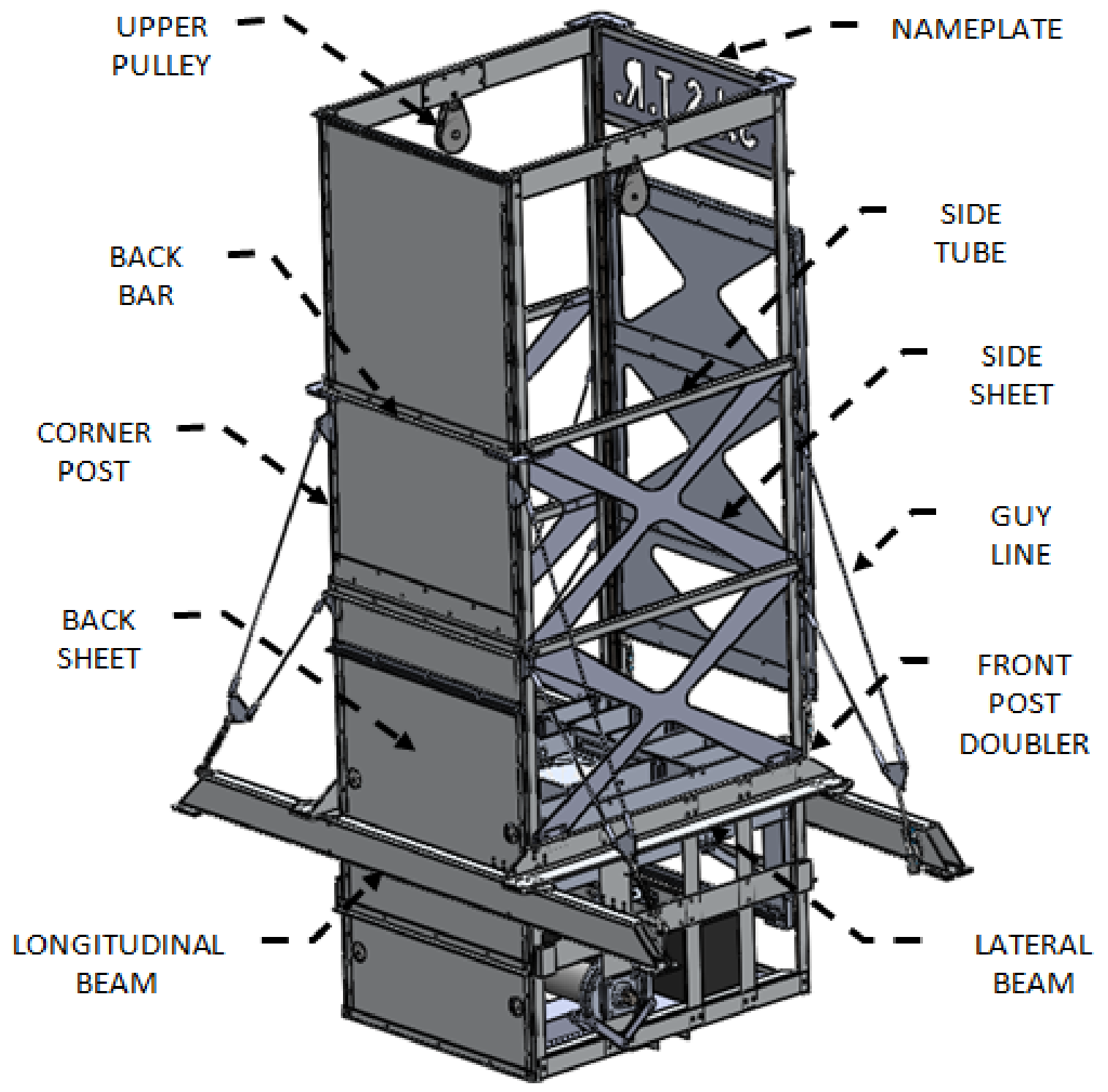

Figure 4.18: Labelled diagram of the cart assembly.

redundant supports will define a statically-indeterminant system, they are omitted from the analysis as if the primary elements resist the full loads. In this section, the secondary elements are mentioned where they are relevant and their support of the primary elements is discussed. Refer to Figure 4.18 for the identification and location of elements that are relevant to this section. 
An analytical approach to stress analysis of the cart will first examine the corner posts. These elements experience direct compression from the reaction force of the seat deck accelerating upwards and bending from the seat deck accelerating horizontally. The potential for buckling will also be evaluated. The profiled rails that guide the motion of the deck assembly are fastened to the corner posts with bolts at $0.076 \mathrm{~m}$ (3 inch) increments so each rail and post are considered joined as a built-up section.

The direct axial compressive stress is caused by the downward force of the wire rope. Each pair of corner posts support one upper pulley. The pulley resists the tension of two wire ropes. The maximum tension in the wire rope is estimated to be $6 \mathrm{kN}$ from the maximum torque of the Emerson motor. Each corner post and profiled rail would then be under direct compression of $6 \mathrm{kN}$. Axial stress is given by the equation

$$
\sigma=\frac{\text { force }}{\text { section area }}
$$

The area of the built-up section is estimated to be $405 \mathrm{~mm}^{2}$. The axial stress in each corner post and rail then is approximately $14.8 \mathrm{MPa}$. These parts are structural steel with a yield strength of $250 \mathrm{MPa}$.

For bending of the corner posts, only the horizontal acceleration is considered. The location of the highest bending moment is above the connection between the corner posts and the longitudinal beams. If the deck is at its topmost position, the height from the longitudinal beams to the upper row of Dual-Vee wheels is $1.7 \mathrm{~m}$. The loads and the heights for the bending moment are shown in Figure 4.19. The bending moment from these three inertial loads is calculated to be approximately $5100 \mathrm{Nm}$. 
The second moment of area is calculated to be approximately $224.5 \times 10^{6} \mathrm{~mm}^{4}$ from the CAD model. The corresponding cut section is shown in Figure 4.20 and the distance from the neutral axis to the point of highest stress is shown as $0.356 \mathrm{~m}$. The axial stress due to bending is given by:

$$
\sigma=\frac{\text { bending moment } \times \text { distance from neutral axis }}{\text { second moment of area }}
$$

and the result is $8.1 \mathrm{MPa}$. Two of the corner posts will experience tension and the other two experience compression.

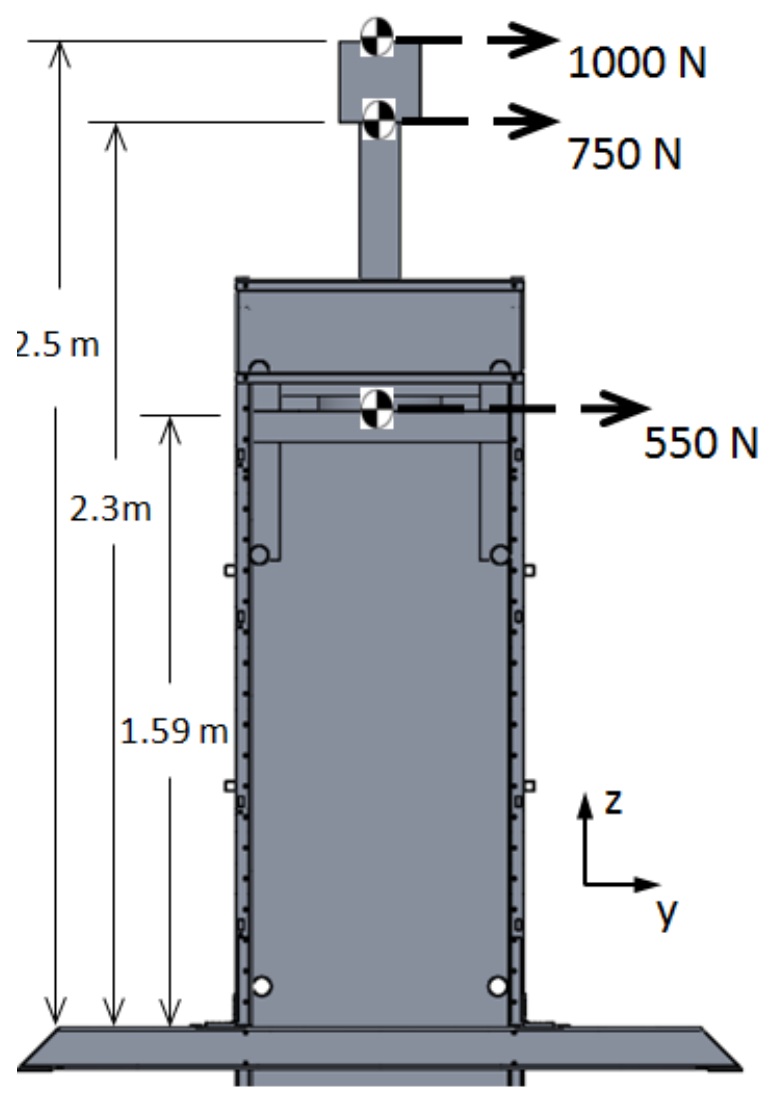

Figure 4.19: Free body diagram of the cart showing bending moment from a horizontal acceleration.

If the maximum acceleration occurs in both axes simultaneously, two of the corners 


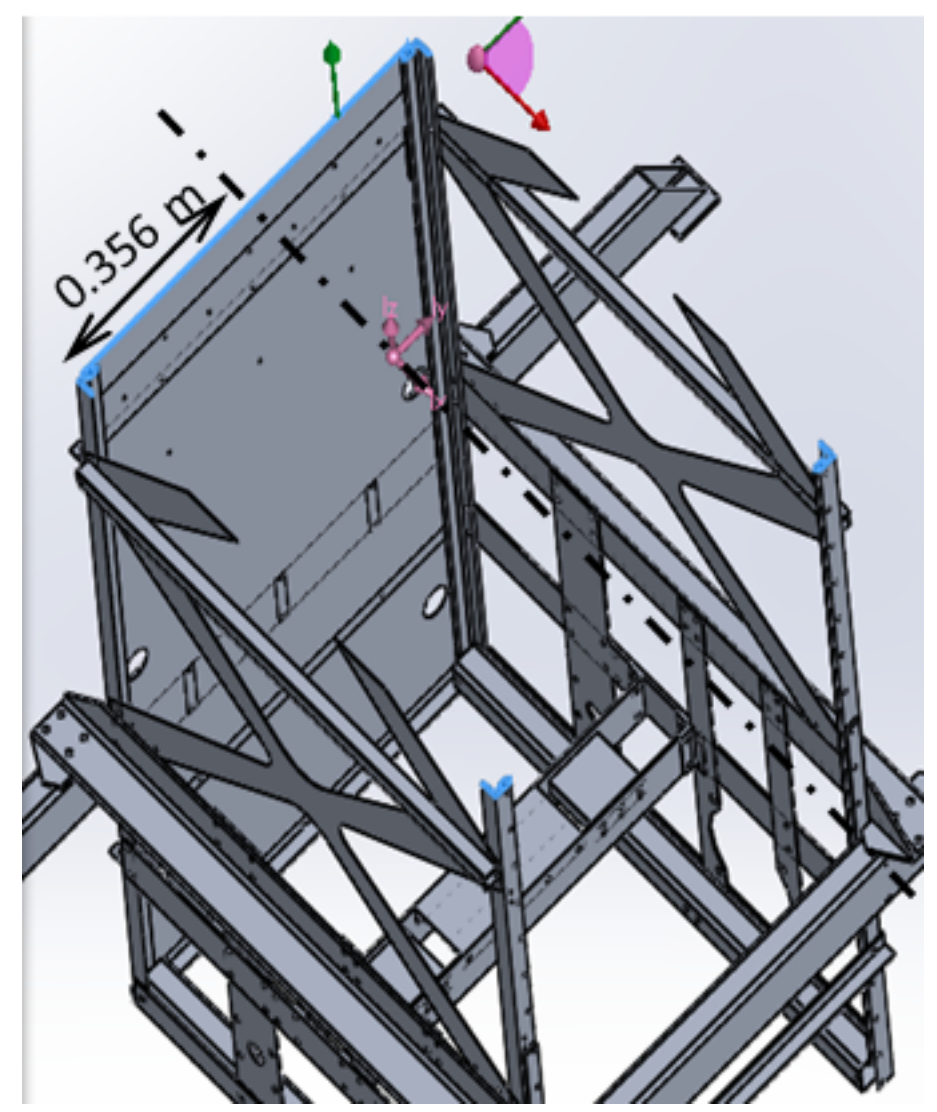

Figure 4.20: Cut section of the cart corner posts used for bending stress analysis.

may experience a total compressive stress of $23 \mathrm{MPa}$. This is still far below the yield strength of $250 \mathrm{MPa}$ for this A36 structural steel. The cart's strength greatly benefits from the wide distances between its corners as a resistance to bending.

There are a few components that were designed as secondary structures to support the corner posts against the inertial load from a horizontal acceleration. They include:

- Two rows of rivets, between the back sheet and the rear longitudinal beam, resist relative rotation between these parts. The rivets are 3/16 inch diameter aluminum with a shear strength of $1700 \mathrm{~N}$ (380 lb). 
- The guy lines, between the corner posts and the longitudinal beams, resist relative rotation between these parts. Each guy line is a $1 / 8$ inch galvanized steel wire rope with a breaking strength of $8.9 \mathrm{kN}(2000 \mathrm{lb})$ and the wire end connectors has a load rating of $7.5 \mathrm{kN}(1700 \mathrm{lb})$. The toggle latch that connects guy lines to the front longitudinal beam has a working load limit of $1.78 \mathrm{kN}$ (400 lb). The turnbuckle that connects guy lines to the back beam has a working load limit of $2.2 \mathrm{kN}(500 \mathrm{lb})$.

- The door, between the corner posts and the longitudinal beams, resists relative rotation between these parts. The door is held in place with eight hinges, each has a load capacity of $1.33 \mathrm{kN}$ (300 lb), and with two draw latches, each having a load capacity of $1.47 \mathrm{kN}(330 \mathrm{lb})$.

- A $0.006 \mathrm{~m}$ (1/4 inch) thick 6061-T6 aluminum strip, between each of the front corner posts and the front longitudinal beam, adds bending resistance to the corner posts where the bending moment is greatest.

One risk of designing with long, narrow columns, is the potential for buckling. The angle profiles used for the corner posts are categorized as compact sections because local buckling of the flat webs will not occur before global column buckling [28]. Aside from material properties and the shape of the section, the resistance to buckling can be improved by shortening the effective length. The corner posts are braced at two points along their height in order to reduce their effective lengths. Some of these bracing elements are only effective in tension, like the side sheets and the guy lines, while other components can be tensile or compressive, like the side tubes, the back bars, and the door tubes.

The result is that the effective length of the corner post segments is approximately $500 \mathrm{~mm}$, or one third of the height above the longitudinal beams. In the Euler 
buckling formula, the type of end conditions is also an important factor in determining the critical force that would cause catastrophic buckling. The standard equation treats the end conditions as being pinned. Here, similar to fixed ends, some resistance to bending of the posts is expected at the supporting points. However, as a conservative assumption, the end conditions are considered to be pinned. With the fixed-fixed end conditions, the critical force would be four times larger.

The Euler buckling formula to determine the critical force is given by

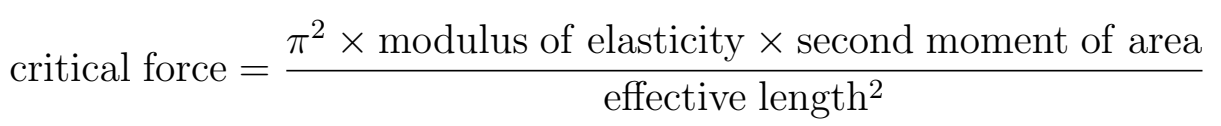

The modulus of elasticity of steel is $200 \mathrm{GPa}$ and the second moment of area for this section shown in Figure 4.21 is $16530 \mathrm{~mm}^{4}$. As mentioned above, the effective length is approximated to be $500 \mathrm{~mm}$. The resulting critical buckling load is $131 \mathrm{kN}$. This is much higher than any operational load, even if the loading conditions occurred together. The corner posts are among the few large components of the machine that are made of steel instead of aluminum. Steel is approximately three times stiffer than aluminum, which is advantageous for applications where buckling is a concern.

Torsion from an off-balanced deck assembly would cause another type of unwanted deflection for the structural shell of the cart. When a seat is mounted to the deck assembly, it will be positioned according to its best physical fit within the cart frame, to avoid interference with the inner sides of the cart. Although seats are typically symmetric laterally, the suspension mechanism shifts the centre of mass towards the back of the seat. The human occupant should shift the centre of mass towards the front and potentially balance the seat over its mounting feet. If the centre of mass 

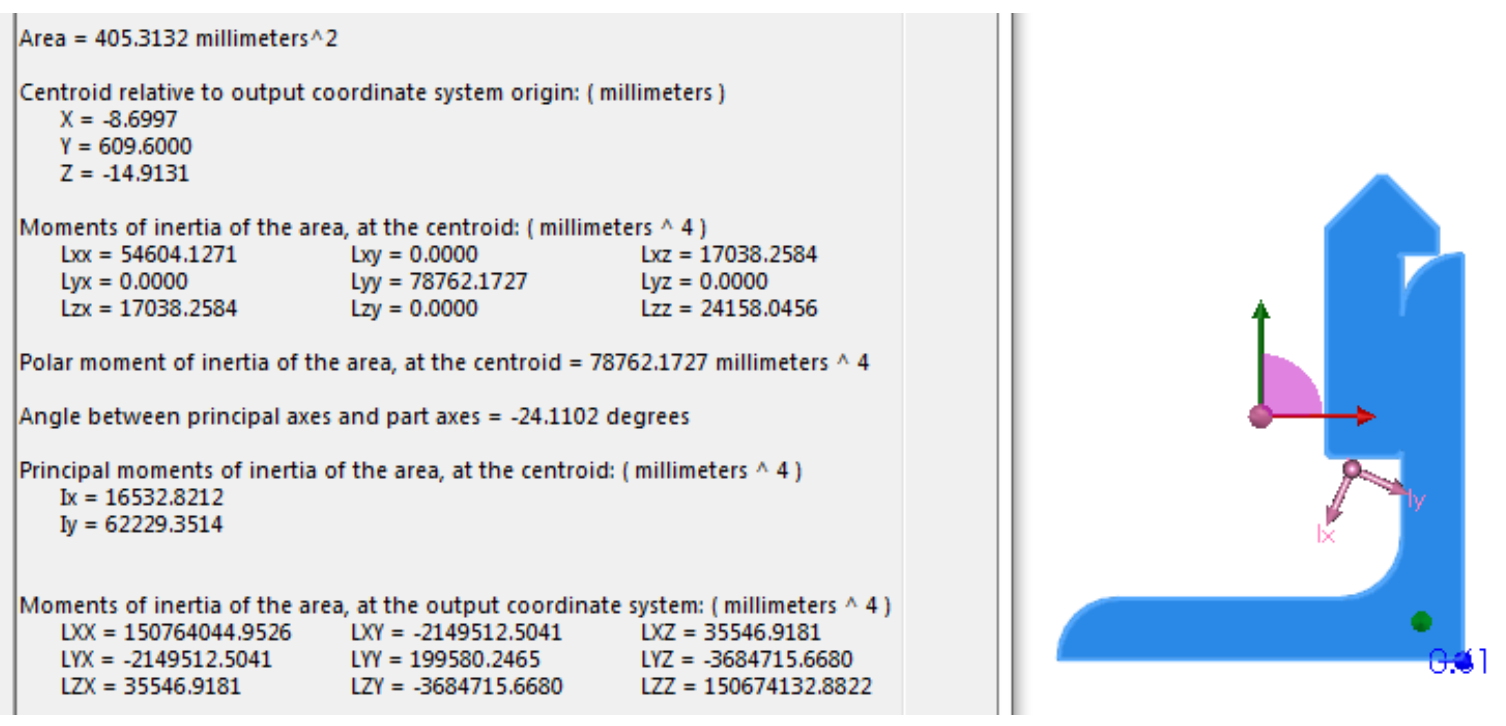

Figure 4.21: Screen capture from the CAD software showing the cut section properties.

is not aligned with the central $\mathrm{y}-\mathrm{z}$ plane of the cart, the cart frame will experience torsion around its z-axis. The side sheets are designed as tensional elements oriented at $45^{\circ}$ to resist torsional shear. The guy lines also resist motion of the corner posts that may be caused by torsion. For either direction of rotation, half of the diagonal elements in the side sheets and half of the guy lines are stressed as tensile elements. The load path through the guy lines and the side sheets as a response to an applied torsion is shown in Figure 4.22. Torsion in this direction would occur if the centre of mass of the deck was closer to the back and the cart was accelerating horizontally in the direction coming out of the page.

Since the side sheets are only useful as tensile elements against torsion, other elements were needed to maintain the spacing between the front and back corner posts. Two square-profiled tubes were chosen for their ability to resist buckling for each side of the cart. Regarding the spacing between the left side and right side corner posts, six angle-profiled bars were distributed along the back sheet and four 


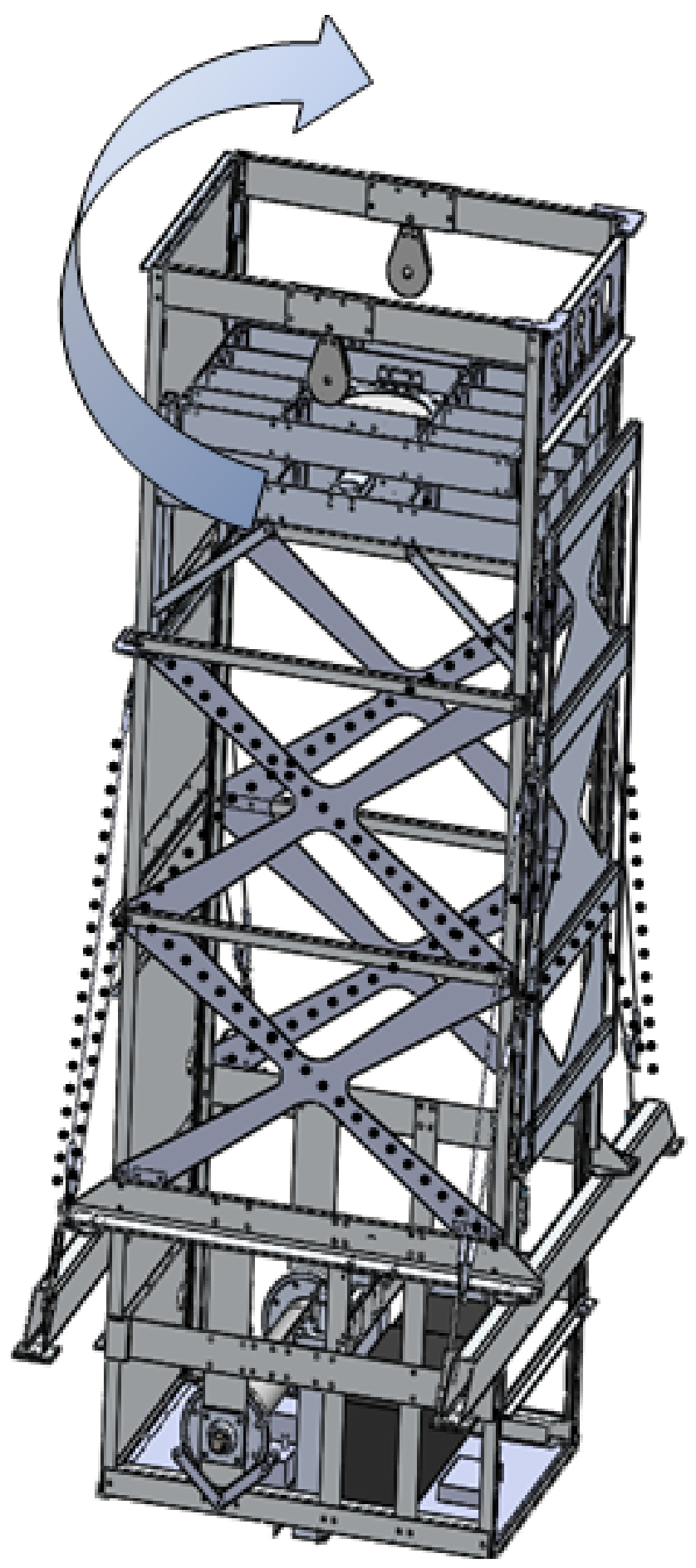

Figure 4.22: Load path indicating torsion from an unbalanced deck load. 
of the same bars exist along the front. At the back, each bar has three rivets along its length, which fix the bar to the sheet. In Figure 4.18, the square-profiled tubes and the angle-profiled bars are labelled as the side tubes and back bars, respectively.

The back bars have a significant effect on resisting shear buckling in the back sheet, which would appear as diagonal ripples. At the front, two of these angle-profiled bars frame the SISTR nameplate at the top and two bars appear below the longitudinal beams. The critical compressive force that could cause buckling in each of these types of bars is evaluated with the Euler buckling formula, given by:

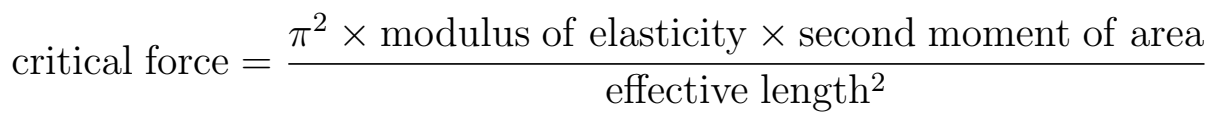

Both types of elements are made from 6061-T6 aluminum and the modulus of elasticity is $69 \mathrm{GPa}$. Similarly to the analysis shown above for the buckling of the corner posts, the end conditions are considered to be pinned as a conservative estimate. For the square-profiled tubes, the second moment of area is $14100 \mathrm{~mm}^{4}$ and the effective length is $870 \mathrm{~mm}$. The resulting critical buckling force is $12.6 \mathrm{kN}$. For the angle-profiled tubes, the second moment of area is $4900 \mathrm{~mm}^{4}$ and the effective length is $680 \mathrm{~mm}$. The resulting critical buckling force is $7.2 \mathrm{kN}$. Both of these critical buckling forces are expected to be above loads experienced during operational conditions.

The mass of the cart and deck assemblies are supported by the longitudinal beams and then onto the guide bearing blocks. The reaction forces in the guide block bearing were calculated as a result of both accelerations. Those reaction forces were then used for stress analysis of the longitudinal beams. 
Horizontal accelerations, while the deck assembly is at its highest position, cause a moment that is resisted by the guide bearing blocks. This moment was calculated earlier for the stress analysis of the corner posts, which was approximately $5100 \mathrm{Nm}$. Figure 4.23 shows the application of this moment onto the cart and the reaction forces at the guide bearing blocks. The center of mass of the cart assembly is approximately at the same height as the guide block bearings so it was assumed that horizontal accelerations of the cart do not produce a moment. Despite the tall stature of the cart's frame, the low center of mass is achieved by the $100 \mathrm{~kg}$ combined mass of the Emerson motor and the gearhead that are below the guide bearing blocks.

The maximum vertical acceleration is represented by the maximum torque from the Emerson motor. The vertical drive system converts the maximum torque into a maximum tensile force of $6 \mathrm{kN}$ in each of the two wire ropes. For the FBD of the cart, the deck assembly is removed and replaced with a downward force of $6 \mathrm{kN}$ on each side, as shown in Figure 4.23. The static weight of the cart is also shown as a downward force of $2.4 \mathrm{kN}$.

By using the equations of static equilibrium, the reaction forces are $4.2 \mathrm{kN}$ at point A and $10.2 \mathrm{kN}$ at point B. Since both points represent two guide bearing blocks, and the contributions of the two blocks are assumed to be equal, then the maximum reaction force through a guide bearing block is $5.1 \mathrm{kN}$. The guide bearing blocks are Thomson 500 series ball guides with the $30 \mathrm{~mm}$ frame size, which have a dynamic load rating of $29.2 \mathrm{kN}$ in the vertical direction.

FEA was performed for one of the longitudinal beams with the maximum loads of 


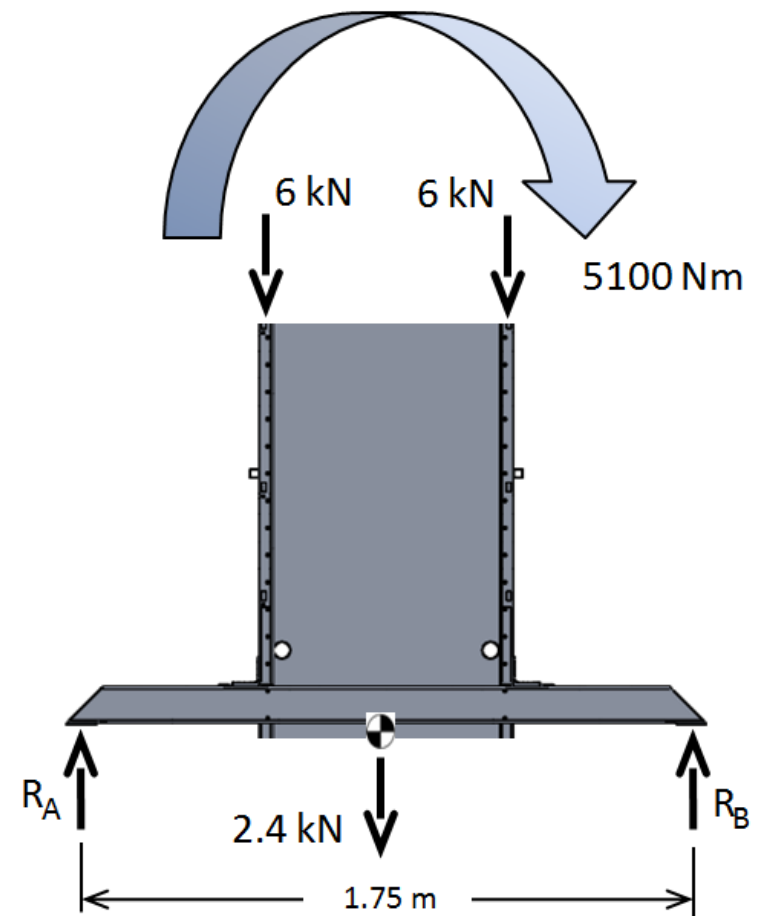

Figure 4.23: Free body diagram of the cart assembly for the reaction forces under the longitudinal beams.

$5.1 \mathrm{kN}$ and $2.1 \mathrm{kN}$ applied under the two welded plates that are bolted to the guide bearing blocks. The resulting stress state is shown in Figure 4.24, where the $5.1 \mathrm{kN}$ load is applied under the end that is shown on the right, and the $2.1 \mathrm{kN}$ load is applied under the plate on the left. The yield strength for this A36 structural steel part is $250 \mathrm{MPa}$. It should be noted that the applied loads used for the longitudinal beams represent the worst case loading, which is not expected to occur in operation because both drive systems are producing maximum accelerations and the deck assembly is at its highest position.

In summary, the cart assembly is sufficient capable of supporting the inertial loads based on the evaluations of the primary structures. 


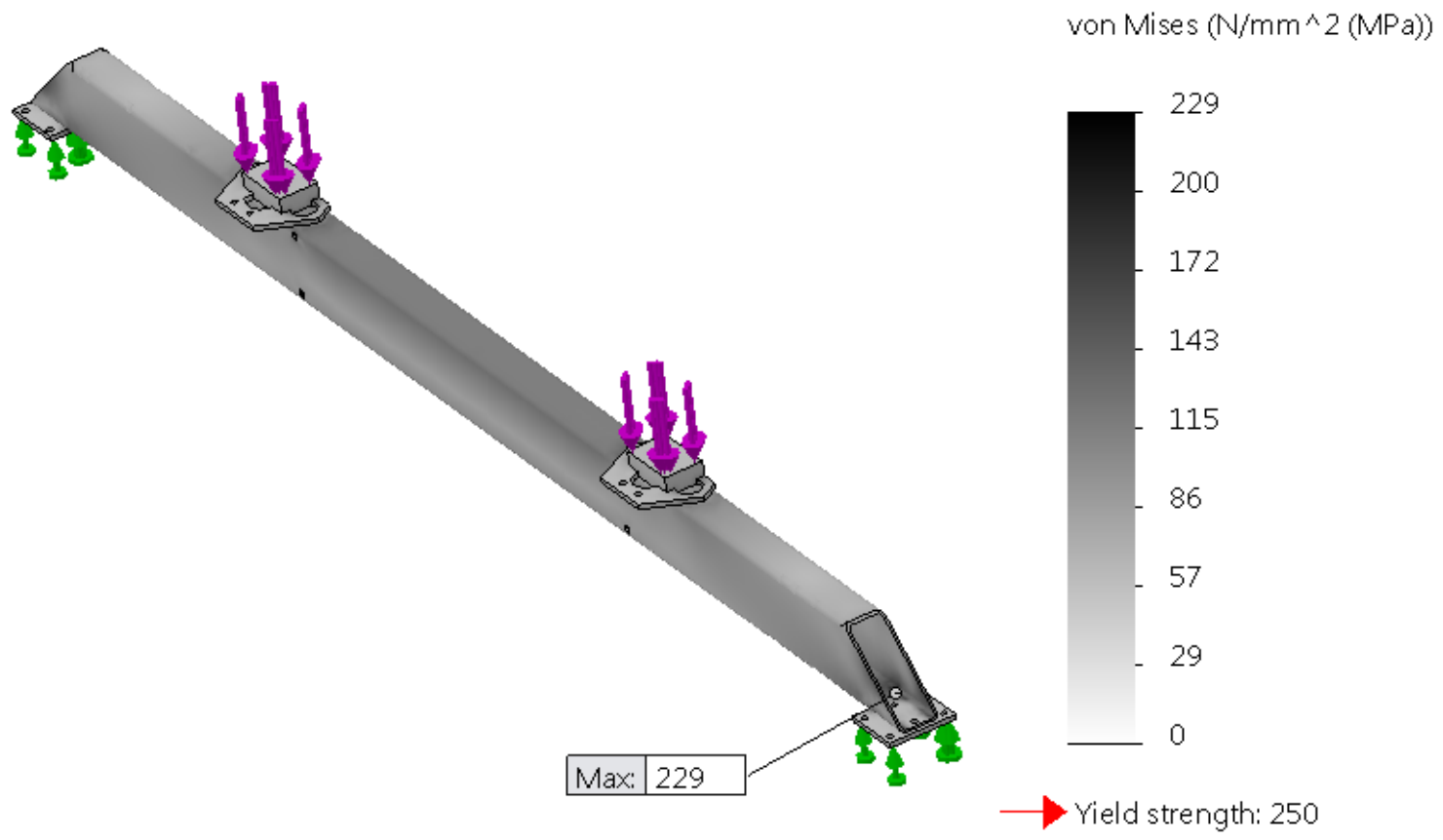

Figure 4.24: Stress state in the longitudinal beams from a vertical acceleration.

\subsubsection{Rail Support Assembly}

The rail support assembly supports the large moving mass of the loaded cart assembly and it is completely stationary. For these reasons, the assembly was designed as an overconstrained and stiff steel structure. The channel beam that is near the wall is braced to the wall at every junction with a post and the ends of each rail is braced to the other wall. The foot of each post is anchored to the floor. Structural analysis of the channel beam applied the maximum reaction forces from the guide bearing blocks in order to represent the worst case scenario. FEA was performed with a representative CAD model and the results are shown in Figure 4.25. In the image, the block on the left carried the $5.1 \mathrm{kN}$ load and the block on the right carried the $2.1 \mathrm{kN}$ load. The yield strength of this structural steel frame is $250 \mathrm{MPa}$. 


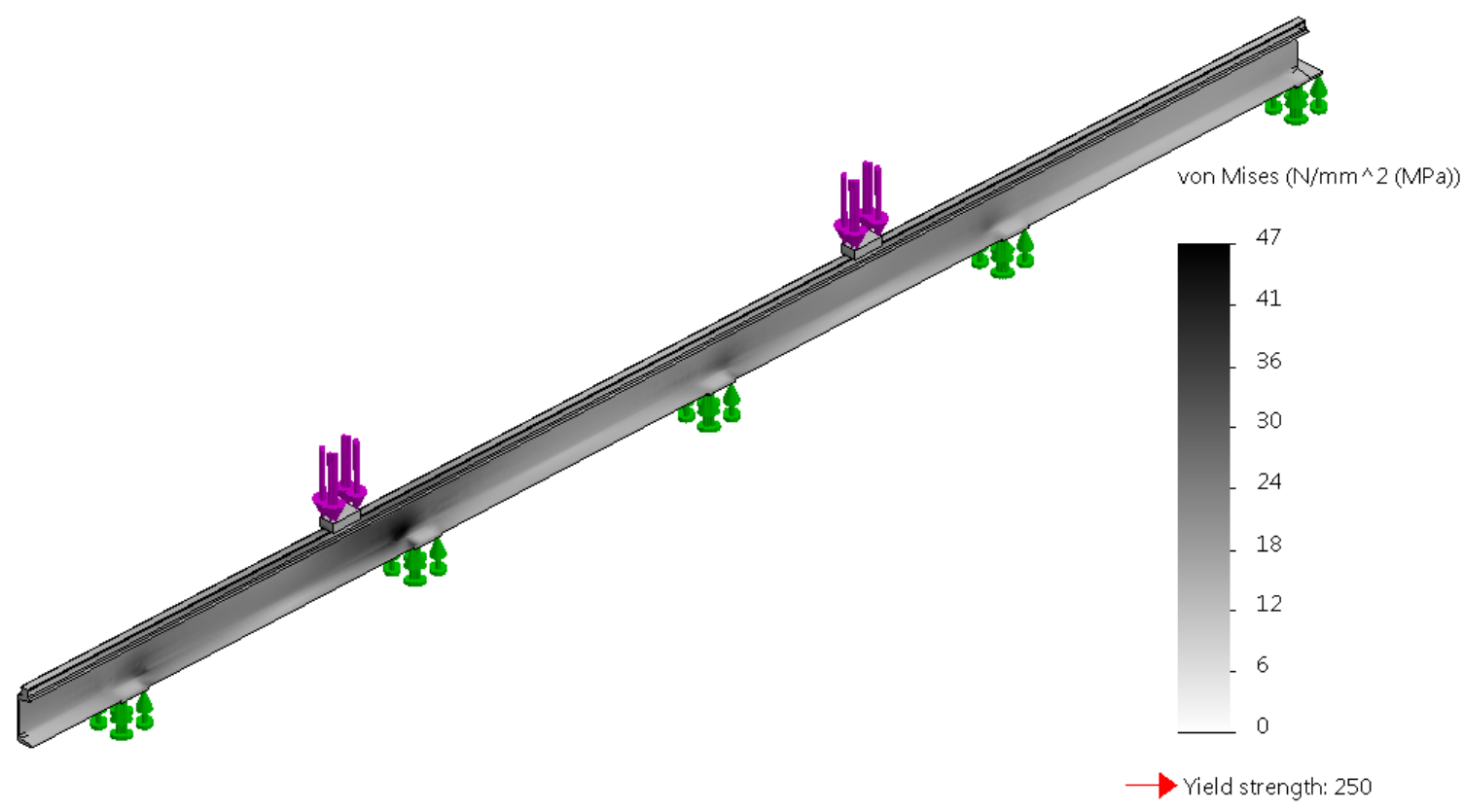

Figure 4.25: Stress state in the rail channel beam from an a reaction of the combined maximum vertical and horizontal accelerations of the cart assembly.

At each end of the horizontal range of motion, there are two polymer compression springs attached to the rail end brace. They are built as mechanical stops for a moving cart that fails to stop at the end of its range of motion. A collision here would cause a rapid deceleration of the cart assembly. These products were selected based on their available energy absorption capacity. On the cart, an impact with the plastic bumper would apply a force onto aluminum tubes that are attached to the outside of the corner posts. The plastic compression springs and the aluminum tubes are shown in Figure 4.26. Behind these aluminum tubes, a bracing bar is attached between the corner posts to distribute the load between the corner posts. In the event of a collision, the plastic bumpers and the aluminum tubes will compress, absorbing some of the energy of the collision. These tubes are designed to be replaceable because they may get damaged. 


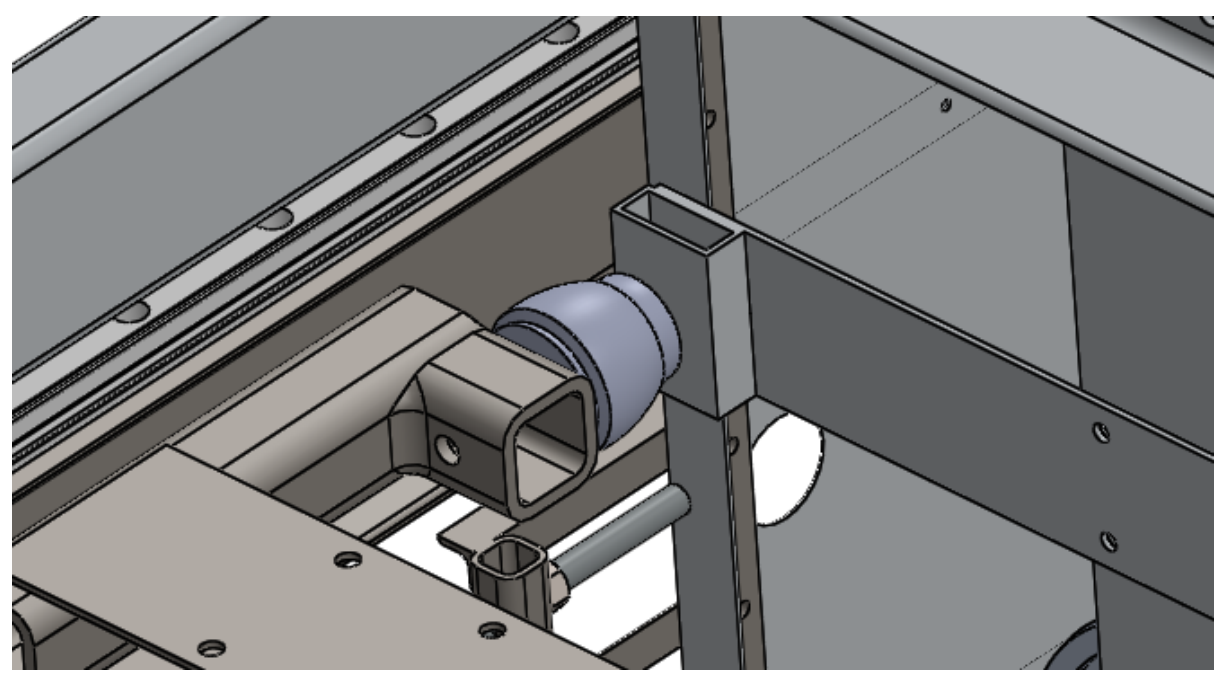

Figure 4.26: Image of a polymer compression spring of the rail support assembly in contact with an aluminum collision tube of the cart assembly.

In summary, the rail support assembly is capable of supporting the inertial loads.

\subsection{Stress States Caused by Freefall Slam Impact}

An important feature of the machine is the ability to produce slam impacts in a similar way to drop testing. For this, the loaded deck frame accelerates downwards at the rate of gravity and collides with the dampers that are fixed in the base of the cart frame. This scenario is initiated by the Emerson motor spinning in the opposite direction from its typical upward driving direction, which will release the tension in the wire rope. If the wire rope is let out at the same accelerated rate as the falling deck assembly, then the deck assembly would not be slowed down by the resistance of back driving the drive system, and the deck's downward acceleration may reach $9.8 \mathrm{~m} / \mathrm{s}^{2}$ and experience a true freefall. 
The application of impulsive loads is different than static loads, in that they are dependent on the change in momentum and the duration of the impulse. A sharp and short duration acceleration peak may correspond to a high dynamic force magnitude, but it will carry a low impulse energy that does not damage the structure. Performing FEA as a simulation of dynamic loading was not feasible during the design phase of this structure because the time-dependent magnitudes of the maximum expected dynamic loads could not be evaluated at the time of the analysis. These dynamic loads are dependent on the ER dampers' capability of shaping an impact pulse, which will be developed during the commissioning phase of the machine. As an alternative, each affected assembly or component in the load path was analysed to determine the maximum static force that the structure could withstand before yielding. The stress distributions and relative weakness between parts can be observed from the FEA results. The weakest part should later be re-evaluated with a simulation of dynamic loading.

Developing the ER dampers' capability of shaping an impact pulse will involve a relationship between the velocity before impact and the resulting peak acceleration profile that is measured by the deck assembly. The dampers will be progressively tested to produce peak impact accelerations up to $10 \mathrm{~g}$, while varying the initial velocity, payload mass, and control voltage. FEA as a dynamic load simulation can be performed for the weakest part in conjunction with this experimental process. To consider the potential for fatigue failure, a safety factor can then be applied to reduce the available yield strength when comparing the material strength to the maximum stresses of the dynamically loaded parts. The safety factor would be based on an expected frequency that these maximum impacts would occur throughout the expected life of the machine.// 
During a slam impact, the piston of each of the ER damping cylinders contacts an aluminum block in the load deck assembly. This is the same block that carries the forces from the vertical drive system's wire rope so the analysis follows a similar load path. Figure 4.27 shows a sectioned view of the deck assembly, with the load path for an impact traced as dotted lines. Each of the components in the load path was independently analysed to identify the minimum force that would cause a yielding condition. The results from FEA are presented in this section.

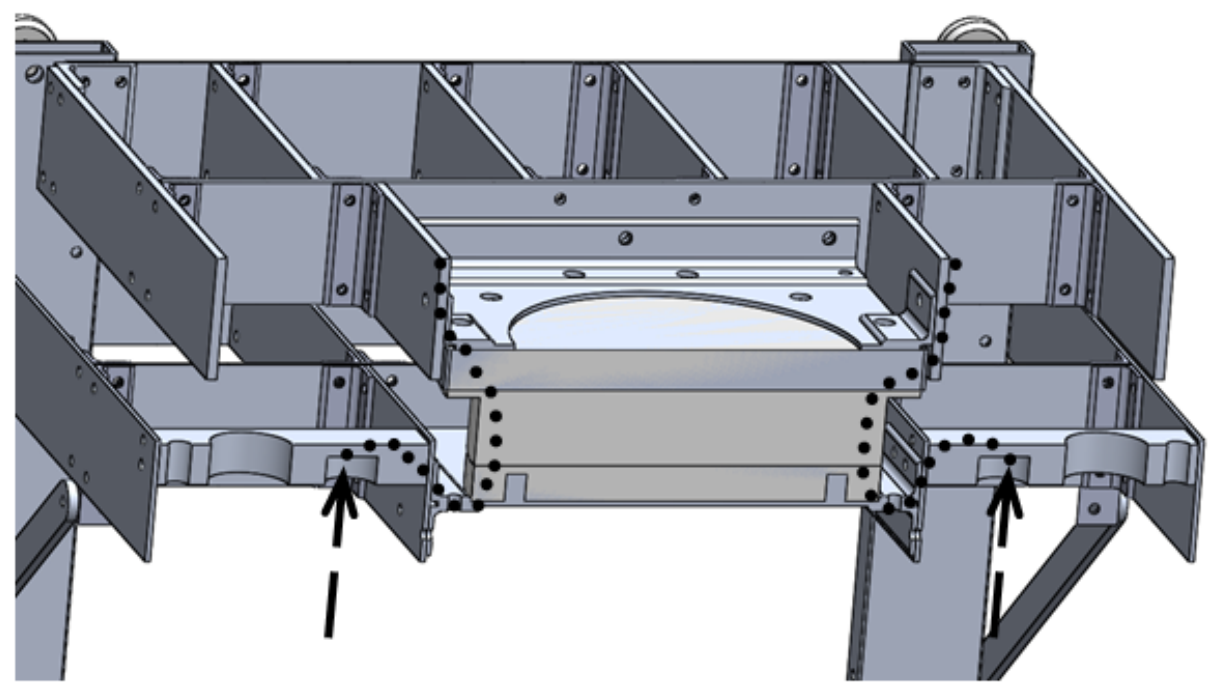

Figure 4.27: Load path through the deck assembly from impact loading. The dotted lines follow the load path and the arrows at the bottom indicate the pockets where the ER dampers contact the assembly.

Figure 4.28 shows the stress state in the seat deck reacting to a load of $25 \mathrm{kN}$, which shows regions that are near their yielding condition.

Figure 4.29 shows the stress state in the load cell lid and the surrounding brackets reacting to a load of $40 \mathrm{kN}$, which shows regions that are near their yielding condition. 


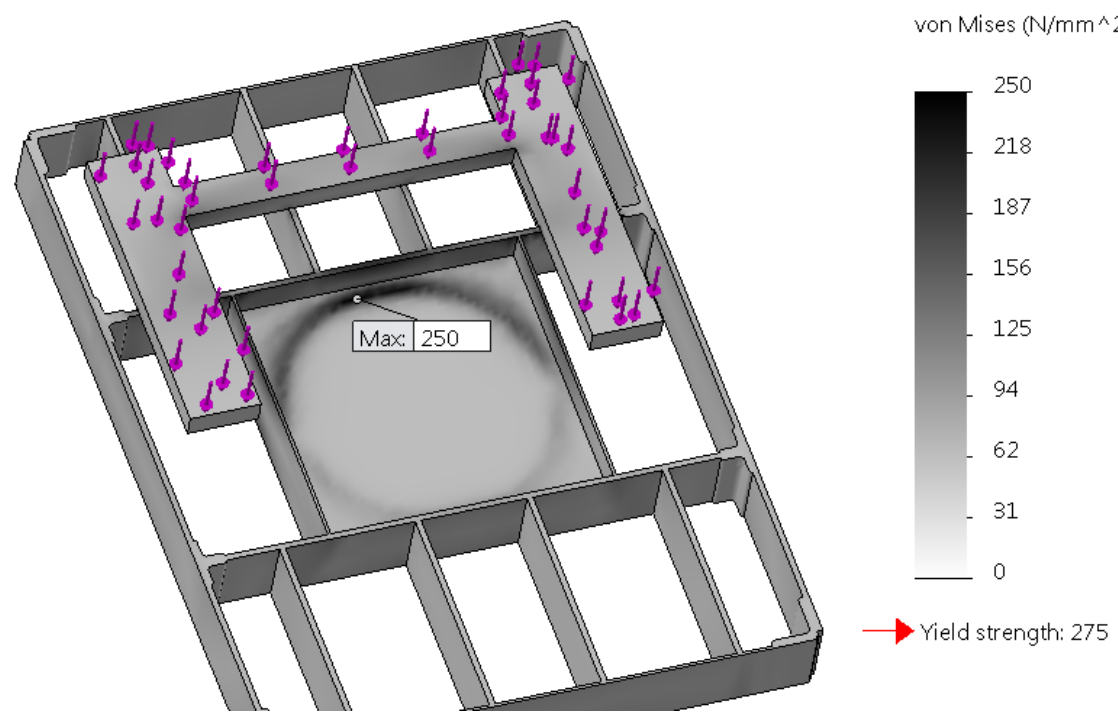

Figure 4.28: Seat deck showing stress state from a $25 \mathrm{kN}$ force.

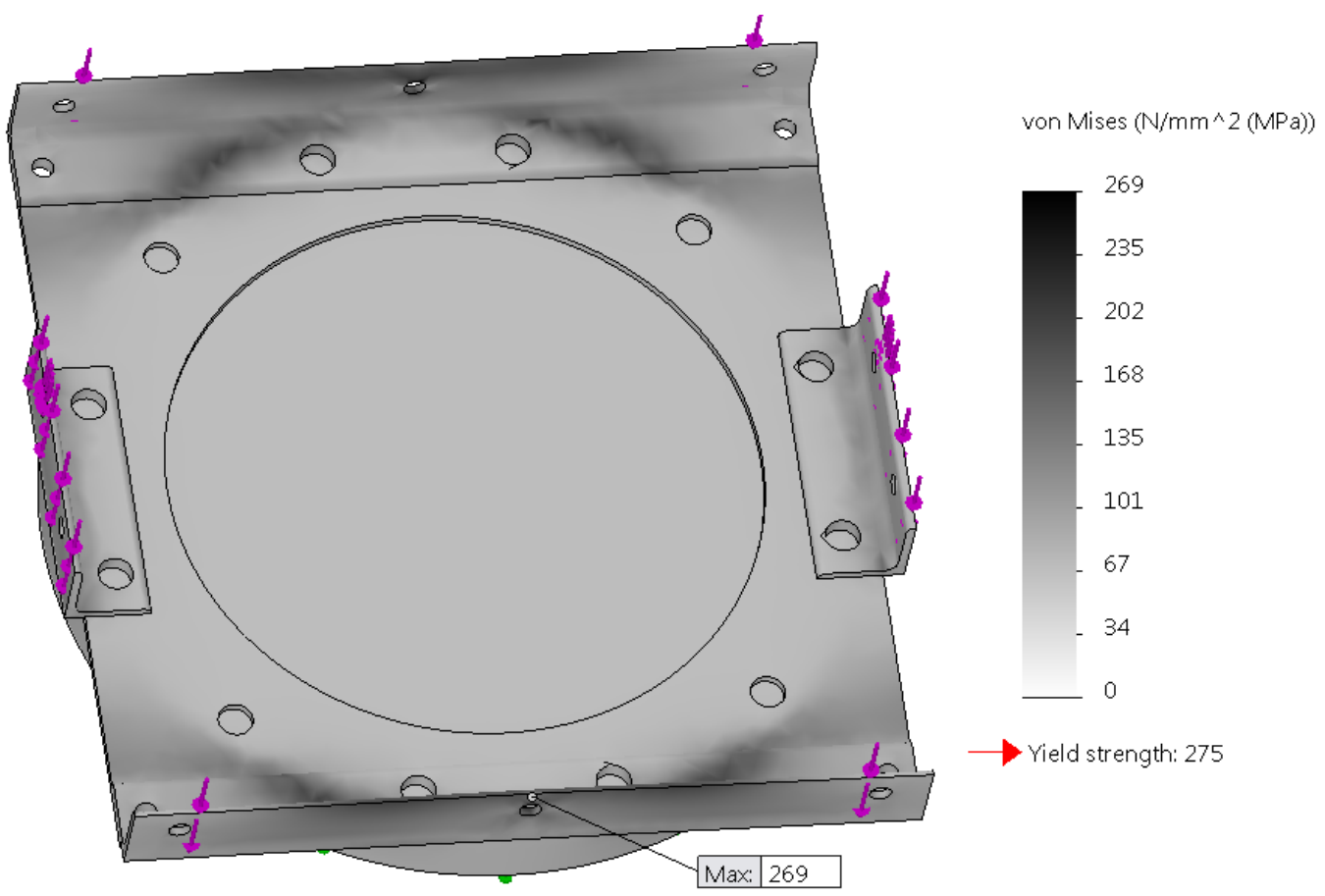

Figure 4.29: The load cell lid plate (above the load cell) and attached brackets showing stress state from a $40 \mathrm{kN}$ force.

Figure 4.30 shows the stress state in the load cell pan (as viewed from below) reacting to a load of $40 \mathrm{kN}$, which is not near its yielding condition, but this load was chosen 
to match the yielding condition of the load cell lid.

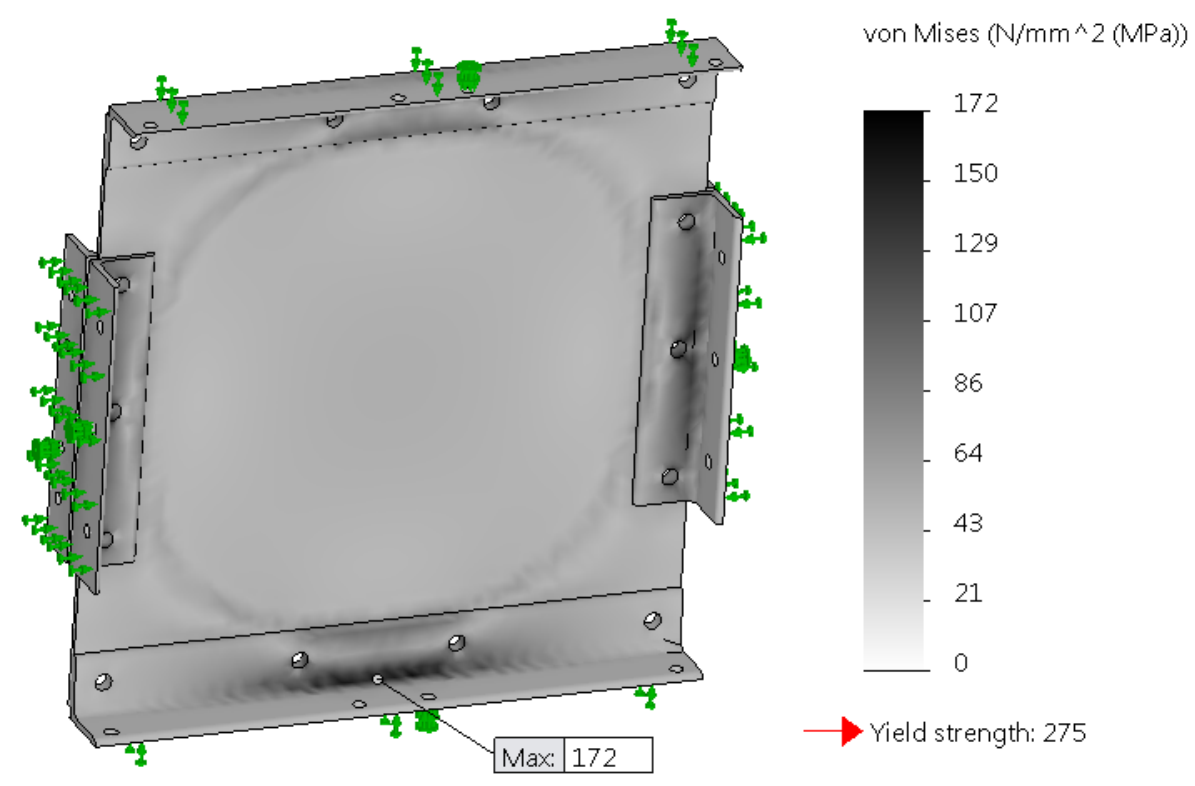

Figure 4.30: The load cell pan plate (below the load cell) and attached brackets showing stress state from $40 \mathrm{kN}$ force.

As shown in the traced load path of Figure 4.27, the loads in the load cell pan bypass the frame of the load deck assembly and enter the deck blocks. The stress state in the deck block that is near a yielding condition is shown in Figure 4.31. The applied force is $40 \mathrm{kN}$.

Each of the two ER damping cylinders is mounted in an aluminum block that is supported by the grid of plates below the lateral beams. Figure 4.32 shows the stress state in the cart assembly as a result of a load of $10 \mathrm{kN}$ applied to each ER mounting block, which shows regions that are near their yielding condition.

In summary, based on FEA results, the minimum static force that could cause a yielding condition was a $10 \mathrm{kN}$ load applied by each of the two ER dampers. With 


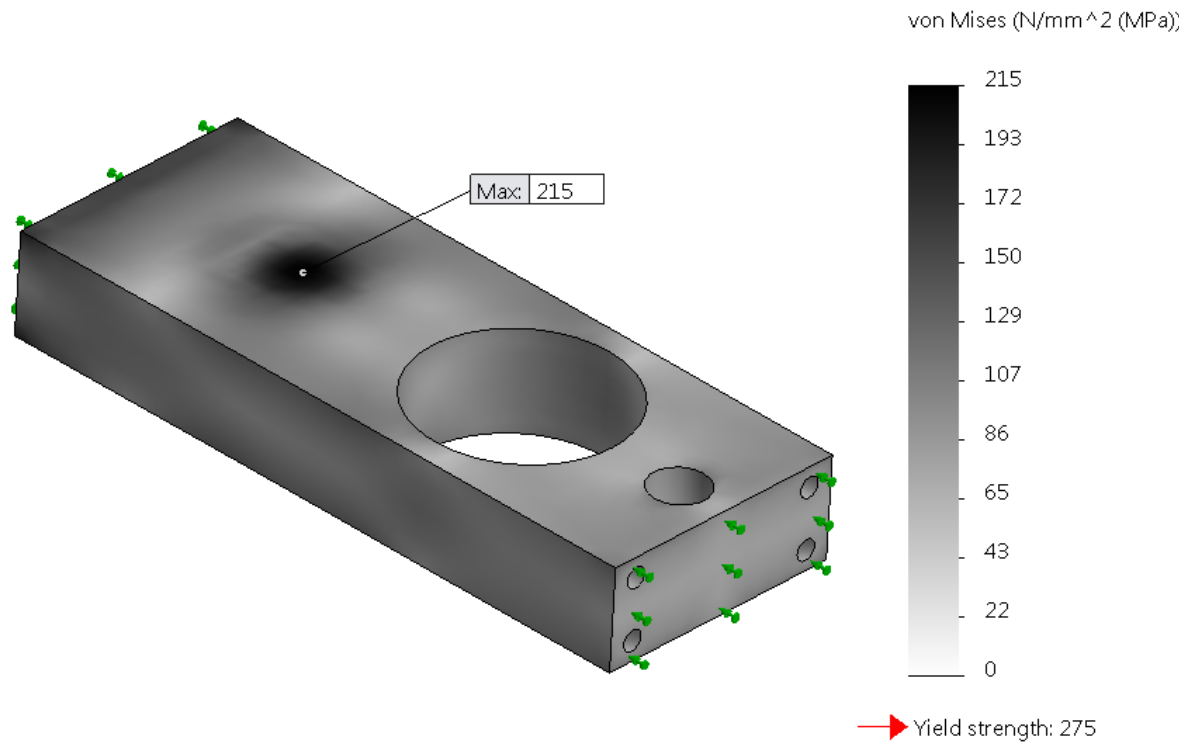

Figure 4.31: Stress state in one of the deck blocks resulting from a $40 \mathrm{kN}$ force applied by each ER damper.

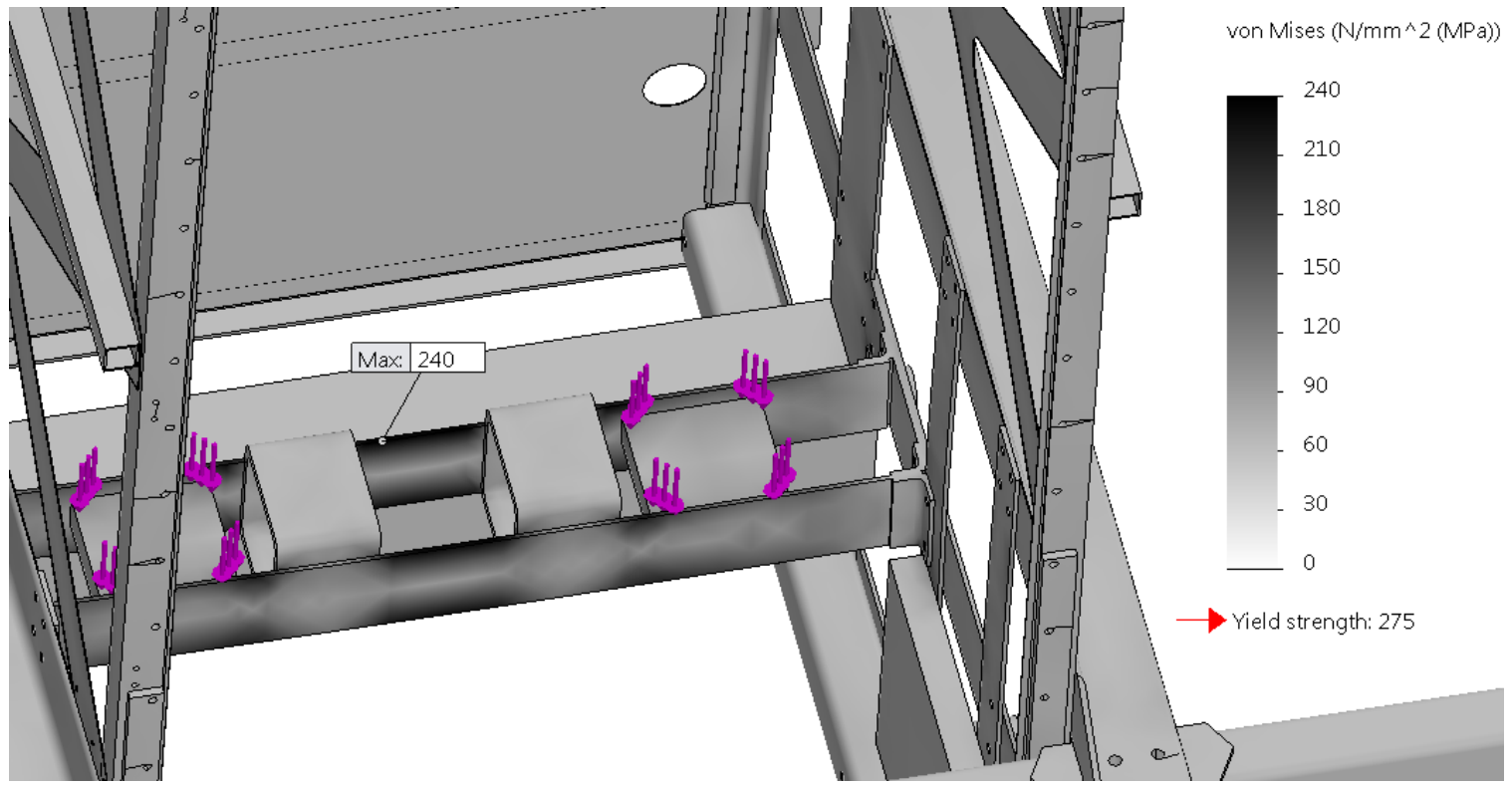

Figure 4.32: Stress state in the cart plates resulting from a $10 \mathrm{kN}$ force applied by each ER damper.

this load, a yielding condition may occur in the cart plates that support the ER dampers. Although the $10 \mathrm{kN}$ load is not directly comparable to the ER dampers' dynamically applied loads, it still serves as an operational guideline during the 
experimentation of the ER dampers.

Motion tests will be required to develop a control algorithm for the ER dampers. This will include repetitive slam impacts while varying deck mass, velocity before impact, and control voltage for the dampers. If some of these tests are performed with a loaded seat mounted on the deck assembly, the resulting peak accelerations can be monitored to recognize the combinations of parameters that lead to the slam impacts that appear in the at-sea testing data. FEA can be performed again, but as a dynamic load simulation, when the applied load profiles can be better defined.

The effect of a slam impact is difficult to apply onto simulated structures. The analysis shown here still illustrates the stress distributions in each of the parts along the load path of an impact between the ER dampers and the deck assembly. During the testing of the ER dampers, the cart plates that hold the ER mounting blocks should be monitored for permanent bending or other damage, which may be observed as a general downward bowing of the plates or localized damage in the centre of the plate or at the end brackets. If permanent bending occurs, those plates can easily be replaced with thicker plates, or a reinforcement brace can be added before they get deformed.

If the slam impact profiles from at-sea testing can be reproduced, without overloading the ER dampers or the cart plates based on reaction force measurements from the Omega 250 load cell, then an operational limit can be defined and not surpassed. 


\subsection{Summary}

The drive system components and the assemblies are structurally capable of withstanding the maximum torques and the maximum accelerations that the motors could produce. The content of this chapter should be reviewed during the commissioning phase of the machine. Each section identified a part or region of a part that should be monitored during the initial motion tests. An awareness of the limitations of the drive systems and of the structures will be helpful when assessing the maximum operating conditions for the machine. 


\section{Chapter 5}

\section{Conclusions}

This chapter summarizes the accomplishments of the research and then lists some recommendations for future work.

\subsection{Accomplishments}

A massive, sophisticated, and practical machine was designed and built during this research. The machine features a large range of motion along two axes and the ability to drop a seat as if it were freefalling under the influence of gravity. The driven motions and slam impact response are both computer-controlled, which will allow for continuous and repeatable motions. The structure was designed to be as reasonably lightweight as possible, while maintaining adequate strength against the worst case loading conditions.

The combination of these features is novel among motion simulating machines. For research in the performance of suspension seats, this machine has the potential to overcome the major challenge of producing continuous and repeatable high-g loading. 
The inclusion of electrorheological dampers is a novel design and will allow for specific impact response profiles to be reproduced. This machine will become an advantageous alternative to at-sea testing, which is costly and not repeatable, or to drop tower testing, which produces a single impulse. Along with future developments of control programs, use of this machine can to contribute to the understanding of the current state of seat technology and lead to improvements in future generations of HSC seats.

The following is a detailed list of notable accomplishments from this research.

- The successful development of this complex structural and dynamic assembly is attributed to adhering to the following design process:

1. Recognition of a need;

2. Identification of requirements and constraints;

3. Research of available actuation, hardware, and structural elements;

4. Generation of ideas for integrating actuation systems with structures;

5. Evaluation of ideas;

6. Detailed design using stock materials and hardware;

7. Validation of the design through analysis;

8. Improvement of the detailed design in view of analysis results and manufacturability.

- Methods of dealing with stress analysis in a complex structure were developed. Despite the variability of loading conditions and the complex structural load paths, the worst case loading conditions were applied and elemental structures were proven to withstand the resulting stresses. The resistance to the impulsive 
load of a slam impact was assessed by applying the maximum static load onto all parts in the relevant load path in order to study the stress distributions for each part. The weakest part was then identified. During the commissioning phase of the machine, that part can be monitored during progressive slam impacts in order to define an operational threshold. FEA should be performed as a dynamic loading simulation to represent a slam impact after the initial few progressive slam impacts can be used to estimate the maximum dynamic loads.

- Extensive research into procuring of drive system components and hardware was performed. The industries that support machine design offer a near infinite number of options for transforming power from a source into forces and motion onto a load. Various types of chains, belts, pneumatics, and impact devices were sized and evaluated during the selection process. McMaster-Carr was an invaluable resource as detailed product information was readily available, and for many parts, CAD models could be downloaded and imported into the machine's CAD assembly. As a note for future maintenance, if parts become worn, then the manufacturer's model numbers and the McMaster-Carr product numbers that are included in this document can be used to acquire replacement parts.

- All parts were manufactured and the machine was assembled. The bulk of the machining was performed by a professional machine shop. All sheets and plates were designed to be cut using their waterjet cutter because of the high speed, good accuracy, and ability to include curved contours. Working drawings were prepared for all other parts that were more complex than the plates. All welding was professionally performed. Additional machining was performed by the researcher for the parts that had to be designed after the bulk of the machining was completed. This was mainly for parts that were added later 
as improvements, or parts that needed alterations during the assembly process; either for improving the fits or for mounting additional components like sensors. Assembly was almost exclusively completed by the researcher, and it required stages of test fits to ensure the best alignment and connection between parts.

- All wiring between components was installed. Power and feedback lines were grouped and bound into appropriate protective conduits. Those conduits were then secured and guided along the paths between the power supplies and the moving cart, the cart and the control operator's desk, and between the base of the cart and the seat deck assembly. The installation of the high-voltage electrical infrastructure required a collaboration with electrical engineering consultants, the Carleton University physical plant manager, and the contracted electrician.

- All sensors and the ER dampers were researched, procured, installed, and then interfaced to Labview. Their operation was confirmed during preliminary motion tests. The capacity of the ER dampers to produce a varying response force will be investigated during the commissioning phase of the machine.

- Communication between each of the drive systems and the computer was established. All setup procedures for both motor drives were followed. This included entering nameplate information for the two motors and the encoders, and reading all operational manuals for the motor drives and the control software.

- Basic motions were demonstrated. For the Baldor motor and drive, a program was developed in Labview that sends position-based index commands to the drive. For the Emerson motor and drive, Powertools Pro was set up to control the motor, and programs were developed that can initiate the built-in motion applications, like homing, indexes, jogs, and cams. The desktop control panel was incorporated into the programs to initiate and abort the motions. A Matlab 
program was developed that could produce data files that were imported into Powertools Pro as a cam motion profile. For both drives, low velocity motions has been demonstrated. Also, coordinated operation of the two drives has been demonstrated, where a position-based profile was sent to each of the drives and the outputs were synchronized. Validating the capability of the drive system to attain the expected accelerations with the design payload was beyond the scope of this phase of the project. This will be established during the commissioning phase of the machine.

- The drive systems were proven to be mechanically functional. During the initial motion tests, both mechanical drive systems performed smoothly through the full $2 \mathrm{DOF}$ range of motion. The available travel is $3.5 \mathrm{~m}$ along the horizontal axis and $1.6 \mathrm{~m}$ along the vertical axis.

- The progress of this project adhered to contractual time constraints for milestones such as design review presentations with the working client and purchasing deadlines.

\section{$5.2 \quad$ Future Work}

The following list provides recommendations for future work that is to be carried out during the commissioning and testing stages, as outlined in Chapter 1:

- The performance of the machine needs to be validated. Progressive tests will be performed to determine the operational limits of the machine by exploring the machine's response to high applied torques and to high loaded masses.

- Advanced programming with the motor drive software needs to be developed to allow the machine's motion to be more representative of the motion that is 
experienced by HSC. This programming will utilize acceleration profiles that are either from at-sea measurements or from synthesized reproductions in order to generate position-based motion control commands.

- The behaviour of the ER dampers needs to be tested and a control algorithm needs to be developed. This may involve complicated relationships between the velocity before impact, test mass, control voltage, and response acceleration.

- The actuation of the vertical drive system and the impact with the dampers needs to be coordinated so that the contributions of each component can be consistently synchronized and the results appear properly superimposed.

- The programming for the motor drives needs to include safeguards to ensure that the motion profiles remain within the boundaries of the travel range. This would involve crash avoidance within the software and potentially additional limit switches installed at the ends of the rails.

- An operating manual should be developed with instructions for start up and shut down procedures. The manual should also include instructions for performing standard motion tests for new suspension seats.

- A maintenance schedule should be produced that includes frequent tasks like lubricating the rails and inspecting bolted connections, and infrequent tasks like removing the vertical drive spool assembly to inspect for wear. 


\section{References}

[1] T. Dobbins, I. Rowley, and L. Cambell. High Speed Craft Human Factors Engineering Design Guide, ABCD-TR-08-01 edition, January 2008.

[2] M. Lougheed. Mitigation of Shock \& Vibration on Fast Boats. http://www. marinelink. com/news/mitigation-vibration358953. aspx. [Online; accessed October-2014].

[3] J. Haynes. As HiPer Boats Evolve Man is the Weakest Link. http://shockmitigationdirectory.com/earticle-detail/ as-hiper-boats-evolve-man-is-the-weakest-link/10/. [Online; accessed October-2014].

[4] http://www.rib.net/forum/f16/wave-jumping-15923.html.

[5] J. Colwell, L. Gannon, T. Gunston, R. Langlois, M.R. Riley, and T. Coats. Shock Mitigation Seat Test and Evaluation. RINA, 2011.

[6] T.E. Coe, K.T. Rutherford, S. Dyne, and J. Hirst. Technical Solutions for Shock Mitigation on High Speed Watercraft. Surveillance, Search and Rescue Craft, 2013.

[7] R. Peterson, E. Pierce, B. Price, and C. Bass. Shock Mitigation for the Human on High Speed Craft - Development of an Impact Injury Design Rule. Technical report, Naval Surface Warfare Center, Panama City, FL, USA, 2004.

[8] M.R. Riley, T. Coats, K. Haupt, and D. Jacobson. Ride Severity Index - A New Approach to Quantifying the Comparison of Acceleration Responses of High Speed Craft. International Conference on Fast Sea Transportation, 2011.

[9] T. Dobbins, S. Myers, R. Dyson, T. Gunston, S. King, and R. Withey. High Speed Craft Motion Analysis - Impact Count Index. UK Conference on Human Resonses to Vibration, 2008. 
[10] ISO 2631-5. Mechanical Vibration and Shock - Evaluation of Human Exposure to Whole-body Vibration - Part 5: Method for Evaluation of Vibration Containing Multiple Shocks. 2004.

[11] SHOXS website. Proposal to industry. http://shoxs.com/images/uploads/ site/Working-Paper-ISSPEC-06252013.pdf. [Online; accessed December2014].

[12] M. Riley and T. Coats. How to Measure Mitigation Characteristics of Passive Shock Isolation Seats. IBEX, 2014.

[13] Shockwave website. Tech-info. http://shockwaveseats.com/tech-info. [Online; accessed December-2014].

[14] M.R. Riley, T.W. Coats, and H.P. Murphy. Acceleration Response Mode Decomposition for Quantifying Wave Impact Load in High Speed Planing Craft. IBEX, 2014.

[15] C. Liam. Testing and Modeling of Shock Mitigating Seats for High Speed Craft. Master's thesis, Virginia Polytechnic Institute and State University, 2011.

[16] http://www.directindustry.com/prod/bruel-kjaer/ electrodynamic-shakers-air-cooled-17114-696711.html.

[17] http://www.moog.com/products/motion-systems/motion-bases/.

[18] http://eyevis.de/en/news/news-detail/?newsid=167.

[19] http://www.nasa.gov/centers/ames/research/technology-onepagers/ vms.html.

[20] (http://www.enidine.com/Industrial/Products/Adjustable_Shock_ Absorbers/).

[21] Fludicon. Electrorheological fluid. (http://www.fludicon.com/technology/). [Online; accessed March-2014].

[22] http://www.allstar.fiu.edu/aero/flight11.htm.

[23] http://www.lebus.us/index.html.

[24] ATI Industrial Solutions - Six-Axis Force/Torque Transducer.

[25] R. Armstrong. Load to Motor Inertia Mismatch: Unveiling the Truth. Drives and Controls Conference, Tellford England, 1998. 
[26] Gates Corporation. Poly Chain GT Carbon Belt Drive Systems. (http://www.gates.com/ /media/Files/Gates/Industrial/Power \ \%20Transmission/Catalogs/PC_Carbon_Manual17595_2011.pdf), May 2012. [Online; accessed October-2014].

[27] S. Kalpakjian. Manufacturing Engineering and Technology. Illinois Institute of Technology, third edition, 1995.

[28] W.F. Chen and E.M. Lui. Handbook of Structural Engineering. CRC Press, second edition, 2005. 


\section{Appendix A}

\section{Matlab Programs}

This appendix contains the Matlab source codes for programs that were developed for this research.

\section{A.1 Baldor Motor Suitability}

$\%$ This program produces a sinusoidal motion from a given amplitde and $\%$ period. The position, velocity, and accelerations are produced for $\%$ each time increment. A motor torque profile is derived from the linear $\%$ acceleration. Similarly, the motor speed is derived from the linear $\%$ velocity. The ideal motor power is produced for each instant.

$\mathrm{m}=480 ; \%$ mass of sliding cart $[\mathrm{kg}]$

reducer $=20 ; \%$ ratio of speed reduction between motor and spindle SprockDiam $=15 ; \%$ Nominal Chain Sprocket size [inch] (drives linear motion) $\%$ always identical results when reducer=sprockdiam 
$\mathrm{R}=$ SprockDiam $* 0.5 * 0.0254 ; \%$ radius of chain sprocket [m]

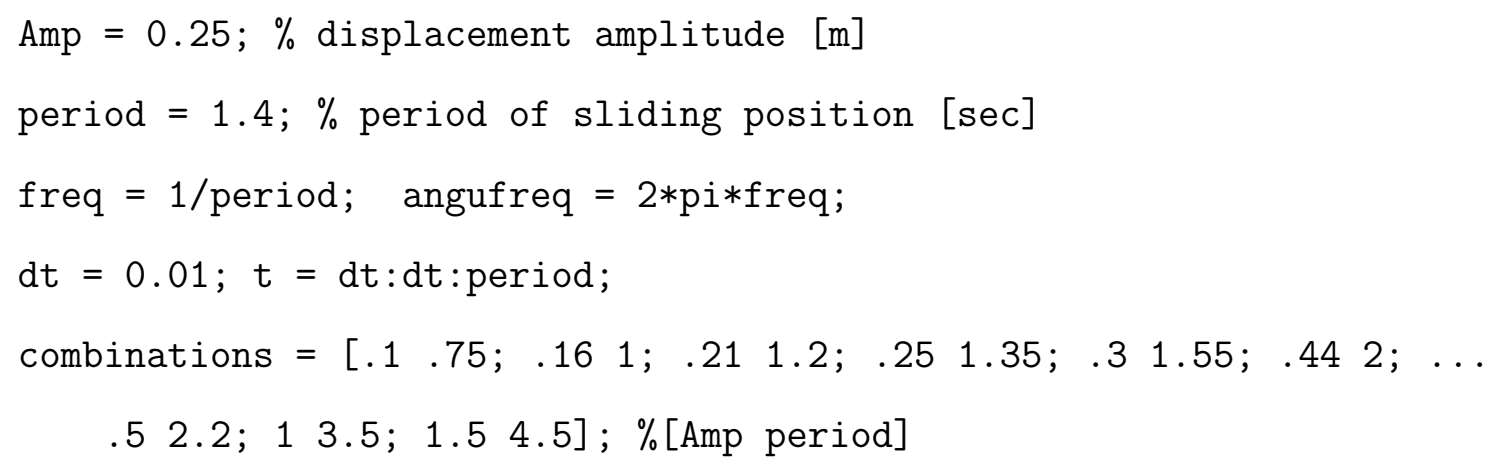




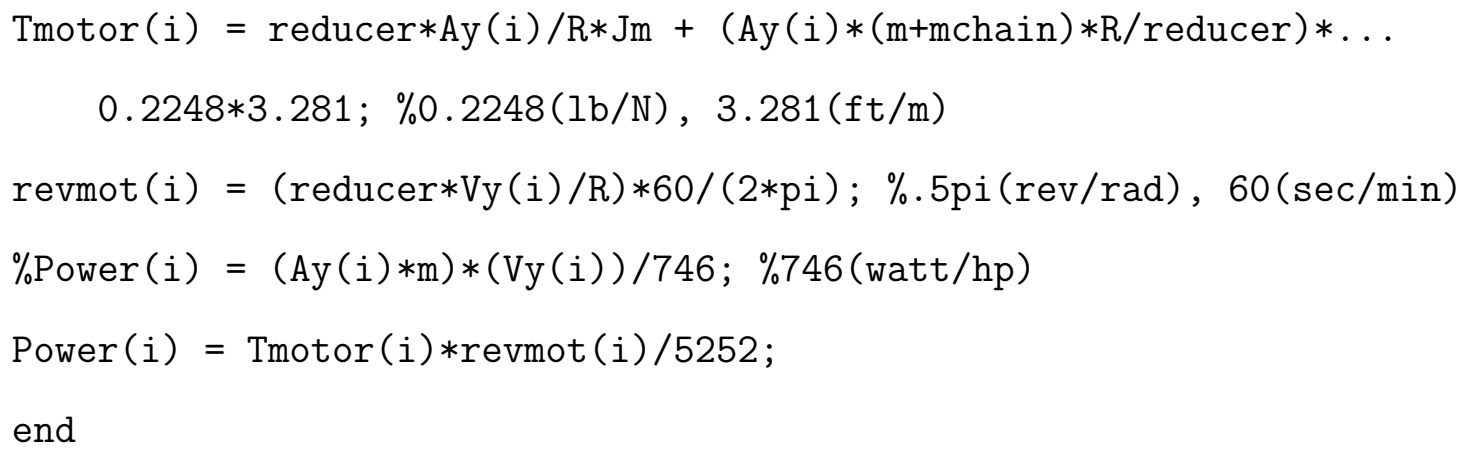

\section{A.2 Horizontal Drive Stress Analysis}

$\%$ This program is used to evaluate the stresses in some of the

$\%$ components of the horizontal drive system. The maximum torque is defined $\%$ and transmitted through the subsequent components. The kinematics of the $\%$ resulting tranlating motion of the assembly were calculated as used to $\%$ determine a suitable overall drive speed ratio. The cable tension is $\%$ calculated. The torsional shear stress of the drive shaft is calculated. $\%$ The shear stress of the drive key is calculated.

Mcart $=475 ; \%$ mass of sliding cart $[\mathrm{kg}]$

$\%$ DensiSteel $=7850 ; \%[\mathrm{~kg} / \mathrm{m} 3]$

$\%$ DensiAlum $=2700 ; \%[\mathrm{~kg} / \mathrm{m} 3]$

\%Drive shaft: McMaster product \#5936K29, \%carbon steel 1045 cold-drawn shaft Sy1 $=530 ; \%[\mathrm{MPa}]$ minimum value from several online sources $\mathrm{E} 1=207 \mathrm{E} 9 ; \%[\mathrm{~Pa}]$ 
$\mathrm{G} 1=79 \mathrm{E} 9 ; \%[\mathrm{~Pa}]$

\%Surface hardness is Rockwell C60-C65 from nitriding

keystock_Sy $=250 ; \%[\mathrm{MPa}]$ mild steel

$\%$ Baldor $2 \mathrm{hp} \mathrm{J}=0.263\left[\mathrm{lb} . \mathrm{ft} \mathrm{f}^{`} 2\right]=0.0111\left[\mathrm{~kg} \cdot \mathrm{m}^{`} 2\right]$

$\%$ starting torque $=25[\mathrm{ftlb}]$ from locked rotor position

$\%$ pull-up torque $=22[\mathrm{ftlb}]$ minimum torque while speeding up

$\%$ break-down torque $=30[\mathrm{ftlb}]$ maximum torque while speeding up

$\%$ note: $1[\mathrm{Nm}\}=0.73756[\mathrm{ftlb}]$

$\%$ starting current $=26[\mathrm{~A}]$

Torq_motor $=25 * 0.3048 * 4.448 ; \%[\mathrm{Nm}]$

Torq_wormgear $=20 *$ Torq_motor;

w0 $=1700 * 2 * \mathrm{pi} / 60 ; \%[\mathrm{rpm}$ into $\mathrm{rad} / \mathrm{s}] \max$ motor speed

$\mathrm{w} 1=\mathrm{w} 0 / 20 ; \%[\mathrm{rad} / \mathrm{s}]$ note: $1 \mathrm{rad} / \mathrm{s}=9.55 \mathrm{rpm}$

railtravel $=3.6 ; \%[\mathrm{~m}]$

$\%$ screwclamp shaft lock max torsion

$\%$ (product \#1058K16 has $\max$ torque of $4824 \mathrm{inlb}=400 \mathrm{ftlb}=540 \mathrm{Nm}$ )

$\%$ Breaking Strength of cable

$\%($ product \#3323T21 Galvanized $6 \times 37$ IWRC $)=6800 \mathrm{Lb}=30250 \mathrm{~N}$ )

Dpulley $=15 * 0.0254 ; \%[\mathrm{~m}]$

Circpulley $=$ Dpulley*pi; \%[m]

revs = railtravel/Circpulley;

Vcable $=\mathrm{w} 1 *(.5 *$ Dpulley $) ; \%[\mathrm{~m} / \mathrm{s}]$

CableTensionN = Torq_wormgear/(.5*Dpulley); \%[N] cable tension 
CableTensionlb $=0.2248 *$ Torq_wormgear $/(.5 *$ Dpulley $) ; \%[1 b]$ cable tension Accel_max $=(1 / g) * C a b l e T e n s i o n N / M c a r t ; \% G ' s$

Dshaft $=1.25 * 0.0254 ; \%[\mathrm{~m}]$ shaft dia steel, through spool

Ishaft $=(\mathrm{pi} / 64) *$ Dshaft^4; $\%$ [m^4] note that $\mathrm{J}=2 * I$

Tau_shaft $=0.25 \mathrm{E}-6 *$ Dshaft $*$ Torq_wormgear $/$ Ishaft;

$\%[\mathrm{MPa}]$ torsional shear stress

$$
\begin{gathered}
\text { keystock_shearstress }=1 E-6 *(\text { Torq_wormgear } /(0.5 * \text { Dshaft })) / \ldots \\
\left((.25 * 1.5) * .0254^{\sim} 2\right) ; \%[\mathrm{MPa}] \text { key area is } 1 / 4 " \mathrm{x} 3 "
\end{gathered}
$$

\section{A.3 Vertical Drive Stress Analysis}

$\%$ This program is used to evaluate the stresses in some of the

$\%$ components of the vertical drive system. The maximum torque of the

\% Emerson motor is defined and transmitted through the subsequent

$\%$ components. The kinematics of the resulting translating motion of the

$\%$ deck assembly were calculated as used to determine a suitable overall

$\%$ drive speed ratio. The centre distance and the belt force were calculated

$\%$ for the selection process of the Gates synchronous toothed belt. The cable

$\%$ tension is calculated, which was used in analysis (not here) of the

$\%$ supporting structure. The bending moment is calculated for the drive

$\%$ shaft and then used to calculate the stresses in the shaft. Other stress

\% calculated are included here for the drive key, spool tube, spool bolts.

$\%$ DensiSteel $=7850 ; \%[\mathrm{~kg} / \mathrm{m} 3]$ 
$\%$ DensiAlum $=2700 ; \%[\mathrm{~kg} / \mathrm{m} 3]$

\%Drive shaft: McMaster product \#5936K29, carbon steel 1045 cold-drawn shaft Sy1 $=530 ; \%$ [MPa $]$ minimum value from several online sources

$\mathrm{E} 1=207 \mathrm{E} 9 ; \%[\mathrm{~Pa}]$

$\mathrm{G} 1=79 \mathrm{E} 9 ; \%[\mathrm{~Pa}]$

\%Surface hardness is Rockwell C60-C65 from nitriding

$\%$

$\%$ Sy2 = 250; \% [MPa] for carbon steel structural A36

$\% \mathrm{E} 2=200 \mathrm{E} 9 ; \%[\mathrm{~Pa}]$

$\%$ G2 $=79 \mathrm{E} 9 ; \%[\mathrm{~Pa}]$

Sy3 = 275E6; \% [Pa] for Aluminum 6061T6

$\mathrm{E} 3=69 \mathrm{E} 9 ; \%[\mathrm{~Pa}]$

$\mathrm{G} 3=26 \mathrm{E} 9 ; \%[\mathrm{~Pa}]$

$\mathrm{g}=9.81$;

Mdeck $=230 ; \%[\mathrm{~kg}]$ mass of loaded seat deck

Torq_motor $=176 ; \%[\mathrm{Nm}]$ System input from $\max$ Tmotor

$\%(\operatorname{Tmax}=176 \mathrm{Nm}$, Tstall $=58.7 \mathrm{Nm})$

Torq_gearhd $=7 *$ Torq_motor; $\%$ torque at the output of the gear reduction w0 $=2000 * 2 * \mathrm{pi} / 60 ; \%[\mathrm{rpm}$ into $\mathrm{rad} / \mathrm{s}] \max$ motor speed $\mathrm{w} 1=\mathrm{w} 0 / 7$;

beltpitch $=.014 ; \%$ drive pitch $[\mathrm{mm}]$ Gates GT3 $14 \mathrm{~mm}$ at $37 \mathrm{~mm}$ width beltlength $=$ beltpitch $* 85 ; \%$ Belt length $[\mathrm{mm}]$ from 85 pitches 
NpulleyA $=36 ; \%$ \# of pulley teeth on motor side "a"

NpulleyB $=36 ; \%$ \# of pulley teeth on dual drive shaft "b"

DpulleyA = NpulleyA*beltpitch/pi; \% [m] diameter of belt pulley

DpulleyB $=$ NpulleyB*beltpitch/pi; \% [m] diameter of belt pulley

DpulleyCable $=8 * 0.0254 ; \%$ [m] bottom pulley for vert conveyor

BeltCentreDistance $=\operatorname{sqrt}(0.25 *($ beltlength - pi $* .5 *($ DpulleyB+DpulleyA $)) \frown 2-\ldots$

$\left.(0.25 *(\text { DpulleyB-DpulleyA }))^{\wedge} 2\right) ; \%[\mathrm{~m}]$ distance between shaft centres

$\%$ alpha12 $=\operatorname{asin}(($ DpulleyB-DpulleyA $) /(2 *$ BeltCentreDistance $)) ;$

$\%$ [rad] angle of belt from centreline

DshaftA $=.055 ; \%[\mathrm{~m}]$ dia of shaft output from gear reduction

DshaftB $=1.25 * 0.0254 ; \%[\mathrm{~m}]$ shaft dia steel, protruding outside of cart

Lcable $=13 * 0.0254 ;$ Lbush $=15 * 0.0254 ;$ Lbelt $=16.5 * 0.0254 ;$

$\%[\mathrm{~m}]$ distances from centre plane

\% Working load of bronze bushings (product \#60695K8)

$\%$ Breaking Strength of wire rope

\% (product \#3323T21 Galvanized 6x37 IWRC) $=6800 \mathrm{Lb}=30250 \mathrm{~N}$

$\%$ Strong-Grip End FittingsFor Lifting

\% (product \#3475T211 same rating as wire rope

$\%$ Screw Clamp shaft bushing

$\%$ (product \#2328K14) has $\max$ torque of $5988 \mathrm{inlb}=500 \mathrm{ftlb}=675 \mathrm{Nm}$

Vbelt $=\mathrm{w} 1 *(.5 *$ DpulleyA $) ; \%[\mathrm{~m} / \mathrm{s}]$
w2 $=$ Vbelt $/(.5 *$ DpulleyB $) ; \%[\mathrm{rad} / \mathrm{s}]$ 

Vdeck $=\mathrm{w} 2 *(.5 *$ DpulleyCable $) ; \%[\mathrm{~m} / \mathrm{s}]$ vertical speed of seat deck
V2bearing $=\mathrm{w} 2 *(.5 *$ DshaftB $) ; \quad \%[\mathrm{~m} / \mathrm{s}]$ mult by 196.85 for $\mathrm{fpm}$

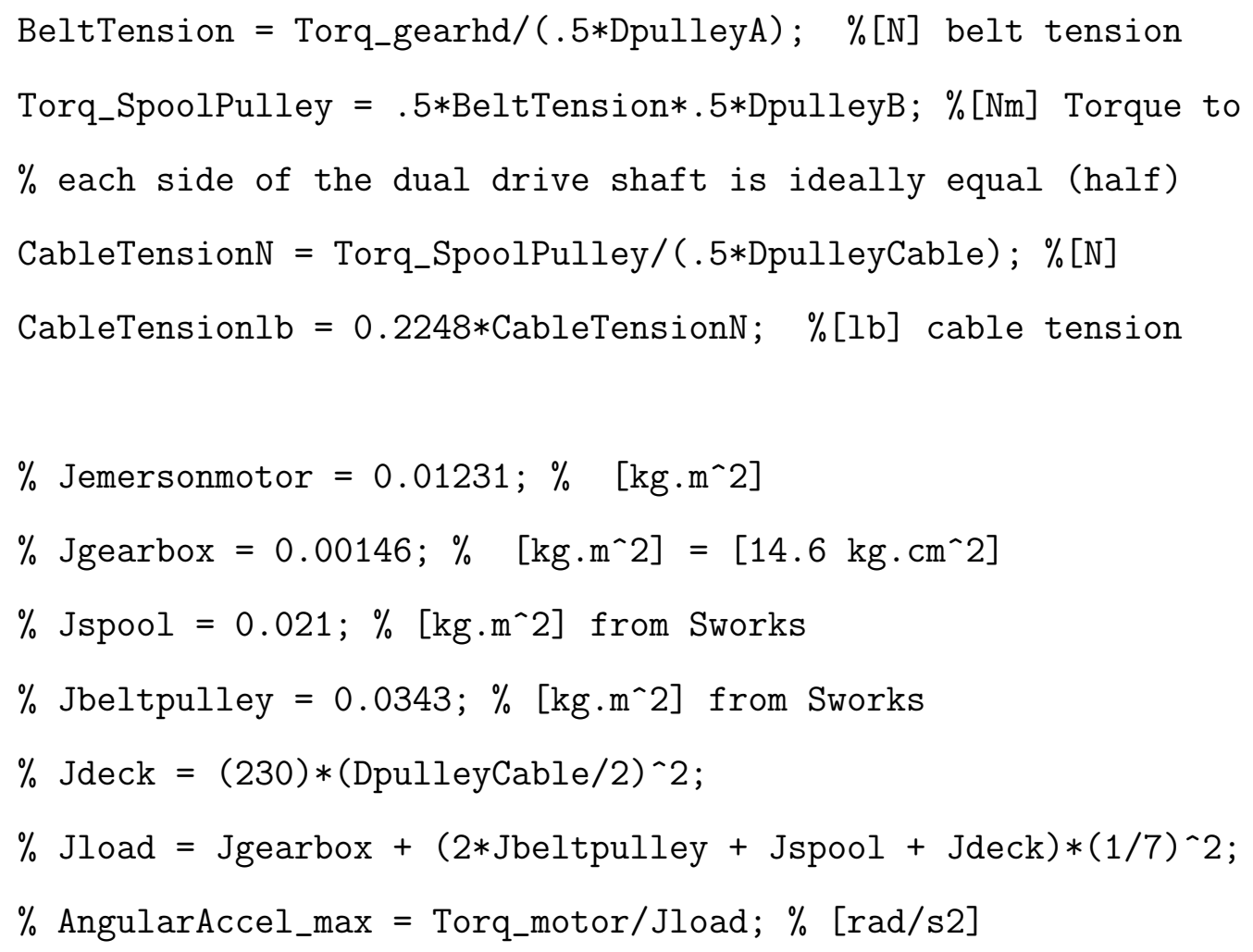




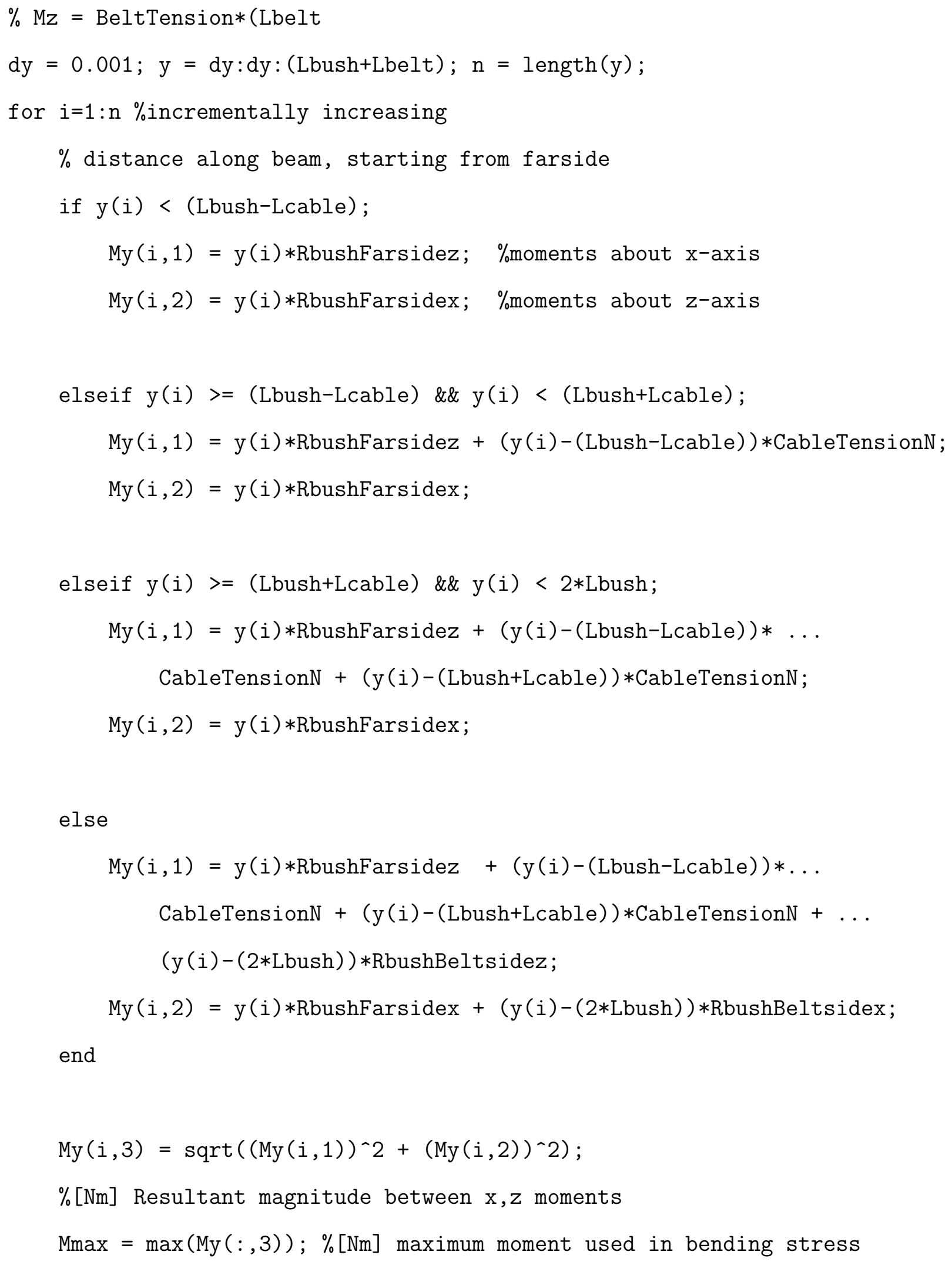


end

Ishaft $=(\mathrm{pi} / 64) *$ DshaftB^ $4 ; \%\left[\mathrm{~m}^{\wedge} 4\right]$ note that $\mathrm{J}=2 * \mathrm{I}$

Itube $=(\mathrm{pi} / 64) *((4 * 0.0254) \wedge 4-(3.88 * 0.0254) \wedge 4) ; \%\left[\mathrm{~m}^{\wedge} 4\right]$

Tau_shaft $=0.25 \mathrm{E}-6 *$ DshaftB $*$ Torq_gearhd $/$ Ishaft;

$\%[\mathrm{MPa}]$ torsional shear stress

Sigma_shaft $=0.5 \mathrm{E}-6 * \mathrm{DshaftB} * \mathrm{Mmax} /$ Ishaft; $\%[\mathrm{MPa}]$ bending stress

Sigma1 $=.5 *$ Sigma_shaft $+\operatorname{sqrt}(.25 *$ Sigma_shaft^2+Tau_shaft^2$) ; \%[\mathrm{MPa}]$

Sigma2 $=.5 *$ Sigma_shaft $-\operatorname{sqrt}(.25 *$ Sigma_shaft`2+Tau_shaft^ 2$) ; \%[\mathrm{MPa}]$

Sigmaeff $=\operatorname{sqrt}($ Sigma1^2 + Sigma1^2 - Sigma1 $*$ Sigma1 $) ; \%[M P a]$

SafetyF_shaft $=$ Sy1/Sigmaeff;

\%Consider max bending stresses must be below fatigue endurance

$\%$ limit for fully reversed load

keystock_shearstress $=1 \mathrm{E}-6 *($ Torq_gearhd $/(0.5 *$ DshaftB $)) / \ldots$

$\left((.25 * 2.5) * .0254^{\wedge} 2\right) ; \%[\mathrm{MPa}]$ key area is $1 / 4 " \mathrm{x} 2.5^{\prime \prime}$

twistspool $=$ Torq_SpoolPulley*2*Lcable/(2*Itube*G3); \%[rad $]$ angle

$\%$ of twist between the two vertical belts

twistcablelength $=$ twistspool $* 0.5 *$ DpulleyCable $; \%[\mathrm{~m}]$

tubetorsionstress $=(1 \mathrm{E}-6) *$ Torq_SpoolPulley $*(2 * 0.0254) /(2 *$ Itube $)$;

$\% \quad[\mathrm{MPa}]$

boltarea $=8 * 0.052 * 0.0254^{\wedge} 2 ; \%[\mathrm{~m} 2] 5 / 16^{\prime \prime}-18$ bolts at interfaces

$\%$ between hub-tube and hub-pulley

boltShearStress $=(1 \mathrm{E}-6) *($ Torq_SpoolPulley $/(.5 * 3.75 * 0.0254)) /$ boltarea; 
$\% \quad[\mathrm{MPa}]$

\section{A.4 Ram Impactor}

$\%$ this program is a simulation tool for the design concept of using $\%$ an actuated hammer under the seat deck. An actuator force (Fmag) was $\%$ defined and would accelerate the hammer mass up towards a freefalling $\%$ deck assembly mass. An ideal spring and damper was included between the $\%$ two masses so the impact response profile could be tuned as desired. $\%$ The parameters were arbitrarily chosen and were adjusted between program $\%$ runs in order to develop an understanding for the feasibility of the $\%$ concept and then for acceptable ranges of the parameters.

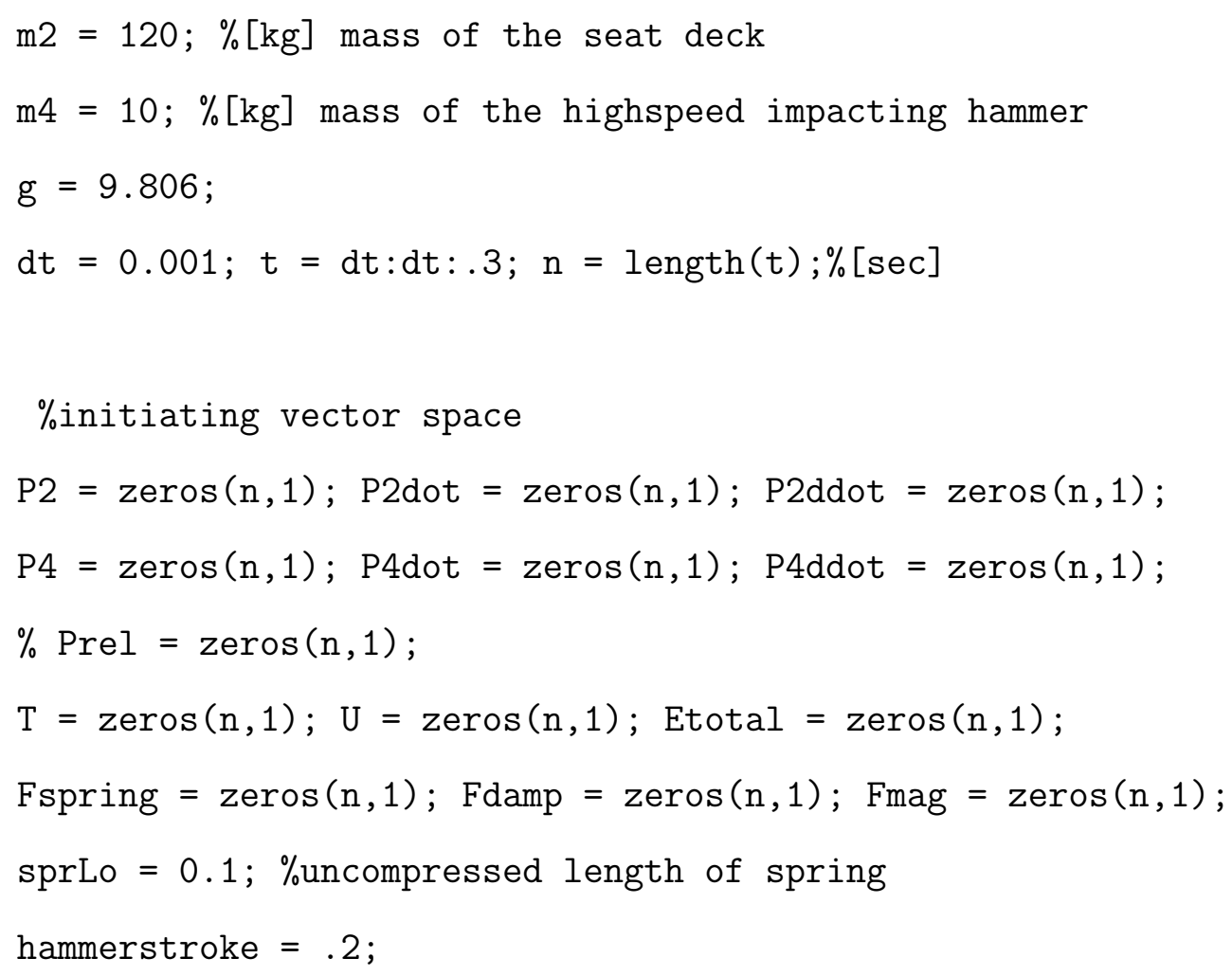




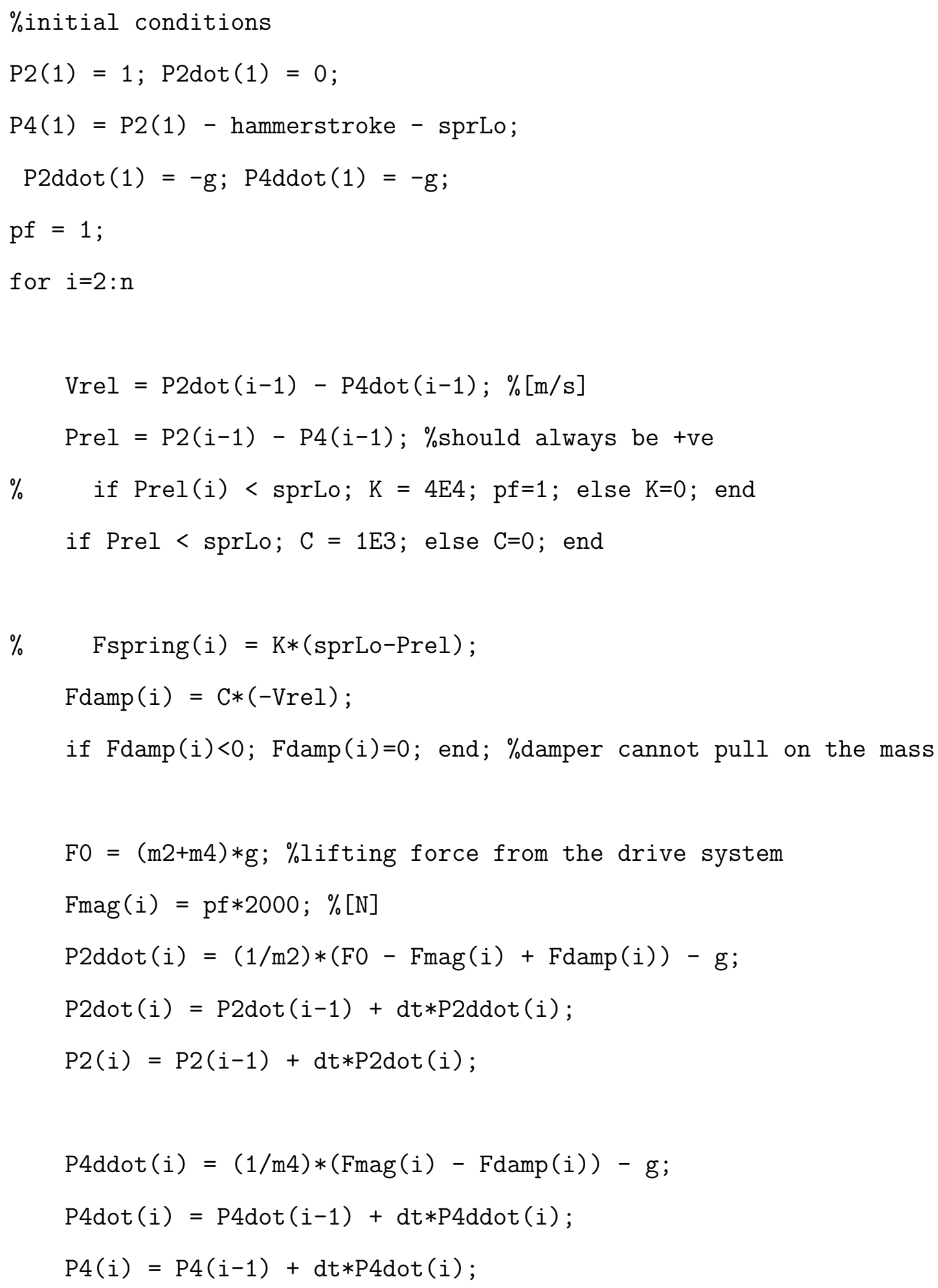


if $\mathrm{P} 2(\mathrm{i})<=0$; break; end

$\% \quad$ if $i==10 ; p f=-1$; end if Prel <= sprLo; pf=0; end \%turns off the Fmag upon impact end

\section{A.5 Masses and Inertia}

$\%$ This program sums the masses of all parts of the cart assembly $\%$ for an estimated total mass. Moments of Inertia are computed for $\%$ all components of each drive system. Then the motor inertia $\%$ ratios are calculated.

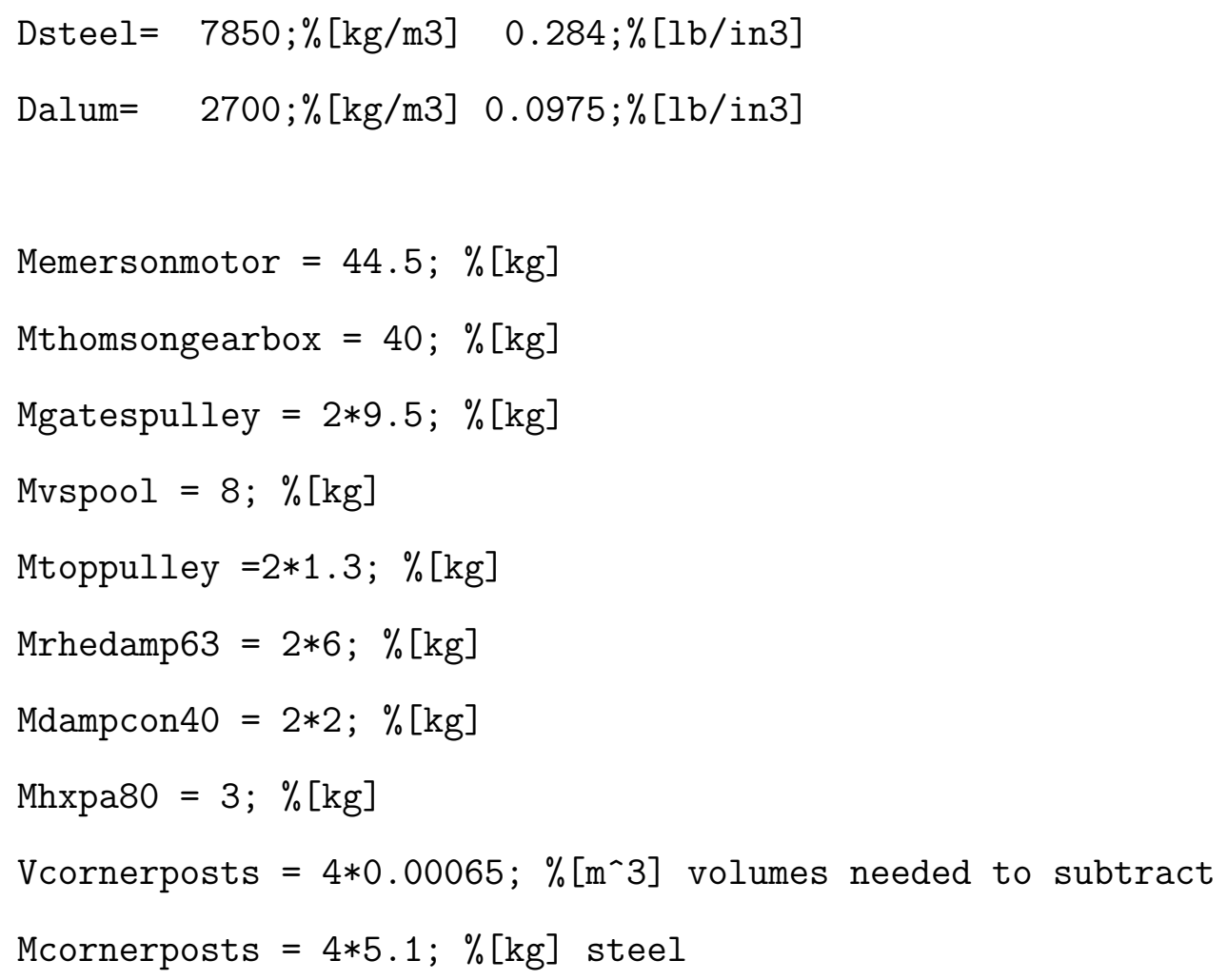




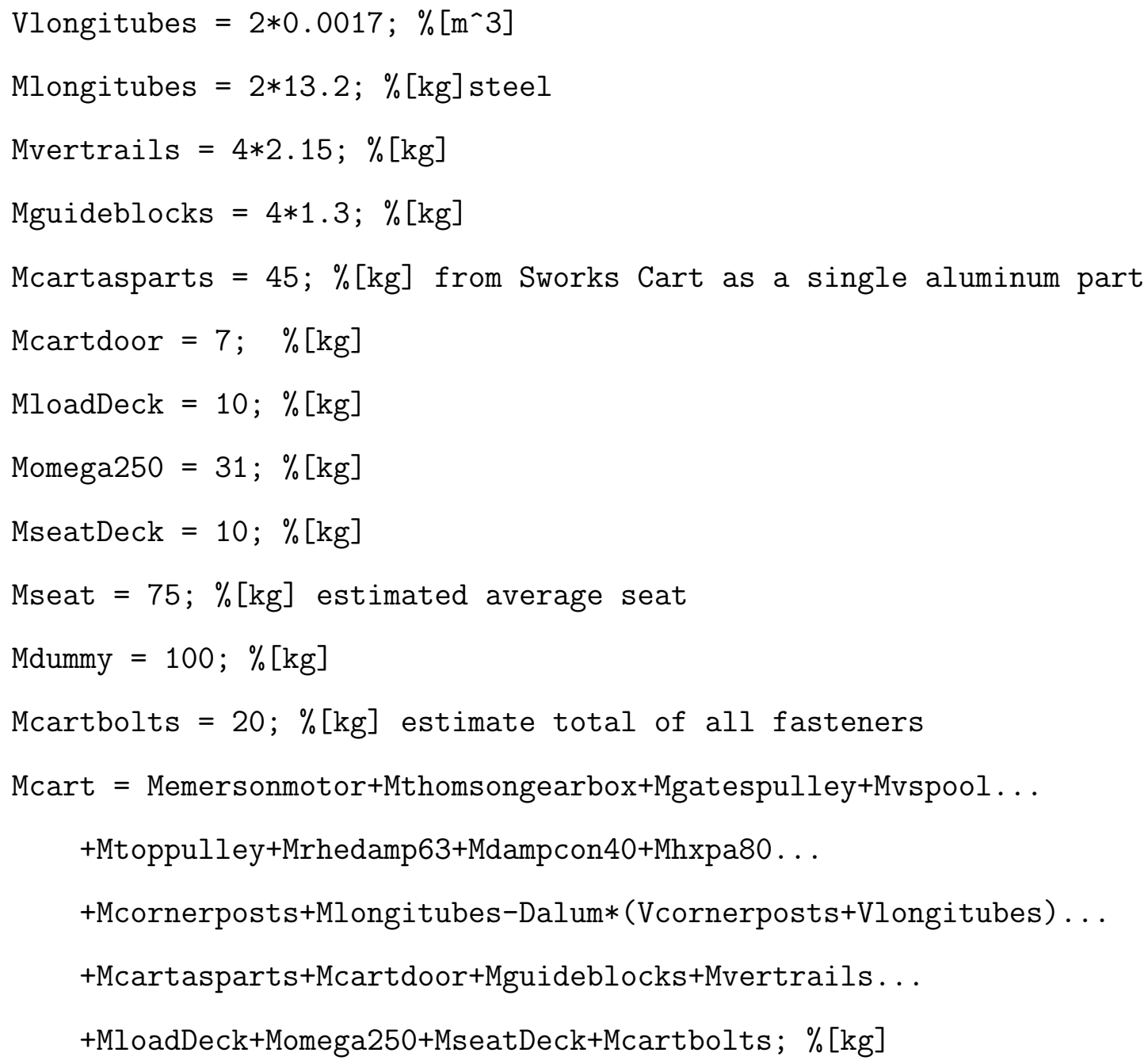

$\% \quad$ Horizontal Drive Inertia

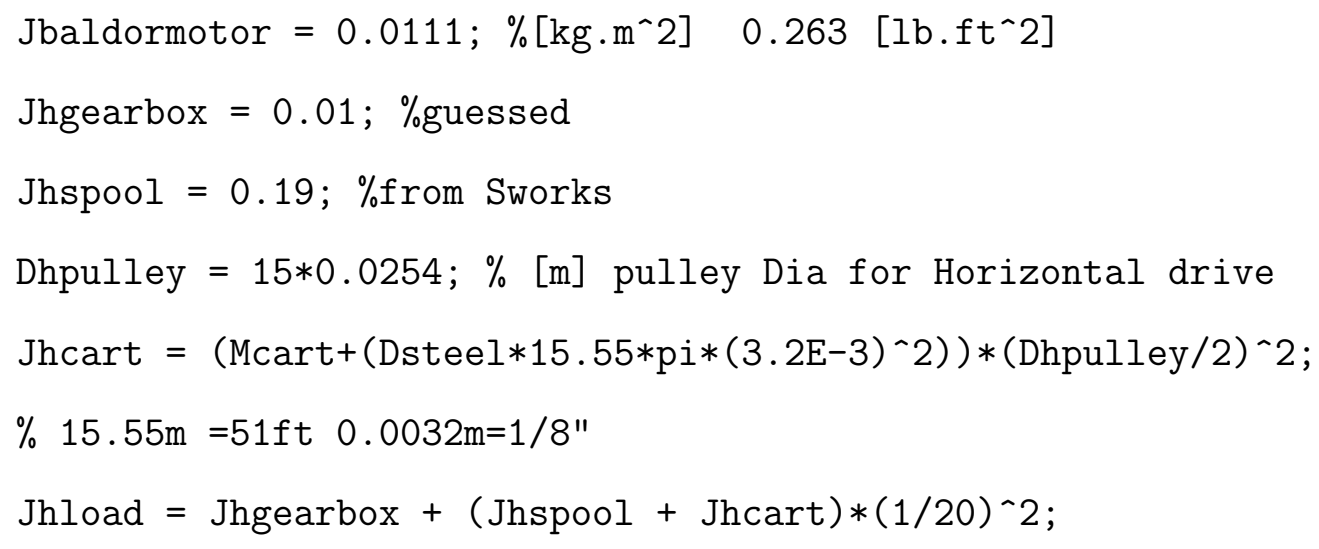




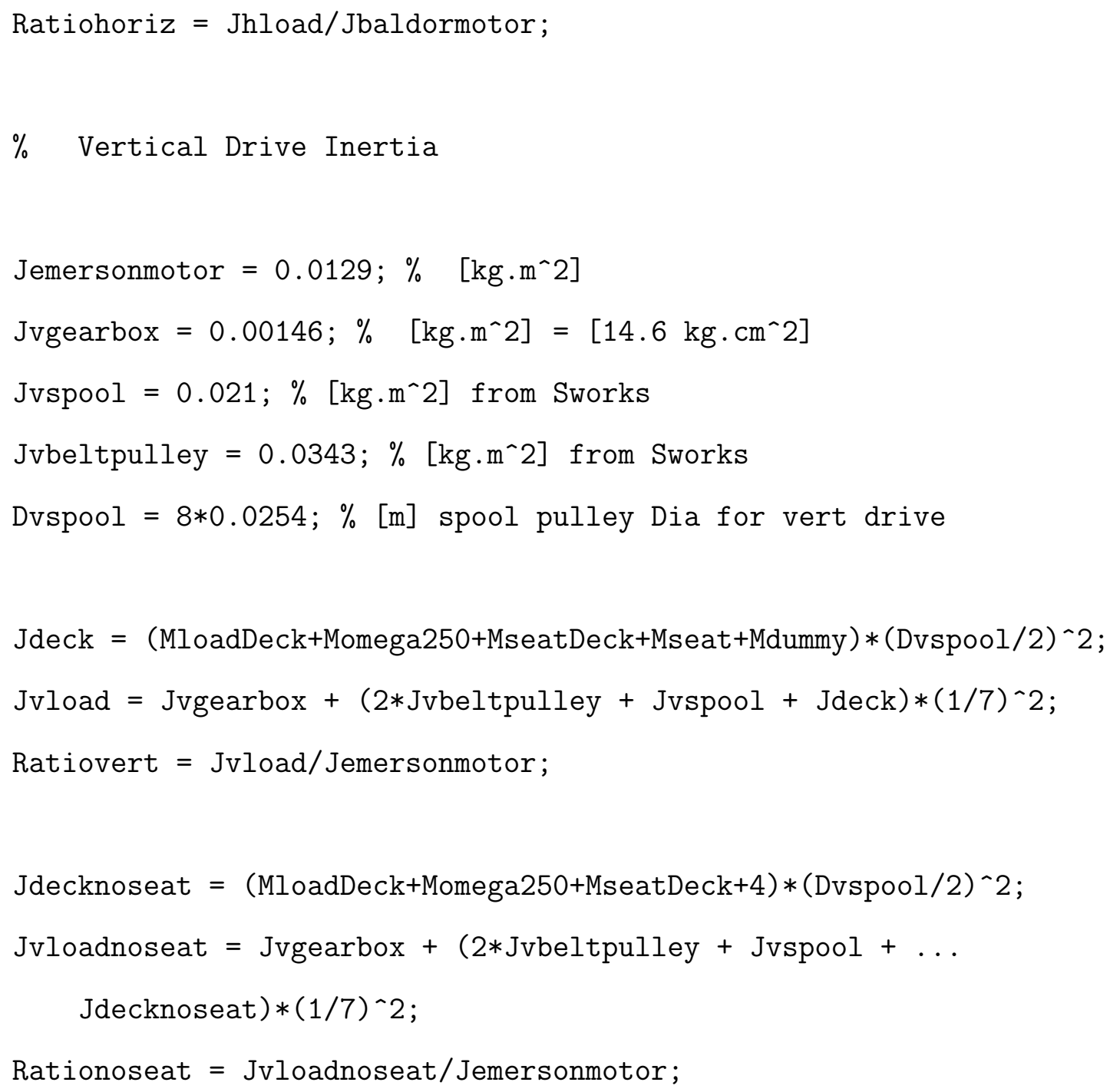

